\title{
Political Determinants of
}

\section{Foreign Aid and International Trade of Emerging Economies}

\author{
Dissertation \\ zur Erlangung des wirtschaftswissenschaftlichen Doktorgrades der \\ Wirtschaftswissenschaftlichen Fakultät der Universität Göttingen
}

\author{
vorgelegt von \\ Andreas Fuchs \\ aus Bad Nauheim
}

Göttingen, 2012 
Erstgutachter: Prof. Dr. Axel Dreher

Zweitgutachter: Prof. Stephan Klasen, Ph.D.

Drittprüferin: Prof. Dr. Stefanie Walter

Tag der mündlichen Prüfung: 16. August 2012 


\section{Acknowledgements}

This dissertation is the outcome of four years of studies to which many different people have contributed. I am deeply grateful to Axel Dreher for his advice, countless discussions and extraordinary support during my Ph.D. studies. Moreover, I feel indebted to Stephan Klasen for his advice and the opportunity to have learnt from him. I would also like to thank Stefanie Walter for the very valuable discussions and comments on my research. Furthermore, I am sincerely grateful to Christina Davis for her advice, the discussions and her invitation to Princeton, from which parts of this dissertation largely benefited. I also want to express my gratitude to Christian Bjørnskov and Martin Gassebner for their strong support and advice during their research visits to Goettingen.

Special thanks to my friend and co-author Nils with whom I stood through the ups and downs that also came along with this dissertation. I also want to thank my office mate Hannes, Jan, Manuel, Nicolás and my other friends and colleagues at the Chair of International and Development Politics in Heidelberg and in the Development Economics Research Group in Goettingen for the interesting discussions, countless special moments and the great time I had during my Ph.D. studies.

This thesis would not exist without the exceptional support of my family over the last thirty years. Furthermore, I am very grateful for the precious support of my girl-friend Iris and my friends in Karben, who enriched my life through non-academic activities and motivated me to pursue my Ph.D. I also want to express my thanks to Felice, Katrin, Marco and Marie for their unconditional support throughout my entire studies. Finally, I would like to thank my fellow students and friends at Dauphine University Paris (not only) for fruitful discussions on Dalai Lama meetings during coffee breaks. 


\section{Table of Contents}

List of Tables

ix

List of Figures $\quad$ xi

List of Abbreviations xiii

Overview: An Empirical Analysis in Five Chapters 1

Chapter I: Does Terror Increase Aid? 9

$\begin{array}{lll}\text { I.1 Introduction } & 10\end{array}$

$\begin{array}{lll}\text { I.2 Aid and Terror } & 12\end{array}$

$\begin{array}{lll}\text { I.3 Aid Effort and Terror over Time } & 15\end{array}$

$\begin{array}{lll}\text { I.3.1 Descriptive Evidence } & 15\end{array}$

$\begin{array}{lll}\text { I.3.2 Method of Estimation and Main Results } & 17\end{array}$

$\begin{array}{lll}\text { I.4 Panel Data Analysis of Aid Allocation } & 21\end{array}$

I.5 Extensions 30

I.5.1 Disaggregating the DAC 30

I.5.2 Disaggregating Aid 31

$\begin{array}{lll}\text { I.6 Conclusions } & 32\end{array}$

Chapter II: Rogue Aid? The Determinants of China's Aid Allocation 35

II.1 Introduction $\quad 36$

$\begin{array}{lll}\text { II.2 Measuring Chinese Aid } & 37\end{array}$

II.3 Need, Merit and Self-Interest - Is China Different?

II.3.1 A Brief History of China's Aid Program 44

$\begin{array}{lll}\text { II.3.2 Hypotheses } & 46\end{array}$ 
II.4 Econometric Analysis of China's Aid Allocation 50

$\begin{array}{lll}\text { II.4.1 Empirical Strategy and Data } & 50\end{array}$

II.4.2 China's Project Aid 54

II.4.3 Total Aid Money, Medical Teams and Food Aid 59

II.5 Comparison with DAC and Other Emerging Donors 61

$\begin{array}{lll}\text { II.6 Summary and Conclusions } & 68\end{array}$

Chapter III: The Needy Donor: An Empirical Analysis of India's Aid Motives 71

III.1 Introduction $\quad 72$

III.2 An Overview of India's Aid Program 75

$\begin{array}{lll}\text { III.3 Theory and Hypotheses } & 78\end{array}$

$\begin{array}{lll}\text { III.4 Empirical Analysis } & 81\end{array}$

$\begin{array}{lll}\text { III.4.1 Overview } & 81\end{array}$

$\begin{array}{lll}\text { III.4.2 Data and Methodology } & 85\end{array}$

III.4.3 Main Results $\quad 87$

III.4.4 Comparison with DAC and Other Non-DAC Donors 91

III.4.5 Robustness Checks 94

$\begin{array}{lll}\text { III.5 Conclusions } & 97\end{array}$

Chapter IV: Emergency Aid 2.0 99

$\begin{array}{llr}\text { IV.1 Introduction } & 100\end{array}$

IV.2 Determinants of Emergency Aid 103

$\begin{array}{lll}\text { IV.3 The New World of Emergency Assistance } & 107\end{array}$

IV.4 Empirical Analysis of Aid Selection 112

$\begin{array}{lll}\text { IV.4.1 Overview } & 112\end{array}$

$\begin{array}{lll}\text { IV.4.2 Empirical Strategy } & 116\end{array}$

IV.4.3 Baseline Results 119

IV.4.4 Testing for Differences between "New" and "Old" Donors 123

IV.5 Empirical Analysis of Aid Promptness 127

$\begin{array}{lll}\text { IV.5.1 Overview } & 127\end{array}$

$\begin{array}{lll}\text { IV.5.2 Empirical Strategy } & 128\end{array}$

$\begin{array}{lll}\text { IV.5.3 Results } & 130\end{array}$

$\begin{array}{lll}\text { IV.6 Conclusions } & 133\end{array}$ 


V.1 Introduction 136

$\begin{array}{lll}\text { V.2 } & \text { The Argument } & 138\end{array}$

V.2.1 Political Determinants of Trade and the 'Dalai Lama Effect' 138

$\begin{array}{lll}\text { V.2.2 Hypotheses } & 141\end{array}$

V.3 Empirical Analysis $\quad 143$

$\begin{array}{lll}\text { V.3.1 Data and Method } & 143\end{array}$

V.3.2 Main Results 147

$\begin{array}{lll}\text { V.3.3 Endogeneity Concerns } & 154\end{array}$

$\begin{array}{lll}\text { V.3.4 Results by Product Group } & 160\end{array}$

$\begin{array}{lll}\text { V.4 Conclusions } & 162\end{array}$

$\begin{array}{ll}\text { References } & 165\end{array}$

$\begin{array}{ll}\text { Appendices } & 183\end{array}$ 


\section{List of Tables}

Table I.1

Table I.2

Table I.3a

Table I.3b

Table II.1

Table II.2

Table II.3

Table II.4

Table III.1

Table III.2

Table IV.1

Table IV.2

Table IV.3

Table IV.4

Table V.1.1

Table V.1.2

Table V.2

Table V.3

Table V.4

Table V.5.1

Table V.5.2
Aid effort (1971-2008)

Aid allocation (1971-2008)

Aid allocation and interactions (Heckman selection model, 19712008)

Aid allocation and interactions (Heckman allocation model, 19712008)

Five Phases of China's aid program

Comparison of China's aid allocation with DAC donors and other emerging donors (1996-2005, baseline regression)

Comparison of China's aid allocation with DAC donors and other emerging donors (1996-2005, institutional quality)

Comparison of China's aid allocation with DAC donors and other emerging donors (1996-2005, natural resource endowment)

Allocation of India's aid commitments (2008-2010)

Comparison of India's aid allocation with other donors (20082010)

Disaster types

113

Determinants of aid selection (Logit, 2000-2009)

Determinants of aid selection by donor group (Logit, SUR, 20002009)

Exports to China and Dalai Lama meetings of government members (Hypothesis 1, all countries)

Exports to China and Dalai Lama meetings of government members (alternative model specifications, 2002-2008)

Exports to China and Dalai Lama meetings at various political levels (Hypothesis 2, all countries, 2002-2008)

Exports to China and Dalai Lama meetings of political leaders (Hypothesis 3, time-event specification, 2002-2008)

Exports to China and Dalai Lama meetings of political leaders (endogeneity, 2002-2008)

Exports to China and Dalai Lama meetings of political leaders (by product groups, all countries, 2002-2008)

Exports to China and Dalai Lama meetings of political leaders (by product groups, European countries, 2002-2008) 
$\begin{array}{lll}\text { Appendix I.2 Descriptive statistics } & 185\end{array}$

Appendix I.3 Aid allocation and interactions (OLS, 1971-2008) 186

Appendix I.4 Aid effort and aid allocation by donor (selected results, 19712008)

Appendix I.5 Share of aid for education (\% of aid budget, OLS, 1971-2008)

Share of aid for government and civil society (\% of aid budget, OLS, 1971-2008)

Share of aid for education and government and civil society ( $\%$ of total aid allocated to recipient, OLS, 1971-2008)

Appendix II.1 Sources and definitions

Appendix II.2 Descriptive statistics

Appendix II.3 Construction of the dataset on China's project aid

\section{Appendix III.3}

Appendix III.4

Appendix III.5

Allocation of India's aid commitments (Probit, 2008-2010): Robustness checks

Allocation of India's aid commitments (OLS, 2008-2010): Robustness checks

Comparison of India's aid allocation with other donors (Indian aid recipients only, 2008-2010)

Appendix IV.1 Humanitarian aid and disaster relief of "new" donors

Appendix IV.2 List of donor countries by definition of "new" donors

Appendix IV.3 Sources and definitions

Appendix IV.4 Descriptive statistics

Appendix IV.5 Determinants of aid selection (Logit, marginal effects, 2000-09)

Appendix V.1 Anecdotal Evidence

Data description members (Hypothesis 1, all countries, excluding SITC9)

Exports to China and Dalai Lama meetings at various political levels (Hypothesis 2, European countries, 2002-2008) 


\section{List of Figures}

Figure 1 Share of non-DAC donors in total food aid (1990-2009) 3

Figure 2 Share of BRICS countries in total trade (1990-2009) 3

$\begin{array}{lll}\text { Figure I.1 Aid effort over time } & 16\end{array}$

Figure II.1 Number of aid projects completed (\% of China's total aid, 19561969)

Figure II.2 Number of aid projects completed (\% of China's total aid, 19701978)

Figure II.3 Number of aid projects completed (\% of China's total aid, 19791987)

Figure II.4 Number of aid projects completed (\% of China's total aid, 19901995)

Figure II.5 Number of aid projects completed (\% of China's total aid, 19962005)

Figure II.6 China's foreign aid over time

Figure III.1 Aid provided by the MEA in millions of constant 2000 US\$ (19662010)

Figure III.2 India's aid allocation by region (MEA, 2008-2010)

Figure III.3 India's aid allocation by sector (MEA, 2008-2010)

Figure III.4 Aid allocation and developmental distance (2008-2010)

Figure IV.1 Emergency aid over time and by donor group (2000-2009)

Figure IV.2 Aid promptness by disaster type and donor group (2000-2009)

Figure V.1 Travel pattern of the Dalai Lama (1991-2008)

Appendix I.8 Number of terror attacks targeted at countries (1967-2007)

Appendix I.9 Number of terror attacks originating from countries (1967-2007) 


\section{List of Abbreviations}

2SLS

BJP

BoP

CDB

CIA

CIS

CRED

DAC

DFID

ECOSOC United Nations Economic and Social Council

ETA

EU-3

Exim Bank

FAIS

FGLS

FLOGIT

FOCAC

FTS

GDP

GHD

GMM

GNI

GWOT

HIPC

IFPRI

IRA

ITEC

Two-Stage Least Squares

Balance of payments

China Development Bank

Central Intelligence Agency

Community of Independent States

Development Assistance Committee United Kingdom)

Export-Import Bank

International Food Aid Information System

Feasible Generalized Least Squares

Fractional Logit model

Forum on China-Africa Cooperation

Financial Tracking System

Gross domestic product

Good Humanitarian Donorship

Generalized method of moments

Gross national income

Global War on Terror

Heavily Indebted Poor Countries

International Food Policy Research Institute

Irish Republican Army

Indian Technical and Economic Cooperation
Bharatiya Janata Party (center-right party in India)

Centre for Research on the Epidemiology of Disasters

Department for International Development (United Kingdom)

Basque nationalist and separatist organization Euskadi Ta Askatasuna

Three largest donors in the European Union (France, Germany and the 
ITERATE International Terrorism: Attributes of Terrorist Events

LDC Least developed countries

LOC Lines of credit

MEA Ministry of External Affairs

MFA Ministry of Foreign Affairs

MOFCOM Ministry of Commerce

NGO Non-governmental organization

ODA Official Development Assistance

OECD Organisation for Economic Co-operation and Development

OLS Ordinary Least Squares

OOF Other Official Flows

RAF Red Army Fraction or Rote Armee Fraktion

SITC Standard International Trade Classification

TEAM-9 Techno-Economic Approach for Africa India Movement

TSG Tibet Support Groups

UN United Nations

UNDEF United Nations Democracy Fund

UNGA United Nations General Assembly

UNSC United Nations Security Council

UPA United Progressive Alliance (coalition of center-left parties in India)

USAID United States Agency for International Development

USSR Union of Soviet Socialist Republics

WDI World Development Indicators 


\section{Overview:}

\section{An Empirical Analysis in Five Chapters}

Major shifts are taking place in the global economy as the share of emerging economies in global production is rapidly increasing. Among the emerging economies, the so-called BRICS

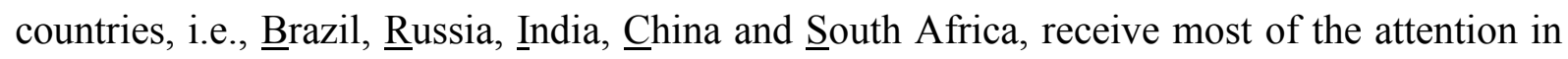
the public debate. ${ }^{1}$ According to Mansfield (2011: 1), "most of the concern expressed about the BRIC countries centers on the prospect that their growth will somehow alter or destabilize the international system." The average annual growth rate of these countries in the 2000s ranged between 3.3 percent (Brazil) and 10.3 percent (China). ${ }^{2}$ However, economic growth is a necessary condition but not in itself sufficient for emerging countries to assert an important role internationally. In addition to growth, it is the size of the BRICS countries that ultimately enables them to reshape the architecture of the international system (see Mansfield 2011). Albeit at different stages of economic development and showing considerable differences in their form of government, the BRICS countries have steadily intensified their cooperation and are increasingly acting in concert, also in areas which were previously the exclusive realm of developed Western economies. ${ }^{3}$

This rise of emerging economies is visible in international development cooperation and international trade. Aid contributions from donor countries operating outside the established group of the OECD's Development Assistance Committee (DAC) have flourished in recent years. Figure 1 highlights this trend and depicts the share of non-DAC donors in total food aid contributions. ${ }^{4}$ The dashed line shows the corresponding share of non-DAC

\footnotetext{
${ }^{1}$ O'Neill (2001) invented the acronym "BRIC." In the beginning, it was employed without the "S" which represents South Africa. The BRICS group may appear too narrow to understand the implications of the increasing importance of emerging economies as a whole. For Vreeland (2010), it is rather the G-20 group that represents the arrival of the emerging economies. He suggests the usage of "MAKTISAS" and "ASK IT SAM!" as acronyms for those emerging countries that are members of the G-20, but not part of the BRIC group (Vreeland 2010).

2 Data from the World Bank's World Development Indicators are available at http://databank.worldbank.org (accessed: July 2012).

${ }^{3}$ This finds expression in annual summits of the leaders of all BRICS countries. See, for example, the website of the 2012 BRICS Summit held in New Dehli available at http://bricsindia.in (accessed: July 2012). There are also multiple forms of cooperation that involve subgroups of the BRICS such as the Shanghai Cooperation Organization (SCO), an intergovernmental security organization grouped around China and Russia, or the IndiaBrazil-South Africa Dialogue Forum (IBSA), which also acts as a joint actor in development cooperation.

${ }^{4}$ I use data on food aid from the World Food Programme (2011) as comparable data on total Official Development Assistance (ODA) are not available for many non-DAC donors.
} 
countries in world GDP for comparison. While only 3.5 percent of reported food aid originated from non-DAC countries in $1990 \mathrm{~s}$, this share increased to 12.1 percent in the 2000s. Aid from this group of donors reached its maximum of 19.5 percent of total food aid in 2007, the year preceding the global financial crisis. Similarly, emerging economies are rapidly gaining in importance as trading partners for both developed and less developed countries. As can be seen in Figure 2, the share in world trade contributed by all five BRICS economies has increased together with their share in world GDP. Specifically, the BRICS' share in world trade grew from 5.2 percent in 1990 to 14.9 percent in 2009. China accounts for more than half of all trade flows of BRICS countries since 2000 (see dotted line).

With the rise of the emerging economies, their usage of foreign aid and international trade as foreign policy tools is likely to gain in importance. The increased economic power of emerging economies enables these countries to exploit dependencies and vulnerabilities of their trading partners and aid recipients. Concerning foreign aid, previous research has shown that aid allocation often follows donors' political interests rather than developmental need (e.g., Alesina and Dollar 2000; Neumayer 2005). In a similar vein, previous research suggests that trading decisions are influenced by political relations (e.g., Pollins 1989; Gowa and Mansfied 1993). However, most prior contributions to these strands of the literature have focused on established world powers such as the United States and other G-7 countries. Given the ongoing rise of many emerging economies, and the BRICS countries in particular, this is a notable omission.

Motivated to fill this gap in the literature, my dissertation analyzes the political determinants of foreign aid and international trade of emerging economies, with a particular emphasis on China and India. This thesis investigates the role of political factors in emerging donors' aid decisions. Moreover, I analyze how China, the most important trading nation among the BRICS countries, uses trade to enforce its political agenda on the international stage. At the intersection of development economics and international political economy, this thesis is part of the literature on aid allocation (e.g., Alesina and Dollar 2000; Dreher et al. 2011) and political determinants of trade (e.g., Mansfield et al. 2000; Nitsch 2007). Moreover, my results offer insights with respect to the literature on aid budgets (e.g., Round and Odedokun 2004; Tingley 2010) and aid effectiveness (e.g., Burnside and Dollar 2000; Dreher et al. forthcoming). The dissertation is structured into five chapters. While the first four chapters focus on emerging economies' motives to provide foreign aid to other developing countries, the final chapter investigates the role of political tensions in trade relationships. 
Figure 1: Share of non-DAC donors in total food aid (1990-2009)

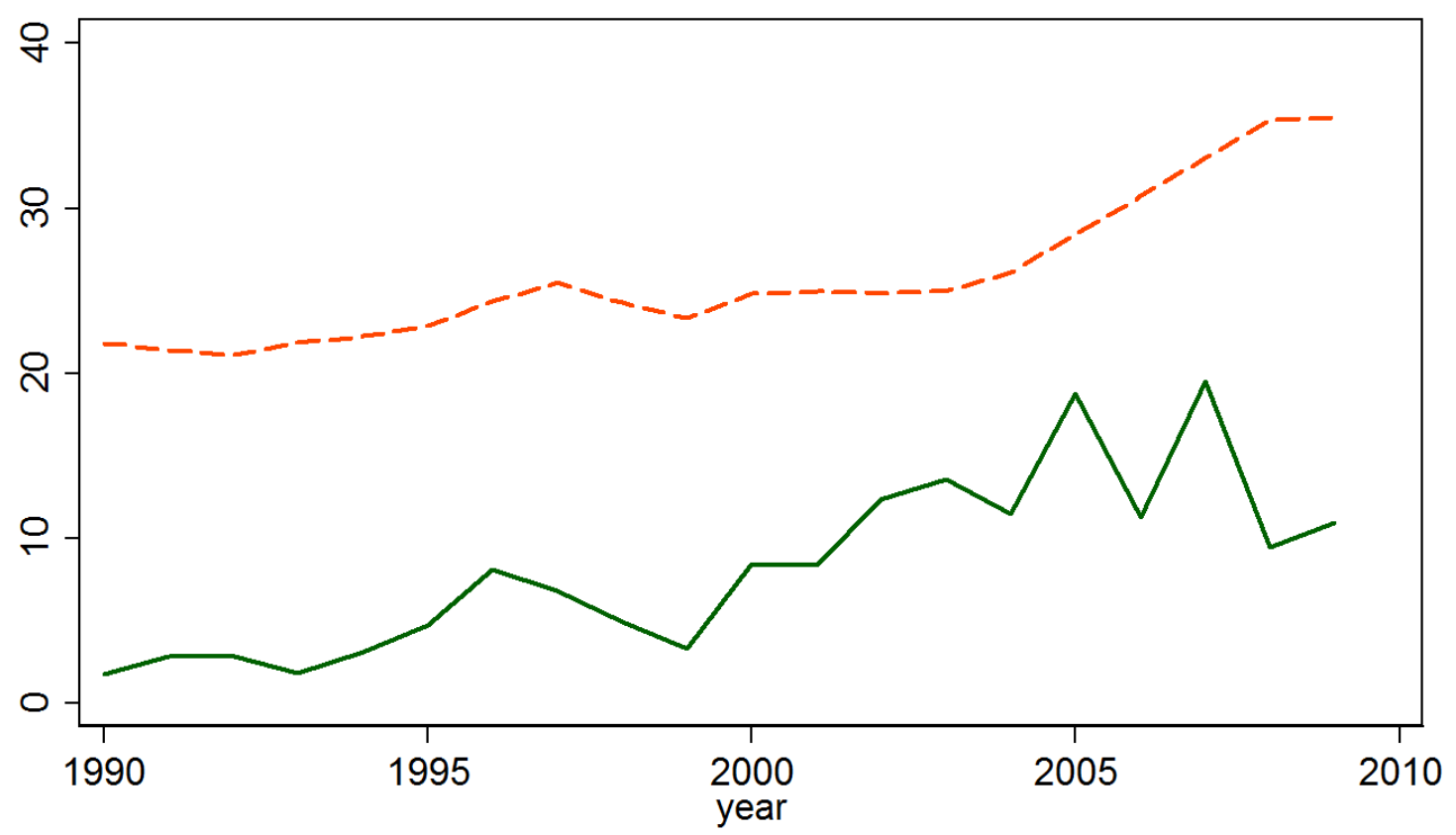

- Food aid provided by non-DAC donors ( $\%$ of world food aid)

- - - - GDP of non-DAC donor countries ( $\%$ of world GDP)

Data: Food Aid Information System (FAIS) \& World Development Indicators (WDI)

Figure 2: Share of BRICS countries in total trade (1990-2009)

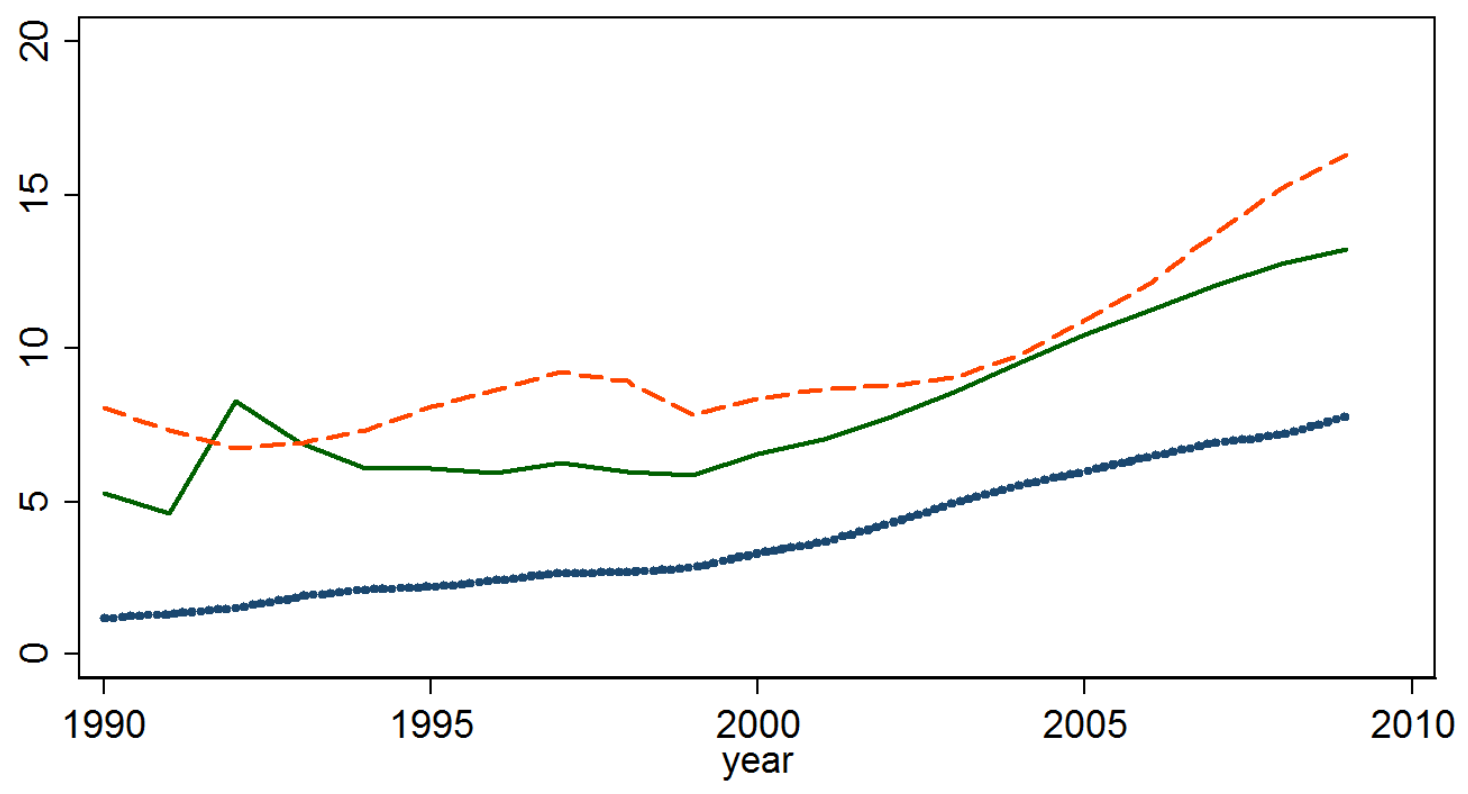

- Trade of BRICS countries (\% of world trade)

- - - - GDP of BRICS countries ( $\%$ of world GDP)

Trade of China (\% of world trade)

Data: World Development Indicators (WDI) 


\section{Political determinants of foreign aid of emerging donors}

A consensus has emerged in the literature that aid allocation frequently follows strategic interests rather than economic needs of recipient countries (e.g., Alesina and Dollar 2000; Kuziemko and Werker 2006; Dreher et al. 2009a, 2009b). This is of particular importance as aid motives are found to impact aid effectiveness (Kilby and Dreher 2010; Dreher et al. forthcoming). Although aid budgets from donor countries operating outside of the DAC are steadily increasing, few contributions have analyzed the aid decisions of emerging donors. ${ }^{5}$ This is striking, as the proliferation of donors is likely to change the existing international aid architecture. Tellingly, Woods (2008: 16) calls this (re)emergence of non-DAC donors a "silent revolution" taking place in the world of development assistance. ${ }^{6}$ Many recipient countries welcome alternative sources of funding. They are attracted by the principle of noninterference in the internal affairs of aid recipients that guides some of the non-DAC donors, or so-called "new" donors, such as China. In contrast, aid from "old" donors and multilateral institutions often comes with restrictive conditionality. The increased competition between donors increases recipient countries' room to maneuver in aid negotiations (Kragelund 2008). Aid from "new" donors, however, is not without its own conditions; it is widely perceived as a foreign economic policy tool because a significant proportion of development finance provided by emerging donors is commercially tied (e.g., Kragelund 2010).

The central aim of the first part of my thesis is to analyze the determinants of emerging donors' aid allocation and to compare their motives with those of traditional DAC donors. Despite the availability of data being particularly challenging, I empirically investigate the determinants of development aid provided by China and India, two of the most important so-called new donors. My dissertation contains the first study that compares China's aid allocation pattern with that of Western donor countries. In a related study within this dissertation, I investigate the determinants of aid allocation under India's foreign aid program and develop a "needy-donor theory." Furthermore, I study the allocation of emergency aid from a broad range of "new" donors. In an attempt to bridge the gap to the literature on aid effectiveness, this dissertation also contains the first empirical assessment of differences in aid promptness between donors.

The first four chapters of this dissertation study donor motives driving aid decisions. Before turning to foreign aid provided by emerging economies, Chapter I starts by analyzing

\footnotetext{
${ }^{5}$ Prior empirical research on emerging donors includes Neumayer (2003a, 2004) on Arab aid and Dreher et al. (2011) on non-DAC aid in general.

${ }^{6}$ Taking note of the aid activities by oil-rich Arab donor countries and Communist countries, most notably the Soviet Union, non-DAC donors are rather reemerging rather than appearing as new actors.
} 
the political aid motives of the "old" group of DAC donors. Having a better understanding of the determinants of aid allocation by Western donors provides the context in which to place the later findings on aid decisions of "new" donors. Specifically, the first chapter focuses on the usage of aid as a foreign policy tool within the framework of the War on Terror. The September 11 attacks marked the most important turning point in international relations after the end of the Cold War. This translated into increased usage of aid flows as a tool for terror prevention (e.g., Fleck and Kilby 2010). The chapter entitled Does Terror Increase Aid?, which is co-authored by Axel Dreher, empirically investigates whether, and in which ways, donors in the DAC responded to transnational terrorist incidents through changes in aid budgets and aid allocation. In a first step, we analyze the importance of the onset of the War on Terror for donor countries' aid budgets in a panel of the 22 DAC member countries. We further test whether ups and downs in terrorist activities can explain changes in aid budgets. In a second step, we investigate whether donor countries hit by terrorist attacks respond to these events through an increase or decrease in aid to the country of the main perpetrator.

According to our results, aid budgets have been on average significantly larger during the War on Terror period. While countries where terror originates are neither more nor less likely to become aid recipients, once they are selected, source countries of terrorism receive larger aid amounts. These findings are in line with the previous literature in the sense that political interests are shown to play an important role in aid budgets and aid allocation.

In Chapter II, I analyze together with Axel Dreher the aid allocation pattern of China, the largest provider of development finance among the BRIC countries. This chapter, entitled Rogue Aid? The Determinants of China's Aid Allocation, empirically investigates a popular claim that China acts as a "rogue donor." "Rogue donors" are said to follow self-interests regardless of developmental need in recipient countries and undermine Western efforts in the promotion of good governance (Naím 2007). To analyze the extent to which political and commercial interests guide China's aid allocation decisions, we collected data on project aid, food aid, medical aid and total aid money allocated to developing countries. This dataset covers all periods in the history of China's aid program (1956-2006). Moreover, we construct a comparable measure of the allocation pattern of project aid from traditional DAC and other emerging donors to compare China's allocation decisions with these donors.

While our results confirm that strategic considerations play an important role in China's allocation of aid, denominating China as a "rogue donor" lacks empirical support. Specifically, the importance of commercial and political self-interests is not outstanding in comparison to DAC donors. Most strikingly, we find no empirical support for the claim that 
China's aid is predominantly motivated by natural resource endowments of recipient countries. Moreover, China's aid allocation seems to be widely independent of the system of governance in recipient countries, which is in line with China's principle of non-interference in internal affairs.

While development finance from China receives a considerable amount of public interest and triggers concerns, India's aid program is less in the focus of academics and policymakers - despite rapidly increasing aid flows. Although India is a lower-middle-income economy that still faces severe developmental problems domestically, it is emerging as an important provider of development assistance to other developing countries. With the intention of understanding why poor countries provide foreign aid, Chapter III, entitled The Needy Donor: An Empirical Analysis of India's Aid Motives, analyzes the importance of political and commercial self-interests in India's aid allocation pattern. We hypothesize that aid from India is guided by self-interests to a larger extent than aid from richer donor countries, given the developmental problems a "needy" donor faces domestically. This study, co-authored by Krishna Chaitanya Vadlammanati, examines aid commitments by India's Ministry of External Affairs during the 2008-2010 period. Moreover, we compare India's bilateral aid allocation with that of DAC and emerging donors.

According to our empirical results, India's aid allocation mirrors to some extent our expectations of the behavior of a "needy" donor. In line with our hypotheses, commercial and political self-interests dominate India's aid allocation decisions. Moreover, India favors countries in its neighborhood as well as countries at a similar developmental stage, which is also in line with our hypotheses. Using donor-recipient voting alignment in the United Nations General Assembly as a proxy for bilateral affinity, we find political interests to play a significantly larger role for aid from India compared to all DAC donors under investigation.

Chapter IV analyzes the aid allocation of 105 donors of humanitarian aid from 2000 to 2009. This enables us to shed light on the consequences of the proliferation of aid donors. This chapter, entitled Emergency Aid 2.0 and written together with Nils-Hendrik Klann, compares aid decisions between DAC members and non-DAC donors, between high-income countries and less developed donors as well as between democracies and authoritarian regimes. We begin with a comparison of the donor decision to provide emergency aid between these donor groups. Since the timeliness of the aid delivery is crucial for disaster relief to be effective, we compile information on the decision time of donors after the occurrence of a disaster. More precisely, we empirically analyze which factors impact upon 
the number of days that pass after a natural disaster before a donor commits to providing emergency relief.

Our results show that "new" and "old" donors alike provide aid based on a combination of humanitarian need and their self-interests, in line with Dreher et al. (2011). Beyond that, we find considerable differences in the importance attached to different factors between the donor groups under investigation. With regard to aid promptness, we find DAC, developed and democratic countries to be significantly faster than non-DAC, developing and autocratic countries. We conclude that, despite increasing aid activities of "new" donors and with respect to aid promptness, "old" providers of aid continue to be important pillars of the emergency aid architecture for the time being.

\section{Political determinants of trade with China}

Previous research has shown that the bilateral political climate plays an important role in trade relationships (e.g., Pollins 1989; Gowa and Mansfield 1993), but doubts have been voiced as to whether this still holds in the era of globalization (Davis and Meunier 2011). The literature to date has largely ignored the growing capacity of rising powers to use trade deals and trade barriers as a form of economic punishment and reward to enforce political interests. In this context, it is essential to consider the possibility that political relations play a greater role in trading decisions for an autocratic emerging economy such as China than for trade between free-market economies. In line with this idea, Mansfield et al. (2000) and Aidt and Gassebner (2010) argue that autocratic governments exert more influence on their international trade flows than democratic administrations.

In this part of my thesis, I contribute to the literature by exploring the link between international politics and trade through an analysis of exports to China, undoubtedly the most important contributor to international trade among the emerging economies. Specifically, Chapter $V$ entitled Paying a Visit: The Dalai Lama Effect on International Trade, which is co-authored by Nils-Hendrik Klann, investigates whether receptions of the Dalai Lama by foreign government officials harm trade ties with China. The travel pattern of the Dalai Lama provides an interesting case to analyze the extent to which bilateral tensions affect trade with autocratic China. More precisely, we augment a gravity model of exports to China for 159 partner countries between 1991 and 2008 with variables capturing the travel pattern of the Tibetan leader. 
Our empirical findings show that countries officially receiving the Dalai Lama at the highest political level are subsequently punished through reduced exports to China. However, export reductions are only of temporary nature and we observe this 'Dalai Lama Effect' only for the $\mathrm{Hu}$ Jintao era and not for earlier periods. An analysis of disaggregated trade data shows that this effect is mainly driven by reduced exports of machinery and transport equipment. Our findings suggest that, with the increasing economic power of China and other (autocratic) emerging economies, the (ab)use of trade ties as a foreign policy tool is likely to grow in importance. 


\title{
Chapter I:
}

\section{Does Terror Increase Aid?}

\author{
Joint work with Axel Dreher ${ }^{\mathrm{a}}$
}

\begin{abstract}
This article empirically investigates whether, and in which ways, donors in the Development Assistance Committee respond to transnational terrorist incidents and the onset of the War on Terror through changes in aid effort and aid allocation. First, an analysis of 22 donor countries shows that aid effort increased during the War on Terror period, but did not respond to the actual number of terror events. Second, using aid allocation equations, we find that countries where terror originates are not more likely to receive aid as a consequence, but if they are selected, they receive larger amounts of aid.
\end{abstract}

Note: A similar version of this research has been published in a special issue of Public Choice on "The Many Faces of Counterterrorism" (Volume 149, Numbers 3-4 (2011), 337-363).

Acknowledgments: We thank participants at the 2011 Workshop on Terrorism and Policy, University of Texas at Dallas, U.S.A., and in particular Todd Sandler and an anonymous referee for helpful comments on an earlier draft. Excellent research assistance was provided by Christin Dietrich, Scott Jobson, Jan Paulick and Timo Plaga.

\footnotetext{
${ }^{a}$ Heidelberg University, Alfred-Weber-Institute for Economics, Bergheimer Strasse 58, 69115 Heidelberg, Germany, University of Goettingen, Germany, CESifo, Germany, IZA, Germany, and KOF Swiss Economic Institute, Switzerland, e-mail: mail[at]axel-dreher.de.
} 


\section{I.1 Introduction}

In their fight against international terrorism, governments and international organizations rely on strategies that are intended to alter the motivations of terrorists and their supporters. Among these carrots and sticks, it has been claimed that development aid has become an increasingly popular weapon in the fight against terrorism, especially in the aftermath of the September 11, 2001 (hereafter, 9/11) attacks. Former president George W. Bush explained that the United States would "fight against poverty because hope is an answer to terror" (cited in Krueger and Maleckova 2003: 119). According to the OECD (2003: 11), donor countries "can reduce support for terrorism by working towards preventing the conditions that give rise to violent conflict in general and that convince disaffected groups to embrace terrorism in particular." The European Union and the United States announced that they "will target [their] external relations actions towards priority Third Countries where counter-terrorist capacity or commitment to combating terrorism needs to be enhanced" and "will mainstream counterterrorist objectives into the work of external assistance programmes" (Council of the European Union 2004: 7). According to Woods (2005), the shift in resources towards fighting poverty is also noticeable in the United Kingdom. As Woods points out, "[t]he strain on the DFID's [Department for International Development] resources and mandate to reduce poverty posed by the war on terror and the war in Iraq is already noticeable" (p. 404).

There is some evidence that aid is effective in fighting terrorism. While Campos and Gassebner (2009) do not find a robust effect of aid on terror, Azam and Delacroix (2006), and Azam and Thelen $(2008,2010,2011)$ find that foreign aid does indeed reduce terror once the militancy of recipient countries is adequately controlled for. Bapat (2011) shows that military aid might not be effective in crushing terrorist organizations in the host country, but can prevent host governments from entering into negotiations with them. ${ }^{7}$

Overall, it seems that aid - if properly designed - might be a useful carrot in the fight against terror. This puts a new emphasis on the aid effectiveness debate. Aid has been shown to be quite ineffective in raising living standards in the recipient country (e.g., Doucouliagos and Paldam 2008). It is often argued that the motivation of the donor country for giving aid has an impact on its effectiveness (Kilby and Dreher 2010). Some donors might be more effective in promoting growth than others because, for example, their aid is not given for strategic or commercial reasons.

\footnotetext{
${ }^{7}$ Preliminary empirical evidence in Sharma et al. (2009), however, shows that terrorists increase the prevalence of their attacks as a consequence of aid flows.
} 
With the end of the Cold War, many observers expected that the effectiveness of aid would increase. However, it seems the period when developmental considerations could have dominated the allocation of aid was short. To the extent that aid is now given to fight terror, the effectiveness of aid would have to be judged with respect to whether this goal is achieved, rather than asking whether or not aid increases economic growth. However, no systematic evidence exists as to whether, and to what extent, donor countries have actually shifted the focus of their aid to fight terror rather than poverty. ${ }^{8}$ The exception is Fleck and Kilby (2010). However, Fleck and Kilby focus on the United States exclusively and capture the War on Terror by using a dummy only, rather than measuring the degree of terror.

We extend Fleck and Kilby's analysis in several ways. Most importantly, we cover all donor countries in the Development Assistance Committee (DAC) rather than limiting the analysis to the United States. A second important difference with respect to Fleck and Kilby is that we take into account the degree of terrorism to which a particular donor is exposed in a specific year. Rather than investigating general trends in aid over time, we can thus analyze whether donors hit harder by terror at a particular point in time react to this by increasing (or decreasing) their aid.

We start with an investigation of 22 DAC donors' aggregate aid effort, i.e., the aid budget as a share of gross national income (GNI). As a next step, using a three-dimensional panel of our 22 donors and 140 recipient countries, we estimate bilateral aid flows to test whether donors adjust their aid to countries from which terror originates. On the one hand, donors might increase their aid flows to the country of the perpetrators if they see development aid as a useful tool for terror prevention. On the other hand, aid flows might be cut as a form of punishment if donors want to signal their dissatisfaction with the domestic anti-terror policies of the recipient country. Which of these two effects prevails might depend on the political regime of the recipient country, as well as on whether the recipient is perceived to be an ally or an enemy, or a state sponsor of terror. Finally, we investigate different donors and types of aid separately.

To foreshadow our results, we find that aid effort increased in the War on Terror period controlling for other determinants, on average. However, aid budgets as a share of GNI do not respond to the number of terrorist incidents. While countries where terror against a particular donor originates are not more likely to receive aid as a consequence, if they are selected, they receive larger amounts of aid. Terror against DAC countries as a group, however, reduces the probability of receiving aid, on average. Introducing models where we

\footnotetext{
${ }^{8}$ The two might go together. However, Abadie (2006), among others, finds that there is no causality from poverty on terror, when controlling for other country characteristics.
} 
interact the number of terrorist incidents against DAC countries with other explanatory variables of interest, we find that this holds in particular for autocratic countries, for countries voting against the donor in the United Nations General Assembly and for state sponsors of terrorism, but not for the War on Terror period. Analyzing donors individually, we find that France and the United States increased their aid effort after 9/11. However, neither donor's aid effort was a function of the frequency of attack. In the allocation equation, we find that the United States increased aid to source countries of terror as a consequence of terrorist attacks, while France, Italy and Sweden reduce their aid to these countries. Disaggregating aid, we do not find that the share of aid tied to education or governance increases as a reaction to terrorism.

We proceed as follows. In Section I.2, we briefly summarize the previous literature on aid and terror. Section I.3 investigates the impact of terror on aid effort, while Section I.4 provides a disaggregated analysis of the effect of terror on aid allocation. We present extensions of the basic analyses in Section I.5. The final section concludes the paper.

\section{I.2 Aid and Terror}

The literature on aid and terror is growing. However, with the exception of two papers (Moss et al. 2005; Fleck and Kilby 2010), the previous literature investigates the effect of aid on terror rather than that of terror on aid. According to the theory of Azam and Delacroix (2006), terrorist groups determine their activities in a country based on militancy and the recipient governments' effort against terror. Their model predicts a co-movement of terrorist attacks and aid, which is confirmed through a simple regression analysis. However, this positive correlation between terror and aid might only reflect that more aid is being allocated to countries where more violent terror comes from, rather than implying that more aid leads to more terrorist activity. Indeed, once Azam and Delacroix introduce dummies for certain groups of countries where militancy is arguably more prevalent than in others, the effect of aid on terror becomes negative. While therefore providing indirect evidence that aid might react to terror, a direct test is lacking.

In exchange for aid, recipient governments are sometimes asked to implement counterterrorism measures against domestic terrorist groups. In this context, Azam and Thelen (2008, 2010, 2011) stress the importance of aid for education as opposed to general budget support. Subsidizing education improves the recipient's human capital, which can either increase or reduce the degree of terrorism. While the theory is thus ambiguous, the empirical results in 
Azam and Thelen show that education reduces terror. Any type of aid can reduce terror because the recipient has to pursue counter-terrorism measures in exchange, yet aid for education has additional positive side effects and is therefore said to be particularly effective. 9 The importance of aid for education is confirmed in Young and Findley (2011). According to their results, aid given to improve health, strengthen civil society and fight terror is also effective in reducing the number of terrorist attacks.

Bandyopadhyay et al.'s (2011) model stresses the relevance of distinguishing aid tied to fight terror from general assistance. In their model, aid can be tied to counter-terrorism measures of the recipient country. While such tied aid increases the recipient government's efforts in fighting resident terrorist groups, it also increases instability. This is because aid tied to fighting terrorism will meet resistance from some groups in the recipient country - e.g., Pakistan, Yemen, and Iraq. On the contrary, untied general aid is perceived as less intrusive as it does not directly involve the recipient government in the fight against terror, thus not posing a threat to the government's stability. To the extent that it helps in keeping US-friendly governments in power, it can be an effective (indirect) means of counter-terrorism. Donors face a trade-off between counter-terrorism aid and general budget support.

The two papers most similar to ours are Moss et al. (2005) and Fleck and Kilby (2010). Fleck and Kilby investigate whether US aid became less focused on poverty as a consequence of the United States' fight against terror. Rather than looking at the degree of terror directed at the United States, they investigate the poverty orientation of US aid in three periods, those being the Cold War, the War on Terror, and the period in between. During the War on Terror period, while the United States placed less emphasis on poverty when selecting countries for aid, once accounting for selection, per-capita GDP became more important for the allocation of aid. Overall, poor and less poor countries alike receive more aid in the War on Terror period in comparison to the interwar period. However, when analyzing year-to-year changes for core-recipients of aid, it became evident that the United States' responsiveness to need shows a decreasing trend since the onset of the War on Terror.

Moss et al. (2005) also focus on the effect of the War on Terror on the allocation of United States Agency for International Development (USAID) funds, comparing the allocation of US aid across recipient countries over the 1998-2001 versus 2002-05 periods.

\footnotetext{
${ }^{9}$ This assumes that aid for education can improve educational outcomes, implying that aid is not fully fungible. As Azam and Thelen (2008) explain, this might be due to differentiated inputs like highly qualified teachers. Dreher et al. (2008) provide empirical support for the effectiveness of aid for education. The positive effect of education on reducing terror stands in contrast to microeconomic evidence, for example reported in Krueger and Maleckova (2003). Azam and Thelen (2008) summarize the literature reconciling the macroeconomic with the microeconomic evidence.
} 
Relying on the presence of foreign terrorist groups in a country, sharing a border with a state sponsor of terrorism, troop contribution in Iraq, and the relative share of Muslim population, Moss et al. find no systematic shift in US aid policies. However, their cross-section exclusively focuses on the United States. They do not look at the overall aid budget or its composition; neither do they control for the effect of terrorist attacks.

Overall, while the previous literature has not come to a consensus as to whether or not aid reduces terror, it predicts that aid increases as a consequence of terror. With respect to the United States, this prediction has been tested. Using different empirical strategies, Moss et al. (2005) find virtually no evidence of an increase of US aid in response to the onset of the War on Terror, while Fleck and Kilby (2010) do find the expected change in allocation behavior when analyzing year-to-year changes. ${ }^{10}$ Arguably, the reorientation of development policies after $9 / 11$ is not restricted to the United States, but also affects most (if not all) donors in the DAC. For example, shortly after 9/11, the fight against terrorism became one of Germany's official objectives for development assistance. In October 2001, Federal Chancellor Gerhard Schröder declared that the "fight against hunger tops our list of the fight against terror." At the same time, Liz O'Donnell, Ireland's Minister of State at the Department of Foreign Affairs, attributed a "vital role" to play for "[d]evelopment coordination and the building of strong democracies [...] in the longer term in the fight against conflict and terrorism" (DFA 2001). In 2003, Australia's aid agency also incorporated the fight against terror into its objectives (AusAID 2003).

While these policy statements thus suggest that countries hosting terrorist groups should receive increased aid flows to assist them in the fight against terror, not all countries that host terrorism can equally expect increased aid inflows. Consider the terrorist attacks on Pan Am flight 103 and UTA flight 772 in 1988/89, which were attributed to state-sponsored terrorists from Libya. Rather than granting development aid to al-Gaddafi's regime, the United States imposed sanctions against the country. We think that this example can be generalized. If terrorist groups are supported by the government of their host country, or the attacks even originate within the government itself, we would expect aid to decrease, while aid will arguably increase to those governments that are considered to be allies in the fight against terror. In the empirical analysis below, we will test for these differences.

\footnotetext{
${ }^{10}$ This is when some outlying countries are taken account of.

${ }^{11}$ taz, 2001, Das Ende der Almosen, Die Tageszeitung, October 18, 2001, p. 12, own translation.
} 
Finally, we do not expect all types of aid to react to terror equally. As outlined above, Azam and Thelen (2008, 2010, 2011) and Young and Findley (2011) stress the importance of aid for education as opposed to general budget support. Bandyopadhyay et al. (2011) highlight the relevance of aid tied to the fight against terror. If donors anticipate the effectiveness of aid for education, we would expect this type of aid to react to terror in particular. If aid can effectively be tied to fight terror, we expect particularly visible effects with respect to this category of aid. We test these predictions below.

\section{I.3 Aid Effort and Terror over Time}

\section{I.3.1 Descriptive Evidence}

Our analysis covers the 22 DAC members in the $1971-2008$ period. ${ }^{12}$ We use data on Official Development Assistance (ODA) as provided by the OECD. All values are transformed into constant 2000 US\$. In order to control for the size of the economy, we follow the previous literature and express aid budgets as a percentage of GNI ("aid effort"). Since aid disbursements also reflect ongoing aid projects partly determined over long periods of time, we make use of aid commitments instead.

Figure I.1 shows the decrease in DAC aid committed during the interwar period and the surge in aid since $9 / 11$. The picture is in line with what we would expect. During the time of the Cold War, plenty of evidence reports that aid was used for strategic reasons. With the fall of the Iron Curtain, the need for such strategic aid became less prevalent. However, rather than sticking with the same level of aid and directing part of the money to where it could have been more effective in terms of other objectives, aid levels declined. Directly after 9/11, the trend reversed and aid levels increased markedly. Note that this is not driven by the United States, as is evident in the lower panel of the figure.

\footnotetext{
${ }^{12}$ Korea joined the DAC in 2010 and is therefore excluded from the analysis.
} 
Figure I.1: Aid effort over time
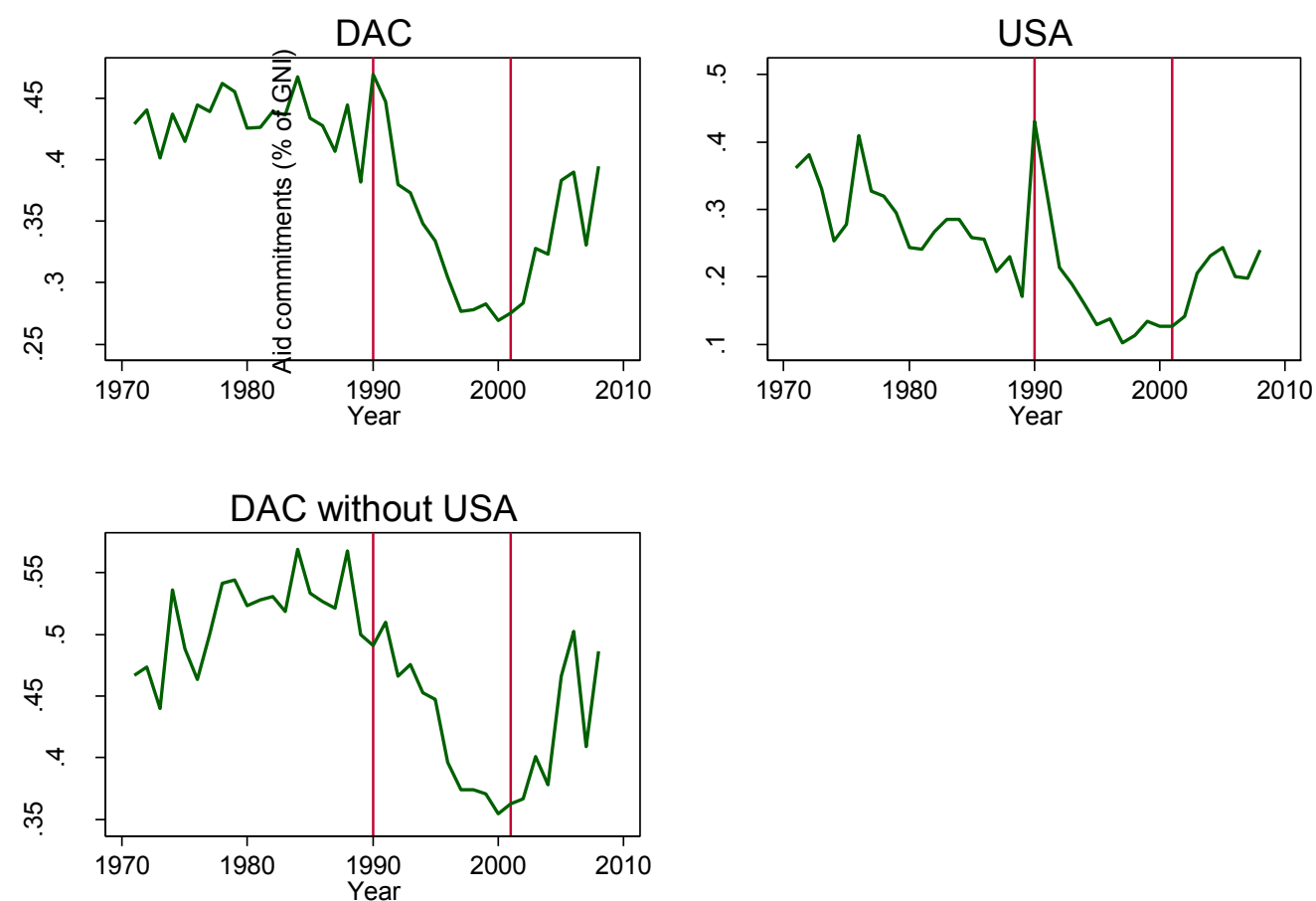

Turning to our measure of terrorist activity, we rely on "International Terrorism: Attributes of Terrorist Events" (ITERATE), collected by Mickolus et al. (2009). ITERATE provides data on global terrorist acts, including information on the type of attack, casualties and fatalities, and information about perpetrators and victims. The data are available over the 1968-2008 period. The definition of transnational terrorism applied in ITERATE follows Mickolus (1980: xiii), who defines transnational terrorism as "the use or threat of use, of anxiety, inducing extranormal violence for political purposes by any individual or group, whether acting for or in opposition to established government authority, when such action is intended to influence the attitudes and behavior of a target group wider than the immediate victims and when, through the nationality or foreign ties of its perpetrators, its location, the nature of its institutional or human victims, or the mechanics of its resolution, its ramifications transcend national boundaries."

The variable we extract from this database measures the number of transnational terror incidents originating from nationals of a particular recipient country, which are carried out on nationals of the donor country. ${ }^{13}$ We do not include domestic terrorism as we assume donors

\footnotetext{
${ }^{13}$ We include attacks against a particular donor in its own country, against its people or facilities in the country of origin of the terrorist, or against its people or facilities in any third country. A potential shortcoming of our terror measure is that it does not capture the intensity of the terrorist incident. While not a priori superior to the
} 
to be particularly interested in attacks potentially directed at them. While even al-Qaida engages in domestic attacks (Blomberg et al. 2011), much of domestic terrorism is of little interest to the international community. ${ }^{14}$ In our sample, 86 of 140 recipient countries were source of a terrorist attack and, with the exception of Luxembourg, all DAC donors were hit by transnational terror. Appendices I.8 and I.9 show maps that graphically display the source countries and targets of transnational terror in the 1967-2007 period. ${ }^{15}$ Interestingly, incidents of terror are decreasing over time, rather than increasing. In particular, the War on Terror period saw a relatively low number of terrorist attacks. Therefore, it seems to be the perceived threat from terrorist attacks that characterizes the War on Terror period, rather than the sheer number of terrorist incidents.

\section{I.3.2 Method of Estimation and Main Results}

We start by pooling all donors. Our regressions are time-series cross-section analyses (panel data) covering the 1971-2008 period. We use robust standard errors clustered at the country level. Since some of the data are not available for all countries or years, the panel data are unbalanced and the number of observations depends on the choice of explanatory variables. Following the previous literature, we include the lag of the dependent variable (e.g., Bertoli et al. 2008). ${ }^{16}$ Focusing on aggregate aid budgets as a share of GNI, the basic equation takes the following form:

$y_{i, t}=\alpha+\beta_{1} y_{i, t-1}+\beta_{2}$ Cold War $_{t}+\beta_{3}$ War on Terror $_{t}+\beta_{4} X_{i, t-1}+\eta_{i}+\varepsilon_{i, t}$,

where $y_{i, t}$ represents aid effort, i.e., total aid commitments as a share of GNI of donor country $i$ in year $t$, and Cold War ${ }_{t}$ and War on Terror $_{t}$ are dummies for the periods 1971-1990 and 2002-2008, respectively. $X_{i, t-1}$ is the vector of (lagged) control variables, $\eta_{i}$ represents country fixed effects, while $\varepsilon_{i, t}$ represents the error term. We include additional variables related to the degree of terror in further regressions.

number of fatalities for instance, terrorist incidents are commonly accepted as measure of terror in the literature (e.g., Gassebner et al. 2008, 2012). We thus assume that an attack can have important consequences even if no one is hurt or killed and leave a differential analysis of alternative measures of terrorism for future research.

${ }^{14}$ Examples are the Irish Republican Army (IRA), the Basque Euskadi Ta Askatasuna (ETA) and the German Rote Armee Fraktion (RAF). In aid-receiving countries, Shining Path (Peru), National Democratic Front for the Liberation of Bodoland and the National Liberation Front of Tripura (India) come to mind.

${ }^{15}$ Terror incidents of these years are considered in our regression analysis as explained below.

${ }^{16}$ Aid budgets evolve slowly over time because of the path dependence of decisions in the budgetary process. 
In choosing our control variables, we follow the literature on aid effort. The vector $X$ includes the donors' general government debt (as a percentage of GDP), assuming countries with higher debt to be less generous. We expect countries to be more generous when they are richer, measured by $(\log )$ per-capita GDP. Adding (log) population as a further control variable, we expect aid efforts to decrease with population size since small countries might be more generous than larger countries as they need to surmount a minimum threshold from which giving aid is meaningful (Round and Odedokun 2004). Finally, we account for a donor country's government size. Since broad categorizations of welfare state attributes are generally stable over time, measures of government size may better reflect donor countries' stance towards redistribution. ${ }^{17}$ Appendix I.1 shows the exact definitions of all variables with their sources, while Appendix I.2 reports descriptive statistics.

Columns 1-4 of Table I.1 show our results with the fixed effects model of equation (I.1). We find that a country's aid effort increases with per-capita GDP, at least at the tenpercent level. The lagged dependent variable is highly significant. The coefficients on debt, population, and government size all exhibit the expected signs but they are not significant at conventional levels. $^{18}$

Turning to our variables of interest, in column 1, both period dummies are significant. With respect to the interwar period, and ignoring longer-term effects via the lagged dependent variable, aid effort has been 0.065 percentage points higher during the Cold War period, at the one-percent level of significance. At the ten-percent level, the results also show that aid effort significantly increased in the War on Terror period, on average. Compared to the Cold War, the increase is smaller; at 0.023 percentage points in the short-run (i.e., again ignoring the lagged dependent variable), it is not negligible but far from dramatic. In fact, the difference in the coefficients for the Cold War and War on Terror periods is not statistically significant at conventional levels.

\footnotetext{
${ }^{17}$ For example, Bertoli et al. (2008) find a positive effect of government revenue (as a share of GDP) on aid effort as a larger government size gives "more room for aid granting" and mirrors the donor country's propensity to redistribute.

${ }^{18}$ This is with the exception of column 4, where the effect of population is significant at the ten-percent level. Note that when we omit the lagged dependent variable, the coefficients of all control variables gain statistical significance, with their expected signs. The coefficients on the War on Terror dummy increase slightly, while their significance decreases somewhat.
} 
Table I.1: Aid effort (1971-2008)

\begin{tabular}{|c|c|c|c|c|c|c|c|c|}
\hline & (1) & $(2)$ & (3) & (4) & (5) & (6) & (7) & (8) \\
\hline & OLS & OLS & OLS & OLS & GMM & GMM & GMM & GMM \\
\hline \multirow[t]{2}{*}{ Aid effort (t-1) } & $0.4745 * * *$ & $0.4535 * * *$ & $0.4534 * * *$ & $0.4532 * * *$ & -0.2509 & $0.3805^{*}$ & $0.5705^{* * *}$ & 0.2424 \\
\hline & $(0.00)$ & $(0.00)$ & $(0.00)$ & $(0.00)$ & $(0.41)$ & $(0.06)$ & $(0.00)$ & $(0.32)$ \\
\hline \multirow[t]{2}{*}{ Debt (t-1) } & -0.0008 & -0.0008 & -0.0008 & -0.0008 & 0.0007 & -0.0008 & $-0.0009 *$ & -0.0006 \\
\hline & $(0.12)$ & $(0.13)$ & $(0.14)$ & $(0.13)$ & $(0.74)$ & $(0.15)$ & $(0.07)$ & $(0.52)$ \\
\hline \multirow[t]{2}{*}{ (log) GDP per capita (t-1) } & $0.1417^{*}$ & $0.1427^{* *}$ & $0.1363 * *$ & $0.1463 *$ & $0.6121 * * *$ & $0.1800 * *$ & 0.0782 & $0.2617^{*}$ \\
\hline & $(0.06)$ & $(0.04)$ & $(0.05)$ & $(0.05)$ & $(0.01)$ & $(0.03)$ & $(0.25)$ & $(0.08)$ \\
\hline \multirow[t]{2}{*}{ (log) Population (t-1) } & -0.2378 & -0.2672 & -0.2653 & $-0.2800 *$ & $-0.0777^{* *}$ & $-0.0352 * *$ & $-0.0208 *$ & $-0.0580 *$ \\
\hline & $(0.12)$ & $(0.11)$ & $(0.12)$ & $(0.10)$ & $(0.01)$ & $(0.04)$ & $(0.06)$ & $(0.07)$ \\
\hline \multirow[t]{2}{*}{ Government size (t-1) } & 0.0021 & 0.0020 & 0.0017 & 0.0020 & $0.0191 * * *$ & $0.0083^{*}$ & 0.0043 & $0.0109 * *$ \\
\hline & $(0.19)$ & $(0.33)$ & $(0.32)$ & $(0.22)$ & $(0.00)$ & $(0.07)$ & $(0.17)$ & $(0.02)$ \\
\hline \multirow[t]{2}{*}{ Cold War } & $0.0653 * * *$ & $0.0661 * *$ & $0.0627^{* *}$ & $0.0664 * *$ & $0.8721 * *$ & $0.2184^{* *}$ & $0.0821^{*}$ & $0.3339 *$ \\
\hline & $(0.01)$ & $(0.01)$ & $(0.01)$ & $(0.01)$ & $(0.01)$ & $(0.01)$ & $(0.10)$ & $(0.08)$ \\
\hline \multirow[t]{2}{*}{ War on Terror } & $0.0227^{*}$ & $0.0231 *$ & $0.0266 * *$ & $0.0232 *$ & $0.3499 * *$ & $0.1892 *$ & $0.2172 * *$ & $0.2043^{* *}$ \\
\hline & $(0.07)$ & $(0.08)$ & $(0.01)$ & $(0.07)$ & $(0.05)$ & $(0.05)$ & $(0.04)$ & $(0.04)$ \\
\hline \multirow[t]{2}{*}{ Terror worldwide (t-1) } & & -0.00002 & & & & 0.0006 & & \\
\hline & & $(0.94)$ & & & & $(0.32)$ & & \\
\hline \multirow[t]{2}{*}{ Terror DAC (t-1) } & & & 0.0001 & & & & 0.0019 & \\
\hline & & & $(0.81)$ & & & & $(0.13)$ & \\
\hline \multirow[t]{2}{*}{ Terror donor (t-1) } & & & & -0.0005 & & & & 0.0046 \\
\hline & & & & $(0.39)$ & & & & $(0.17)$ \\
\hline Number of observations & 614 & 603 & 603 & 603 & 614 & 603 & 603 & 603 \\
\hline Number of countries & 22 & 22 & 22 & 22 & 22 & 22 & 22 & 22 \\
\hline Adjusted R-squared & 0.34 & 0.32 & 0.32 & 0.32 & & & & \\
\hline Number of instruments & & & & & 9 & 13 & 13 & 13 \\
\hline Arellano-Bond test $(\mathrm{Pr}>\mathrm{z})$ & & & & & 0.11 & 0.67 & 0.40 & 0.99 \\
\hline Hansen test (Prob>chi2) & & & & & 0.72 & 0.43 & 0.44 & 0.41 \\
\hline
\end{tabular}

Note: Robust $p$-values in parentheses $\left(* * * p<0.01,{ }^{* *} p<0.05, * p<0.1\right)$.

In column 2, we control for the number of terror events which occurred over the last four years worldwide. ${ }^{19}$ While the dummy for the War on Terror stays significant, the number of terror incidents has no significant effect on aid effort at conventional levels. Taking the result at face value, while there has been a general increase in aid budgets as a share of GNI since 2001, aid effort did not rise in the aftermath of a high prevalence of terror. It thus seems that the aid regime shifted due to the increased risk of terror perceived after $9 / 11$, while aid has not been systematically used to fight terror over the whole sample period.

\footnotetext{
${ }^{19}$ We chose four years as this period corresponds to the typical planning horizon of the government budget.
} 
Donor countries might be particularly concerned about terrorist attacks against allied nations or against the 'Western world' in general. Therefore, column 3 replaces the number of worldwide incidents with the number of incidents against citizens of DAC countries. Yet again, the coefficient is not significant at conventional levels. The same holds when we include terrorist attacks on the individual donor countries rather than total attacks against the country group (column 4$){ }^{20}$

Arguably, terror might be endogenous to aid. If aid does actually reduce terror, as shown by Azam and Thelen (2008, 2010, 2011), our estimates are likely to reflect a lower bound. As an attempt to address this issue, we proceed with the System GMM estimator, developed in Arellano and Bover (1995) and Blundell and Bond (1998). As we admittedly lack good external instruments for terror, we rely on internal instrumental variables. The results are based on the two-step estimator implemented by Roodman (2009) in Stata, including Windmeijer's (2005) finite sample correction. We treat the lagged dependent variable and terror incidents (as well as the interactions with attacks on a particular donor) as endogenous, and debt, GDP per capita, population and government size as exogenous instruments.

In a comparably long panel like ours, the number of instruments is excessive if all possible lags are employed. In order to minimize the number of instruments in the regressions, we restrict the matrix of instruments, using only lags $t-2$ to $t-4$, and collapse the matrix of instruments. Given that terrorist incidents are averaged over four years, we use lags t-5 to t-7 here. The Hansen test on the validity of the instruments used (amounting to a test for the exogeneity of the covariates), and the Arellano-Bond test of second-order autocorrelation (which must be absent from the data in order for the estimator to be consistent), do not reject the specifications at conventional levels and thus support our choice of the variables to be modeled as exogenous.

The results are shown in columns 5-8 of Table I.1. Qualitatively, they are similar to those reported above. Aid effort is higher in the War on Terror period than in the interwar period. The number of terrorist incidents is again not significant at conventional levels.

\footnotetext{
${ }^{20}$ Although we do not find that aid effort responds to the number of terrorist incidents, it may be the case that governments started responding to the intensity of terror during the War on Terror period. However, when adding interaction terms between the period dummies and the number of terrorist attacks on a particular donor country, the interaction effects are not significant at conventional levels. This implies that the average donor did not adjust its aid effort during the War on Terror period as a response to terrorism against its citizens.
} 


\section{I.4 Panel Data Analysis of Aid Allocation}

Using bilateral ODA flows instead of aggregate aid amounts, we test for the impact of the War on Terror and transnational terrorist incidents on the allocation of aid. The basic equation changes to:

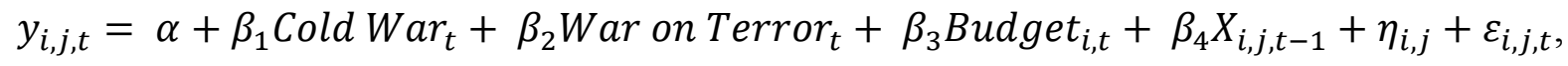

where $y_{i, j, t}$ represents $(\log )$ aid commitments in constant 2000 US\$ of donor $i$ to recipient $j$ in year $t$, and Cold War W $_{t}$ and War on Terror $_{t}$ are dummies for the periods 1971-1990 and 2002-2008 respectively, as was the case before. ${ }^{21} X_{i, j, t-1}$ is the vector of (lagged) control variables. Rather than controlling for individual donor characteristics, we include the donors' (log) overall aid commitments Budget ${ }_{i, t}$. As before, $\varepsilon_{i, j, t}$ represents the error term, while $\eta_{i, j}$ now represents donor-recipient-pair fixed effects. We again add additional variables related to the degree of terror in further regressions.

As Neumayer (2002) points out, there are essentially two options for dealing with the bounded nature of the dependent variable. The first option is based on the assumption that donors decide - in the first step - whether to allocate aid to a country at all, while - in the second step - they decide on the amount of aid to be given once recipients are selected. For the first step of this model, Probit (or Logit) is the adequate technique of estimation. Ideally, the second step should take account of information derived from the first step. This can be achieved if the inverse Mills ratio derived from the first step is included in an ordinary least squares (OLS) estimation of the sample of selected countries.

The second option is based on the assumption that the variables determine both whether a country is selected as an aid recipient, and how much aid is being allocated to that country in the same way. Tobit would then be the preferred method. Arguably, the underlying assumption is a strict one. Neumayer (2002) thus suggests OLS as an alternative method of estimation, ignoring the selection bias that tends to result from not considering the inverse Mills ratio. The bias associated with OLS might be moderate when the sample contains a limited number of zero observations.

\footnotetext{
${ }^{21}$ Note that here and in the following we added 1 to the underlying variables before taking the log to avoid losing zero observations where appropriate (see also Appendix I.1). Note that we do not include the lagged dependent variable here, in line with the literature on aid allocation (e.g., Kilby 2011). Focusing on individual recipient countries, it is not obvious whether the likelihood of receiving aid commitments in $t$ increases or decreases with the amount of aid received in $\mathrm{t}-1$. On the one hand, a country that has received an aid package in $\mathrm{t}-1$ might receive even more in $\mathrm{t}$ because of strong aid ties, but on the other hand, a country might be excluded from new aid funds in $\mathrm{t}$ because of high aid commitments in $\mathrm{t}-1$.
} 
With this in mind, we estimated a Heckman selection model and compared the selection to the allocation equation. This was done in order to see whether restricting their coefficients to be equal would be an option here, so that we could estimate Tobit regressions instead. We also tested whether the selection and allocation equations are independent from one another, so that separate selection and allocation equations could be estimated. The results show that neither independent equations, nor Tobit models are adequate. The results reported below therefore rely on the Heckman approach (with standard errors clustered by donorrecipient pairs). Note that the donor-recipient-pair fixed effects included in equation (I.2) can only be included in the (linear) allocation equation but not in the (non-linear) selection equation, due to the incidental parameter problem. We therefore replaced them by country and recipient fixed effects in the selection equation.

In line with the previous literature on aid allocation, $X$ contains a set of possible determinants as explanatory variables (see Chapter II). We control for (logged) population of recipient countries in order to control for the size of a country. Larger countries need more resources to develop. The recipient's (logged) per-capita GDP and the (logged) total number of people affected by a natural disaster in the recipient country are used as indicators for recipient need. Our measure for merit is a dummy for democracy, following the definition of Cheibub et al. (2009).

To proxy donors' political self-interests, the literature suggests a recipient country's voting behavior in the United Nations General Assembly (UNGA). Various empirical studies show that developing countries receive more aid and better conditions from donors when they have closer political ties with the donor, as measured by their UNGA voting alignment (e.g., Kilby 2009b, 2011). Relying on data from Voeten and Merdzanovic (2009), we calculate the number of times a country votes in line with the respective donor (either both voting yes, both voting no, both voting abstentions, or both being absent). We then divide it by the total number of votes in a particular year to derive a measure of voting coincidence between zero and one. To account for commercial interests, we include the respective donor's (log) total exports to a particular recipient country in constant US\$, as well as a recipient country's (log) oil production in barrels per day. Again, all variables with their definitions and sources are provided in Appendix I.1, while Appendix I.2 reports descriptive statistics.

Table I.2 shows the results. While column 1 shows the selection equation of a Heckman model, column 2 reports the corresponding allocation equation. ${ }^{22}$ Given the

\footnotetext{
${ }^{22} \mathrm{We}$ do not impose an exclusion restriction on the allocation equation but identify the model based on the nonlinearity inherent in the selection equation. Note that the Wald test for independent equations is highly
} 
inclusion of fixed effects, note that the results for the selection equation have to be interpreted in terms of deviations from the donor and recipient means, and in terms of deviations from the average values of the donor-recipient pair in case of the allocation equation.

The results for the control variables are largely in line with the previous literature. Both the estimated probability of receiving aid and the estimated amount of aid are below the recipient country's norm when its per-capita GDP is above its norm, at the one-percent level of significance. Also at the one-percent level, countries receive more aid with rising population (and more frequently). In both equations, disasters increase aid. Countries are more likely to receive aid when they become a democracy, and receive more aid with democracy once selected (at the one-percent level).

While the results indicate that need is important for the allocation of aid, the same holds for political and commercial motives. Countries voting in line with a particular donor in the UNGA are more likely to receive aid, at the five-percent level of significance (but the positive coefficient in the allocation equation is not statistically significant). Bilateral exports are significant in both equations (at the one-percent level), with the expected positive coefficient. The coefficient on oil production is not statistically significant at conventional levels, while larger donor budgets increase aid and the probability to be selected as aid recipient at the one-percent level.

We now turn to our variables of main interest. Compared to the interwar period, countries are more likely to be selected as recipients of aid in the Cold War period and receive more aid once selected. The picture is different for the period after $9 / 11$. At the one-percent level, countries are more likely to be selected, but - once selected - the amount of aid they receive is less compared to the interwar period. In other words, the increased aid effort in the War on Terror period leads to a higher proliferation to more recipients with smaller individual aid portions (11.1 percent $[=\exp (-0.1172)-1]$ smaller compared to the interwar period). 
Table I.2: Aid allocation (1971-2008)

\begin{tabular}{|c|c|c|c|c|c|c|c|c|}
\hline & (1) & (2) & (3) & (4) & \multirow{3}{*}{$\begin{array}{c}\text { (5) } \\
\text { GMM } \\
(\log ) \text { ODA }\end{array}$} & (6) & (7) & \multirow{3}{*}{$\begin{array}{c}\text { (8) } \\
\text { GMM } \\
(\log ) \text { ODA }\end{array}$} \\
\hline & \multicolumn{2}{|c|}{ Heckman } & \multicolumn{2}{|c|}{ Heckman } & & \multicolumn{2}{|c|}{ Heckman } & \\
\hline & $O D A>0$ & $(\log )$ ODA & $\mathrm{ODA}>0$ & $(\log )$ ODA & & $O D A>0$ & $(\log )$ ODA & \\
\hline (log) GDP per capita (t-1) & $\begin{array}{c}-0.1747^{* * *} \\
(0.00)\end{array}$ & $\begin{array}{c}-0.4324 * * * \\
(0.00)\end{array}$ & $\begin{array}{c}-0.2014 * * * \\
(0.00)\end{array}$ & $\begin{array}{c}-0.4522 * * * \\
(0.00)\end{array}$ & $\begin{array}{c}-0.3441 * * * \\
(0.00)\end{array}$ & $\begin{array}{c}-0.1783^{* * *} \\
(0.00)\end{array}$ & $\begin{array}{c}-0.4313^{* * *} \\
(0.00)\end{array}$ & $\begin{array}{c}-0.3379 * * * \\
(0.00)\end{array}$ \\
\hline (log) Population (t-1) & $\begin{array}{c}0.9989 * * * \\
(0.00)\end{array}$ & $\begin{array}{c}0.3119 * * * \\
(0.00)\end{array}$ & $\begin{array}{c}1.0116^{* * *} \\
(0.00)\end{array}$ & $\begin{array}{c}0.3010^{* * *} \\
(0.01)\end{array}$ & $\begin{array}{c}0.4249 * * * \\
(0.00)\end{array}$ & $\begin{array}{c}1.0095^{* * *} \\
(0.00)\end{array}$ & $\begin{array}{c}0.3097^{* * *} \\
(0.00)\end{array}$ & $\begin{array}{c}0.4345^{* * *} \\
(0.00)\end{array}$ \\
\hline (log) Disaster (t-1) & $\begin{array}{c}0.0093^{* * *} \\
(0.00)\end{array}$ & $\begin{array}{c}0.0060^{* * *} \\
(0.00)\end{array}$ & $\begin{array}{c}0.0089 * * * \\
(0.00)\end{array}$ & $\begin{array}{c}0.0049 * * * \\
(0.00)\end{array}$ & $\begin{array}{c}-0.0073 \\
(0.31)\end{array}$ & $\begin{array}{c}0.0093^{* * *} \\
(0.00)\end{array}$ & $\begin{array}{c}0.0060^{* * *} \\
(0.00)\end{array}$ & $\begin{array}{c}-0.0008 \\
(0.89)\end{array}$ \\
\hline Democracy $(\mathrm{t}-1)$ & $\begin{array}{c}0.2745^{* * *} \\
(0.00)\end{array}$ & $\begin{array}{c}0.1967^{* * *} \\
(0.00)\end{array}$ & $\begin{array}{c}0.2481^{* * *} \\
(0.00)\end{array}$ & $\begin{array}{c}0.1757^{* * *} \\
(0.00)\end{array}$ & $\begin{array}{c}-0.3639 * * \\
(0.04)\end{array}$ & $\begin{array}{c}0.2723^{* * *} \\
(0.00)\end{array}$ & $\begin{array}{c}0.1966^{* * *} \\
(0.00)\end{array}$ & $\begin{array}{c}-0.2122 \\
(0.12)\end{array}$ \\
\hline UNGA voting (t-1) & $\begin{array}{c}0.2691^{* *} \\
(0.02)\end{array}$ & $\begin{array}{c}0.0558 \\
(0.68)\end{array}$ & $\begin{array}{c}0.0239 \\
(0.86)\end{array}$ & $\begin{array}{c}-0.2188 \\
(0.13)\end{array}$ & $\begin{array}{c}-0.6087 \\
(0.22)\end{array}$ & $\begin{array}{c}0.2645^{* *} \\
(0.02)\end{array}$ & $\begin{array}{c}0.0575 \\
(0.67)\end{array}$ & $\begin{array}{c}-0.2257 \\
(0.39)\end{array}$ \\
\hline (log) Bilateral exports (t-1) & $\begin{array}{c}0.0633^{* * *} \\
(0.00)\end{array}$ & $\begin{array}{c}0.0212^{* * *} \\
(0.00)\end{array}$ & $\begin{array}{c}0.0627^{* * *} \\
(0.00)\end{array}$ & $\begin{array}{c}0.0167 * * \\
(0.01)\end{array}$ & $\begin{array}{c}0.1259^{* * *} \\
(0.00)\end{array}$ & $\begin{array}{c}0.0634^{* * *} \\
(0.00)\end{array}$ & $\begin{array}{c}0.0211^{* * *} \\
(0.00)\end{array}$ & $\begin{array}{c}0.1152^{* * *} \\
(0.00)\end{array}$ \\
\hline (log) Oil production (t-1) & $\begin{array}{c}-0.0052 \\
(0.31)\end{array}$ & $\begin{array}{c}0.0053 \\
(0.35)\end{array}$ & $\begin{array}{c}0.0000 \\
(1.00)\end{array}$ & $\begin{array}{c}0.0085 \\
(0.13)\end{array}$ & $\begin{array}{c}-0.0443^{* * *} \\
(0.00)\end{array}$ & $\begin{array}{c}-0.0047 \\
(0.36)\end{array}$ & $\begin{array}{c}0.0052 \\
(0.36)\end{array}$ & $\begin{array}{c}-0.0456^{* * *} \\
(0.00)\end{array}$ \\
\hline (log) Donor total commitments (t-1) & $\begin{array}{c}0.3494^{* * *} \\
(0.00)\end{array}$ & $\begin{array}{c}0.9624^{* * *} \\
(0.00)\end{array}$ & $\begin{array}{c}0.3317^{* * * *} \\
(0.00)\end{array}$ & $\begin{array}{c}0.9446^{* * *} \\
(0.00)\end{array}$ & $\begin{array}{c}0.8402 * * * \\
(0.00)\end{array}$ & $\begin{array}{c}0.3494^{* * *} \\
(0.00)\end{array}$ & $\begin{array}{c}0.9622 * * * \\
(0.00)\end{array}$ & $\begin{array}{c}0.8555^{* * *} \\
\quad(0.00)\end{array}$ \\
\hline Cold War & $\begin{array}{c}0.1354^{* * *} \\
(0.00)\end{array}$ & $\begin{array}{c}0.3249 * * * \\
(0.00)\end{array}$ & $\begin{array}{c}0.1353^{* * *} \\
(0.00)\end{array}$ & $\begin{array}{c}0.3136^{* * *} \\
(0.00)\end{array}$ & $\begin{array}{c}-2.0125 \\
(0.14)\end{array}$ & $\begin{array}{c}0.1375^{* * *} \\
(0.00)\end{array}$ & $\begin{array}{c}0.3247^{* * *} \\
(0.00)\end{array}$ & $\begin{array}{c}-0.7643 \\
(0.36)\end{array}$ \\
\hline War on Terror & $\begin{array}{c}0.0945^{* * *} \\
(0.00)\end{array}$ & $\begin{array}{c}-0.1172 * * * \\
(0.00)\end{array}$ & $\begin{array}{c}0.0747^{* * *} \\
(0.01)\end{array}$ & $\begin{array}{c}-0.1349 * * * \\
(0.00)\end{array}$ & $\begin{array}{c}-0.9438 \\
(0.31)\end{array}$ & $\begin{array}{c}0.0909 * * * \\
(0.00)\end{array}$ & $\begin{array}{c}-0.1163^{* * *} \\
(0.00)\end{array}$ & $\begin{array}{c}-0.4284^{*} \\
(0.07)\end{array}$ \\
\hline Bilateral terror donor $(\mathrm{t}-1)$ & & & $\begin{array}{c}-0.0428 \\
(0.26)\end{array}$ & $\begin{array}{c}0.0725^{* * *} \\
(0.00)\end{array}$ & $\begin{array}{c}0.3418^{*} \\
(0.09)\end{array}$ & & & \\
\hline Bilateral terror DAC (t-1) & & & & & & $\begin{array}{c}-0.0148^{* *} \\
(0.03)\end{array}$ & $\begin{array}{c}0.0033 \\
(0.61) \\
\end{array}$ & $\begin{array}{c}0.0335 \\
(0.33) \\
\end{array}$ \\
\hline Donor dummies & Yes & No & Yes & No & No & Yes & No & No \\
\hline Recipient dummies & Yes & No & Yes & No & No & Yes & No & No \\
\hline Pair effects & No & Yes & No & Yes & No & No & Yes & No \\
\hline Number of observations & \multicolumn{2}{|c|}{71279} & \multicolumn{2}{|c|}{68082} & 45694 & \multicolumn{2}{|c|}{71279} & 47132 \\
\hline Number of country-pairs & \multirow{4}{*}{\multicolumn{2}{|c|}{2856}} & \multirow{4}{*}{\multicolumn{2}{|c|}{2794}} & 2633 & \multirow{4}{*}{\multicolumn{2}{|c|}{2856}} & 2699 \\
\hline Number of instruments & & & & & 21 & & & 21 \\
\hline Arellano-Bond test $(\mathrm{Pr}>\mathrm{z})$ & & & & & 0.39 & & & 0.37 \\
\hline Hansen test (Prob>chi2) & & & & & 0.80 & & & 0.12 \\
\hline
\end{tabular}

Note: Robust $p$-values in parentheses $\left({ }^{* * *} p<0.01,{ }^{* *} p<0.05,{ }^{*} p<0.1\right)$. 
Columns 3 and 4 of Table I.2 replicate the model with the inclusion of the number of terrorist incidents on the individual donor countries. As can be seen, this has no substantial effect on the War on Terror dummy and the control variables. The number of incidents involving a particular donor country has no significant effect on the probability of giving aid to the country the terror attacks originate from. However, once a country is part of the victim's aid program, the donor country increases its aid flows to the country from which the terror attack originates by 7.3 percent per incident, on average. This provides initial evidence that countries who are already in good standing with donors through established aid relationships receive more aid in the fight against terror, while countries with weaker alliances do not. $^{23}$

Next, we replicate the allocation equation with System GMM to control for endogeneity as discussed above. We treat the number of terrorist incidents as endogenous and all other control variables as exogenous. Again we use lags greater than t-4 given that terrorist incidents are averaged over four years. ${ }^{24}$ We find that neither the period after 9/11, nor terrorist incidents have a significant effect on the allocation of aid, but the Arellano-Bond test rejects the specification (results available on request). When we restrict the instrument matrix until $\mathrm{t}-15$, the Arellano-Bond test does accept the specification and terrorist events increase aid commitments at the ten-percent level (column 5). ${ }^{25}$

Columns 6-8 focus on bilateral terror against DAC countries rather than against a particular donor exclusively. ${ }^{26}$ The probability of receiving aid decreases at the five-percent level when more terror originates from a particular country (column 6). The amount of aid is not affected however (columns 7 and 8). In other words, once a donor country provides aid to a particular recipient, a terror attack originating from citizens of the recipient country does not lead to a reduction in the amount of aid committed, but will make it less likely that a country is selected as an aid recipient in the first place. This is again in line with the idea that countries which are in no good standing with the donor through established aid relationships

\footnotetext{
${ }^{23}$ As an additional explanation, the public good character of aid might dominate here, so that on average countries rely on other donors to increase their resources in the fight against terror. We thank Todd Sandler for pointing this out.

${ }^{24}$ Given the higher number of observations compared to the analysis of aid budgets in Section I.3, we do not need to restrict the number of lags to three in order to keep the number of instruments sufficiently low.

${ }^{25}$ This result does not depend on the specific cut-off chosen. When using t-20 for example, the coefficient is significant at the five-percent level.

${ }^{26}$ Note that the number of observations is larger when we employ the DAC terror measure instead of the donor terror measure, since missing observations of terror incidents of individual donor-recipient pairs are disregarded in the calculation of the DAC total numbers. If we restrict the regressions of columns 6-8 to the sample of columns 3-5 the results are unchanged.
} 
get punished for terror arising from their citizens. Comparing the results to those of columns 3 and 4 , the difference in the effect of terror on the donor compared to the DAC as a whole might be explained by compositional effects. With an aid relationship already in place, it seems less likely that terror against the donor is, on average, state-sponsored. Such statesponsored terror is more likely to arise from countries with which no friendly (aid-)relationships exist. Aid thus increases to countries with already established relationships, but does not go to additional countries. However, recipients of aid from a specific donor might well sponsor terrorist attacks on other DAC donors. As a consequence, other DAC donors interrupt their aid relationships with the state sponsor of terror.

In Tables I.3a and I.3b, we introduce several interactions to test for differential treatment of recipient countries. First, we investigate whether the impact of terror incidents on aid has changed in the War on Terror period. Second, as we argued above, it is more likely that some types of countries will receive more aid as a consequence of terror originating from their soil than others. We use three variables to test for this proposition. Arguably, democracies are less likely to be perceived as a threat to the average DAC donor country as their values are more in conjunction with the donor. On average, it seems reasonable to assume that government support for terrorism declines with democracy. We thus assume that aid as a reaction to terror surges in democracies in particular. For similar reasons, we also interact the number of terrorist incidents with a country's voting behavior in the United Nations General Assembly and a dummy for state sponsors of terror. ${ }^{27}$ We expect countries with similar political views to receive more aid in reaction to terror originating from their soil, and state sponsors of terror to receive less.

Table I.3a shows the results for the selection equation of the Heckman model, while Table I.3b reports the corresponding results for the allocation of aid. However, estimating an interaction term in a non-linear model - such as the selection model used here - is not straightforward (Ai and Norton 2003). While Table I.3a shows coefficients rather than marginal effects, we also calculated the significance of the interaction terms in a linear probability model and rely on the resulting t-statistics of the linear model. The marginal effects of the linear allocation model shown in Table I.3b can directly be interpreted.

\footnotetext{
${ }^{27}$ The dummy is coded 1 if a recipient country in a particular year is classified by the US Secretary of State as a state sponsor of terror, i.e., "to have repeatedly provided support for acts of international terrorism" (see website of the US Department of State available at http://www.state.gov/j/ct/c14151.htm (last accessed: July 2012); see also a report on the list of state sponsors provided by the Korea Economic Institute at http://www.keia.org/sites/default/files/publications/spotlist.pdf, last accessed: July 2012).
} 
Table I.3a: Aid allocation and interactions (Heckman selection model, 1971-2008)

\begin{tabular}{|c|c|c|c|c|c|c|c|c|}
\hline & (1) & $(2)$ & (3) & (4) & (5) & (6) & (7) & (8) \\
\hline & $O D A>0$ & $O D A>0$ & $O D A>0$ & $O D A>0$ & $O D A>0$ & $O D A>0$ & $O D A>0$ & $O D A>0$ \\
\hline \multirow[t]{2}{*}{ (log) GDP per capita (t-1) } & $-0.2012 * * *$ & $-0.2024 * * *$ & $-0.2007 * * *$ & $-0.2256 * * *$ & $-0.1794 * * *$ & $-0.1834 * * *$ & $-0.1782 * * *$ & $-0.1920 * * *$ \\
\hline & $(0.00)$ & $(0.00)$ & $(0.00)$ & $(0.00)$ & $(0.00)$ & $(0.00)$ & $(0.00)$ & $(0.00)$ \\
\hline \multirow[t]{2}{*}{ (log) Population (t-1) } & $1.0116^{* * *}$ & $1.0140 * * *$ & $1.0113^{* * *}$ & $0.7862^{* * *}$ & $1.0239 * * *$ & $1.0214^{* * *}$ & $1.0111^{* * *}$ & $0.6628^{* * *}$ \\
\hline & $(0.00)$ & $(0.00)$ & $(0.00)$ & $(0.00)$ & $(0.00)$ & $(0.00)$ & $(0.00)$ & $(0.00)$ \\
\hline \multirow[t]{2}{*}{ (log) Disaster (t-1) } & $0.0089 * * *$ & $0.0089 * * *$ & $0.0089 * * *$ & $0.0068^{* * *}$ & $0.0091 * * *$ & $0.0092^{* * *}$ & $0.0093^{* * *}$ & $0.0069 * * *$ \\
\hline & $(0.00)$ & $(0.00)$ & $(0.00)$ & $(0.00)$ & $(0.00)$ & $(0.00)$ & $(0.00)$ & $(0.00)$ \\
\hline \multirow[t]{2}{*}{ Democracy (t-1) } & $0.2480^{* * *}$ & $0.2448^{* * *}$ & $0.2488^{* * *}$ & $0.1529 * * *$ & $0.2749 * * *$ & $0.2504^{* * *}$ & $0.2727^{* * *}$ & $0.1920 * * *$ \\
\hline & $(0.00)$ & $(0.00)$ & $(0.00)$ & $(0.00)$ & $(0.00)$ & $(0.00)$ & $(0.00)$ & $(0.00)$ \\
\hline \multirow[t]{2}{*}{ UNGA voting (t-1) } & 0.0353 & 0.0254 & 0.014 & -0.1061 & $0.2568 * *$ & $0.2658^{* *}$ & $0.2192^{*}$ & 0.1447 \\
\hline & $(0.80)$ & $(0.85)$ & $(0.92)$ & $(0.47)$ & $(0.03)$ & $(0.02)$ & $(0.06)$ & $(0.24)$ \\
\hline \multirow[t]{2}{*}{ (log) Bilateral exports (t-1) } & $0.0627^{* * *}$ & $0.0627^{* * *}$ & $0.0627^{* * *}$ & $0.0667^{* * *}$ & $0.0636^{* * *}$ & $0.0634^{* * *}$ & $0.0633^{* * *}$ & $0.0682^{* * *}$ \\
\hline & $(0.00)$ & $(0.00)$ & $(0.00)$ & $(0.00)$ & $(0.00)$ & $(0.00)$ & $(0.00)$ & $(0.00)$ \\
\hline \multirow[t]{2}{*}{ (log) Oil production (t-1) } & 0.0000 & -0.0001 & -0.0001 & -0.0087 & -0.0040 & -0.0053 & -0.0049 & $-0.0167 * * *$ \\
\hline & $(1.00)$ & $(0.99)$ & $(0.99)$ & $(0.12)$ & $(0.44)$ & $(0.30)$ & $(0.34)$ & $(0.00)$ \\
\hline \multirow[t]{2}{*}{ (log) Donor total commitments (t-1) } & $0.3339 * * *$ & $0.3322 * * *$ & $0.3312^{* * *}$ & $0.4503^{* * *}$ & $0.3493 * * *$ & $0.3494 * * *$ & $0.3495 * * *$ & $0.4626^{* * *}$ \\
\hline & $(0.00)$ & $(0.00)$ & $(0.00)$ & $(0.00)$ & $(0.00)$ & $(0.00)$ & $(0.00)$ & $(0.00)$ \\
\hline \multirow[t]{2}{*}{ Cold War } & $0.1404^{* * *}$ & $0.1357^{* * *}$ & $0.1350^{* * *}$ & $0.1358^{* * *}$ & $0.1612^{* * *}$ & $0.1386 * * *$ & $0.1386 * * *$ & $0.1226 * * *$ \\
\hline & $(0.00)$ & $(0.00)$ & $(0.00)$ & $(0.00)$ & $(0.00)$ & $(0.00)$ & $(0.00)$ & $(0.00)$ \\
\hline \multirow[t]{2}{*}{ War on Terror } & $0.0735^{* * *}$ & $0.0743 * * *$ & $0.0748^{* * *}$ & $0.0733^{* *}$ & $0.0800^{* * *}$ & $0.0894 * * *$ & $0.0906^{* * *}$ & $0.1039 * * *$ \\
\hline & $(0.01)$ & $(0.01)$ & $(0.01)$ & $(0.01)$ & $(0.00)$ & $(0.00)$ & $(0.00)$ & $(0.00)$ \\
\hline \multirow[t]{2}{*}{ Bilateral terror donor $(\mathrm{t}-1)$} & 0.114 & -0.1087 & -0.1186 & 0.1008 & & & & \\
\hline & $(0.41)$ & $(0.11)$ & $(0.25)$ & $(0.23)$ & & & & \\
\hline \multirow[t]{2}{*}{ Bilateral terror DAC $(\mathrm{t}-1)$} & & & & & -0.0059 & $-0.0316 * * *$ & $-0.0767 * *$ & -0.0067 \\
\hline & & & & & $(0.40)$ & $(0.00)$ & $(0.04)$ & $(0.30)$ \\
\hline \multirow[t]{2}{*}{ State sponsor of terror $(t-1)$} & & & & 0.2574 & & & & $0.3854^{*}$ \\
\hline & & & & $(0.21)$ & & & & $(0.07)$ \\
\hline \multirow[t]{6}{*}{ Interaction of terror with: } & War on Terror & Democracy & UNGA voting & State Terror & War on Terror & Democracy & UNGA voting & State Terror \\
\hline & 0.3319 & 0.1048 & 0.1997 & $-0.4733^{* * *}$ & $0.0376 * * *$ & $0.0285^{* * *}$ & $0.0901^{*}$ & $-0.0423^{*}$ \\
\hline & $(0.28)$ & $(0.13)$ & $(0.46)$ & $(0.01)$ & $(0.00)$ & $(0.01)$ & $(0.08)$ & $(0.06)$ \\
\hline & Cold War & & & & Cold War & & & \\
\hline & $-0.2226^{*}$ & & & & $-0.0312 * * *$ & & & \\
\hline & $(0.06)$ & & & & $(0.00)$ & & & \\
\hline Donor dummies & Yes & Yes & Yes & Yes & Yes & Yes & Yes & Yes \\
\hline Recipient dummies & Yes & Yes & Yes & Yes & Yes & Yes & Yes & Yes \\
\hline Number of observations & 68082 & 68082 & 68082 & 58730 & 71279 & 71279 & 71279 & 60439 \\
\hline Number of country-pairs & 2794 & 2794 & 2794 & 2794 & 2856 & 2856 & 2856 & 2856 \\
\hline
\end{tabular}

Note: Robust $p$-values in parentheses $\left(* * * p<0.01,{ }^{* *} p<0.05,{ }^{*} p<0.1\right)$. 
Table I.3b: Aid allocation and interactions (Heckman allocation model, 1971-2008)

\begin{tabular}{|c|c|c|c|c|c|c|c|c|}
\hline & $\begin{array}{c}(1) \\
(\log ) \text { ODA }\end{array}$ & $\begin{array}{c}(2) \\
(\log ) \text { ODA }\end{array}$ & $\begin{array}{c}(3) \\
(\log ) \text { ODA }\end{array}$ & $\begin{array}{c}(4) \\
(\log ) \text { ODA }\end{array}$ & $\begin{array}{c}(5) \\
(\log ) \text { ODA }\end{array}$ & $\begin{array}{c}(6) \\
(\log ) \text { ODA }\end{array}$ & $\begin{array}{c}(7) \\
(\log ) \text { ODA }\end{array}$ & $\begin{array}{c}(8) \\
(\log ) \text { ODA }\end{array}$ \\
\hline \multirow[t]{2}{*}{ (log) GDP per capita (t-1) } & $-0.4537 * * *$ & $-0.4526 * * *$ & $-0.4541 * * *$ & $-0.3532 * * *$ & $-0.4334 * * *$ & $-0.4380 * * *$ & $-0.4314 * * *$ & $-0.3059 * * *$ \\
\hline & $(0.00)$ & $(0.00)$ & $(0.00)$ & $(0.00)$ & $(0.00)$ & $(0.00)$ & $(0.00)$ & $(0.00)$ \\
\hline \multirow[t]{2}{*}{ (log) Population (t-1) } & $0.3031^{* * *}$ & $0.3018^{* * *}$ & $0.3017^{* * *}$ & 0.1510 & $0.3378 * * *$ & $0.3255^{* * *}$ & $0.3097^{* * *}$ & 0.0353 \\
\hline & $(0.00)$ & $(0.01)$ & $(0.01)$ & $(0.25)$ & $(0.00)$ & $(0.00)$ & $(0.00)$ & $(0.79)$ \\
\hline \multirow[t]{2}{*}{ (log) Disaster (t-1) } & $0.0048^{* * *}$ & $0.0049 * * *$ & $0.0049 * * *$ & $0.0048^{* * *}$ & $0.0058^{* * *}$ & $0.0059 * * *$ & $0.0059 * * *$ & $0.0063^{* * *}$ \\
\hline & $(0.00)$ & $(0.00)$ & $(0.00)$ & $(0.00)$ & $(0.00)$ & $(0.00)$ & $(0.00)$ & $(0.00)$ \\
\hline \multirow[t]{2}{*}{ Democracy (t-1) } & $0.1762^{* * *}$ & $0.1747^{* * *}$ & $0.1746^{* * *}$ & $0.0999 * *$ & $0.2017^{* * *}$ & $0.1684^{* * *}$ & $0.1955^{* * *}$ & $0.1233^{* * *}$ \\
\hline & $(0.00)$ & $(0.00)$ & $(0.00)$ & $(0.02)$ & $(0.00)$ & $(0.00)$ & $(0.00)$ & $(0.00)$ \\
\hline \multirow[t]{2}{*}{ UNGA voting (t-1) } & -0.2066 & -0.2178 & -0.2021 & -0.2093 & 0.0507 & 0.0583 & 0.1042 & 0.1229 \\
\hline & $(0.15)$ & $(0.13)$ & $(0.16)$ & $(0.18)$ & $(0.71)$ & $(0.67)$ & $(0.46)$ & $(0.41)$ \\
\hline \multirow[t]{2}{*}{ (log) Bilateral exports (t-1) } & $0.0166^{* *}$ & $0.0167^{* *}$ & $0.0167^{* *}$ & 0.0110 & $0.0211^{* * *}$ & $0.0212^{* * *}$ & $0.0211^{* * *}$ & $0.0135^{* *}$ \\
\hline & $(0.01)$ & $(0.01)$ & $(0.01)$ & $(0.11)$ & $(0.00)$ & $(0.00)$ & $(0.00)$ & $(0.04)$ \\
\hline \multirow[t]{2}{*}{ (log) Oil production (t-1) } & 0.0088 & 0.0085 & 0.0086 & 0.0057 & 0.0060 & 0.0041 & 0.0053 & 0.0006 \\
\hline & $(0.12)$ & $(0.13)$ & $(0.12)$ & $(0.35)$ & $(0.29)$ & $(0.46)$ & $(0.34)$ & $(0.92)$ \\
\hline \multirow[t]{2}{*}{ (log) Donor total commitments (t-1) } & $0.9460 * * *$ & $0.9449 * * *$ & $0.9453^{* * *}$ & $0.8803^{* * *}$ & $0.9615^{* * *}$ & $0.9631^{* * *}$ & $0.9620 * * *$ & $0.8849 * * *$ \\
\hline & $(0.00)$ & $(0.00)$ & $(0.00)$ & $(0.00)$ & $(0.00)$ & $(0.00)$ & $(0.00)$ & $(0.00)$ \\
\hline \multirow[t]{2}{*}{ Cold War } & $0.3177^{* * *}$ & $0.3137^{* * *}$ & $0.3140 * * *$ & $0.2797^{* * *}$ & $0.3616^{* * *}$ & $0.3260^{* * *}$ & $0.3241 * * *$ & $0.2737 * * *$ \\
\hline & $(0.00)$ & $(0.00)$ & $(0.00)$ & $(0.00)$ & $(0.00)$ & $(0.00)$ & $(0.00)$ & $(0.00)$ \\
\hline \multirow[t]{2}{*}{ War on Terror } & $-0.1378^{* * *}$ & $-0.1350 * * *$ & $-0.1356^{* * *}$ & $-0.1182^{* * *}$ & $-0.1227 * * *$ & $-0.1185^{* * *}$ & $-0.1159 * * *$ & $-0.0857^{* *}$ \\
\hline & $(0.00)$ & $(0.00)$ & $(0.00)$ & $(0.00)$ & $(0.00)$ & $(0.00)$ & $(0.00)$ & $(0.01)$ \\
\hline \multirow[t]{2}{*}{ Bilateral terror donor $(\mathrm{t}-1)$} & $0.0611^{*}$ & 0.0593 & $0.1485^{* *}$ & $0.0807^{* * *}$ & & & & \\
\hline & $(0.05)$ & $(0.26)$ & $(0.02)$ & $(0.00)$ & & & & \\
\hline \multirow[t]{2}{*}{ Bilateral terror DAC (t-1) } & & & & & $0.0141^{*}$ & $-0.0203^{* *}$ & $0.0578^{*}$ & 0.0083 \\
\hline & & & & & $(0.05)$ & $(0.04)$ & $(0.06)$ & $(0.21)$ \\
\hline \multirow[t]{2}{*}{ State sponsor of terror $(t-1)$} & & & & -0.0210 & & & & 0.0745 \\
\hline & & & & $(0.93)$ & & & & $(0.75)$ \\
\hline \multirow[t]{6}{*}{ Interaction of terror with: } & War on Terror & Democracy & UNGA voting & State Terror & War on Terror & Democracy & UNGA voting & State Terror \\
\hline & $0.0993 * *$ & 0.0180 & -0.2141 & -0.0573 & 0.0124 & $0.0356^{* * *}$ & $-0.0814^{*}$ & $-0.0347^{*}$ \\
\hline & $(0.05)$ & $(0.77)$ & $(0.17)$ & $(0.64)$ & $(0.11)$ & $(0.00)$ & $(0.06)$ & $(0.09)$ \\
\hline & Cold War & & & & Cold War & & & \\
\hline & -0.0585 & & & & $-0.0410 * * *$ & & & \\
\hline & $(0.45)$ & & & & $(0.00)$ & & & \\
\hline Pair effects & Yes & Yes & Yes & Yes & Yes & Yes & Yes & Yes \\
\hline Number of observations & 68082 & 68082 & 68082 & 58730 & 71279 & 71279 & 71279 & 60439 \\
\hline Number of country-pairs & 2794 & 2794 & 2794 & 2794 & 2856 & 2856 & 2856 & 2856 \\
\hline
\end{tabular}

Note: Robust $\mathrm{p}$-values in parentheses $\left(* * * p<0.01,{ }^{* *} \mathrm{p}<0.05,{ }^{*} \mathrm{p}<0.1\right)$. 
As can be seen from the Heckman selection model reported in Table I.3a, the coefficients of the interaction terms exhibit the expected signs. However, they are not significant at conventional levels when focusing on terror directed at a particular donor country (columns 1-4). ${ }^{28}$ When analyzing aid addressed to all DAC donors (columns 5-8), the coefficients turn significant at the ten-percent level at least. Specifically, the probability of receiving aid as a consequence of terror increases during the War on Terror period, with democracy and with increasing voting similarity in the United Nations General Assembly, but decreases when countries become state sponsors of terror. ${ }^{29}$

Next, we turn to the corresponding results of the Heckman allocation model shown in Table I.3b. The increase of aid as a reaction to terror attacks against the donor is significantly larger in the War on Terror period (16 percent overall per attack, according to column 1) compared to the interwar period (6.1 percent) and the Cold War period ( 0.3 percent). The other interaction effects again do not turn out to be significant when focusing on terror directed at the individual donor country (columns 2-4). Analyzing the impact of terror directed at the DAC community (columns 5-8), our results show that aid amounts decrease with terror from autocratic countries by 2 percent per attack, while they increase by 1.5 percent for democracies. Countries becoming state sponsors of terrorism receive 3.5 percent less aid per attack. Surprisingly, when countries vote in line with the donor more frequently, they receive less aid in reaction to terror. While this is puzzling, it is in line with the observation by Moss et al. (2005: 5) of "a possible trend of increases [in aid] in GWOT [Global War on Terror]-relevant countries [...], and decreases to more traditional U.S. allies in the Middle East, Europe, and Latin America that had received substantial aid in the 1990s."

Overall, the evidence is in line with our expectations: While countries which are on friendly terms with the donor receive more aid as a consequence of terror arising from their soil, other countries do not (or less so).

\footnotetext{
${ }^{28}$ Column 4 seems to imply that state sponsors of terror are significantly less likely to be selected as recipients of aid as a consequence of terror. However, the interaction term is not significant at conventional levels in the linear probability model. The same applies to the Cold War coefficient in column 1. See Appendix I.3.

${ }^{29}$ Note that the number of observations is lower when the state sponsor of terror dummy is introduced as this classification of countries was introduced in 1979 only. The positive coefficient of the state sponsor variable in column 8 is also noteworthy. However, when we calculate the marginal effect of state sponsorship for varying number of terror attacks, the dummy is not significant at conventional levels for any value (based on the linear probability model).
} 


\section{I.5 Extensions}

\section{I.5.1 Disaggregating the DAC}

Arguably, the average results for all donors pooled together might hide important differences between donors. Focusing on the G7 donors and the so-called 'good donors' (Denmark, Netherlands, Norway and Sweden) to reduce clutter, we estimate regressions for individual donors rather than aggregating all donors. We run nested regressions for these donors instead of performing regressions for each of them. Pooling the donors enables us to statistically test for differences and similarities among them. We introduce dummies for each individual donor and interact these dummies with our explanatory variables, mirroring individual regressions for the individual donors.

The results are reported in Appendix I.4. We find that, controlling for all other factors, the United States increased its annual aid budget as a share of GNI by 0.087 percentage points in the period after 9/11, at the five-percent level of significance. This effect is sizable in comparison to the target of the United Nations that 0.7 percent of GNI has to be devoted to development assistance, and the average value for the United States of 0.16 percent over the 1991-2001 period. Among the other DAC donors, only France shows a significant increase in its budget after 9/11, also at the five-percent level (and by more than one percentage point). When we control for terrorist attacks on the individual donor countries, the positive coefficient on the War on Terror dummy for Canada turns significant at the ten-percent level. While the United States did increase its aid budget as a share of GNI following the perceived threat of terror after 9/11, the country did not adjust its aid effort in response to shorter periods of more numerous attacks. The United Kingdom is the only country to react to attacks against its citizens with significant decreases in its aid effort.

We also looked at differences between donors in their allocation of aid. Similar to the budget regressions, we run nested regressions for all donors. Controlling for donor-recipient fixed effects and in contrast to our findings for all DAC donors, we find that US aid amounts are significantly larger in the War on Terror period compared to the interwar period. The same holds for Norway and Sweden, while smaller aid portions come from Germany, Japan and the Netherlands. Among the countries we separated from the aggregate analysis, we find that only the United States increases its foreign aid to countries where terror against its citizens originates, while France, Italy and Sweden even reduce their aid to these countries. To the extent that these donors are hit by terror from the same countries of origin, this could imply that the United States provide a public good, with European countries benefitting from increased safety even while reducing their aid to countries where terror originates. 


\section{I.5.2 Disaggregating Aid}

As outlined above, donors effectively fighting against the terrorist threat should especially rely on aid for education, or aid tied explicitly to the fight against terrorism. In this section, we test whether the mechanisms underlying the models by Azam and Thelen (2008, 2010, 2011) and Bandyopadhyay et al. (2011) are understood by the donor community. If aid for education, aid tied to the fight against terrorism, and general aid have differential effects on the fight against terror, we would expect donor governments to change their composition of aid as a consequence of terror. First, we consequently investigate whether terrorism affects the share of aid that a donor devotes to education. As a second step, we also employ the donors' share of aid for government and civil society (DAC purpose code 150), as most projects linked explicitly to (the prevention of) terrorist activities are included in this category. ${ }^{30}$ The detailed results are reported in Appendices I.5-I.7.

When we estimate the share of a donor's aid committed to education in a donor's aid budget as dependent variable, all coefficients on the War on Terror, as well as those on the number of terrorist incidents, are not significant at conventional levels. ${ }^{31}$ In other words, we find no evidence that donors shifted their focus to the education sector where aid is expected to be particularly effective in preventing terror. When we use the share of aid granted to improve governance and strengthen civil society, the picture looks different. Rather than increasing the share of aid for governance, we find that a smaller share of total aid is committed to this sector when more incidents occur worldwide and in DAC countries, while the dummy for the War on Terror is insignificant. ${ }^{32}$ Focusing on shares in bilateral aid flows rather than in a donor's aggregate aid budget, the share of aid for education is not significantly affected by the terror variables either. The share of aid to strengthen governance and the civil sector is reduced rather than increased following bilateral attacks. ${ }^{33}$ Overall, there is no

\footnotetext{
3077 percent of all projects reported by AidData that have 'terror', 'terrorism' or 'terrorist' in their title or description are classified as aid for government and civil society. Note that we do not use these terror-related projects from AidData in our regressions, because the available information covers only a limited number of countries and years (see Tierney et al. 2011).

${ }^{31}$ We control for (logged) per-capita GDP, the (logged) number of NGOs per 100,000 inhabitants present in a donor country as proxy for the strength of civil society, and tertiary school enrollment rates as an indicator of the importance that a donor country attaches to education.

${ }^{32}$ Note that the set of control variables includes (logged) per-capita GDP, the (logged) number of nongovernmental organizations (NGOs) and civil liberties (taken from Freedom House 2009) as an indicator of the importance that a donor country attaches to related issues.

${ }^{33}$ We control for (logged) per-capita GDP and democracy in the recipient country, the share of aid devoted to the particular sector in the donor's total budget as well as for sector-specific need indicators (logged school enrollment rates in the education model and logged number of international NGOs operating in the recipient country in the governance equation).
} 
evidence that the shares of these aid types increased as a reaction to terrorist attacks and the onset of the War on Terror. ${ }^{34}$

\section{I.6 Conclusions}

Previous research has concluded that aid is surprisingly ineffective in reducing poverty in recipient countries. At the same time, a number of authors have argued that aid has not been given to fight poverty in the first place. The importance of political considerations for the allocation of aid during the Cold War is well known. With the fall of the Iron Curtain, many hoped that humanitarian motives would guide donors when choosing where to give aid, and how much. However, rather than devoting aid to where it could be most useful in terms of poverty reduction or the promotion of high-quality institutions, the amount of aid declined considerably with the end of the Cold War, despite some rhetoric suggesting the opposite. With the terrorist attacks of September 11, 2001, political motives to grant aid became fashionable once again. Leaders in the United States, the European Union, and other DAC countries publicly announced to substantially increase their aid to fight terror.

A number of previous papers have investigated whether aid is indeed effective in fighting terror. The results are ambiguous, theoretically and empirically. However, this is the first study to test whether, and to what extent, a large group of donors increased their aid effort during the War on Terror period, controlled for other determinants of aid. Although we find this to be the case on average, there is no evidence that donors increased their budgets after years with a particularly large number of attacks, or reduced their aid when terror decreased.

As a next step, we investigated whether countries where terror originates received increasing aid inflows, using a Heckman selection model. According to the results, while countries where terror originates are not more likely to receive aid as a consequence, if they are selected, they receive larger aid amounts from the donor hit by the attack. Terror against the Western world, proxied by the number of terrorist incidents against citizens of a DAC country, even reduces the probability to receive aid, on average. This holds in particular for autocratic countries, for countries voting against the donor in the United Nations General Assembly and for state sponsors of terrorism, but not for the War on Terror period.

\footnotetext{
${ }^{34}$ As shown in Young and Findley (2011), targeting aid towards health might be equally crucial in reducing terrorism. Bandyopadhyay et al. (2011) also point to a trade-off between regime stability and aid tied to counterterrorism. We leave these issues for future investigations.
} 
We disaggregated the analysis across two dimensions to provide deeper insights than can be provided at the aggregate level. First, we investigated whether there are differences in how donor countries react to terror, finding that indeed there are. Specifically, we find that France and the United States increased their aid effort after 9/11, however, without responding to the actual number of terror events. Concerning the allocation of funds, we find that the United States increased aid to source countries of terror as a consequence of terrorist attacks, while France, Italy and Sweden reduced their aid to these countries. Our second disaggregation by type of aid shows no evidence that donors allocate a larger share of their budgets to education or government and civil society as a reaction to terrorism, which recent models suggest they should.

In summary, we find that politicians may still have to learn from economic research. To the extent that development aid can effectively combat terror across the world, as recent research suggests it does, politicians would be well-advised to target aid to those countries where terrorist groups exist in abundance, as well as promoting education and the fight against terror in particular. Our research also contributes to the aid effectiveness debate. When aid is given to fight terror rather than economic growth, its effectiveness would have to be judged by whether or not it is effective in fighting terror rather than promoting growth.

The analysis in this paper provides a starting point for more detailed investigations in to how donors react to the terrorist threat. It could be complemented by a study focusing on domestic terrorist events in addition to transnational ones. Investigating whether different types of terrorist events, particularly severe events or only those involving fatalities for example, have different effects on aid would also be useful. A more detailed disaggregation of aid according to donors, types of aid, and the specific conditions under which aid is used to fight terror might provide deeper insights than this study could provide.

Finally, we suggest not only investigating how aid impacts countries where terror originates, but also looking at their neighbors, major trading partners, or their enemies. A spatial model employing a range of weighting matrices could prove to be fruitful in this context. We leave these questions for future research. 


\title{
Chapter II:
}

\section{Rogue Aid? The Determinants of China's}

\section{Aid Allocation}

\author{
Joint work with Axel Dreher ${ }^{\mathrm{a}}$
}

\begin{abstract}
Foreign aid from China is often characterized as 'rogue aid' that is not guided by recipient need but by China's national interests alone. However, no econometric study so far confronts this claim with data. We make use of various datasets, covering the 1956-2006 period, to empirically test to which extent political and commercial interests shape China's aid allocation decisions. We estimate the determinants of China's allocation of project aid, food aid, medical staff and total aid money to developing countries, comparing its allocation decisions with traditional and other so-called emerging donors. We find that political considerations are an important determinant of China's allocation of aid. However, in comparison to other donors, China does not pay substantially more attention to politics. In contrast to widespread perceptions, we find no evidence that China's aid allocation is dominated by natural resource endowments. Moreover, China's allocation of aid seems to be widely independent of democracy and governance in recipient countries. Overall, denominating aid from China as 'rogue aid' seems unjustified.
\end{abstract}

\footnotetext{
Acknowledgements: This research is part of the project "Foreign Aid of Emerging Donors and International Politics" supported by the Deutsche Forschungsgemeinschaft (DR 640/4-1). We are grateful for their generous financial support. I would like to thank the Woodrow Wilson School in Princeton, where a part of this research was done, and the German Academic Exchange Service (DAAD), who financed this research stay. Excellent research assistance was provided by Scott Jobson, Stefan Keitel, Alexander Leinemann and Sandra Schmidt. We thank participants at the Spring Meeting of Young Economists (Groningen 2011), the European Public Choice Society Meeting (Rennes 2011), the Workshop "The Transatlantic Community and Rising Powers in the Global Economy" (Berlin 2011), the Beyond Basic Questions Workshop (Brussels 2011), the Verein für Socialpolitik Research Committee "Development Economics" Conference (Berlin 2011), the Annual Conference of the International Political Economy Society (Madison 2011), seminar participants at the Faculty of Economic Sciences in Goettingen and the Woodrow Wilson School in Princeton, Ruxanda Berlinschi, Deborah Bräutigam, Christina Davis, Nils-Hendrik Klann, Stephan Klasen, Eoin McGuirk, Kris Johnson, Christopher Kilby, Katharina Michaelowa, Hannes Öhler, May-Britt U. Stumbaum, Manuel Wiesenfarth, Meredith Wilf, and Shu $\mathrm{Yu}$ for helpful comments on earlier drafts of this paper.

${ }^{\text {a }}$ Heidelberg University, Alfred-Weber-Institute for Economics, Bergheimer Strasse 58, 69115 Heidelberg, Germany, University of Goettingen, Germany, CESifo, Germany, IZA, Germany, and KOF Swiss Economic Institute, Switzerland, e-mail: mail[at]axel-dreher.de.
} 


\section{II.1 Introduction}

Development aid plays a pivotal role as an economic reward and punishment mechanism between nations. An extensive literature on the allocation of aid by traditional donors exists, which emphasizes that aid is frequently given for political reasons rather than economic needs (e.g., Alesina and Dollar 2000; Neumayer 2005; Kuziemko and Werker 2006; Dreher et al. 2009a, 2009b; Kilby 2009a, 2011; Reynaud and Vauday 2009). With the ongoing redistribution of world power, foreign aid provided by donor countries operating outside of the Development Assistance Committee (DAC) is gaining in prominence. Only recently have scholars started analyzing the allocation of aid from these so-called "new" donors with quantitative methods (see Neumayer 2003a, 2004; Dreher et al. 2011). According to the results in Dreher et al. (2011), "new" donors attach less importance to recipient need than donors of the DAC when allocating aid. However, concerns that commercial self-interest distorts the allocation of aid seem to be overstated for new and old donors alike. Arguably, these findings might be driven by the omission of the major "new" donor, China. ${ }^{35}$

China is often described as the chief villain among the "new" donors. Naím (2007) characterizes its development aid as 'rogue aid' as it is not guided by need in developing countries, but rather by China's national interests. The determinants of Chinese development assistance are, according to Naím, access to resources and boosting international alliances. Moreover, 'rogue donors' are said to undermine the development efforts of Western donors to promote good governance in the developing world. However, this verdict is based on selective case studies only. No empirical study exists confronting the various claims about Chinese 'rogue aid' with data. This is because comprehensive data on the allocation of China's development aid are difficult to obtain. ${ }^{36}$

In this paper, we make use of various datasets on the allocation of Chinese foreign aid. First, we use data on the number of aid projects completed. Data are obtained from Bartke (1989), who collected news items on China's economic aid between 1956 and 1987, and from the China Commerce Yearbook, which covers the 1990-2005 period (Ministry of Commerce 1984-2009; Hawkins et al. 2010). Second, we use data on the estimated amount of Chinese foreign aid (in US\$) that has been provided to recipient countries until the mid-1980s. Data

\footnotetext{
${ }^{35}$ Taken literally, China is not a new donor. Its aid program already started in the 1950s. By 1975, it provided aid to more African countries than the United States (Bräutigam 2008). This is true for many other "new" donors as well. What is new however, is the attention they receive. Apart from that, China does not perceive itself as a donor but rather as a partner in "South-South cooperation" (Davies 2007).

${ }^{36}$ In the words of Berthélemy (2009: 2), "data are simply not available.” Berthélemy (2009) thus uses data on contracted projects with Chinese companies as a proxy for aid, given that aid is usually tied to contracts with Chinese companies.
} 
are collected from various intelligence reports of the CIA (1975-1984), from a study of the Organisation for Economic Co-operation and Development (OECD 1987) and again from Bartke (1989). Third, we make use of data on the number of medical staff that has been dispatched at the end of a year, also collected from the China Commerce Yearbook. Finally, we employ a dataset on food aid (World Food Programme 2011), which reports the amount of emergency aid, program aid and project aid in tons of grain equivalent allocated since 1988 for 108 donors, including China.

We use these data to empirically test the various hypotheses about China's aid allocation proposed in the previous literature. First, we analyze China's allocation of development aid in five phases of the Chinese aid program between 1956 and 2006. Second, in a cross-section of 132 recipient countries over the 1996-2005 period, we compare the allocation of China's project aid to that of DAC and emerging donor countries.

To foreshadow our results, we find that political considerations are an important determinant of China's allocation of aid. However, when we compare its allocation to those of other donors, China does not pay significantly more attention to politics. We find only mixed evidence that commercial motives determine China's aid allocation decisions. Neither democracy nor governance play an important role. Overall, denominating aid from China as 'rogue aid' thus seems unjustified.

We proceed as follows. In Section II.2, we introduce our data on China's allocation of aid, while outlining our hypotheses regarding the determinants of China's aid allocation in Section II.3. The method of estimation and our main econometric results are presented in Section II.4. In Section II.5, we compare China's allocation of aid to those of the DAC and other "new" donors. The final section concludes the paper and draws policy implications.

\section{II.2. Measuring Chinese Aid}

A substantial number of players are involved in the Chinese development assistance program (Davies 2007; Bräutigam 2008, 2010; Kobayashi 2008). Strategic decisions are made by the State Council, which is the highest authority of the state administration. The main government body responsible for China's aid is the Ministry of Commerce (MOFCOM). However, the Ministry of Foreign Affairs (MFA) is also involved. Another major player is the ExportImport Bank - China Exim Bank - established in 1994, which provides concessional loans in addition to pure export credits. Also set up in 1994, the China Development Bank (CDB) 
offers commercial credits and is expected to provide the bulk of the additional resources to Africa promised in the "new strategic partnership" (Davies 2007). ${ }^{37}$

Estimations of the total size of China's aid flows vary considerably. In 2006, Premier Wen Jiabao quantified Chinese aid to Africa over the 1949-2006 period to be about US\$ 5.6 billion (He 2006). According to Davies (2007) however, this figure is considered to be too low by Chinese scholars she interviewed. She provides data on concessional loans by the China Exim Bank outstanding in February 2007, which amount to US\$ 8-9 billion (as reported in Manning 2007: 7). She also cites estimates from Kurlantzick (2006), estimating aid to Africa to be worth US\$ 2.7 billion in 2004, the United Kingdom's Department for International Development (DFID), ${ }^{38}$ estimating aid for Africa amounting to US\$ 1.3-1.4 in 2006, and Qi (2007), who estimates aid for Africa to be worth US\$ 1.05 billion and China's total aid budget to be US\$ 1.38 in 2007. According to the Financial Times, China outperformed the World Bank as the world's largest provider of overseas loans to developing countries through its China Development Bank and China Export-Import Bank, amounting to at least US\$ 110 billion in 2009 and $2010 .{ }^{39}$ Parts of the huge variations between the estimates stem from different delineations of which flows are considered as development aid. Missing information on the degree of concessionality of Chinese loans makes it difficult to apply the definition of Official Development Assistance (ODA) from the DAC. ${ }^{40}$

With the intention of meeting objections that China does not provide sufficient information on its aid program, the Chinese government published a White Paper on China's Foreign Aid (State Council 2011). According to this official document, China has provided aid to 161 countries until 2009, of which 123 developing countries received aid on a regular basis. This corresponds to 256.29 billion yuan (US\$ 38.54 billion), of which 41.4 percent were provided as grants, 29.9 percent as interest-free loans, and 28.7 percent in the form of concessional loans (State Council 2011). Still, it is not clear which financial flows are included in these calculations. Moreover, the Chinese government declines to publish full information on its annual bilateral aid allocations.

\footnotetext{
${ }^{37}$ According to Davies (2007), further actors are the Chinese embassies, which monitor project implementation, and the Ministry of Finance, which negotiates the yearly aid budget and is in charge of China's contributions to international financial organizations. The Ministry of Health is involved when it comes to medical and health projects. Similarly, the Ministries of Education, Agriculture and Science and Technology are in charge of China's aid in their respective fields.

${ }^{38}$ According to an unpublished document, DFID China, January 3, 2007.

39 "China's lending hits new heights," Financial Times, January 17, 2011.

40 Bräutigam (2008) lists package financing of concessional loans together with export credits, multi-year reporting of aid, as well as media mistakes as additional sources of overestimated aid figures. Note that ODA is defined as concessional financial flows to developing countries that are provided by official agencies, with the objective to promote economic development and welfare and that contain a grant element of at least 25 percent (see http://stats.oecd.org/glossary/detail.asp?ID=6043, accessed: July 2012).
} 
Nevertheless, we are able to make use of several data sources that provide information on four variables that capture the lion's share of China's foreign aid activities since the foundation of its aid program in the $1950 \mathrm{~s}$, and that by and large qualify as ODA. ${ }^{41}$ First, we use data on the number of aid projects completed from Bartke (1989) and from the China Commerce Yearbook (Ministry of Commerce 1984-2009). Bartke (1989) collected 2,500 news items on China's economic aid between 1956 and 1987. Most of them were collected from the Chinese press, with less than 10 percent originating from secondary sources (mainly from the recipient countries). 528 completed aid projects in 69 developing countries (plus Kuwait and Malta) are recorded in the dataset. The first completed aid project registered in the database was the construction of a textile mill in Thamaing (Burma) in 1956. The single most outstanding project was the construction of the Tanzania-Zambia railway line. Bartke (1989) stresses that only small projects may be missing in the dataset, which presumably was the case if China felt that they were not sufficiently important to be published.

Data on completed aid projects for more recent years are obtained from China's Ministry of Commerce (1984-2009), which provides this information in the China Commerce Yearbook and its predecessors. This information on aid projects, completed during the 19902005 period, was compiled in a comprehensive dataset by Hawkins et al. (2010) and is publicly available. The first completed aid project recorded in the dataset was the construction of a sporting complex in Jordan in 1990, and the last one was the provision of teaching appliances, medical apparatus and agricultural machines to Colombia in 2005. Altogether, the dataset consists of 304 aid projects provided to 97 developing countries (and Malta).

At first, it may seem a drawback that these data only cover aid projects run by the Ministry of Commerce and exclude those administered by the Exim Bank and the China Development Bank (as well as technical assistance). However, loans from the China Development Bank and the vast majority of Exim Bank loans are not concessional in nature and therefore do not qualify as ODA. According to Bräutigam (2011: 761), "the large lines of credit offered by Chinese policy banks are not provided as ODA but represent OOF [other official flows], chiefly export credits." Estimates from Bräutigam (2010) suggest that the remaining concessional loans provided by the Exim Bank represent 16.7 percent of China's official aid flows over the 1996-2005 period. Ideally, one would want to include these in an analysis of China's foreign aid - if they have a grant element that satisfies the definition of ODA. Unfortunately, the Exim Bank does not release this information. The advantage of the omission of data from both banks is that the remaining projects run by the Ministry of

\footnotetext{
${ }^{41}$ For a discussion on which of China's aid flows are likely to qualify as ODA see Kobayashi (2008) and Bräutigam $(2010,2011)$.
} 
Commerce itself can be considered as $\mathrm{ODA},{ }^{42}$ which will allow a meaningful comparison with aid allocation of DAC donors in Section II.5. Appendix II.3 provides a detailed explanation of the construction of the database of China's project aid.

Figure II.1: Number of aid projects completed (\% of China's total aid, 1956-1969)

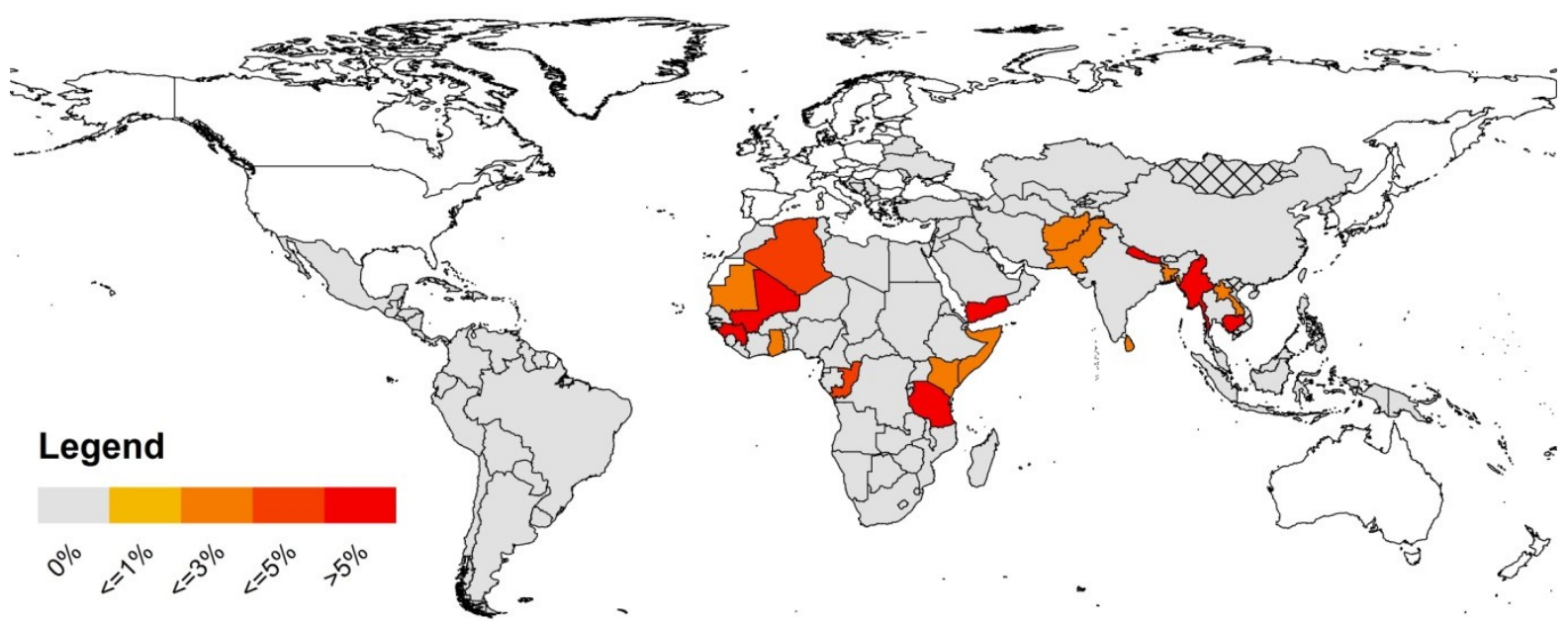

Note: No information available on Albania, Cuba, Mongolia, People's Republic of Korea and Vietnam (shaded area).

Figure II.2: Number of aid projects completed (\% of China's total aid, 1970-1978)

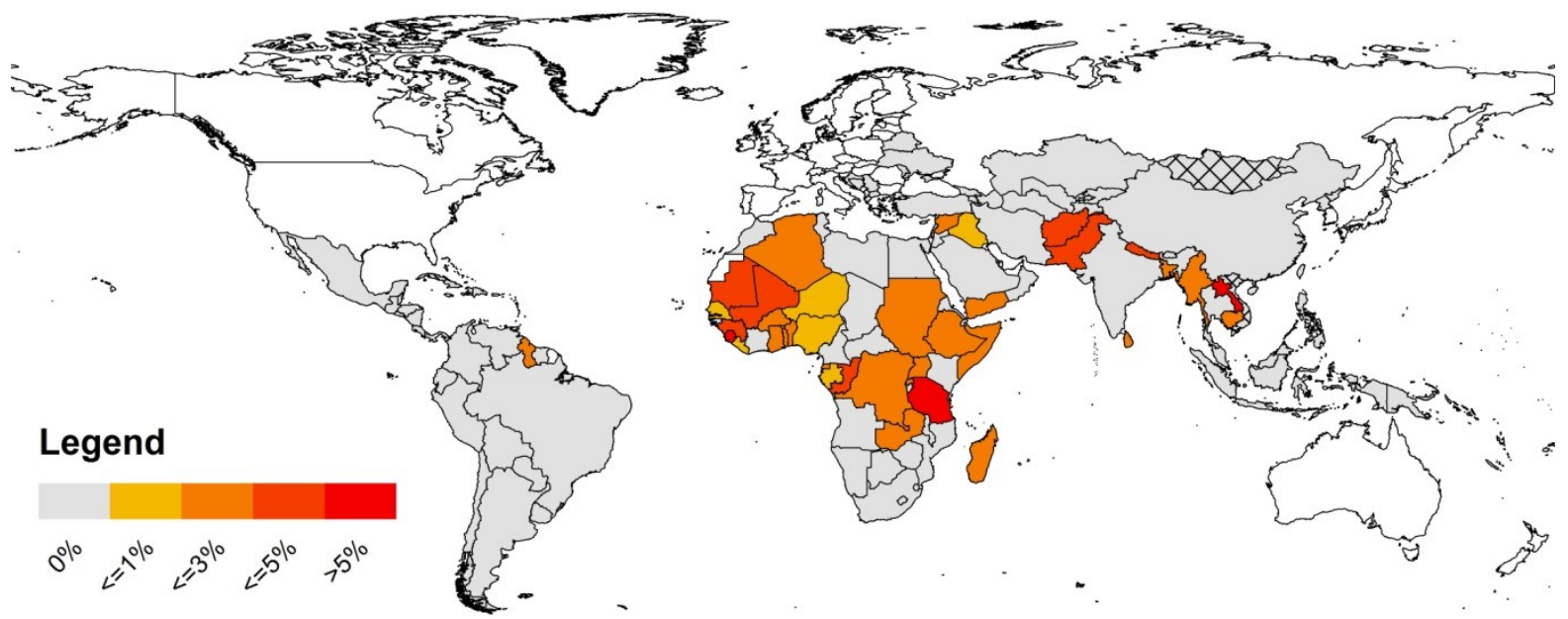

Note: No information available on Albania, Cuba, Mongolia, People's Republic of Korea and Vietnam (shaded area).

\footnotetext{
${ }^{42}$ According to Bräutigam (2011: 756), "[b]y and large, activities financed out of their external assistance budget largely parallel the kinds of activities financed by DAC donors." The State Council (2011) notes that complete projects are provided as grants or interest-free loans.
} 
Figure II.3: Number of aid projects completed (\% of China's total aid, 1979-1987)

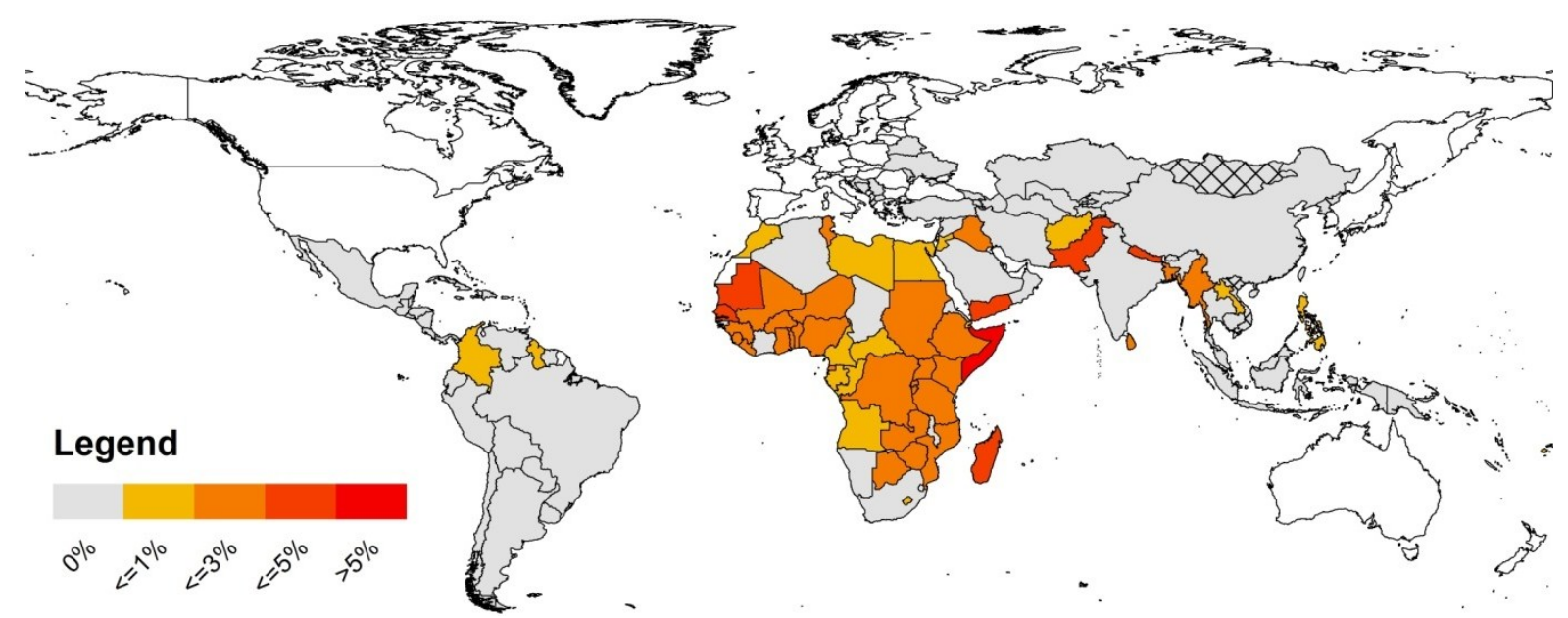

Note: No information available on Albania, Cuba, Mongolia, People's Republic of Korea and Vietnam (shaded area).

Figure II.4: Number of aid projects completed (\% of China's total aid, 1990-1995)

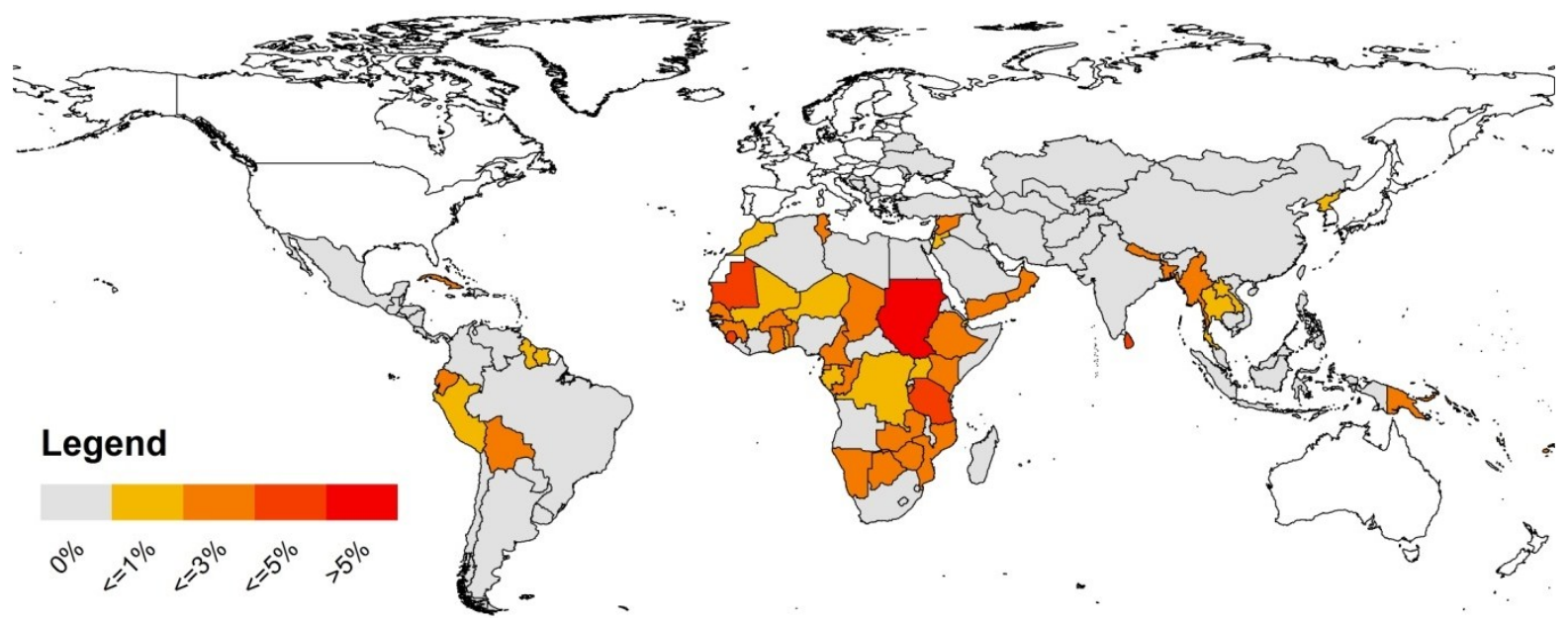

Figure II.5: Number of aid projects completed (\% of China's total aid, 1996-2005)

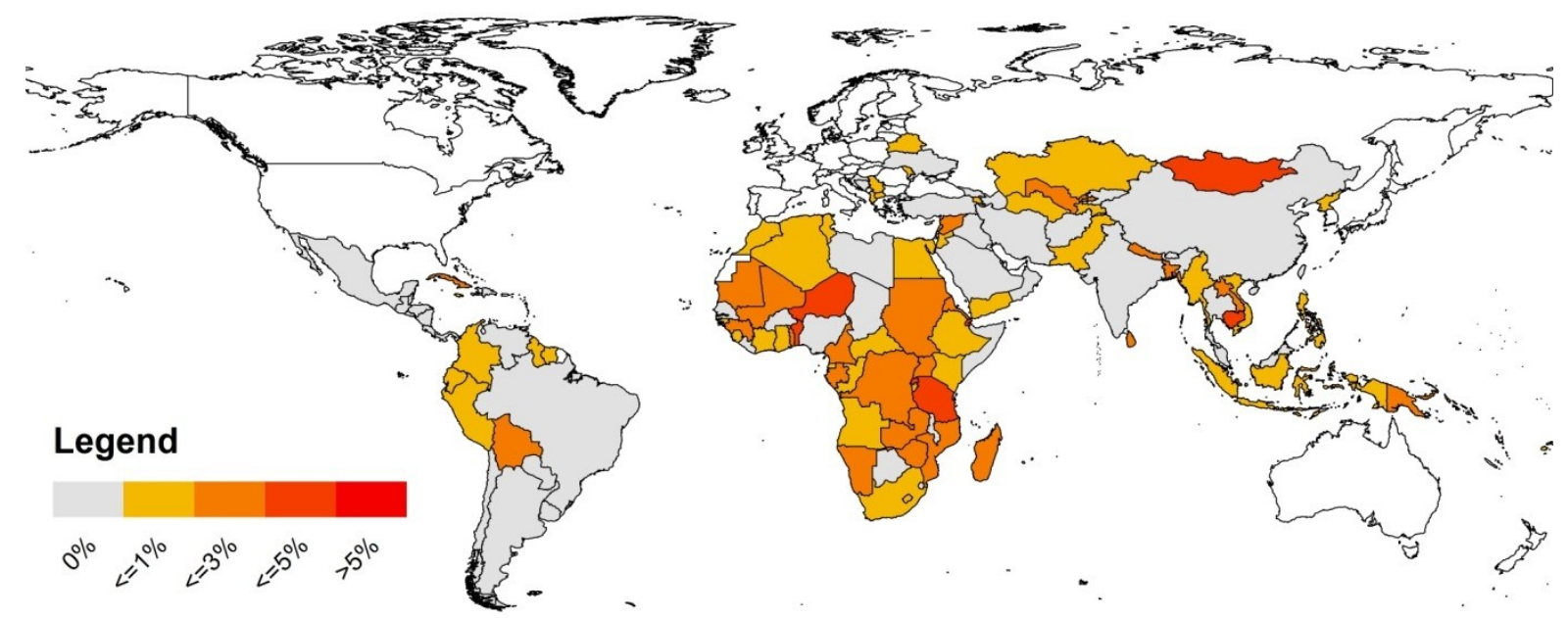


The share of China's aid projects completed in a particular recipient country over various periods is represented graphically in Figures II.1-II.5. ${ }^{43}$ Over the 1956-69 period (Figure II.1), few countries received aid from China, and those that did were exclusively located in Africa, the Arabian peninsula and in China's immediate neighborhood. Figure II.2 shows the expansion of China's aid in Africa in the 1970-78 period, as well as the first projects carried out in Latin America. This expansion continues further in the years 1979-87 (Figure II.3). As can be seen in Figures II.4 and II.5, China's expansion focused on Latin America in the early 1990s, and on Eastern Europe and Central Asia in the 1996-2005 period.

Second, we study China's allocation of aid amounts in US\$. Data are collected from various intelligence reports of the CIA (1975-1984), from a study of the OECD (1987), and from Bartke (1989). The estimates of China's total aid to recipient countries retrieved from Bartke (1989) include loans and donations and are compiled from Chinese sources, secondary sources and the author's estimates. Tanzania was the single most important recipient of Chinese economic aid between 1956 and 1987. 62.0 percent of China's economic aid between 1956 and 1987 has been provided to Africa, highlighting China's aspirations to become the leading power in the Third World (Bartke 1989). 22.7 percent of China's economic aid in this period was provided to Asia, with the intention of creating "friendly relations with its closest neighbours" (Bartke 1989: 10).

The second dataset on aid amounts (US\$) has been established based on several intelligence reports from the CIA (1975-1984). This series of handbooks served as the intelligence community's official database on foreign aid activities of communist countries. Data are taken from the most recent report, in which data were reported for a particular year. The established dataset covers economic aid extended to non-communist recipient countries in the 1956-1984 period. ${ }^{44}$ Concessional loans and grants are both included. The third dataset is from the OECD (1987). It reports aid commitments in US\$ for the 1970-1985 period. The information has been collected from news items from the Xinhua news agency, statements by recipient countries, and press reports. The OECD judges its aid data as reliable, with the exception of aid flows to Vietnam and North Korea. ${ }^{45}$

Third, we examine China's allocation of medical staff to developing countries. Starting in 1963 in Algeria, medical staff is usually sent to underdeveloped areas to cure

\footnotetext{
${ }^{43}$ The choice of periods is explained below.

44 Therefore, the dataset does not cover aid flows to the following communist countries: Cambodia (after 1975), Cuba, Laos (after 1975), North Korea, Vietnam and Yugoslavia. In addition, aid to South Africa is not reported.

${ }^{45}$ Both countries have been excluded from the dataset. Also, in some cases the dataset indicates that a country received aid from China without quantifying it. Therefore, the reported aid values from the OECD should be treated as lower bound estimates.
} 
patients, train local medical staff, and improve medical and health services in the recipient countries (State Council 2011). Data on the size of medical teams dispatched are obtained from the China Commerce Yearbook (Ministry of Commerce 1984-2009) and cover the 19831994 period (except 1993). Throughout this period, medical staff was dispatched to 45 countries. In 1984 alone, China claims to have treated about one million patients (Ministry of Commerce 1985).

Fourth, we make use of a dataset on food aid from the International Food Aid Information System (FAIS), which was developed by the World Food Programme (2011). The amount of food aid is reported in tons of grain equivalent for 109 donor countries, including China, from 1988 onwards and is continuously updated. ${ }^{46}$ The values include commodities delivered or locally purchased. Food aid is grouped into three categories: Emergency aid, project aid and program aid. While emergency aid is intended to support the victims of natural or man-made disasters, project aid supports specific poverty reduction and disaster prevention activities. In contrast, program food aid is not targeted at specific beneficiary groups and takes the form of a resource transfer for balance of payments or budgetary support. China provides all three types of aid. Between 1990 and 2006, China supplied 41 countries with food aid, of which the largest delivery went as emergency aid to North Korea in 2005 (531,416 tons of grain equivalent).

Based on these four aid indicators, Figure II.6 provides an overview of the evolution of China's aid program over time. As can be seen, the number of aid projects follows a positive trend, but volatility is high. Aid amounts peaked in the early 1970 s, and fluctuated in the second half of the 1970s and the 1980s at around US\$ 600 million (constant year 2000) according to the Bartke and CIA measures. The estimates from the OECD are lower and fluctuate at around US\$ 350 million (constant year 2000). The number of medical personnel dispatched is substantially lower in the 1990s compared to the 1980s, while food aid only reaches noteworthy amounts as of 1996. Appendix II.4 shows the resulting shares for each recipient of China's total aid for each aid indicator.

\footnotetext{
${ }^{46}$ Neumayer (2005) analyzes the determinants of food aid in the 1990s and finds that the United States and the European Union use it to reward their political supporters. His study neither covers China nor other emerging donors, however. Note that we employ data on food aid measured in tons of grain equivalent rather than simply taking food in metric tons to assure comparability between different types of food aid. Data are available on http://www.wfp.org/fais.
} 
Figure II.6: China's foreign aid over time
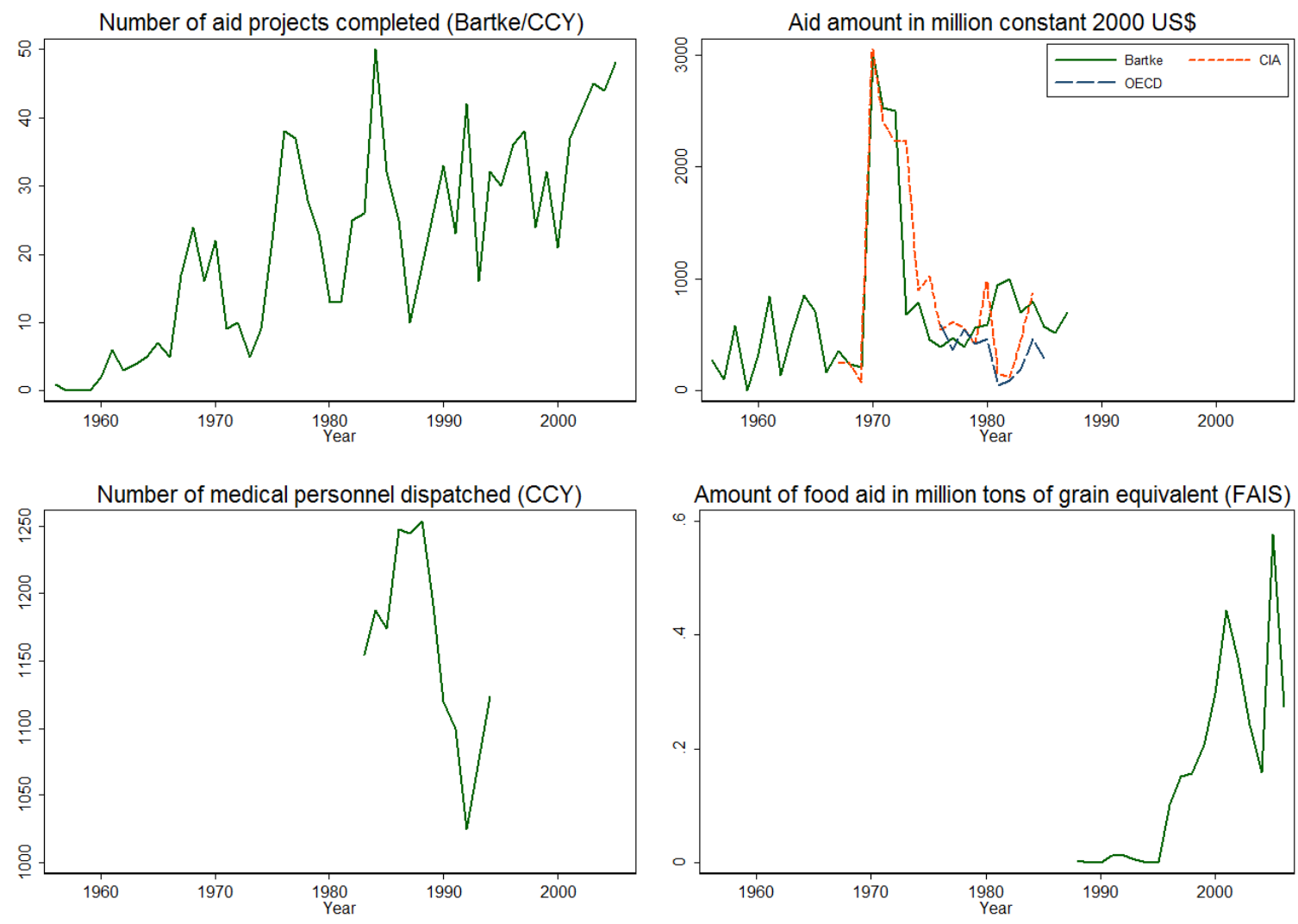

Note: No annual aid amounts available from CIA before 1967 and from OECD before 1976.

\section{II.3 Need, Merit and Self-Interest - Is China Different?}

\section{II.3.1 A Brief History of China's Aid Program}

China began providing foreign assistance to developing countries in 1950 with aid to North Korea, extending its aid to non-communist countries in 1956 in the aftermath of the AsianAfrican conference in Bandung (State Council 2011). According to Bartke (1989), Cambodia, Nepal and Egypt were the first (non-communist) recipient countries in 1956. China's aid policy can be divided into five phases. ${ }^{47}$ In the first phase (1956-1969), China's aid, which at that time only consisted of grants and interest-free loans, is said to have been mainly driven by political and ideological considerations. China supported African countries' independence movements and used its aid to support resistance against colonial powers (e.g., Davies 2007). Even then, the principles of giving aid stressed the self-reliance of the recipient countries and

\footnotetext{
${ }^{47}$ Davies (2007), Bräutigam $(2008,2010)$ and Kobayashi (2008) provide a detailed overview on the history of China's aid program. See also Lin (1995) for a good overview on the history of research on China's foreign aid by both Chinese and Western scholars.
} 
mutual benefit. ${ }^{48}$ The 9th Party Congress in 1969 can be seen as the starting point of the second phase (1970-1978). The amount of aid delivered sharply increased, which is seen as being in line with Mao Zedong's claim to assume political leadership in the Third World. In line with this claim to power, China replaced Taiwan on the United Nations Security Council in 1971, which was supposedly supported by aid flows to African countries (Davies 2007). However, after the death of the Communist Party's Vice Chairman Lin Biao in the same year, economic aid was squeezed in 1973 through the influence of Prime Minister Zhou Enlai (Bartke 1989).

After the death of Mao Zedong in 1976, China opened its doors to the West and pursued more pragmatic foreign (and aid) policies. ${ }^{49}$ Deng Xiaoping took the leadership of the Communist Party in December 1978, which initiated the third phase (1979-1989). His economic reform program, labeled "Reform and Opening Up," started introducing market principles and gradually opened the Chinese economy to foreign investment and international trade. Economic considerations became more influential in China's aid allocation decisions. The scale of individual projects was reduced, but mutually advantageous programs were promoted (OECD 1987). While Chinese aid was provided as interest-free long-term loans or grants in the beginning, conditions became stricter, but were still very favorable in the 1980s: The grant element of Chinese aid fluctuated between 60 and 75 percent over the 1980-1985 period (OECD 1987). Another new focus of China's foreign aid in the 1980s was the emphasis on the upgrading and maintenance of existing projects. ${ }^{50}$

The fourth phase (1990-1995) started after the Tiananmen Square incident in 1989. China sought actively for diplomatic support and increased its aid substantially, in particular to African countries (Taylor 1998; Bräutigam 2008, 2010). As pointed out by Taylor (1998), African reactions to the massacre were substantially softer compared to Western reactions, and sometimes even supportive. According to Taylor (1998: 450), “[s]uch a[n aid] policy was a quick and comparatively cheap way by which Beijing could reward those countries that had stood by China during the 1989 crisis as well as cementing relations for the future." Moreover, China reinforced its “checkbook diplomacy” in response to Taiwan's democratic transition in the late 1980s (Bräutigam 2010; see also Rich 2009).

\footnotetext{
${ }^{48}$ The principles were put forward by China's Premier Zhou Enlai while visiting Africa in 1964 (Davies 2007; Bräutigam 2008).

${ }^{49}$ Chinese Premier Zhao Ziyang stressed four principles on the economic and technical cooperation between China and Africa in the early 1980s: Equality and mutual benefit, stress on practical results, diversity in form, and common progress (as listed in Bräutigam 2010).

${ }^{50}$ These consolidation efforts included the overhaul and provision of equipment, supply of accessories and spare parts, technical guidance and involvement of Chinese nationals in management and the operation of completed projects (Ministry of Commerce 1986: 487).
} 
At the same time, planners "were well aware that resource scarcities, particularly in domestic energy, would soon become an issue for domestic production, and they moved to position the country to overcome that challenge" (Bräutigam 2008: 11). The importance of economic considerations is said to have become more and more predominant in China's aid strategy (Davies 2007; Pehnelt 2007). In particular, the aid reform of 1995 introduced marketoriented principles and emphasized the linkages between aid, trade and investment (Bräutigam 2010). This reform, after which “China's aid activities have entered a completely different phase compared to the previous periods" (Kobayashi 2008: 7), is taken as the starting point for the fifth phase (1996-2006). The central aim of the reform was to multiply the ways in which foreign financing is supplied to developing countries. In addition to grants and interest-free loans as a flexible and quick form of financing, China offered interestsubsidized preferential loans as well as joint ventures and co-operations of complete projects.

A new era for China's aid program started in 2006, with China declaring a "new strategic partnership" at the Forum on China-Africa Cooperation (FOCAC). China announced to double its 2006 aid effort to Africa by 2009, with the aim "to reach the target of mutual benefit and win-win situation between China and African countries" (Ministry of Commerce 2007: 416)..$^{51}$

\section{II.3.2 Hypotheses}

Chinese aid is not linked to conditions typically imposed by Western donors, such as good policies, democracy or respect for human rights. Furthermore, Chinese financial assistance is quickly made available (e.g., Davies 2007). ${ }^{52}$ China is thus a welcome alternative to DAC donors with their bureaucratic procedures and detailed policy conditionality. At the same time, development aid from China is criticized as being driven by domestic economic and political interests to a higher extent than development aid from traditional DAC donors. Motives for the allocation of aid can be broadly grouped into three categories; first, aid should depend on recipient need; second, the quality of policies and institutions might matter; and third, the donor's commercial or political self-interests have been shown to play a role (e.g., Alesina and Dollar 2000). We discuss these motives in turn.

\footnotetext{
${ }^{51}$ President $\mathrm{Hu}$ Jintao presented a "five point pledge" at the United Nations in 2005, promising debt relief and increased aid flows. Eight concrete measures with regard to Africa followed at the FOCAC meeting in 2006 (Davies 2007; Bräutigam 2010).

${ }^{52}$ Hilsum (2006: 7) quotes Sierra Leone's ambassador to Beijing: "If a G8 country had wanted to rebuild the stadium, for example, we'd still be holding meetings! The Chinese just come and do it. They don't start to hold meetings about environmental impact assessment, human rights, bad governance and good governance." Bräutigam (2008: 21) quotes Senegalese President Abdoulaye Wade, who said in 2006 that "[w]ith the Asian countries it's fast and it's direct."
} 
With respect to poverty and development, the Ministry of Commerce (1985: 413) emphasizes that its aid projects play "a positive role in expanding the national economies of the recipient countries and improving the material and cultural life of the people in these countries." Emphasizing the idea of 'mutual benefit,' the ministry claims "to help the recipient countries develop their national economies and bring about economic progress for both China and these countries" (Ministry of Commerce 1985: 413). The State Council (2011: 6) emphasizes the need orientation in China's aid allocation by claiming that the country "sets great store by people's living conditions and economic development of recipient countries, making great efforts to ensure its aid benefits as many needy people as possible." In the early 1980s, even the CIA (1980: 6) confirmed that the Chinese aid program "fits the needs of the poorest LDCs [least developed countries].” More recently, Bräutigam (2008: 7) stresses that China uses its aid to reflect its "vision of itself as a responsible, significant power, quick to deliver humanitarian assistance." Its focus on infrastructure projects might foster developmental needs largely neglected by DAC donors (Bräutigam 2008). These views largely contradict Naím's (2007: 95) claim that rogue donors like China “couldn't care less about the long-term well-being of the population of the countries they "aid."”"

The quality of policies and institutions in recipient countries is said to matter for several reasons in the allocation of aid by Western donors. First, donor countries use aid as an incentive mechanism by rewarding recipient countries with good institutions. For example, Öhler et al. (2012) find that aid conditional on good governance leads to incentives for potential recipient countries to improve their controls on corruption. However, other studies raise doubts on whether aid for the promotion of democracy and governance is indeed effective (see Knack 2004; Busse and Gröning 2009). Second, donors might follow a widespread belief that aid is more effective if it is allocated to countries with good economic policies (e.g., Burnside and Dollar 2000), although this relationship lacks robust empirical support (e.g., Easterly et al. 2004) ${ }^{53}$ In contrast to this, one of the main principles of China's aid policy and foreign policy in general is non-interference in a country's internal affairs and respect for sovereignty (Davies 2007; Bräutigam 2008). This implies that China's aid allocation is independent of the regime type and institutional quality in the recipient countries. The Ministry of Commerce (1990: 63) itself claims that it pays "full respect for the recipient's sovereignty, without attaching any conditions and not asking for any special privileges, which

\footnotetext{
53 The claim that the effectiveness of aid depends on good governance is also disputed (Doucouliagos and Paldam 2010). Bjørnskov (2010) even finds that aid increases inequality in democracies, but not in autocratic countries. Hodler and Dreher (2012) provide a model and empirical evidence explaining the failure of policy paradigms.
} 
displayed the true spirit of sincere cooperation." Chinese aid "comes without Western lectures about governance and human rights" (The Economist May 6, 2010). ${ }^{54}$ We would thus expect Chinese aid to be unaffected by institutional characteristics of the recipient countries.

It has even been argued that China may concentrate on recipient countries with rather bad governance (Halper 2010). In the words of Pehnelt (2007: 8), since China faces "higher opportunity costs of morality and governance and human rights-oriented policies" compared with DAC donors, China has a "comparative advantage" in providing assistance to "unstable and problematic regions and rogue states." From a Western perspective, such an aid allocation behavior should be considered as particularly worrisome in the light of the results in Bermeo (2011), who finds empirical support for a negative link between aid from authoritarian regimes and the likelihood of a democratic transition.

Still, it is open to debate whether Chinese aid differs significantly from the allocation of DAC aid in terms of rewarding "deserving” recipient countries with better governance. This is because previous research points to a considerable gap between the DAC rhetoric of rewarding good governance and their actual allocation of aid. For instance, Isopi and Mattesini (2010) show that Germany, Finland, France, Japan, and the Netherlands give more, rather than less, aid to more corrupt countries. ${ }^{55}$ It is frequently expected that absent of any conditionality, Chinese aid will weaken democracy, governance, and human rights, fail to promote development, weaken social and environmental standards, and increase corruption (e.g., Davies 2007). ${ }^{56}$ According to Taylor (1998), China enthusiastically opposed democratization in Africa as it could use failed African democratizations as an argument against demands for its own democratization. ${ }^{57}$

Turning to self-interest, facilitating the export of natural resources to China is seen as a central aim of Chinese aid. China's "insatiable needs" for resources (oil, minerals, and timber in particular) are mentioned most frequently as commercial motives of its aid (e.g., Alden 2005; Tull 2006; Davies 2007; Naím 2007; Halper 2010). In addition to resource

\footnotetext{
${ }^{54}$ See also Alden (2005), Tull (2006) and Lammers (2007). Halper (2010: 100) cites president Museveni of Uganda: "The Western ruling groups are conceited, full of themselves, ignorant of our conditions, and they make other people's business their business, while the Chinese just deal with you as one who represents your country, and for them they represent their own interests and you just do business." Tull (2006: 466-467) quotes a spokesman of the Kenyan government as follows: "You never hear the Chinese saying that they will not finish a project because the government has not done enough to tackle corruption."

${ }^{55}$ See also Alesina and Weder (2002). Similarly, Neumayer (2003b) finds no consistent evidence that DAC donors reward recipients with a good human rights record.

${ }^{56}$ As one example, European Investment Bank president Philippe Maystadt claims that "[t]hey [i.e., the Chinese] don't bother about social or human rights conditions" (Financial Times, November 28, 2006). However, given that Chinese aid is given in kind rather than cash, it might also be less prone to corruption. China clearly tries to tackle corruption where repayment of its loans is at risk (Bräutigam 2008).

${ }^{57}$ According to Deng Xiaoping, "talk about human rights, freedom and democracy is only designed to safeguard the interests of the strong, rich countries [who] practice power politics" (as quoted in Taylor, 1998: 453).
} 
security, Chinese aid is accused of targeting future access to export markets and profitable investments (e.g., Davies 2007). Medical aid, for example, is considered as a tool to improve the reputation of Chinese medicine and as "a clever and low cost way to introduce Chinesemade medications to the African market" (Shinn 2006). Note that the Chinese Ministry of Commerce is the head agency in the provision of bilateral aid. This clearly indicates the overriding importance of commercial motives (Lammers 2007). Moreover, Chinese aid is tied, which is a further indication that China uses aid to improve business opportunities (Pehnelt 2007; Schüller et al. 2010). The Ministry of Commerce (1999: 75) openly concluded from aid activities in 1998 that, through aid, China's "enterprises entered the markets of the developing countries very quickly and were welcomed by the governments and enterprises of these countries."

With respect to political motivations of China's aid allocation, the Ministry of Commerce (1996: 70) openly admits that grants are used to coordinate diplomatic work and that the construction of "some public institutions [...] produced great political influences." Moreover, the aid program is aimed at supporting high-level diplomatic events. For example, to achieve a higher participation of heads of state and heads of government in the opening and closing ceremonies of the 2008 Olympic Games in Beijing, China "speeded up the implementation of the projects concerned by bilateral leaders" (Ministry of Commerce 2009: 348). According to the State Council (2011: 3), however, "China never uses foreign aid as a means to $[\ldots]$ seek political privileges for itself."

The literature has given special attention to the political motivation of China's aid allocation to Africa. ${ }^{58}$ As Davies (2007: 27) points out, “Africa is important for China's policy agenda and the building of alliances." It provided support for the People's Republic to represent China in the United Nations instead of Taiwan (Davies 2007). Specifically, China uses aid to realize its "One-China policy," rewarding countries that do not recognize Taiwan as an independent country (Taylor 1998; Bräutigam 2008). ${ }^{59}$ However, despite the One-China policy, China does provide aid to countries that recognize Taiwan in some cases (see also Davies 2007). ${ }^{60}$ African aid recipients supported Chinese efforts to prevent sanctioning its

\footnotetext{
${ }^{58}$ While most researchers focus on Africa, there is less work on China's aid to Asia. A notable exception is Schüller et al. (2010), who exploit detailed data on China's engagement in Cambodia, among others.

${ }^{59}$ Taiwan also uses aid to reward countries for recognizing it as an independent country, sparking "something of a bidding war" (Bräutigam 2008: 11). Its dollar diplomacy has been successful in maintaining its international profile (Taylor 1998). See also Rich (2009) for the connection between foreign aid and diplomatic recognition of the two Chinas.

${ }^{60}$ In most but not all of these cases, countries that recognized Taiwan and received aid from China established diplomatic relations with China in the same or the following year. In the dataset on aid amounts collected for this paper, Bartke's data show one case (Benin 1972), the CIA data list three cases (Benin 1972, Chad 1971 and Niger 1973) and the OECD data four cases (Gabon 1973, Gambia 1973, Malaysia 1973 and Niger 1973). The
} 
human rights record in international fora such as the United Nations (UN) Commission of Human Rights (Lammers 2007; Lancaster 2007). ${ }^{61}$ China expects African countries to gain in political weight in such organizations and seems determined to increase their voice in them (Taylor 1998). Also pointing at Africa's weight in international organizations, Tull (2006: 460) argues that China is trying "to build coalitions to shield Beijing from Western criticism."

Given that our data vary over time, we can evaluate whether, and to what extent, Chinese aid allocation shows (the expected) different patterns over the five phases outlined above. In summary, we expect the first phase (1956-69) to be dominated by political and ideological considerations. The second phase (1970-78) should equally be dominated by political motives, while economic motives should become more relevant in the third phase (1979-89). In search for support after the Tiananmen Square massacre and for the "One-China policy," political clout should dominate again in the fourth phase (1990-95), while commercial and more market-liberal considerations should be important for China's allocation of aid in the fifth phase (1996-2006). In all phases, we expect the non-interference principle to be reflected in China allocating aid independent of the regime type and institutional quality of recipient countries. We expect the allocation of Chinese aid to be driven by resource considerations. However, we also expect its aid to take account, at least to some degree, of poverty and need in the recipient countries.

\section{II.4 Econometric Analysis of China's Aid Allocation}

\section{II.4.1 Empirical Strategy and Data}

To test our hypotheses, we look at the four types of aid indicators explained above and estimate the share each developing country receives of total Chinese aid allocated in a particular phase of China's aid program. ${ }^{62}$ More specifically, we analyze (1) the number of aid projects compiled from Bartke (1989) and the Ministry of Commerce (1984-2009), (2a) aid amounts in US\$ from Bartke (1989), (2b) aid amounts in US\$ from CIA (1975-1984), (2c) aid amounts in US\$ from OECD (1987), (3) the number of medical staff dispatched from

picture is different for food aid. In twelve out of thirteen of those cases, China did neither entertain relations with the recipient in the year preceding nor in the year following the delivery of food aid.

${ }^{61}$ According to Taylor (1998: 451), China is "[a]lways mindful of the fact that the West is in a minority in international organisations such as the United Nations, the courting of support from developing nations enabled China to successfully resist Western 'hegemonism' at a time when the old bi-polar world was crumbling."

${ }^{62}$ We use the share of the overall aid budget to be able to compare marginal effects over time, even when the average size of China's aid projects changes over time and when focusing on periods that cover a different number of years. We restrict our analysis to recipient countries that are on the DAC List of ODA Recipients as of January 1, 2006 (available at: http://www.oecd.org/dataoecd/23/34/37954893.pdf, accessed: February 14, 2011). 
the Ministry of Commerce (1984-2009) and, finally, (4) the amount of food aid supplied as collected by the World Food Programme (2011). ${ }^{63}$

We estimate the models using a Fractional Logit model (FLOGIT) with standard errors clustered by recipient country. ${ }^{64}$ FLOGIT directly estimates a fractional response variable without requiring any adjustment of the data. As described in Papke and Wooldridge (1996), FLOGIT guarantees that the predicted values lie in the unit interval and is adequate if the dependent variable contains a large fraction of zeros (or ones).

We estimate our models by employing five cross-sections rather than time-series cross-sectional data. Each cross-section corresponds to one of the five phases of China's aid program outlined in the previous section. The reason for estimating cross-sections rather than a panel with yearly data is that China's aid flows are rather volatile from one year to the next (see again Figure II.6). The variables that we employ below, however, can hardly be assumed to explain this volatility. Rather, we expect them to be able to explain the average share of total aid that a particular country receives from China in certain years (see also Gupta et al. 2006). Given that we are interested in the differential effects of the explanatory variables over time, we do not pool the cross-sections either, but allow the coefficients of all variables to be different in each cross-section. This choice is supported by a test for equality in coefficients, at the one-percent level of significance. The test thus clearly indicates that pooling would not be appropriate. ${ }^{65}$ For each aid indicator, we thus estimate the following model:

$$
E\left(\text { aidshare }_{i t} \mid x_{i t}\right)=\mathrm{G}\left(x_{i t} \beta_{t}\right)
$$

where $G(\cdot)$ is the logistic function, aidshare at $_{\text {it }}$ is the share of China's total aid that country $i$ receives in phase $t$ of China's aid program; $x_{i t}$ is a vector containing a set of explanatory variables (including a constant) interacted with a set of period dummies; $\beta_{t}$ is a vector of unknown period-specific parameters; and $\varepsilon_{i t}$ is stochastic term with unit conditional mean.

In line with the previous literature on aid allocation, we include a set of possible determinants as explanatory variables (e.g., Dreher et al. 2011). Note that all these variables are averaged over the respective time period under consideration. Assuming that "new"

\footnotetext{
${ }^{63}$ We include all three measures of aid amounts in US\$ since we have no a priori belief which data source is best suited. The correlation between the three measures is 75.4 percent (Bartke-CIA), 77.1 percent (Bartke-OECD) and 80.3 percent (CIA-OECD), respectively.

${ }^{64}$ If we estimated the aid share each developing country receives with Ordinary Least Squares (OLS) regressions instead, this would not account for the bounded nature of our dependent variables and assume a misleading constant effect of our explanatory variables.

${ }^{65}$ For this test, we used our baseline specification in column 1 of Table II.1.
} 
donors such as China are more likely to give aid to countries that are geographically closer to them, we account for the (logged) distance between the recipient and the donor country. ${ }^{66}$

We control for (logged) population of recipient countries in order to control for the size of a recipient country. Larger countries need more resources to develop. Given that our dependent variable is not in per-capita terms, we expect aid to rise with population. The logged per-capita GDP is a commonly used indicator of recipient need, which has repeatedly been shown to shape the distribution of aid (e.g., Fleck and Kilby 2010). In line with China's official objectives quoted above, we expect the effects of per-capita GDP to be significantly negative in our regressions. As a further proxy for recipient need, we use the (logged) total number of people affected by a natural disaster in the recipient country.

Our primary measure for merit is a dummy for democracy coded as 1 if multiple parties are legally allowed and exist outside the regime front, as well as if at the same time the selection of the executive and the legislature involve an either direct or indirect mandate from an electorate (Cheibub et al. 2010). Moreover, in order to qualify as a democracy, incumbents must not be able to unconstitutionally close the lower house of the legislature and rewrite the rules in their favor. Following China's non-interference principle, we expect this variable to be insignificant. If the claim that China favors autocratic regimes over democracies was true, we would expect a negative effect of the dummy variable on the recipient's aid share.

To proxy donors' political self-interests, the literature suggests a recipient country's voting behavior in the United Nations General Assembly (UNGA). Various empirical studies show that developing countries get more aid and better conditions from donors when they have closer political ties with the donor, as measured by their UNGA voting alignment (Thacker 1999; Alesina and Dollar 2000; Barro and Lee 2005; Kilby 2009a, 2011, forthcoming). Relying on data from Kilby (2009b), ${ }^{67}$ we calculate the number of times a country votes in line with China (either both voting yes, both voting no, both voting abstentions, or both being absent). We then divide by the total number of votes in a particular year to derive a measure of voting coincidence between zero and one. In the 1996-2005 period, average voting compliance of developing countries with China ranges from 42.1 percent (Palau) to 92.2 percent (Indonesia). Since China's seat in all UN bodies was held by Taiwan (Republic of China) until 1971, we make use of voting alignment with Taiwan for the years up to 1971. While we expect that countries voting in line with China in the UNGA

\footnotetext{
${ }^{66}$ For example, Harmer and Cotterrell (2005) find that humanitarian aid by non-DAC donors is concentrated in neighboring countries. See also Dreher et al. (2011). In our dataset, bilateral distances are computed as the average of the distance between the major cities of the two countries, which are weighted by the share of the city in the overall population, as defined in Mayer and Zignago (2006).

${ }^{67}$ We thank Christopher Kilby for sharing his revision of Voeten and Merdzanovic's (2009) UNGA data.
} 
receive more aid, countries voting in line with Taiwan are expected to obtain less aid from China (if any). ${ }^{68}$

An important political factor driving China's aid allocation decisions might be the recipient country's adherence to the "One-China policy." A country cannot maintain diplomatic relations with both Chinas. While 169 countries recognized the People's Republic of China in 2008, only 23 countries had established diplomatic relations with Taiwan at that time. ${ }^{69}$ We make use of a dummy variable that takes a value of 1 if a country has diplomatic relations with Taiwan for six months or more in a particular year (Rich 2009). ${ }^{70}$

To account for commercial interests, we include China's (logged) total exports to a particular recipient country in constant US\$, as well as a recipient country's (logged) oil production in millions of barrels per day. While the former variable intends to capture the idea that China might use its foreign aid program as a tool for export promotion, with the latter variable we intend to test our hypothesis that aid is employed to secure China's access to natural resources. All variables with their definitions and sources are provided in Appendix II.1. Appendix II.2 shows descriptive statistics.

As evident from our regression equation, we use contemporaneous values of these explanatory variables to explain China's aid shares attributed to developing countries. This may raise some endogeneity concerns. For example, China may not only reward countries that have voted in line with it in the UNGA, but countries may also vote in line after receiving aid from China in the first place. Similarly, China might not only provide more aid to countries with deep commercial ties, but ties might also intensify as a consequence of aid flows. A natural solution is the use of lagged values of our explanatory variables, i.e., the corresponding values before the onset of the respective phase of China's aid program. However, such an approach leads to some pitfalls. First, these past values seem to be decoupled from the actual aid allocations. In the most extreme case, explanatory variables in 1995 would be assumed to explain aid allocations in 2006. Second, bilateral relations need to be in good shape at the moment when the aid money was disbursed or an aid project was completed. This is of particular importance as China's aid has been suspended in many cases after a deterioration of diplomatic relations with recipients (see Bartke 1989 for a discussion). Beyond that, the question of timing is not central to our research, which aims to examine

\footnotetext{
${ }^{68}$ Therefore, the variable takes the value of 1 minus the voting alignment with Taiwan until 1971.

${ }^{69}$ Bhutan had no diplomatic relations with either of them.

${ }^{70}$ We thank Timothy Rich for providing the data. He constructed the variable from an analysis of the written record and data provided by the Ministry of Foreign Affairs of the Republic of China (Taiwan) and the People's Republic of China.
} 
whether, and to what extent, political and commercial interests matter for China's aid allocation, rather than whether aid is used to bribe or reward the countries.

\section{II.4.2 China's Project Aid}

The results are shown in Table II.1. We run nested regressions for all periods, rather than performing regressions for each phase and comparing the individual results. This means that we introduce dummies for each individual phase; we interact these dummies with our explanatory variables, mirroring individual regressions for the individual phases. Running nested regressions in such a way enables us to statistically test for differences and similarities among them. Table II.1 reports the marginal effects of all explanatory variables in each of the five phases. We also report the p-values of a Wald test for differences in the coefficient of a variable for a particular phase with respect to the most recent phase for which data are available (in italics). ${ }^{71}$ A heteroskedasticity-robust RESET test evaluates the adequacy of our models. ${ }^{72}$ The corresponding p-values shown in Table II. 1 indicate that all six models pass the RESET test at the five-percent level of significance. ${ }^{73}$

In column 1, we focus on the share of aid projects, based on 528 observations. As can be seen here, the share of projects a country receives is not related to its distance from China, at conventional levels of significance. The exception is the fourth phase (1990-95), where the share of projects increases with distance. However, the effect is only significant at the tenpercent level. With respect to the fifth phase, distance matters more in the fourth, also at the ten-percent level. Overall, there is no evidence that China gives more aid to countries that are geographically closer, which is contrary to the results in Dreher et al. (2011) for non-DAC donors (excluding China). China, having global ambitions, seems to behave differently than the other (smaller) emerging donors. ${ }^{74}$

\footnotetext{
${ }^{71}$ Note that comparisons of the first three phases with phase 5 need to be interpreted with caution as we draw data from two different data sources.

${ }^{72}$ More precisely, we test whether the squared fitted values of the explained variable have any explanatory power. If so, our model would be considered misspecified.

${ }^{73}$ At the ten-percent level, the estimation based on aid data from the CIA does not pass the test, while the other regressions do.

${ }^{74}$ However, the fact that we do not find a negative effect of distance on aid allocation in the first three phases may be driven by missing data on Communist countries in China's neighborhood, as mentioned above.
} 
Table II.1: Five Phases of China's aid program

\begin{tabular}{|c|c|c|c|c|c|c|}
\hline & $\begin{array}{c}\text { (1) } \\
\text { Aid projects } \\
\text { (Bartke/CCY) }\end{array}$ & $\begin{array}{c}\text { (2) } \\
\text { Aid amount } \\
\text { (Bartke) }\end{array}$ & $\begin{array}{c}(3) \\
\text { Aid amount } \\
\text { (CIA) }\end{array}$ & $\begin{array}{c}(4) \\
\text { Aid amount } \\
\text { (OECD) }\end{array}$ & $\begin{array}{c}\text { (5) } \\
\text { Medical Staff } \\
\text { (CCY) }\end{array}$ & $\begin{array}{c}(6) \\
\text { Food aid } \\
\text { (FAIS) }\end{array}$ \\
\hline \multicolumn{7}{|l|}{ Distance } \\
\hline \multirow{3}{*}{$\begin{array}{l}\text { 1st phase } \\
(1956-1969)\end{array}$} & -0.068 & $-2.309 * *$ & $-1.993^{* *}$ & & & \\
\hline & $(0.830)$ & (0.029) & $(0.025)$ & & & \\
\hline & 0.861 & 0.040 & 0.033 & & & \\
\hline 2nd phase & -0.255 & -0.088 & -0.015 & -0.055 & & \\
\hline \multirow{2}{*}{$(1970-1978)$} & $(0.130)$ & $(0.350)$ & $(0.930)$ & $(0.806)$ & & \\
\hline & 0.232 & 0.922 & 0.377 & 0.430 & & \\
\hline 3rd phase & 0.194 & -0.051 & -0.236 & 0.247 & $0.778 *$ & \\
\hline \multirow[t]{2}{*}{ (1979-1989) } & $(0.326)$ & $(0.879)$ & $(0.337)$ & $(0.355)$ & $(0.075)$ & \\
\hline & 0.322 & & & & 0.617 & \\
\hline 4th phase & $0.415^{*}$ & & & & $0.928 * *$ & -0.049 \\
\hline \multirow[t]{2}{*}{ (1990-1995) } & $(0.051)$ & & & & $(0.016)$ & $(0.750)$ \\
\hline & 0.050 & & & & & 0.740 \\
\hline 5th phase & -0.009 & & & & & 0.002 \\
\hline (1996-2006) & (0.949) & & & & & $(0.352)$ \\
\hline \multicolumn{7}{|l|}{ Population } \\
\hline \multirow{3}{*}{$\begin{array}{l}\text { 1st phase } \\
(1956-1969)\end{array}$} & -0.156 & $-0.809 *$ & -0.432 & & & \\
\hline & $(0.434)$ & $(0.085)$ & $(0.180)$ & & & \\
\hline & 0.477 & 0.095 & 0.060 & & & \\
\hline \multirow{3}{*}{$\begin{array}{l}\text { 2nd phase } \\
\text { (1970-1978) }\end{array}$} & -0.024 & -0.042 & -0.016 & 0.028 & & \\
\hline & $(0.617)$ & $(0.230)$ & $(0.735)$ & (0.689) & & \\
\hline & 0.003 & 0.763 & 0.148 & 0.464 & & \\
\hline 3rd phase & 0.002 & -0.006 & 0.263 & 0.169 & -0.110 & \\
\hline \multirow{2}{*}{ (1979-1989) } & $(0.983)$ & $(0.958)$ & $(0.142)$ & $(0.356)$ & (0.385) & \\
\hline & 0.005 & & & & 0.158 & \\
\hline 4th phase & $-0.173^{*}$ & & & & $-0.270 *$ & -0.059 \\
\hline (1990-1995) & $(0.064)$ & & & & $(0.080)$ & $(0.223)$ \\
\hline & 0.226 & & & & & 0.237 \\
\hline 5th phase & $-0.309 * * *$ & & & & & -0.002 \\
\hline$(1996-2006)$ & $(0.000)$ & & & & & $(0.143)$ \\
\hline GDP per capita & & & & & & \\
\hline $\begin{array}{l}\text { 1st phase } \\
(1956-1969)\end{array}$ & $\begin{array}{l}-0.134 \\
(0.545)\end{array}$ & $\begin{array}{r}-0.638 \\
(0.467)\end{array}$ & $\begin{array}{r}-0.499 \\
(0.447)\end{array}$ & & & \\
\hline & 0.101 & 0.527 & 0.595 & & & \\
\hline 2nd phase & $-0.211 *$ & $-0.190 * *$ & -0.119 & -0.233 & & \\
\hline (1970-1978) & $(0.067)$ & $(0.011)$ & $(0.252)$ & (0.139) & & \\
\hline & 0.038 & 0.589 & 0.933 & 0.661 & & \\
\hline 3rd phase & $-0.330 * * *$ & -0.094 & -0.141 & -0.122 & $-0.530 * * *$ & \\
\hline (1979-1989) & $(0.006)$ & (0.592) & $(0.580)$ & $(0.564)$ & $(0.007)$ & \\
\hline & 0.220 & & & & 0.041 & \\
\hline 4th phase & $-0.441 * * *$ & & & & $-0.755^{* * *}$ & -0.104 \\
\hline (1990-1995) & $(0.002)$ & & & & $(0.000)$ & $(0.328)$ \\
\hline & 0.535 & & & & & 0.366 \\
\hline $\begin{array}{l}\text { 5th phase } \\
(1996-2006)\end{array}$ & $\begin{array}{c}-0.530 * * * \\
(0.000)\end{array}$ & & & & & $\begin{array}{c}-0.008^{* *} \\
(0.020)\end{array}$ \\
\hline Disaster & & & & & & \\
\hline 1st phase & 0.015 & -0.007 & -0.074 & & & \\
\hline (1956-1969) & $(0.466)$ & $(0.933)$ & (0.149) & & & \\
\hline & 0.385 & 0.923 & 0.337 & & & \\
\hline 2nd phase & 0.008 & $0.031^{* * *}$ & $0.048 * * *$ & $0.055^{* * *}$ & & \\
\hline (1970-1978) & $(0.518)$ & $(0.003)$ & $(0.002)$ & $(0.000)$ & & \\
\hline & 0.244 & 0.495 & 0.039 & 0.502 & & \\
\hline 3rd phase & 0.031 & 0.002 & -0.018 & 0.032 & -0.031 & \\
\hline (1979-1989) & $(0.104)$ & $(0.965)$ & $(0.515)$ & $(0.302)$ & $(0.161)$ & \\
\hline & 0.645 & & & & 0.160 & \\
\hline 4th phase & -0.010 & & & & 0.009 & 0.017 \\
\hline (1990-1995) & $(0.664)$ & & & & (0.811) & (0.529) \\
\hline & 0.134 & & & & & 0.533 \\
\hline 5th phase & 0.048 & & & & & 0.000 \\
\hline (1996-2006) & $(0.124)$ & & & & & $(0.946)$ \\
\hline Democracy & & & & & & \\
\hline 1st phase & 0.018 & -0.679 & -0.592 & & & \\
\hline (1956-1969) & $(0.922)$ & $(0.353)$ & $(0.298)$ & & & \\
\hline & 0.735 & 0.990 & 0.436 & & & \\
\hline 2nd phase & -0.114 & 0.081 & 0.159 & 0.039 & & \\
\hline (1970-1978) & $(0.635)$ & $(0.641)$ & $(0.435)$ & $(0.907)$ & & \\
\hline & 0.842 & 0.086 & 0.099 & 0.092 & & \\
\hline 3rd phase & $-1.167^{* *}$ & -0.690 & -1.376 & $-1.628^{*}$ & -2.031 & \\
\hline (1979-1989) & $(0.010)$ & $(0.120)$ & $(0.135)$ & $(0.089)$ & $(0.102)$ & \\
\hline & 0.021 & & & & 0.458 & \\
\hline 4th phase & 0.128 & & & & $-1.269 * *$ & -0.213 \\
\hline (1990-1995) & (0.499) & & & & $(0.043)$ & $(0.442)$ \\
\hline & 0.375 & & & & & 0.439 \\
\hline 5th phase & -0.060 & & & & & 0.002 \\
\hline (1996-2006) & $(0.706)$ & & & & & $(0.267)$ \\
\hline
\end{tabular}


Table II.1 (continued): Five Phases of China's aid program

\begin{tabular}{|c|c|c|c|c|c|c|}
\hline & $\begin{array}{c}\text { (1) } \\
\text { Aid projects } \\
\text { (Bartke/CCY) }\end{array}$ & $\begin{array}{c}\text { (2) } \\
\text { Aid amount } \\
\text { (Bartke) }\end{array}$ & $\begin{array}{c}\text { (3) } \\
\text { Aid amount } \\
\text { (CIA) }\end{array}$ & $\begin{array}{c}\text { (4) } \\
\text { Aid amount } \\
\text { (OECD) }\end{array}$ & $\begin{array}{c}\text { (5) } \\
\text { Medical Staff } \\
\text { (CCY) }\end{array}$ & $\begin{array}{c}\text { (6) } \\
\text { Food aid } \\
\text { (FAIS) }\end{array}$ \\
\hline \multicolumn{7}{|c|}{ Taiwan recognition } \\
\hline \multirow{3}{*}{$\begin{array}{l}\text { 1st phase } \\
\text { (1956-1969) }\end{array}$} & -1.290 & $-5.448 *$ & $-4.704 *$ & & & \\
\hline & $(0.387)$ & $(0.075)$ & $(0.081)$ & & & \\
\hline & 0.072 & 0.008 & 0.007 & & & \\
\hline \multirow{3}{*}{$\begin{array}{l}\text { 2nd phase } \\
(1970-1978)\end{array}$} & 0.078 & -0.037 & 0.031 & -0.600 & & \\
\hline & (0.789) & $(0.870)$ & $(0.900)$ & $(0.395)$ & & \\
\hline & 0.000 & 0.000 & 0.001 & 0.520 & & \\
\hline 3rd phase & $-19.632 * * *$ & $-22.295 * * *$ & $-33.371 * * *$ & -1.481 & $-2.925^{* *}$ & \\
\hline \multirow{2}{*}{ (1979-1989) } & $(0.000)$ & $(0.000)$ & $(0.001)$ & $(0.213)$ & $(0.023)$ & \\
\hline & 0.000 & & & & 0.552 & \\
\hline 4th phase & $-2.400 * * *$ & & & & $-2.094 * *$ & 0.170 \\
\hline \multirow[t]{2}{*}{ (1990-1995) } & $(0.000)$ & & & & $(0.015)$ & $(0.456)$ \\
\hline & 0.061 & & & & & 0.450 \\
\hline 5th phase & $-4.749 * * *$ & & & & & -0.002 \\
\hline (1996-2006) & $(0.000)$ & & & & & $(0.538)$ \\
\hline \multicolumn{7}{|l|}{ UNGA voting } \\
\hline \multirow{3}{*}{$\begin{array}{l}\text { 1st phase } \\
(1956-1969)\end{array}$} & $5.246^{*}$ & 3.689 & 3.921 & & & \\
\hline & $(0.086)$ & $(0.508)$ & (0.339) & & & \\
\hline & 0.152 & 0.830 & 0.995 & & & \\
\hline \multirow{3}{*}{$\begin{array}{l}\text { 2nd phase } \\
(1970-1978)\end{array}$} & $7.489 * * *$ & $6.703 * * *$ & $7.940 * * *$ & $6.109 * *$ & & \\
\hline & $(0.000)$ & $(0.000)$ & $(0.000)$ & $(0.018)$ & & \\
\hline & 0.001 & 0.739 & 0.437 & 0.898 & & \\
\hline 3rd phase & $5.628^{* *}$ & 5.192 & 3.878 & 5.476 & $9.183^{* *}$ & \\
\hline \multirow{2}{*}{ (1979-1989) } & $(0.028)$ & $(0.210)$ & $(0.404)$ & $(0.208)$ & $(0.022)$ & \\
\hline & 0.044 & & & & 0.190 & \\
\hline \multirow{3}{*}{$\begin{array}{l}\text { 4th phase } \\
(1990-1995)\end{array}$} & $3.587 * * *$ & & & & $4.616 * * *$ & 1.100 \\
\hline & $(0.004)$ & & & & $(0.004)$ & $(0.216)$ \\
\hline & 0.048 & & & & & 0.217 \\
\hline 5th phase & 0.670 & & & & & 0.004 \\
\hline (1996-2006) & $(0.499)$ & & & & & $(0.675)$ \\
\hline \multicolumn{7}{|l|}{ Exports } \\
\hline \multirow[t]{2}{*}{$\begin{array}{l}\text { 1st phase } \\
(1956-1969)\end{array}$} & $\begin{array}{r}-0.023 \\
(0.165)\end{array}$ & $\begin{array}{r}0.076 \\
(0.325)\end{array}$ & $\begin{array}{r}0.084 \\
(0.248)\end{array}$ & & & \\
\hline & 0.010 & 0.751 & 0.191 & & & \\
\hline \multirow{3}{*}{$\begin{array}{l}\text { 2nd phase } \\
\text { (1970-1978) }\end{array}$} & -0.002 & 0.028 & 0.019 & 0.024 & & \\
\hline & $(0.890)$ & $(0.133)$ & $(0.433)$ & $(0.470)$ & & \\
\hline & 0.018 & 0.411 & 0.376 & 0.817 & & \\
\hline 3rd phase & $0.111 * *$ & 0.118 & -0.038 & 0.039 & 0.086 & \\
\hline \multirow[t]{2}{*}{ (1979-1989) } & $(0.049)$ & $(0.283)$ & $(0.541)$ & (0.519) & $(0.365)$ & \\
\hline & 0.596 & & & & 0.853 & \\
\hline 4th phase & 0.073 & & & & 0.069 & 0.026 \\
\hline (1990-1995) & $(0.286)$ & & & & $(0.364)$ & $(0.424)$ \\
\hline & 0.356 & & & & & 0.464 \\
\hline 5th phase & $0.157^{* *}$ & & & & & 0.002 \\
\hline (1996-2006) & $(0.020)$ & & & & & $(0.155)$ \\
\hline Oil production & & & & & & \\
\hline 1st phase & 0.016 & 0.105 & 0.084 & & & \\
\hline (1956-1969) & $(0.493)$ & $(0.211)$ & $(0.182)$ & & & \\
\hline & 0.214 & 0.080 & 0.132 & & & \\
\hline 2nd phase & -0.017 & 0.004 & -0.013 & -0.033 & & \\
\hline (1970-1978) & (0.319) & $(0.686)$ & (0.509) & (0.299) & & \\
\hline & 0.988 & 0.170 & 0.816 & 0.402 & & \\
\hline 3rd phase & $-0.052 * *$ & -0.039 & -0.025 & -0.084 & $0.076^{*}$ & \\
\hline (1979-1989) & $(0.011)$ & $(0.219)$ & $(0.636)$ & (0.129) & $(0.054)$ & \\
\hline & 0.160 & & & & 0.355 & \\
\hline 4th phase & -0.012 & & & & $0.102 * *$ & -0.048 \\
\hline (1990-1995) & $(0.596)$ & & & & $(0.027)$ & (0.115) \\
\hline & 0.783 & & & & & 0.118 \\
\hline 5th phase & -0.018 & & & & & -0.000 \\
\hline (1996-2006) & $(0.331)$ & & & & & $(0.352)$ \\
\hline \# observations & 528 & 267 & 260 & 205 & 240 & 261 \\
\hline \# countries & 132 & 105 & 101 & 107 & 128 & 132 \\
\hline RESET & 0.573 & 0.290 & 0.079 & 0.655 & 0.734 & 0.919 \\
\hline $\begin{array}{l}\text { Notes: } \\
\text { - Estimation tec } \\
\text { - All regressions } \\
\text { - We report mar } \\
\text { - In italics: p-val } \\
-*(* *, * * *) \text { ind } \\
\text { - Datasets do no }\end{array}$ & $\begin{array}{l}\text { Logit with stanc } \\
\text { d dummies and } \\
\text { explanatory va } \\
\text { of equal margin } \\
\text { at the ten (five, } \\
r \text { all years of the }\end{array}$ & $\begin{array}{l}\text { rors clustered b } \\
\text { olanatory variab } \\
\text { (correspondin } \\
\text { cts of the respe } \\
\text { ercent level } \\
\text { ctive phase of } C\end{array}$ & $\begin{array}{l}\text { oient country } \\
\text { interacted wi } \\
\text { ues in parenth } \\
\text { eriod compare } \\
\text { aid program (s }\end{array}$ & $\begin{array}{l}\text { e dummies } \\
\text { e last period } \\
\text { tion } 2 \text { and Ap }\end{array}$ & data are avail & \\
\hline
\end{tabular}


Regarding population size, we find no significant effects on the share of aid projects a country receives in the first three phases. Only since the 1990s do we find that larger countries receive fewer projects, at the ten-percent level between 1990 and 1995 (phase 4), and at the one-percent level in the 1996-2005 period (phase 5). Given that our dependent variable is not in per-capita terms, this result is surprising. Compared to the fifth period, we find that population was significantly less important for China's decision to grant aid in the second and third period, at the one-percent level of significance.

Turning to per-capita income, we find that recipient need is important for China's allocation of aid. Specifically, a country's share of aid projects decreases with per-capita GDP, the effect being statistically significant at conventional levels in phases 2-5. The results also show that the importance of recipient income for China's aid allocation increased in magnitude over time. At the mean of the continuous explanatory variables (and setting the dummies to zero), an increase in per-capita GDP by ten percent reduces a country's share in China's aid projects by 0.020 percentage points in phase $2(0.211 * \ln (1.1)), 0.031$ in phase 3 , 0.042 in phase 4 , and 0.051 in phase 5 . With respect to the fifth phase, the marginal effect in phase 2 is significantly smaller at the five-percent level. Our evidence is thus in line with the CIA (1980) and Bräutigam (2008), who stress that China's allocation of aid does focus on the need of developing countries. Controlling for per-capita GDP, however, the second needrelated variable in the model - natural disasters - is not significant at conventional levels in any phase. Apparently, China's project aid does not react to short-term disasters, but rather focuses on the overall level of development. ${ }^{75}$

Column 1 confirms that Chinese aid is largely unrelated to the recipient countries' degree of democracy, in line with our hypothesis presented above. ${ }^{76}$ Only in the third phase is democracy significant in explaining the allocation of China's aid projects, with a negative marginal effect. Rather than rewarding more democratic countries, China provided less aid to more democratic countries in the 1979-1987 period, at the five-percent level of significance. Quantitatively, the share of China's aid budget a democracy receives is 1.17 percentage points lower compared to non-democracies. This is in line with Taylor (1998), stressing China's enthusiastic opposition to democratization in Africa at a time when demands for more democracy became prevalent in China.

\footnotetext{
${ }^{75}$ Note that China's disaster relief is not directly administered by the Ministry of Commerce, but predominantly by the Ministry of Civil Affairs (Kobayasi 2008) and thus not included in this dataset.

${ }^{76}$ We test for the robustness of these results by substituting the democracy index with six alternative measures of governance and institutions in Section II.5.
} 
The results show that recognition of Taiwan is important for a country's aid share. At the one-percent level of significance, countries recognizing Taiwan have received less aid since the 1979-1987 period. ${ }^{77}$ Quantitatively, the impact of recognition is more important in the third phase, and less important in the fourth phase, when compared to the fifth. Holding all other variables constant, the share of China's aid projects to countries recognizing Taiwan is 4.75 percentage points lower in the fifth phase, and 19.63 percentage points lower in the third phase than for countries that entertain diplomatic relations with the People's Republic instead.

Our second proxy for political interests is a country's voting behavior in the UN General Assembly. As can be seen, voting is important. In all phases, countries voting in line with China (or voting against Taiwan up to 1971) receive a larger aid share. The marginal effect is statistically significant at conventional levels, with the exception of the most recent phase (1996-2005). ${ }^{78}$ The quantitative impact of voting is sizeable. In the 1956-1969 period, a country changing its voting behavior from zero to one (i.e., from always voting with Taiwan to never) receives an aid share that is 5.2 percentage points higher. The impact increases to 7.4 in the second period, but decreases thereafter. In phases $2-4$, the impact of voting was significantly more important compared to the fifth phase, at least at the five-percent level. There is thus strong evidence that Chinese aid supports its political friends. However, we do not find empirical support for the idea that political considerations became more important in the period after the Tiananmen incident compared to the previous two phases. Taking the results for both political variables together, our empirical evidence suggests that political factors have been important drivers of China's aid allocation decisions across all phases of its aid program.

Finally, we look at whether or not commercial motives are important for China's aid allocation. The results are mixed here. We find a significant impact of a recipient country's exports to China only in two of the five phases. However, these are the two periods in which we expected commercial interests to be predominant. Specifically, a recipient country's aid share increases with its bilateral exports in the 1979-1987 period (phase 3), the period of Deng Xioping's "Reform and Opening Up," and the 1996-2005 period (phase 5), the period after the aid reform of 1995 that emphasized the linkages between aid, trade and investment. In quantitative terms, an increase in exports by ten percent increases a country's share in

\footnotetext{
${ }^{77}$ When we exclude the other variable for political motives - UNGA voting alignment - from the regression, the effect of the recognition of Taiwan becomes statistically significant from the second phase onwards (results available on request).

${ }^{78}$ Note that the effect of UNGA voting alignment becomes statistically significant at the five-percent level in the fifth phase when we drop the Taiwan recognition variable from our regression (results available on request).
} 
China's aid projects by 0.011 percentage points in phase $3\left(0.111^{*} \ln (1.1)\right)$ and 0.015 percentage points in phase $5 .{ }^{79}$ Nevertheless, given the perceptions about China granting aid for predominantly commercial reasons, this is a surprisingly low effect. This impression is strengthened by looking at the results for oil production. In only one phase do we observe a significant effect (phase 3). However, the marginal effect is negative rather than positive (at the five-percent level). The expectation that China is a resource-hungry donor, granting money mainly to oil-rich countries for the sake of securing its resource needs, is therefore not supported. $^{80}$

\section{II.4.3 Total Aid Money, Medical Teams and Food Aid}

Columns 2-6 replicate the analysis employing our alternative dependent variables. The results are in line with those of column 1 to some extent. With respect to the share of the aid amount a country receives, distance hardly seems to matter. Using the data obtained from Bartke (column 2) and the CIA (column 3), we find that more distant countries received significantly less aid in the first phase, but not thereafter. This seems to reflect that China was a small donor in its early years, thus focusing on its neighbors, as is the case for many new donors in recent years (Dreher et al. 2011). Using the OECD data (column 4), the coefficients are not significant at conventional levels for the two phases these data are available. The same holds for food aid (column 6). The exception is medical staff. As can be seen in column 5, more medical personnel goes to countries that are further away. Population is not significant at conventional levels in most regressions, with two exceptions where the effect is again negative.

Regarding the need orientation of China's total aid amount, we find that more aid money goes to poorer countries in only one of the specifications (phase 2, column 2). While the other marginal effects are all negative (as expected), they are not significant at conventional levels. Moreover, fewer medical personnel are sent to richer countries (statistically significant at conventional levels in the third and fourth phase - see column 5), and richer countries also receive less food aid (significant in the fifth phase - column 6). According to columns 2-4, countries hit by more disasters receive larger aid amounts in the second phase, at the one-percent level of significance. However, disasters do not seem to

\footnotetext{
${ }^{79}$ When replacing bilateral exports by bilateral trade, i.e., exports plus imports, the marginal effects in these two phases are again positive, significant at the one-percent level. However, bilateral imports to China alone do not turn out to be statistically significant in any of the five phases of China's aid program (results available on request).

${ }^{80}$ We test for the robustness of these results by substituting the oil production variable with 15 alternative measures of natural resources in Section II.5.
} 
matter for the allocation of medical staff and food aid, both being aid types that are expected to be particularly responsive to these catastrophes.

The results for democracy are similar to those reported for column 1 above. In phase 3, more democratic countries receive less money, with marginal effects being significant at the ten-percent level or slightly below. Similarly, fewer medical personnel are dispatched to democracies than to autocracies in the 1990-1995 period (phase 4), at the five-percent level of significance.

Turning to political motives, both the recognition of Taiwan and UNGA voting are again important determinants of China's allocation of aid. In all phases of China's aid program, there is strong evidence that politics play an important role in the allocation of aid money and medical staff to recipient countries. Only the allocation of food aid does not appear to be shaped by political motivations. With respect to commercial interests, we again find only weak evidence that they drive aid allocation decisions. In particular, there is no evidence that the allocation of aid amounts, medical teams and food aid is used as a tool for export promotion. All of these respective effects are not statistically significant at conventional levels. With the exception of medical staff dispatched, we find no evidence that China's aid allocation is guided by natural resource endowments. An increase of a recipient's oil production by 10 percent is found to increase this country's share in receiving Chinese medical personnel by 0.007 in the third phase, and by 0.010 in the fourth phase, the marginal effects being statistically significant at the ten- and five-percent level, respectively.

In summary, we did not find much evidence that China ignores recipient need when deciding on its aid allocation, as claimed by its critics. Nor did we find strong evidence that commercial interests matter or recipient countries with bad governance are favored. ${ }^{81}$ However, we did find that politics are important in all five phases of China's aid program. While some of the more extreme concerns regarding China's allocation of aid seem to be exaggerated ('rogue aid'), to some extent, China's critics might be right. To the extent that other donors reward democratic countries with more aid, the availability of aid from China could undermine the effectiveness of other countries' aid. Even if recipient need is important for Chinese aid allocation, it could well be that the elasticity of aid to income is substantially lower compared to those of other countries. On the contrary, while we found that politics are important, it might well be that aid from other countries reacts even more to political

\footnotetext{
${ }^{81}$ Note that our main conclusions hold when we use OLS instead of the Fractional Logit approach (results available on request). Our finding that there is only mixed evidence for commercial interests in China's aid allocation decisions is further strengthened by these results: The positive effect of exports on aid projects in the fifth period (1996-2005) loses its statistical significance at conventional levels in the OLS setting.
} 
considerations, in line with evidence reported by Alesina and Dollar (2000) and Kuziemko and Werker (2006). In order to assess these questions, we need to compare the allocation of China's aid with those of other donors. This is what we turn to next.

\section{II.5 Comparison with DAC and Other Emerging Donors}

In order to study whether China's aid is really different, Tables II.2-II.4 compare China's aid allocation decisions in the 1996-2005 period with those of the DAC donor countries, as well as emerging donors. First, we compare China's aid allocation to that of the United States, Japan, and the average of the three biggest EU countries (EU-3, i.e., Germany, France and the United Kingdom). Second, Chinese aid allocation is compared to the so-called 'like-minded donors' or 'good donors' (Canada, Denmark, Netherlands, Norway and Sweden), which are widely expected to provide development aid predominantly based on humanitarian motives. ${ }^{82}$ Finally, comparisons are made with Korea, another large emerging Asian donor, and with Saudi Arabia and Kuwait, two Arab non-DAC donors with sizeable aid budgets. Since no information on aid amounts allocated to recipient countries is available for China since the mid-1980s, we rely on the number of aid projects completed under China's aid program and construct a comparable variable for our benchmark countries. ${ }^{83}$

Unfortunately, no direct information on the annual number of aid projects completed is available for the benchmark countries. Therefore, we construct such a variable in three different ways, using data from the project-level aid database AidData (Tierney et al. 2011). ${ }^{84}$ First, we use information on the projected completion date at the time of the commitment of each aid project to derive the year of completion. Second, we estimate the year of completion by taking the mean duration of all projects of a particular country as this entry is missing for earlier years for some countries. Third, since the entry of the year of completion is entirely missing for some countries, we estimate the year of completion for these countries by taking the average of the estimated mean duration of all countries. Since the correlation of the resulting three variables is very high for those countries for which we can construct all three measures, we take the coarsest proxy variable, which is based on the single estimated average

\footnotetext{
${ }^{82}$ In the aid quality index of Knack et al. (2011), Denmark, the Netherlands, Sweden and Norway score first, third, fourth and seventh, respectively, for all bilateral donors. Easterly and Williamson (2011), however, rank aid agency practices and Scandinavian donors perform surprisingly bad. Sweden, for example, only scores $18^{\text {th }}$ out of the 23 bilateral donors ranked.

${ }^{83}$ Focusing on the number or existence of projects rather than or in addition to investigating amounts of aid is standard in the aid allocation literature (e.g., Dreher et al. 2009a, 2009b).

${ }^{84}$ Data are available online at http://www.aiddata.org/research/releases.
} 
project duration for all countries, and is hence available for all donor countries. ${ }^{85}$ Finally, in order to increase the comparability of our variable with the Chinese data, we restrict the projects considered to bilateral flows and to those sectors also included in the Chinese aid dataset. $^{86}$

We again run nested regressions. So that we can test for differences in the effects of the individual variables on the different donors, we include all donors rather than performing regressions for each individual donor and comparing the individual results. In Table II.2, we use the same explanatory variables as in Table II.1 above. The RESET test statistic is not statistically significant at conventional levels, i.e., there is no evidence that our model is misspecified. As can be seen, distance has a significant impact on aid allocation for all countries except China and the United States. However, while the EU-3 and the 'good donors' give a larger share of their aid projects to more distant countries, Japan, Korea and the Arab donors focus instead on countries that are less distant. This is in line with the observation that "new" donors focus on their own region (e.g., Dreher et al. 2011). The obvious exception to this rule is China, and the differences in the marginal effects are significant at the five-percent level at least, for both other "new" donors under investigation (again indicated by the Wald tests in italics).

With respect to population, all donors (except China) provide a larger share of their projects to more populous countries, as expected. The effect is statistically significant at conventional levels for the United States, the EU-3, and the 'good donors' only. Regarding recipient income, this same group of countries gives more aid to poorer countries, at the fivepercent level of significance, while GDP per capita has no significant impact on the aid allocation of Japan, Korea and the Arab donors. Surprisingly however, the marginal effect of (logged) per-capita GDP in the regression for China exceeds those of the other donors by a factor of at least 3. These differences are significant at the one-percent level throughout. Consequently, rather than ignoring recipient need in its allocation of aid, China shows the strongest concern for recipient income among the sample of donors we investigate, with a marginal effect even larger than that of the 'good donors'. However, these positive results with respect to recipient need are mitigated through the fact that China's aid shares do not react to population size.

\footnotetext{
${ }^{85}$ The correlation between the direct measure and the coarsest proxy ranges between 94.62 (United Kingdom) and 99.43 (Korea).

${ }^{86}$ The sectors included are the following (DAC purpose codes in parentheses): Agriculture, forestry, fishing (311, 312, 313), communications (220), education (111, 112, 113, 114), energy (230), health (121, 122), industry, mining, construction $(321,322,323)$, other multisector $(430)$, other social infrastructure and services (160), transport and storage (210), and water supply and sanitation (140).
} 
Table II.2: Comparison of China's aid allocation with DAC donors and other emerging donors (1996-2005, baseline regression)

\begin{tabular}{|c|c|c|c|c|c|c|c|c|c|}
\hline & Distance & Population & $\begin{array}{c}\text { GDP } \\
\text { per capita }\end{array}$ & Disaster & Democracy & $\begin{array}{l}\text { Taiwan } \\
\text { recognition }\end{array}$ & $\begin{array}{l}\text { UNGA } \\
\text { voting }\end{array}$ & Exports & $\begin{array}{c}\text { Oil } \\
\text { production }\end{array}$ \\
\hline \multirow[t]{2}{*}{ China } & -0.009 & $-0.309^{* * *}$ & $-0.530 * * *$ & 0.048 & -0.060 & $-4.523^{* * *}$ & 0.670 & $0.157^{* *}$ & -0.018 \\
\hline & (0.949) & $(0.000)$ & $(0.000)$ & $(0.124)$ & $(0.705)$ & $(0.000)$ & (0.499) & $(0.020)$ & $(0.331)$ \\
\hline \multirow[t]{3}{*}{ USA } & -0.167 & $0.152^{* *}$ & $-0.151 * *$ & 0.013 & -0.039 & -0.009 & $1.260^{*}$ & $0.112^{* * *}$ & $-0.024 * *$ \\
\hline & $(0.176)$ & $(0.015)$ & $(0.029)$ & $(0.657)$ & $(0.727)$ & (0.938) & $(0.051)$ & $(0.009)$ & $(0.027)$ \\
\hline & 0.388 & 0.000 & 0.002 & 0.350 & 0.903 & 0.000 & 0.630 & 0.520 & 0.754 \\
\hline \multirow[t]{3}{*}{ EU-3 } & $0.115^{* *}$ & $0.076 * *$ & $-0.119 * *$ & $0.027 * *$ & 0.006 & -0.028 & -0.026 & $0.151^{* * *}$ & $-0.026 * * *$ \\
\hline & $(0.048)$ & $(0.017)$ & $(0.011)$ & $(0.037)$ & $(0.924)$ & $(0.650)$ & $(0.965)$ & $(0.000)$ & $(0.000)$ \\
\hline & 0.407 & 0.000 & 0.000 & 0.489 & 0.687 & 0.000 & 0.533 & 0.928 & 0.636 \\
\hline \multirow[t]{3}{*}{ 'Good donors' } & $0.219 * * *$ & $0.126^{* *}$ & $-0.119 * *$ & $0.055^{*}$ & -0.219 & 0.003 & $1.437^{*}$ & $0.100 * * *$ & $-0.039 * * *$ \\
\hline & $(0.007)$ & $(0.017)$ & $(0.035)$ & $(0.080)$ & (0.119) & $(0.976)$ & $(0.076)$ & $(0.000)$ & $(0.001)$ \\
\hline & 0.124 & 0.000 & 0.001 & 0.871 & 0.407 & 0.000 & 0.537 & 0.416 & 0.323 \\
\hline \multirow[t]{3}{*}{ Japan } & $-0.308 * * *$ & 0.030 & -0.060 & $0.031^{* *}$ & -0.009 & $0.148^{* * *}$ & $1.504^{* * *}$ & $0.086 * * *$ & -0.010 \\
\hline & $(0.000)$ & (0.389) & $(0.226)$ & $(0.037)$ & $(0.868)$ & $(0.005)$ & $(0.008)$ & $(0.001)$ & $(0.131)$ \\
\hline & 0.051 & 0.000 & 0.000 & 0.601 & 0.754 & 0.000 & 0.465 & 0.305 & 0.672 \\
\hline \multirow[t]{3}{*}{ Korea } & $-0.481^{* * *}$ & 0.021 & -0.059 & 0.002 & -0.064 & $0.160^{* *}$ & 1.244 & 0.045 & 0.010 \\
\hline & $(0.000)$ & (0.499) & $(0.283)$ & $(0.894)$ & $(0.391)$ & $(0.043)$ & $(0.224)$ & (0.143) & $(0.372)$ \\
\hline & 0.002 & 0.000 & 0.000 & 0.157 & 0.978 & 0.000 & 0.658 & 0.112 & 0.159 \\
\hline \multirow[t]{3}{*}{ Arab donors } & $-0.360 * * *$ & 0.041 & -0.096 & $-0.046 * *$ & -0.044 & $0.314 * * *$ & $3.499 * * *$ & 0.012 & -0.031 \\
\hline & $(0.000)$ & $(0.371)$ & (0.109) & $(0.017)$ & $(0.774)$ & $(0.000)$ & $(0.000)$ & $(0.156)$ & $(0.103)$ \\
\hline & 0.030 & 0.000 & 0.000 & 0.004 & 0.938 & 0.000 & 0.032 & 0.032 & 0.591 \\
\hline \# observations & & & & & 1817 & & & & \\
\hline \# countries & & & & & 132 & & & & \\
\hline RESET & & & & & 0.897 & & & & \\
\hline
\end{tabular}

- Estimation technique: Fractional Logit with standard errors clustered by recipient country

- Dependent variable: Number of aid projects completed in recipient country (\% of total number of aid projects provided by donor), 1996-2005

- The regression includes donor (group) dummies and all explanatory variables are interacted with these dummies

- We report marginal effects of the explanatory variables (corresponding z-values in parentheses)

- In italics: $p$-values of a Wald test of equal marginal effects of the respective donor (group) compared to China

$-*(* *, * * *)$ indicates significance at the ten (five, one) percent level

Table II.3: Comparison of China's aid allocation with DAC donors and other emerging donors (1996-2005, institutional quality)

\begin{tabular}{|c|c|c|c|c|c|c|c|c|}
\hline & $\begin{array}{c}\text { (1) } \\
\text { Democracy }\end{array}$ & $\begin{array}{c}(2) \\
\text { Voice }\end{array}$ & $\begin{array}{l}\text { (3) } \\
\text { Political } \\
\text { stability }\end{array}$ & $\begin{array}{c}\text { (4) } \\
\text { Government } \\
\text { effectiveness }\end{array}$ & $\begin{array}{l}\text { (5) } \\
\text { Regulatory } \\
\text { quality }\end{array}$ & $\begin{array}{c}(6) \\
\text { Control of } \\
\text { corruption }\end{array}$ & $\begin{array}{l}\text { (7) } \\
\text { Economic } \\
\text { freedom }\end{array}$ & $\begin{array}{c}(8) \\
\text { Military } \\
\text { dictatorship }\end{array}$ \\
\hline China & $\begin{array}{r}-0.060 \\
(0.705)\end{array}$ & $\begin{array}{l}-0.037 \\
(0.747)\end{array}$ & $\begin{array}{r}0.103 \\
(0.390)\end{array}$ & $\begin{array}{c}-0.213 \\
(0.174)\end{array}$ & $\begin{array}{r}-0.037 \\
(0.787)\end{array}$ & $\begin{array}{c}-0.202 \\
(0.164)\end{array}$ & $\begin{array}{r}-0.084 \\
(0.341)\end{array}$ & $\begin{array}{r}0.361 \\
(0.324)\end{array}$ \\
\hline USA & $\begin{array}{l}-0.039 \\
(0.727)\end{array}$ & $\begin{array}{r}0.088 \\
(0.198)\end{array}$ & $\begin{array}{r}0.003 \\
(0.961)\end{array}$ & $\begin{array}{r}0.086 \\
(0.379)\end{array}$ & $\begin{array}{l}0.188 * * \\
(0.037)\end{array}$ & $\begin{array}{l}-0.082 \\
(0.365)\end{array}$ & $\begin{array}{l}0.467 * * * \\
(0.000)\end{array}$ & $\begin{array}{c}-0.789 * * \\
(0.013)\end{array}$ \\
\hline & 0.903 & 0.307 & 0.410 & 0.048 & 0.127 & 0.435 & 0.000 & 0.003 \\
\hline EU-3 & $\begin{array}{r}0.006 \\
(0.924)\end{array}$ & $\begin{array}{l}0.106^{* * *} \\
(0.005)\end{array}$ & $\begin{array}{r}0.051 \\
(0.164)\end{array}$ & $\begin{array}{l}0.123^{* *} \\
(0.034)\end{array}$ & $\begin{array}{l}0.148^{* * *} \\
(0.008)\end{array}$ & $\begin{array}{r}0.016 \\
(0.760)\end{array}$ & $\begin{array}{c}0.143^{*} \\
(0.059)\end{array}$ & $\begin{array}{l}-0.124 \\
(0.250)\end{array}$ \\
\hline & 0.687 & 0.230 & 0.666 & 0.029 & 0.156 & 0.122 & 0.015 & 0.137 \\
\hline 'Good donors' & $\begin{array}{r}-0.219 \\
(0.119) \\
0.407\end{array}$ & $\begin{array}{r}0.092 \\
(0.228) \\
0.333\end{array}$ & $\begin{array}{r}0.105 \\
(0.121) \\
0.987\end{array}$ & $\begin{array}{c}0.279 * * * \\
(0.005) \\
0.004\end{array}$ & $\begin{array}{c}0.166^{*} \\
(0.077) \\
0.171\end{array}$ & $\begin{array}{c}0.149 * \\
(0.074) \\
0.022\end{array}$ & $\begin{array}{r}0.112 \\
(0.441) \\
0.147\end{array}$ & $\begin{array}{c}-0.672 * * \\
(0.033) \\
0.000\end{array}$ \\
\hline Japan & $\begin{array}{r}-0.009 \\
(0.868) \\
0.754\end{array}$ & $\begin{array}{r}0.012 \\
(0.768) \\
0.681\end{array}$ & $\begin{array}{c}0.101^{* *} \\
(0.023) \\
0.985\end{array}$ & $\begin{array}{c}0.153^{* *} \\
(0.014) \\
0.026\end{array}$ & $\begin{array}{c}0.189 * * * \\
(0.001) \\
0.095\end{array}$ & $\begin{array}{c}0.121 * * \\
(0.047) \\
0.035\end{array}$ & $\begin{array}{c}0.121^{*} \\
(0.079) \\
0.015\end{array}$ & $\begin{array}{r}0.159 \\
(0.345) \\
0.597\end{array}$ \\
\hline Korea & $\begin{array}{r}-0.064 \\
(0.391) \\
0.978\end{array}$ & $\begin{array}{c}-0.090 * * \\
(0.029) \\
0.646\end{array}$ & $\begin{array}{r}0.018 \\
(0.735) \\
0.502\end{array}$ & $\begin{array}{r}-0.101 \\
(0.169) \\
0.496\end{array}$ & $\begin{array}{r}-0.063 \\
(0.220) \\
0.850\end{array}$ & $\begin{array}{c}-0.121^{*} \\
(0.060) \\
0.586\end{array}$ & $\begin{array}{r}-0.023 \\
(0.745) \\
0.545\end{array}$ & $\begin{array}{r}0.134 \\
(0.289) \\
0.553\end{array}$ \\
\hline Arab donors & $\begin{array}{r}-0.044 \\
(0.774) \\
0.938 \\
\end{array}$ & $\begin{array}{r}-0.022 \\
(0.831) \\
0.907 \\
\end{array}$ & $\begin{array}{r}-0.118 \\
(0.232) \\
0.143 \\
\end{array}$ & $\begin{array}{r}-0.143 \\
(0.262) \\
0.691 \\
\end{array}$ & $\begin{array}{r}-0.072 \\
(0.413) \\
0.815 \\
\end{array}$ & $\begin{array}{r}-0.116 \\
(0.234) \\
0.607 \\
\end{array}$ & $\begin{array}{c}-0.176 * * * \\
(0.005) \\
0.403\end{array}$ & $\begin{array}{r}0.138 \\
(0.288) \\
0.535\end{array}$ \\
\hline \# observations & 1817 & 1796 & 1796 & 1796 & 1796 & 1796 & 1266 & 1429 \\
\hline \# countries & 132 & 130 & 130 & 130 & 130 & 130 & 91 & 103 \\
\hline AIC & 254.985 & 254.666 & 254.632 & 254.467 & 254.557 & 254.623 & 232.403 & 236.074 \\
\hline BIC & 640.331 & 639.198 & 639.165 & 638.999 & 639.090 & 639.155 & 592.457 & 604.605 \\
\hline RESET & 0.897 & 0.236 & 0.367 & 0.644 & 0.591 & 0.555 & 0.666 & 0.542 \\
\hline
\end{tabular}

Notes:

- Estimation technique: Fractional Logit with standard errors clustered by recipient country

- Dependent variable: Number of aid projects completed in recipient country (\% of total number of aid projects provided by donor), 1995-2005

- All regressions include donor (group) dummies and all explanatory variables are interacted with these dummies

- All regressions include the same control variables as in Table 2

- We report marginal effects of the explanatory variables (corresponding z-values in parentheses)

- In italics: p-values of a Wald test of equal marginal effects of the respective donor (group) compared to China

$-*(* *, * * *)$ indicates significance at the ten (five, one) percent level 
The results also show that some donors allocate significantly larger aid shares to countries hit by disasters. This holds for the EU-3 and Japan at the five-percent level as well as for the 'good donors' at the ten-percent level. Surprisingly (also at the five-percent level), Arab donors allocate fewer projects to countries that experienced catastrophes. Compared to China, the only significant difference holds with respect to these Arab donors, with China allocating more aid to countries hit by disasters, at the one-percent level of significance. Again, there is no evidence that China's allocation of aid is inferior from a humanitarian point of view compared to other donor countries.

With regard to democracy, none of the marginal effects turns out to be significant at conventional levels. Also, the difference between China and any of the other donors under investigation is not significant at conventional levels. Table II.3 tests for the robustness of these results. We report the results for our baseline model with the democracy variable in column 1 and show the results of seven alternative model specifications in columns 2-8, each time replacing the democracy variable with another indicator for institutional quality. ${ }^{87}$ First, we use five indicators of governance provided by Kaufmann et al. (2009). Voice and accountability refers to the extent to which a country's citizens can participate in selecting their governments, as well as freedom of expression, association and the media. Political stability captures a population's perception of its government's stability. It is the perceived likelihood that the government could be overthrown by violent or unconstitutional means. Government effectiveness reflects the quality of the administration and of civil servants, and the credibility of a government. It focuses on inputs that governments need to produce, and the implementation of sound policies and delivery of public goods. Regulatory quality measures the government's ability to formulate and implement sound and market-friendly policies and regulations. Finally, the control of corruption index is an aggregate measure of the extent of corruption (defined as the exercise of public power for private gain). ${ }^{88}$ Second, we use a composite indicator of economic freedom provided by Gwartney et al. (2009) ranging between 0 and 10, with higher values indicating more freedom. Finally, we employ a dummy variable as an indicator of military dictatorships (taken from Hsu 2008).

Columns 1-8 of Table II.3 show that China clearly does not take account of institutional quality when deciding on its allocation of aid. In none of the regressions does the marginal effect of any of the governance variables turn out to be significant at conventional

\footnotetext{
${ }^{87}$ Due to the lack of space, we do not report the results for the other explanatory variables. The full results are available on request.

${ }^{88}$ We did not use the rule of law as it is highly correlated with the control of corruption and government effectiveness.
} 
levels. Comparing the aid allocation of China with that of the other donors, the 'good donors' allocate significantly more aid to more effective and less corrupt countries, and less aid to military dictatorships. Significant differences also emerge with respect to the EU-3 (2 variables), the United States (3 variables), and Japan (4 variables) - in all cases favoring recipients with good institutions. Therefore, overall it seems the fears that Chinese aid would undermine the efforts of other donors to promote democracy and good governance are exaggerated. Interestingly, Korea favors countries that score worse on the voice and accountability and control of corruption indices. The Arab donors in our analysis entertain fewer aid projects in countries with a larger economic freedom, at the one-percent level of significance.

Regarding politics, the results in Table II.2 show that the United States and Japan reward countries voting in line with them in the United Nations General Assembly. The importance of political considerations for these donors is in line with previous research (Kuziemko and Werker 2006; Kilby 2011). We also find that Arab donors allocate a larger share of their aid projects to countries voting with them in the General Assembly, and surprisingly, the same holds for the average 'good donor'. The Arab donors are, according to the UNGA voting measure, the only donors that put significantly more weight on political motives than China does. ${ }^{89}$ At the one-percent level of significance, Japan, Korea and the Arab donors give more aid to countries recognizing Taiwan. It seems that Japan and Korea, as China's main regional competitors, support countries opposing China. Note however, that the quantitative effect of recognition is substantially larger in absolute terms for China than for the Arab donors, Korea and Japan.

It is well known that donors' commercial interests affect their allocation of aid. This is clearly confirmed in Table II.2. The share in the donor's aid portfolio a country receives increases significantly with exports for most of the donors covered here. At the one-percent level, this holds for the United States, the EU-3, the 'good donors' and Japan. Exports do not enter significantly into the regressions for Korea and the Arab donors. Interestingly, exports are not significantly more important for the allocation of Chinese aid compared to any of the other donors (with the exception of the Arab donors). Similarly, China does not place significantly more emphasis on oil production than its peers, as can be seen in the final column of Table II.2.

\footnotetext{
${ }^{89}$ On strategic influences in Arab aid, see Villanger (2007). When we omit the Taiwan recognition variable from our regression, the importance of the UNGA voting alignment is again not statistically different from the effect for the United States, the 'good donors', Japan and Korea. However, China puts significantly more weight on politics than the EU-3, at the ten-percent level of significance (full results available on request).
} 
The oil production variable has been chosen primarily for its good data coverage, but arguably it does not capture all facets of a country's endowment with natural resources. In Table II.4, oil production (column 1) is replaced by fifteen alternative measures of natural resource endowment; introduced one at a time. We start by varying the data source of the oil production variable (column 2), replace the oil amount by a dummy variable simply indicating whether a country produces oil or not (column 3), and use oil reserves instead of production to better account for the future availability of oil (column 4). Rather than just focusing on oil, we also employ variables capturing the production of gas, coal, and diamonds (columns 5-7), and the unit resource rents and quantities of energy and minerals extracted (columns 8-9) to display a wider range of natural resources. As a next step, we account for total and bilateral trade of fuel, ore, and agricultural raw materials (columns 10-15). Finally, we use a measure of a country's natural capital as calculated by the World Bank (2010), which is defined as the sum of crop, pasture land, timber, non-timber forest, protected areas, oil, natural gas, coal, and minerals (column 16). Appendix II.1 provides an overview of the sources and definitions of these variables.

As illustrated in Table II.4, other than one exception (bilateral imports of agricultural raw materials, column 15), there is no evidence that China provides, on average, significantly more aid to countries that are more abundant in natural resources, and the same holds for most other donor countries. With a few exceptions, there is also no evidence that China's aid reacts more to natural resources compared to other donors. Compared to Korea, it even seems that China pays less attention to these resources. Holding all other variables constant, the respective tests of equal coefficients indicate that Korea's aid program is more targeted at important producers of oil, gas and coal than is the case for China (columns 2 and 4-6). Again, it seems that objections against aid from China are overstated. 
Table II.4: Comparison of China's aid allocation with DAC donors and other emerging donors (1996-2005, natural resource endowment)

\begin{tabular}{|c|c|c|c|c|c|c|c|c|c|c|c|c|c|c|c|c|}
\hline & $\begin{array}{c}(1) \\
\text { oil } \\
\text { production }\end{array}$ & $\begin{array}{c}(2) \\
\text { oil } \\
\text { production }\end{array}$ & $\begin{array}{l}(3) \\
\text { oil } \\
\text { dummy }\end{array}$ & $\begin{array}{c}\begin{array}{c}(4) \\
\text { Oil } \\
\text { reserves }\end{array} \\
\end{array}$ & $\begin{array}{c}\text { (5) } \\
\text { Gas } \\
\text { production }\end{array}$ & $\begin{array}{c}(6) \\
\text { Coal } \\
\text { production }\end{array}$ & $\begin{array}{c}\text { (7) } \\
\text { Diamond } \\
\text { production }\end{array}$ & $\begin{array}{c}\text { (8) } \\
\text { Energy } \\
\text { depletion }\end{array}$ & $\begin{array}{c}(9) \\
\text { Mineral } \\
\text { depletion } \\
\end{array}$ & $\begin{array}{c}(10) \\
\text { Total fuel } \\
\text { exports }\end{array}$ & $\begin{array}{c}(11) \\
\text { Total OM } \\
\text { exports }\end{array}$ & $\begin{array}{c}\text { (12) } \\
\text { Total ARM } \\
\text { exports } \\
\end{array}$ & $\begin{array}{c}\text { (13) } \\
\text { Bilateral fuel } \\
\text { imports } \\
\end{array}$ & $\begin{array}{c}\text { (14) } \\
\text { Bilateral OM } \\
\text { imports } \\
\end{array}$ & $\begin{array}{c}\text { (15) } \\
\text { Bilateral ARM } \\
\text { imports } \\
\end{array}$ & $\begin{array}{c}\begin{array}{c}\text { (16) } \\
\text { Natural } \\
\text { capital }\end{array} \\
\end{array}$ \\
\hline \multirow[t]{2}{*}{ China } & -0.018 & -0.014 & -0.181 & $\begin{array}{l}-0.016^{*} \\
\end{array}$ & -0.020 & -0.017 & 0.003 & 0.009 & -0.005 & -0.012 & -0.000 & 0.035 & 0.005 & -0.012 & $0.040^{* *}$ & 0.012 \\
\hline & $(0.331)$ & $(0.238)$ & $(0.416)$ & $(0.096)$ & $(0.174)$ & $(0.301)$ & $(0.833)$ & $(0.409)$ & $(0.615)$ & $(0.536)$ & (0.999) & $(0.316)$ & $(0.706)$ & $(0.696)$ & $(0.017)$ & $(0.875)$ \\
\hline \multirow[t]{3}{*}{ USA } & $-0.024^{* *}$ & -0.010 & -0.160 & -0.007 & -0.009 & $-0.016^{*}$ & -0.006 & $-0.012^{*}$ & 0.001 & 0.011 & $0.042^{* *}$ & 0.037 & -0.029 & $0.039 * *$ & 0.001 & $-0.102^{*}$ \\
\hline & $(0.027)$ & $(0.140)$ & $(0.249)$ & $(0.190)$ & $(0.272)$ & $(0.077)$ & $(0.647)$ & $(0.081)$ & $(0.875)$ & $(0.350)$ & $(0.020)$ & $(0.107)$ & $(0.181)$ & $(0.042)$ & $(0.949)$ & $(0.056)$ \\
\hline & 0.754 & 0.780 & 0.935 & 0.404 & 0.440 & 0.942 & 0.580 & 0.057 & 0.590 & 0.244 & 0.164 & 0.964 & 0.163 & 0.156 & 0.038 & 0.169 \\
\hline \multirow[t]{3}{*}{ EU-3 } & $-0.026^{* * *}$ & $-0.011^{* * *}$ & $-0.192^{* *}$ & $-0.009 * * *$ & $-0.009^{*}$ & -0.004 & 0.004 & $-0.008^{* *}$ & 0.001 & -0.006 & 0.012 & 0.012 & $-0.020^{*}$ & $0.021^{* *}$ & -0.003 & $-0.122^{* * *}$ \\
\hline & $(0.000)$ & $(0.004)$ & $(0.014)$ & $(0.002)$ & $(0.050)$ & $(0.497)$ & $(0.478)$ & $(0.036)$ & $(0.869)$ & $(0.454)$ & $(0.267)$ & $(0.412)$ & $(0.079)$ & $(0.044)$ & $(0.781)$ & $(0.000)$ \\
\hline & 0.636 & 0.824 & 0.964 & 0.492 & 0.419 & 0.364 & 0.918 & 0.114 & 0.569 & 0.745 & 0.657 & 0.492 & 0.148 & 0.280 & 0.020 & 0.070 \\
\hline \multirow[t]{3}{*}{ 'Good donors' } & $-0.039 * * *$ & $-0.019 * *$ & $-0.357^{* *}$ & $-0.015^{* *}$ & $-0.016^{*}$ & 0.004 & $0.018^{*}$ & -0.004 & 0.003 & 0.011 & $0.032^{*}$ & $0.062^{* *}$ & -0.016 & 0.100 & 0.005 & $-0.125 * *$ \\
\hline & $(0.001)$ & $(0.012)$ & $(0.038)$ & $(0.010)$ & $(0.051)$ & $(0.691)$ & $(0.097)$ & $(0.480)$ & $(0.619)$ & $(0.398)$ & $(0.068)$ & (0.014) & $(0.518)$ & $(0.199)$ & $(0.800)$ & $(0.043)$ \\
\hline & 0.323 & 0.717 & 0.525 & 0.908 & 0.770 & 0.154 & 0.331 & 0.226 & 0.442 & 0.276 & 0.309 & 0.449 & 0.451 & 0.177 & 0.170 & 0.093 \\
\hline \multirow[t]{3}{*}{ Japan } & -0.010 & -0.000 & 0.005 & -0.001 & -0.005 & -0.003 & 0.004 & $-0.008^{* *}$ & $0.006^{*}$ & -0.006 & $0.026^{* *}$ & $0.031^{* *}$ & -0.026 & 0.016 & $0.031^{* * *}$ & $-0.054^{*}$ \\
\hline & $(0.131)$ & $(0.955)$ & $(0.942)$ & $(0.826)$ & $(0.276)$ & $(0.661)$ & $(0.563)$ & $(0.013)$ & $(0.099)$ & $(0.354)$ & $(0.016)$ & $(0.025)$ & $(0.320)$ & $(0.212)$ & $(0.002)$ & $(0.054)$ \\
\hline & 0.672 & 0.269 & 0.420 & 0.131 & 0.285 & 0.378 & 0.950 & 0.081 & 0.257 & 0.761 & 0.342 & 0.907 & 0.282 & 0.388 & 0.640 & 0.395 \\
\hline \multirow{3}{*}{ Korea } & 0.010 & $0.010^{* *}$ & $0.146^{* * *}$ & $0.007^{* *}$ & $0.012^{* *}$ & $0.011^{* *}$ & -0.018 & -0.002 & -0.000 & 0.003 & 0.009 & $0.029^{*}$ & $-0.035^{* *}$ & -0.007 & $0.027^{*}$ & -0.022 \\
\hline & $(0.372)$ & (0.025) & $(0.002)$ & $(0.029)$ & $(0.035)$ & $(0.018)$ & $(0.106)$ & $(0.704)$ & $(0.988)$ & $(0.715)$ & $(0.442)$ & $(0.099)$ & $(0.038)$ & $(0.769)$ & $(0.078)$ & $(0.657)$ \\
\hline & 0.159 & 0.043 & 0.134 & 0.015 & 0.024 & 0.082 & 0.246 & 0.312 & 0.647 & 0.457 & 0.772 & 0.880 & 0.057 & 0.887 & 0.531 & 0.687 \\
\hline \multirow[t]{3}{*}{ Arab donors } & -0.031 & $-0.021^{*}$ & -0.423 & $-0.016^{*}$ & -0.010 & -0.006 & 0.002 & -0.018 & -0.004 & -0.007 & 0.028 & 0.010 & -0.063 & -0.046 & 0.034 & -0.074 \\
\hline & $(0.103)$ & $(0.086)$ & $(0.169)$ & $(0.062)$ & $(0.456)$ & $(0.608)$ & $(0.907)$ & $(0.181)$ & $(0.592)$ & $(0.517)$ & $(0.334)$ & $(0.775)$ & $(0.213)$ & $(0.263)$ & $(0.240)$ & $(0.180)$ \\
\hline & 0.591 & 0.684 & 0.515 & 0.959 & 0.599 & 0.573 & 0.977 & 0.086 & 0.943 & 0.815 & 0.457 & 0.581 & 0.196 & 0.505 & 0.852 & 0.292 \\
\hline \# observations & 1817 & 1817 & 1817 & 1817 & 1817 & 1817 & 1333 & 1761 & 1761 & 1617 & 1631 & 1631 & 633 & 957 & 1156 & 1512 \\
\hline \# countries & 132 & 132 & 132 & 132 & 132 & 132 & 96 & 128 & 128 & 117 & 118 & 118 & 126 & 132 & 132 & 109 \\
\hline AIC & 254.985 & 255.105 & 255.147 & 255.064 & 255.332 & 255.510 & 235.119 & 252.390 & 252.574 & 245.913 & 246.465 & 246.427 & 186.884 & 207.923 & 217.450 & 240.746 \\
\hline BIC & 640.331 & 640.451 & 640.493 & 640.410 & 640.678 & 640.856 & 598.782 & 635.544 & 635.728 & 623.096 & 624.252 & 624.213 & 498.417 & 548.389 & 571.140 & 613.229 \\
\hline RESET & 0.897 & 0.739 & 0.679 & 0.712 & 0.386 & 0.197 & 0.447 & 0.311 & 0.594 & 0.484 & 0.332 & 0.149 & 0.112 & 0.436 & 0.827 & 0.969 \\
\hline
\end{tabular}

technique: Fractional Logit with standard errors clustered by recipient country

作

A production in (1) uses data from Humphreys (2005) and BP (2010); Oil production in (2) relies only on BP (2010)

(anatory variables (corres ponding z-values in parentheses)

Whe donor (group) compared to China ${ }^{*}\left({ }^{* *}, * *\right)$ indicates significance at the ten (five, one) percent level 


\section{II.6 Summary and Conclusions}

China is said to be the chief villain among the so-called new donors. It has been claimed that it strategically allocates its aid in order to gain easy access to natural resources, as well as to bribe countries into providing their support in international politics. China is often accused to neglect the recipient countries' institutional quality, thus undermining other donors' efforts to promote the worldwide spread of democracy and the rule of law. China's development aid has even been characterized as 'rogue aid' (Naím 2007). In this paper, we confronted these claims with data. We collected information on the number of Chinese aid projects completed over the 1956-2005 period, the amount of aid money (1956-1987), the number of medical staff sent (1983-1994), and food aid delivered (1988-2006).

Using these data, we tested whether, and to what extent, Chinese aid was motivated by developmental, governance-related, political, or commercial motives over five phases of China's aid program. In the first phase (1956-1969), we expected China's aid to be mainly driven by political and ideological considerations. In the second phase (1970-1978), Mao Zedong's claim to assume political leadership in the Third World should have further strengthened political considerations in China's aid allocation. After the death of Mao Zedong in 1976, China opened to the West and pursued more pragmatic foreign (and aid) policies. With the reforms of Deng Xiaoping, we expected economic considerations to become more influential in China's aid allocation decisions in the third phase (1979-1989). Political considerations were expected to dominate again in the fourth phase (1990-1995), which started after the Tiananmen Square massacre in 1989, where China sought actively for diplomatic support and increased its aid substantially. In the fifth phase (1996-2006), we expected market-oriented principles and the linkages between aid, trade and investment to become more important.

Our empirical results are only partly in line with these expectations. Indeed, commercial motives seem to be more relevant for China's allocation of aid in the third and fifth phases. We find that politics are important in all five phases of China's aid program. Countries that vote in line with China in the United Nations General Assembly and do not recognize Taiwan as independent country receive larger aid shares. The results show some evidence that China follows recipient need when deciding on its aid allocation, as it favors countries with low per-capita income. Finally, China's aid is, for the most part, independent of the recipients' institutional characteristics, which seems to confirm the non-interference principle. 
To put these results in perspective, we compared China's aid allocation decisions in the 1996-2005 period with those of traditional DAC donor countries and other emerging donors. There is no evidence that China's allocation of aid is inferior from a humanitarian point of view when compared to other donor countries. When it comes to democracy and indicators of governance, there is also little evidence that China's allocation of aid is inferior. We found that China does not take account of institutional quality when deciding on its allocation of aid. However, the same holds for most other donors in our sample. In particular, we did not find that China's aid is biased towards autocratic or corrupt regimes as claimed by its critics. Based on China's aid allocation decisions, it seems that fears Chinese aid undermines the efforts of other donors to promote democracy and good governance are exaggerated. The same holds for commercial motives. While commercial interests matter, our empirical evidence does not support the idea that China places greater emphasis on giving aid to countries with strong commercial ties, or to countries that are more abundant in natural resources, in comparison to other donors.

Our empirical findings confirm that China's aid allocation decisions are shaped by politics. However, compared to the DAC and other emerging donors, the fact that political self-interest is part of China's aid motives is not exceptional. While both China and DAC donors use aid for strategic reasons, China communicates more openly that its aid is mutually beneficial. We find that China's aid is independent of institutional characteristics, which confirms the non-interference principle. Overall, the verdict that China's foreign aid is 'rogue aid' seems wide of the mark.

A potential drawback of our study is the omission of aid provided by the China Exim Bank. However, since our study covers aid allocated by the Ministry of Commerce, it is unlikely that this omission biases our results against finding a significant impact of commercial motives. The omission could only be overcome if China was willing to publish detailed statistics on its development aid and other official flows. According to our results, greater transparency would be in China's own interest. Comparing our results with anecdotal evidence prevalent in the media, it seems that China has little reason to be non-transparent. In fact, transparency might reduce fears about China's aid program.

Other donors seem to see China mainly as a competitor (Bräutigam 2008) and this contributes to its negative image. They favor their own models of development. However, there is little evidence that the traditional development model works better. As pointed out by Bräutigam (2008), the close relationship between Japan as a donor and China as recipient, might serve as a role model for China's aid in Africa. China is still a recipient of substantial 
development aid and has a lot in common with many recipients of its own aid. Therefore, Chinese aid might be more effective than that of the DAC donors, and developing countries might be more willing to listen to its advice (Davies 2007). That being said, the effectiveness of aid depends on factors other than the motives for its allocation. Different modes of delivery, as well as project design and supervision, might make Chinese aid more, or perhaps less effective compared to aid of other donors. We leave this important question for future research.

A new era of China's aid program started in 2006 with China declaring a "new strategic partnership" at the FOCAC. China announced that it would double its 2006 aid effort to Africa by 2009 with the aim "to reach the target of mutual benefit and win-win situation between China and African countries" (Ministry of Commerce 2007: 416). Given the nontransparent allocation of China's aid, it remains to be seen whether these promises will (or have been) materialize(d). According to the results of this paper, a surge in Chinese aid is nothing to fear. 


\title{
Chapter III:
}

\section{The Needy Donor: An Empirical Analysis of India's Aid Motives}

Joint work with Krishna Chaitanya Vadlamannati ${ }^{\text {a }}$

\begin{abstract}
It is puzzling that India, which has a large domestic constituency of people suffering from underdevelopment, chronic poverty and mal-governance, is emerging as an important aid donor. With the intension of understanding why poor countries provide foreign aid, this article is the first to econometrically analyze India's aid allocation decisions. First, we utilize cross-sectional data on aid commitments by the Ministry of External Affairs to 125 developing countries, obtained in US dollars from AidData for the 2008-2010 period. Second, we compare India's aid allocation with that of other donors. Our findings show that India's aid allocation is partially in line with our expectations of the behavior of a "needy" donor. Commercial and political self-interests dominate India's aid allocation. We find the importance of political interests to be significantly larger for India than for all donors of the Development Assistance Committee. Moreover, we find that countries which are closer geographically are favored, and that countries at a similar developmental stage are more likely to enter India's aid program.
\end{abstract}

\begin{abstract}
Acknowledgements: This research is part of the project "Foreign Aid of Emerging Donors and International Politics" supported by the Deutsche Forschungsgemeinschaft (DR 640/4-1). We further thank the Göttingen Graduate School of Social Sciences (GGG) for financial support. We also thank Axel Dreher, Nils-Hendrik Klann, Stephan Klasen, Hannes Öhler, Devesh Roy, Rainer Thiele, Stefanie Walter and participants at the 2011 PEGnet conference in Hamburg, Germany, at the Ph.D. Colloquium of the German Development Institute (DIE) in Bonn, Germany, at the seminar of the "Verein Freiburger Wirtschaftswissenschaftler e.V." at University of Freiburg, Germany, at the Development Economics Research Group Seminar at University of Goettingen, Germany, at the Second World Congress of the Public Choice Societies in Miami, U.S.A., at the Annual Convention of the International Studies Association in San Diego, U.S.A., and at the Nordic Conference in Development Economics in Gothenburg, Sweden, for useful comments on earlier drafts of this work. Excellent research assistance was provided by Jiaqi Ji and Jan Paulick, who supported us with the construction of the databases on Indian development assistance. We thank Scott Jobson for his proof-reading of an earlier version of the paper, as well as for supporting us with the construction of the database on Commonwealth membership.
\end{abstract}

\footnotetext{
${ }^{a}$ Heidelberg University, Alfred-Weber-Institute for Economics, Bergheimer Strasse 58, 69115 Heidelberg, Germany, University of Goettingen, Germany, e-mail: krishna.vadlamannati@awi.uni-heidelberg.de
} 
"Mr. Speaker, Sir, a stage has come in our development where we should [...] extend support to the national efforts of other developing countries."

Jaswant Singh, India's Minister of Finance, in the 2003-2004 budget speech given on February 28, 2003

\section{III.1 Introduction}

India, widely seen as one of the success stories of globalization, has significantly accelerated its economic growth since the inception of economic reforms in 1991 (Basu and Maertens 2007; Basu 2008; Panagariya 2010). The country is one of the fastest growing economies in the world and host to some of the largest foreign investment inflows in recent years (UNCTAD 2010). Yet, for many, India's progress since its independence 65 years ago is disappointing. Despite rapid economic growth over the last decade, some areas in India continue to be severely underdeveloped (Banerjee 2010). India has a large domestic constituency of people suffering from underdevelopment, chronic poverty and malgovernance. According to the World Bank's (2011) estimates, 37 percent of the Indian population is below the poverty line of US\$ 1.25 a day. Moreover, India ranks below its neighbors Bangladesh, Bhutan, Nepal, Pakistan and Sri Lanka in terms of life expectancy, access to sanitation, infant immunization, and underweight children. It also ranks below Bangladesh, Bhutan and Sri Lanka in controlling the infant mortality rate (Drèze and Sen 2011), below Sri Lanka in terms of the literacy rate and access to education (UNESCO 2011), below Nepal in the 2011 Global Hunger Index (IFPRI 2011), and below Bangladesh with respect to controlling literacy among female youths (Drèze and Sen 2011).

Therefore, it is not surprising to note that despite its rapid economic growth in recent years, India still receives development aid. In 2009, the total net official development assistance received by India from all donor countries was about US\$ 2.502 billion, of which US\$ 1.578 billion was in the form of net bilateral aid flows from countries organized in the Development Assistance Committee (DAC) (OECD 2012). ${ }^{90}$ At US\$ 630 million, India is still the single largest recipient of development aid from the United Kingdom (OECD 2012). Moreover, India also receives a substantial amount of aid from international nongovernmental organizations (NGOs). For example, in 2010, the Bill \& Melinda Gates

\footnotetext{
${ }^{90}$ The DAC is a donor organization that consists of the European Union and 23 OECD countries. Specifically, Australia, Austria, Belgium, Canada, Denmark, Finland, France, Germany, Greece, Ireland, Italy, Japan, Korea, Luxembourg, the Netherlands, New Zealand, Norway, Portugal, Spain, Sweden, Switzerland, the United Kingdom and the United States are currently DAC members.
} 
Foundation committed US\$ 100 million to India (OECD 2012). That being said, it is puzzling to note that India itself is an aid donor. ${ }^{91}$

In fact, Indian engagement in delivering foreign aid goes back to the $1950 \mathrm{~s}$, with its primary target being to provide development assistance to neighboring countries. Traditionally, Indian foreign aid has focused on technical assistance. Ever since it began in 1964, the Indian Technical and Economic Cooperation (ITEC), India's flagship external assistance program, has provided training, education and technical expertise to about 40,000 NGO personnel, scholars and leaders from developing countries (Agrawal 2007). Over the last few years, aid from India has diversified and gained prominence. During the economic reforms period spanning from 1992 to 2009, official foreign assistance provided under the umbrella of the Ministry of External Affairs (MEA) amounted to 18,950 crores Indian rupees (US\$ 4.47 billion) according to its annual reports (MEA 1993-2010). The Ministry allocated 2,359 crores Indian rupees (US\$ 444 million) to aid-related activities in the 2009 financial year alone (MEA 2010). According to Manning (2006: 375), India, together with China, is one of the two 'heavyweights' among the non-DAC donors. India's increased commitment to providing development aid is reflected in the government's decision to set up a separate agency by 2012 in order to oversee the aid allocation process. ${ }^{92}$

In contrast to the extensive empirical literature on the allocation of development aid from Western donor countries (e.g., Alesina and Dollar 2000), studies on development assistance provided by non-DAC donors lack rigorous empirical analysis. Exceptions are Neumayer (2003a, 2004) on Arab aid, Chapter II of this dissertation on China's foreign assistance, and Dreher et al. (2011) on aid from donors outside the DAC in general (excluding India). Given that India is poorer in terms of income per capita than any of the donors covered in Dreher et al. (2011), India serves as an excellent case to study the behavior of "needy" donors. Concerning India's foreign aid in particular, to the best of our knowledge, no prior study provides an econometric analysis of the determinants of India's aid allocation decisions. This paper aims to fill this gap in the literature. A better understanding of the factors driving India's aid allocation decisions may offer important insights into why poor countries serve as donors of foreign aid to other developing countries.

India claims that its aid is more need-oriented than aid from richer donor countries as its economic and political structure is closer to that of other developing countries. If this is the

\footnotetext{
${ }^{91}$ Note that India avoids the term 'donor.' It rather perceives itself as a partner in South-South cooperation (see Chaturvedi 2008 for a discussion).

92 "India to Create Central Foreign Aid Agency," The Guardian, July 26, 2011, available at: http://www.guardian.co.uk/global-development/2011/jul/26/india-foreign-aid-agency (accessed: July 11, 2012).
} 
case, India should provide more aid to countries that are closer to India in terms of economic development. We test this prediction empirically. At the same time, many suspect that India might be increasingly using foreign aid as an instrument to gain access to overseas markets for its goods and services, pave the way for Indian investment abroad, and secure access to natural resources (e.g., Agrawal 2007; Kragelund 2008). Another argument put forward is that Indian aid is extensively used as a foreign policy tool to expand the country's geopolitical and diplomatic influence (e.g., Agrawal 2007).

The consensus in the literature is that political and commercial interests are important determinants of aid allocation for the DAC group of "rich" donors (e.g., Alesina and Dollar 2000; Neumayer 2005; Kuziemko and Werker 2006), as well as for multilateral organizations (e.g., Dreher et al. 2009a, 2009b; Kilby 2011). Not only do we also expect to find this for the "needy" donor India, we expect these relationships to be even more pronounced. We argue that India has more incentives to provide politically and commercially motivated aid since the country lags behind DAC donors in terms of economic development. We will elaborate this hypothesis below and test it empirically.

Our findings show that India's aid allocation is partially in line with our expectations of the behavior of a "needy" donor. Commercial and political self-interests dominate India's aid allocation. We find the importance of political interests, proxied by the voting alignment between donor and recipient in the United Nations, to be significantly larger for India than for all DAC donors. Moreover, we find that the "needy" donor favors countries which are closer geographically and that countries at a similar developmental stage are more likely to enter India's aid program.

The paper is structured as follows. Section III.2 introduces India's foreign aid program and examines its evolution over time. Based on the previous aid literature, Section III.3 develops our hypotheses on the aid allocation behavior of a "needy" donor. In Section III.4, we empirically analyze the determinants of aid allocations by the MEA based on data for the years 2008-2010 from AidData, a project-level database (Tierney et al. 2011). To analyze whether Indian aid is special, we further compare India's aid allocation decisions with those of other donors. In particular, we test whether Indian aid is motivated to a higher extent by political and commercial considerations and to a lesser extent by recipient needs compared to aid from "rich" donors. Finally, Section III.5 summarizes our results, concludes, and provides policy implications. 


\section{III.2 An Overview of India's Aid Program}

The origins of Indian development aid date back to the Colombo Plan of 1950, which a group of Commonwealth countries (including India) formulated in Sri Lanka with the objective of providing assistance to developing countries in order to raise their respective living standards. Along with the Colombo Plan, India started providing aid in the form of grants and loans. India's primary target in its early days after independence was to support neighboring countries, in particular Bhutan, Myanmar, and Nepal. ${ }^{93}$ However, despite its active role, Indian development aid largely remained confined to the field of technical assistance, mainly due to resource scarcity and strong demand for developmental funds within the country. ${ }^{94}$ As a founding member of both groups of states, India's aid program was anchored in the NonAligned Movement and the Group of 77 at the United Nations. After the collapse of the USSR and a severe balance-of-payments crisis, India introduced pro-market economic reforms in 1991. Eventually, as the economy grew stronger, India deepened its engagement with developing countries and extended its aid program.

The 2003-04 budget speech is considered as a sharp break in India's role as an actor in international development cooperation. India wanted to be perceived primarily as an aid donor and not as a recipient of foreign assistance. Following the speech, India announced several key changes to its development cooperation (e.g., Price 2004). First, the country would only accept government-to-government aid that is untied and provided by five selected countries or the European Union. Second, India would repay its debt to most of its bilateral donors and multilateral institutions. Third, it would extend its own aid effort to other developing countries through debt cancellations for some Highly Indebted Poor Countries, and an increase in its grant and project assistance under the so-called India Development Initiative. Although the actual policy changes were softer in the beginning than the speech seemed to imply (see Price 2004 for a discussion), it became clear that India intended to play an important role in the world of international development cooperation. The provision of credit lines via India's Exim Bank is one of the most prominent outcomes of these reforms.

To provide a better understanding of how India's aid program evolved over time, we compiled data on India's aid budget since 1966 based on the annual reports of the Ministry of

\footnotetext{
${ }^{93}$ For 1958, Chanana (2009) highlights Indian aid commitments of about Rs. 100 million (US\$ 21 million) in multi-year grants to Nepal, Rs. 200 million (US\$ 42 million) to Myanmar, and the financing of 60 percent of Bhutan's budget.

${ }^{94}$ According to Dutt (1980), a total of 1,442 people received technical training in India under the Colombo Plan up until 1960. According to the Colombo Plan Reports (as cited in Dutt 1980), this number increased to 3,550 between 1961 and 1971 .
} 
External Affairs (MEA 1967-2011). ${ }^{95}$ This information needs to be interpreted with caution because of significant changes over time in the way the ministry categorizes its aid amounts. ${ }^{96}$ Apart from that, note that the data exclude aid flows from institutions other than the MEA. Moreover, we lack detailed information on which fraction of the calculated aggregated aid values satisfy the OECD's definition of Official Development Assistance (ODA). Nevertheless, the figures should provide the reader with an intuition of the overall evolution of the size of India's aid program.

As can be seen from Figure III.1, there is a spike in India's aid budget in $1972 .{ }^{97}$ This is largely due to the additional external assistance provided by India to Bangladesh, which obtained independence from then West Pakistan (now Pakistan) in 1971 with the help of India. According to the MEA annual report in 1973, India allocated about 167.6 crores Indian rupees (about US\$ 369.7 million in 2000 constant prices) of aid to Bangladesh in 1972 (mostly in the form of grants and concessional loans). India's aid disbursements suffered a decline during the early 1990s, a period marred by balance-of-payments problems and political crises. However, from the mid-1990s onwards, there has been a surge in disbursements of development aid. Though there were ups and downs, which could be attributed to the change in government in 2004 and to the Global Financial Crisis starting in 2008, India's aid budget shows an increasing trend since the mid-1990s. Taken together, India's aid budget rose from 13.4 crores Indian rupees (about US\$ 40.3 million in constant 2000 prices) in 1966, to 2,917.4 crores Indian rupees (US\$ 362.8 million in constant 2000 prices) in 2010, which is roughly 0.04 percent of India's GDP. This amount, which only captures MEA aid, is comparable to Austria's total bilateral ODA (US\$ 395.2 million in constant 2000 prices) and amounts to about two thirds of Italy's total bilateral ODA (US\$ 547.0 million in constant 2000 prices). A comparison with the figures on non-DAC donors provided in Dreher et al. (2011: 1952) underlines that India is one of the most important providers of development assistance outside the DAC.

\footnotetext{
${ }^{95}$ Note that the DAC defines ODA as financial flows to developing countries provided by official agencies with the objective to promote economic development and welfare, and that contain a grant element of at least 25 percent (see http://stats.oecd.org/glossary/detail.asp?ID=6043, accessed: July 2012). Although we lack detailed information on the concessionality of each individual loan, it seems that aid provided by the MEA by and large qualifies as ODA. According to a study by ECOSOC (2008), 80 percent of India's total aid disbursed is grants. The remaining fraction is loans with an estimated grant element of 53-57 percent.

${ }^{96}$ Values for grant-in-aid to the Indian Council of Cultural Relations and support to the African National Congress are excluded from our analysis. See Agrawal (2007) for a discussion of limitations of the use of data from MEA annual reports as a proxy for India's aid budget.

${ }^{97}$ Using data on India's GDP deflator and exchanges rates obtained from the World Development Indicators (available at: http://databank.worldbank.org/ddp/home.do, accessed: May 2012), we converted all aid values from Indian rupees to constant 2000 US\$.
} 
Figure III.1: Aid provided by the MEA in millions of constant 2000 US\$ (1966-2010)

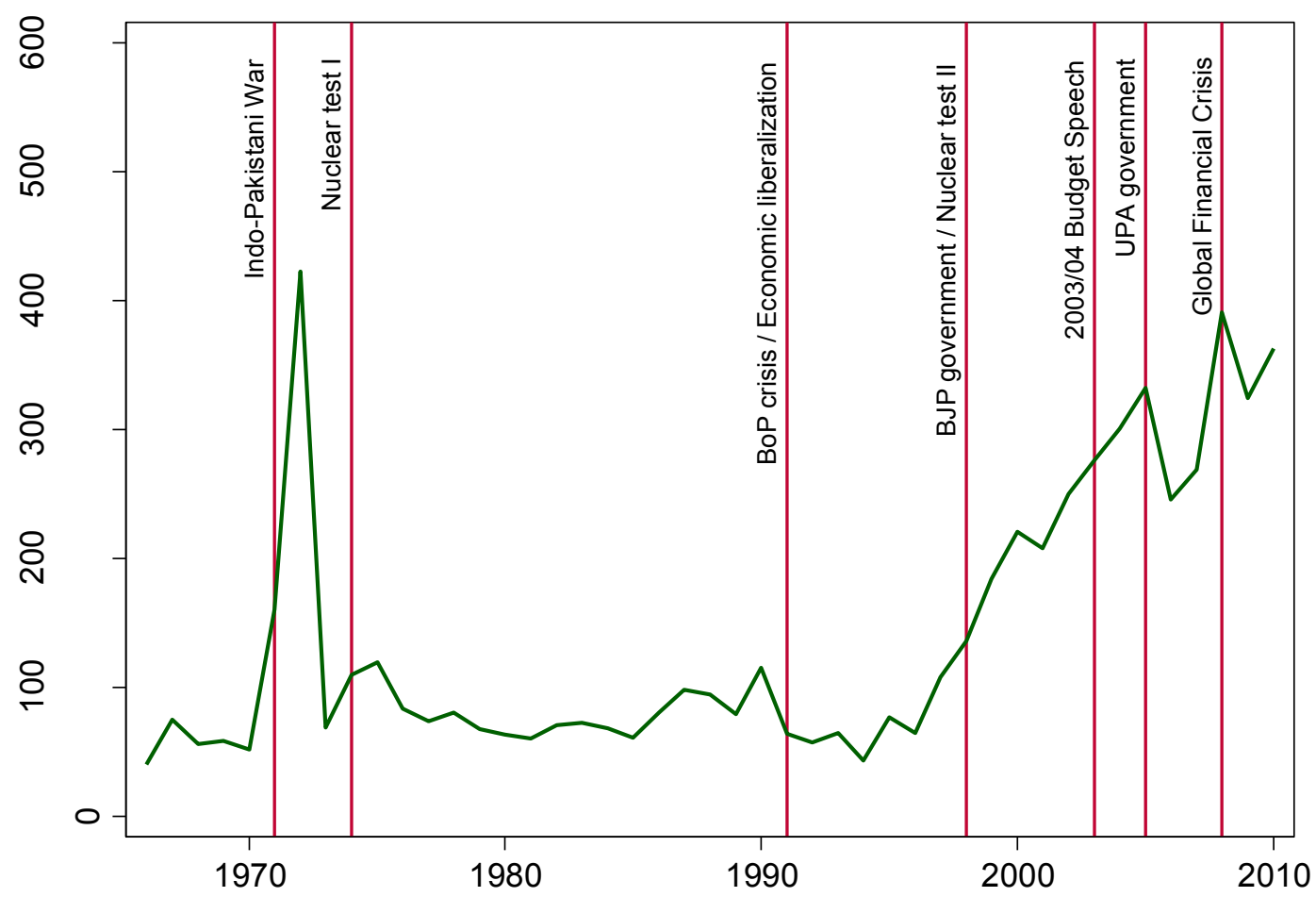

Note: BJP: Bharatiya Janata Party; UPA: United Progressive Alliance led by Indian National Congress.

In addition to the MEA, India provides concessional finance via its Export-Import (Exim) Bank. The sum of all financial flows provided by the Exim Bank between 2005 and 2009 and registered on AidData (Tierney et al. 2011) amounts to US\$ 2.45 billion (in constant 2000 prices). In contrast to MEA aid, the largest share of Exim Bank loans (73.2 percent) was allocated to Sub-Saharan African countries. Although Sinha and Hubbard (2011) find that most credits satisfy the criteria of a grant element of at least 25 percent, they conclude that Indian lines of credit (LOCs) do not qualify as ODA as defined by the OECD. Since the credit lines are extended for the purpose of export promotion, these flows meet the criteria of officially supported export credits instead. ${ }^{98}$ Therefore, we restrict our empirical analysis below to cover financial flows provided by the MEA only.

\footnotetext{
${ }^{98}$ According to Sinha and Hubbard, the grant element varies between 41.25 percent for Heavily Indebted Poor Countries (HIPC) and 17.11 percent to 24.56 percent for middle income countries with medium to high levels of debt.
} 


\section{III.3 Theory and Hypotheses}

The extensive literature on the allocation of development aid emphasizes that aid from Western donors and multilateral institutions is guided by strategic interests, in addition to economic needs in developing countries (Alesina and Dollar 2000; Kuziemko and Werker 2006; Dreher et al. 2009a, 2009b; Kilby 2009a). In contrast, research on non-DAC aid is still in its infancy. Manning (2006), ECOSOC (2008) and Kragelund (2008, 2010) provide good overviews of the aid activities of these so-called new donors. Among the few econometric studies on aid allocation by non-DAC donors are Neumayer (2003a, 2004) on Arab aid, Chapter II of this dissertation on China's foreign assistance, and Dreher et al. (2011) on aid from donors outside the DAC in general.

The literature usually groups the determinants of a donor's aid allocation into three categories. First, aid allocation follows recipient needs. Based on humanitarian motives, altruist countries provide more assistance to poorer countries. An important goal is poverty reduction. Second, aid is allocated based on good policies. Following the idea of merit, countries with good policies and good institutions are supported through increased aid flows. Third, donors' aid patterns are shaped by political and commercial self-interests. In the following, we discuss whether and how these motives are reflected in India's aid policy.

Referring to the role that Indian values might play in India's aid provision, Meier and Murphy (2011: 7) point out that, "Hinduism, Buddhism, Islam and Sikhism all espouse solidarity with the suffering and giving without expectations for return." In line with this, the Indian government claims that its aid program indeed responds to the economic needs of developing countries. For example, the MEA describes the ITEC program as "an earnest attempt by India to share the fruits of its [i.e., India's] socio-economic development and technological achievement with other developing countries" (ITEC 2011). According to Banerjee (1982: 27), India provides aid to neighboring countries "with the sole objective of restoring the local citizens to a place of primacy." If this is the case, India's aid should be targeted to needier countries. ${ }^{99}$ We test the following hypothesis:

Hypothesis 1a: India's aid allocation responds to the economic needs of developing countries.

In this regard, Banerjee (1982: 55) claims that India's aid is particularly need-oriented since it provides the "appropriate technology and managerial experience" to other developing

\footnotetext{
${ }^{99}$ Dreher et al. (2011), in turn, find that non-DAC donors care less for recipient need than traditional DAC donors. Note, however, that their study excludes aid from India.
} 
countries. He argues that India's aid is more need-oriented than aid provided by "rich" donors as its economic and political structure is closer to that of other developing countries. Similarly, the Indian MEA claims that it "possess[es] skills of manpower and technology more appropriate to the geographical and ecological conditions and the stage of technological development of several developing countries." ${ }^{100}$ If we take this argument at face value, this implies that India should allocate more aid to countries that are at a similar stage of development. Consequently, aid from India should decrease with a recipient country's distance to India's own development level. We will test the following hypothesis:

Hypothesis 1b: The "needy" donor India allocates more aid to countries at a similar stage of development.

At the same time, India emphasizes that its aid serves "mutual benefit" (ITEC 2011), i.e., its aid allocation is also motivated by Indian interests that are not directly related to the developmental concerns of its partner countries in the developing world. In this regard, the MEA (2004: 133) openly admits that "[t]he Government has been using development aid, including grants and LOCs on concessional terms as tools for promotion of India's political, economic and commercial interests." With respect to commercial interests, Indian aid is seen as an instrument not only to gain access to overseas markets for its goods and services, but also to pave the way for Indian investment abroad (Price 2004; Agrawal 2007; Kragelund 2008). The fact that India's aid is mainly 'tied aid' suggests that commercial interests play a dominant role.

Moreover, India's aid is said to be targeted at developing countries possessing oil and other natural resources in order to meet the rising demand for energy resources back home (e.g., Chanana 2009). While the MEA (2009: xiii) admits that its aid was "helping Indian companies get project contracts and orders for supply of goods," it is emphasized that "the LOCs have helped in infrastructure development in these regions thereby creating considerable goodwill for the country." With respect to the TEAM- $9^{101}$ program, Kragelund (2008) also identifies an overlap with the business activities of Indian oil companies.

In addition to commercial interests, the Indian foreign aid program is seen as a foreign policy tool to expand the country's geopolitical and diplomatic influence beyond the South Asian region, as well as an attempt to build military alliances elsewhere (e.g., Agrawal 2007).

\footnotetext{
${ }^{100}$ Quoted on several websites of Indian embassies, e.g., the Indian embassy in Azerbaijan (available at: http://indianembassybaku.org/en/8/, accessed: February 8, 2012).

${ }^{101}$ The Techno Economic Approach for Africa India Movement (TEAM-9) program offers LOCs to nine West African countries.
} 
In this regard, Lafargue (2006) notes that Zambia, an Indian aid recipient, did not criticize India's nuclear tests in 1998 and recognized in 2003 that the Jammu and Kashmir regions are a part of India. Aid is considered a part of India's efforts to obtain support for the country's bid for a permanent seat in the United Nations Security Council (e.g., Kragelund 2008). ${ }^{102}$ Moreover, India perceives its aid program as a tool to improve its image around the world. In this regard, the MEA states that the ITEC program "has generated immense goodwill and substantive cooperation among the developing countries," and that it "constitutes an integral part of India's South-South Cooperation effort which has been a traditional pillar of the country's foreign policy and diplomacy” (ITEC 2011). According to Agrawal (2007: 2), India aims to "develop a viable 'pro-India' constituency among key decision makers in recipient countries."

Contrasting these views, Banerjee (1982: 54) argues that "India does not provide aid to its neighbours with the hope of extending its influence in the region." He criticizes allegations that India's aid was motivated by selfish motives. ${ }^{103}$ Focusing on how India can actually use aid as a foreign policy tool, Dutt (1980) lists five elements: first, to improve bilateral relations, second, to improve India's image, third, to gain leverage and influence over recipient countries, fourth, to reward recipients' policy position, and fifth, to maintain the stability and status quo in recipient countries. Taken together, we test the following hypothesis:

Hypothesis 2a: India's aid allocation is guided by India's political and commercial self-interests.

With India emerging on the world stage as a significant provider of development assistance, critics of its aid program question the diversion of resources away from internal development given the chronic socio-economic problems plaguing India. It is this paradox which raises suspicion that India's aid has mainly been allocated in accordance with the country's own interests. We expect a "needy" donor to behave differently than a developed donor country. More precisely, the importance of self-interest should be larger in India's case than for "rich" donor countries for several reasons.

\footnotetext{
102 Price (2004) hypothesizes that India, as an aid recipient, only accepts aid from three current permanent Council members and from three proposed Council members for the very same reason.

${ }^{103}$ Banerjee (1982) claims that India does not make recipient countries dependent on its assistance, instead strengthening their self-reliance. Moreover, he argues that India has not installed any military bases in a major recipient country.
} 
First, a "needy" donor is more exposed to public criticism of its aid allocation because of domestic deficiencies. In order to defend its aid allocation vis-à-vis its electorate, the country might be more inclined to follow political and commercial interests to a larger extent. In this regard, Price (2004) notes that the Indian government had to emphasize the benefits that accrue to India in order to gain domestic support for its foreign aid policy, especially the aid reforms after the 2003-04 Finance Minister's budget speech. Note that this need to defend aid expenditure is even larger in democracies like India, where the government faces elections, than in autocratic donor countries.

A second explanation is evident if one assumes a declining marginal utility of wealth, i.e., a "needy" donor like India values an additional dollar of wealth more than richer countries. The "needy" donor, lagging behind the "rich" donor in terms of wealth, consequently has more incentives to provide strategic aid than the "rich" donor does. We formulate the following hypothesis:

Hypothesis 2b: While the elasticity to recipient needs is lower for a "needy" donor like India compared to "rich" donors, the opposite is true for political and commercial factors in regards to their respective aid allocations.

\section{III.4 Empirical Analysis}

\section{III.4.1 Overview}

In this section, we employ data on aid commitments by the MEA in constant 2000 US dollars, obtained from the project-level database AidData (Tierney et al. 2011). ${ }^{104}$ Data are available for the 2008-2010 period. $^{105}$ In what follows, we only analyze aid projects traceable to countries, thus excluding aid provided to world regions if we lack information on the country breakdown. ${ }^{106}$ To follow the OECD's definition of ODA, we further exclude projects related to military assistance, as well as aid provided to countries that are not on the DAC list of aid recipients. ${ }^{107}$ Our aim is to estimate the motives behind India's aid allocation decisions.

\footnotetext{
${ }^{104}$ While the first entry in the aid database is "Welfare Activities for the Muktijoddhas (Freedom Fighters)" in Bangladesh in 2008, the database ends with an IT center in Osh in the Kyrgyz Republic in 2010.

${ }^{105}$ Note that our study period coincides with the Global Financial Crisis. This might have an effect on the aid allocation decisions made by India. Nevertheless, the drop in India's aid budget during this period is not substantial compared to previous years as we will see later in Figure III.1.

${ }^{106}$ About 5 percent of the total aid amount is not traceable to recipient countries.

${ }^{107}$ The DAC List of ODA Recipients is available at: http://www.oecd.org/dataoecd/23/34/37954893.pdf, as of January 1, 2006 (accessed: February 14, 2011).
} 
Beyond that, we compare India's aid allocation to that of other donor countries in order to investigate whether aid from the "needy" donor India is allocated based on different grounds.

The lion's share ( 89.7 percent) of India's aid administered by the MEA was allocated to South Asian countries (see Figure III.2). With the exception of Pakistan, all six South Asian countries were beneficiaries of Indian aid in this period of time. Southeast Asian countries received 5.5 percent of MEA aid during this period. This corresponds to a total of 18 countries which have obtained development assistance in this region. 2.2 percent of the Ministry's total aid amount has been received by 38 Sub-Saharan African countries, and 1.6 percent was directed to eight transition economies in Eastern Europe and Central Asia. In the Middle East and North Africa, only Palestine and Syria benefited from Indian aid (1.2 percent of India's total aid amount in the 2008-2010 period). Indian support in this region was significantly concentrated on providing various types of humanitarian assistance to Palestine. Finally, less than 0.1 percent of total aid allocations by the MEA were made available to ten Latin American countries. Taken together, it is evident that India strongly favors countries in its neighborhood, as has been argued previously (e.g., Price 2005; Katti et al. 2009; Meier and Murphy 2011).

Figure III.3 puts the spotlight on sectoral aid allocations. As can be seen, 23.1 percent of the aid committed was targeted to the energy sector (DAC purpose code: 230), covering both the production and distribution of energy in recipient countries. The second most important sector was drinking water provision and sanitation facilities (code: 140), making up 15.0 percent of the Ministry's total aid amount. 12.8 percent of MEA aid was allocated to transport and storage facilities in recipient countries (code: 210 ), closely followed by 11.8 percent earmarked for commodity aid and general program assistance (code: 500). We also find that about 9.5 percent of total aid was allocated towards the development of activities associated with strengthening the administrative apparatus and government planning, activities promoting good governance, strengthening civil society, and other social infrastructure projects in the recipient countries, respectively (codes: 150 and 160). 8.7 percent of the Ministry's aid was allocated to multi-sector activities (code: 400), and 7.5 percent to the development of health-related activities such as building hospitals and health centers, and the provision of other health infrastructure (code: 120). The MEA also earmarked 5.6 percent for industrial development (codes: 321-323). The remaining sectors are: education (3.2 percent, code: 110), communications (1.4 percent, code: 331-332), agriculture, forestry and fishing (0.5 percent, code: 311-313), humanitarian purposes (0.9 percent, code: 700), unspecified (0.5 percent, code: 998), and banking and financial services (code: 240). 
Figure III.2: India's aid allocation by region (MEA, 2008-2010)
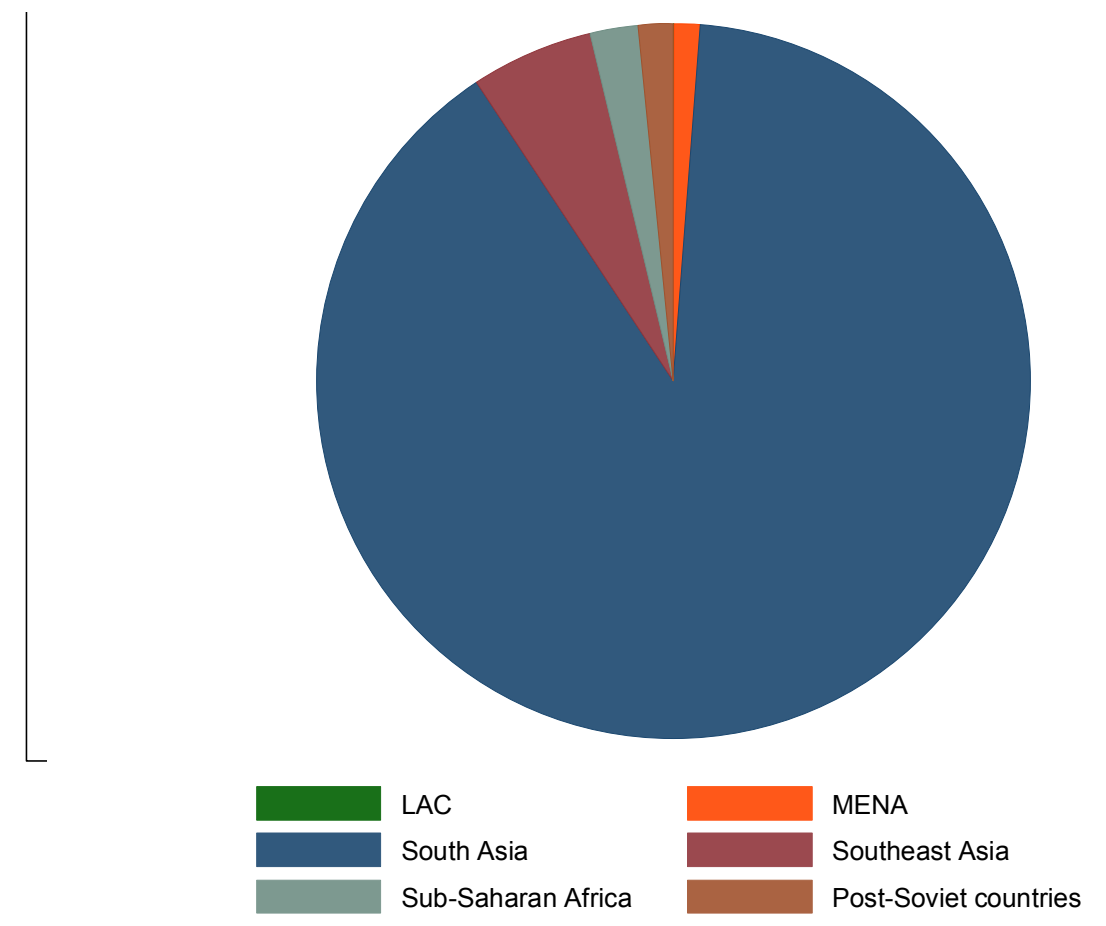

Figure III.3: India's aid allocation by sector (MEA, 2008-2010)

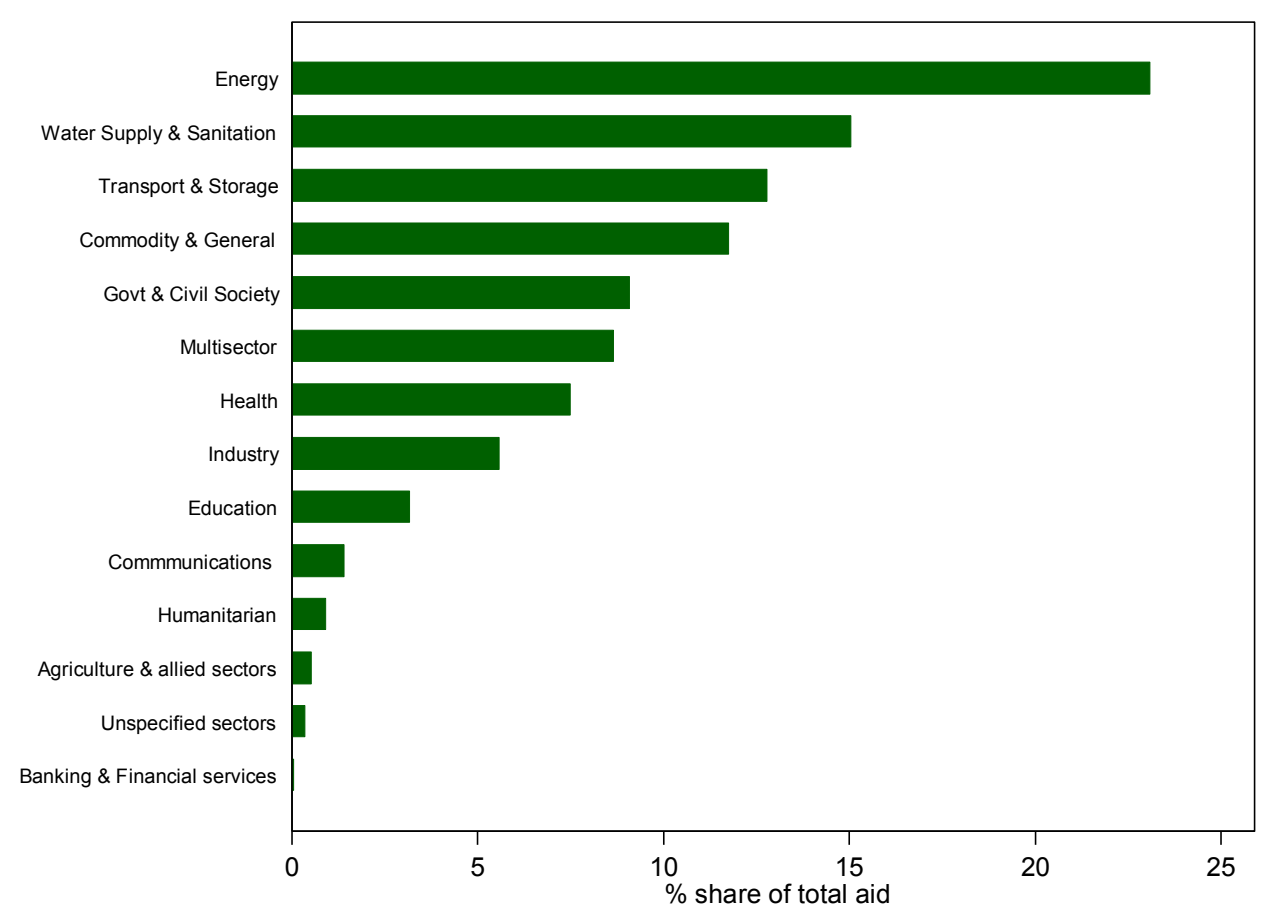


These numbers serve as a first indication that India's foreign aid is motivated to a higher extent by commercial interests in comparison to need-based issues plaguing recipient countries. This is reflected in the fact that about 45 percent of the Ministry's aid has been directed at commercial sectors. Nevertheless, the development aid provided by the MEA also covers sectors concerned with the overall development of basic public goods (such as health, drinking water, education and agriculture), which made up about 24 percent of total aid allocations.

With respect to the role of developmental distance between India and recipient countries for aid allocation, Figure III.4 provides first descriptive evidence in favor of hypothesis $1 \mathrm{~b}$. The graph on the left shows the expected strong negative link between the (logged absolute) developmental distance and the probability of receiving aid from India. A country's developmental distance to India is measured as the (log) absolute difference between the income per capita of India and that of a particular recipient country (measured in 2005 international dollars). The graph on the right, however, shows only a weak negative correlation between developmental distance and (logged) aid commitments from India. We now turn to the econometric analysis.

Figure III.4: Aid allocation and developmental distance (2008-2010)
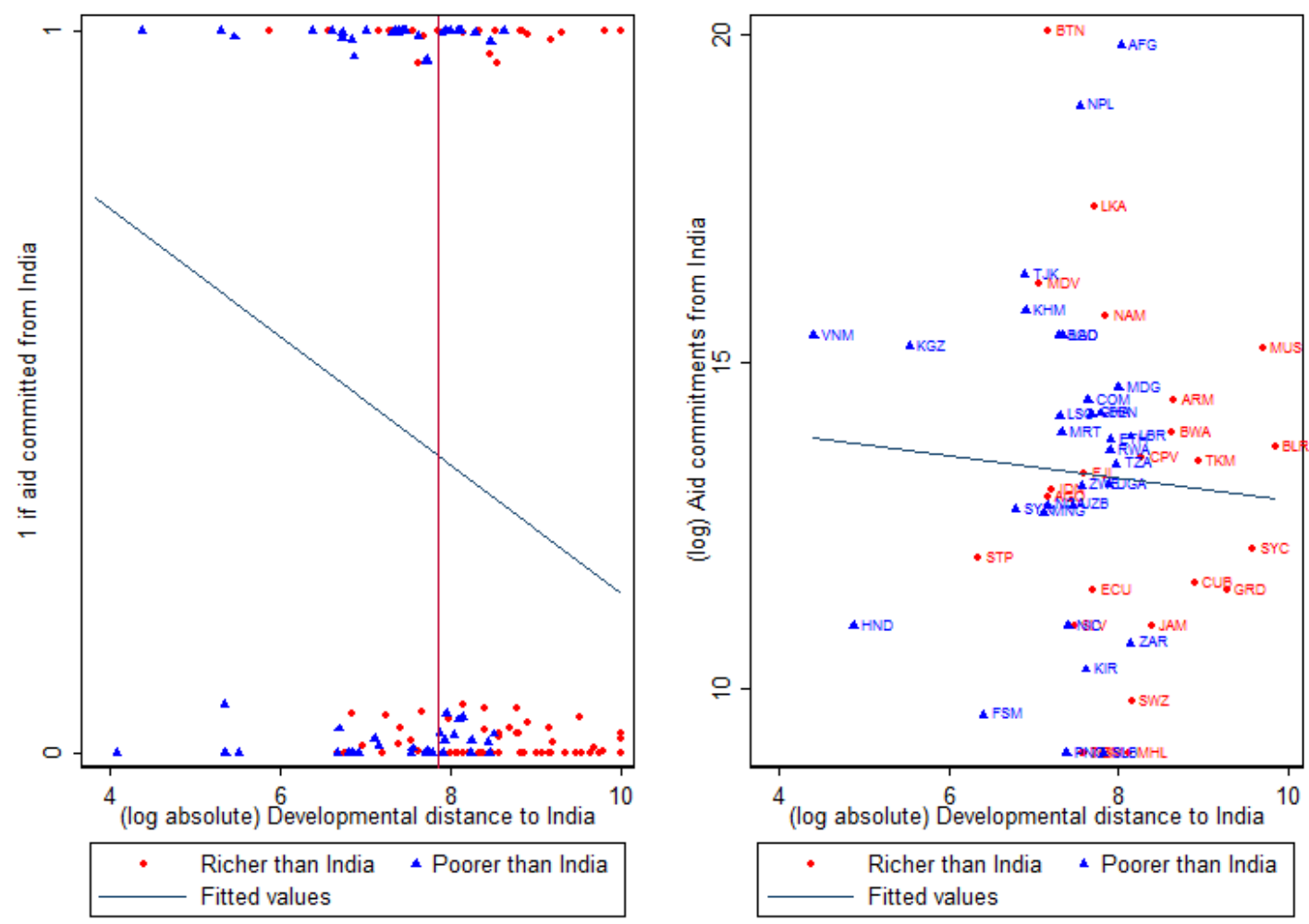


\section{III.4.2 Data and Methodology}

We follow a common practice in the aid allocation literature and estimate India's aid allocation in two steps (e.g., Neumayer 2002). First, we estimate which countries enter India's aid program. Our dependent variable is a dummy that takes a value of 1 if India provided aid to a developing country on the DAC list of aid recipients. Second, given that a country receives aid from India, we estimate the (logged) amount of aid in constant 2000 US dollars that has been committed to a particular recipient country. One way to estimate the first step (the so-called gate-keeping stage) is through a Probit (or Logit) model, which takes the binary nature of the data into account. In the second step, it may be preferable to include the inverse Mills ratio derived from the first step to avoid selection bias. Since we lack a suitable exclusion variable, we run a Heckman model without an exclusion variable, i.e., we identify the model based on the non-linearity inherent in the selection equation. The resulting Wald test does not reject the null hypothesis of independent equations (p-value: 0.650$).{ }^{108}$ Therefore, we opt for an Ordinary Least Squares (OLS) estimation of the aid amount allocated to a recipient country.

For our econometric analysis, we sum bilateral aid allocation over the 2008-2010 period since it is difficult to explain aid allocation on a yearly basis due to its volatility (see also Gupta et al. 2006; Dreher et al. 2011). Concerning the selection of our explanatory variables, we follow the previous literature on aid allocation, in particular that on emerging donors (e.g., Dreher et al. 2011; see also Chapter II). To control for the effect of geographic proximity, we account for the (logged) distance between the recipient and donor country. ${ }^{109}$ Distance can be seen as a proxy for costs associated with the provision of development aid. Aid costs are expected to be a particular concern for a "needy" donor with limited resources like India. Apart from this explanation, India might favor countries in its neighborhood (with the exception of Pakistan due to the bilateral conflict over Kashmir) as it aspires to become a regional power. Dreher et al. (2011) find that, in general, so-called new donors are more likely to provide aid to countries that are closer to them geographically. Given that India is even poorer in terms of income per capita than any of the donors covered in Dreher et al. (2011), we expect to find a pronounced effect of distance on aid allocation for the "needy" donor under investigation.

\footnotetext{
${ }^{108}$ Results available upon request.

109 As defined in Mayer and Zignago (2006), bilateral distances are computed as the average of the distance between the major cities of the two countries, which are weighted by the share of the city in the overall population.
} 
We use several variables to examine whether India's aid responds to the needs of other developing countries (hypothesis 1a). To reflect humanitarian motives, the need orientation of donors is proxied by the recipient country's (logged) GDP per capita (measured in 2005 international dollars). A need-oriented donor should provide more aid to poorer countries. Thus, we expect a negative sign for this income measure. Next, we control for the (log) population of recipient countries. The intuition here is that larger countries need more resources to obtain visible effects of aid provision. In addition, we control for the (log) total number of people affected by natural disasters as an additional indicator of recipient need since disaster relief is part of the aid program of the MEA. Furthermore, we include developmental distance to test hypothesis $1 \mathrm{~b}$, as outlined above. We expect India's aid to decrease with the developmental distance to a recipient country.

To proxy donors' political self-interests, we follow the literature and employ a recipient country's voting alignment with India in the United Nations General Assembly (UNGA). The UNGA voting alignment seems to be of large relevance for India since "marshalling support for Indian positions in forums such as the UN take up much of India's diplomatic effort" (Dutt 1980: 678). Relying on data from Voeten and Merdzanovic (2009), we calculate the number of times a country votes in line with India (either both voting yes, both voting no, both voting abstentions, or both being absent). We then divide the resulting value by the total number of votes in a particular year to derive a measure of voting coincidence between zero and one. We follow Dreher et al. (2011) and compute the voting alignment based on key votes as defined by the U.S. State Department (Kilby 2009b). ${ }^{110}$ Various empirical studies find that developing countries are favored in donors' aid allocation decisions when they have closer political ties (Thacker 1999; Alesina and Dollar 2000; Barro and Lee 2005; Dreher et al. 2009a, 2009b; Kilby 2009a).

We also include a dummy variable that takes a value of 1 if a recipient country is a non-suspended member of the Commonwealth of Nations. It can be argued that India uses the Commonwealth as a forum to develop political and commercial ties. For example, over the years India has developed strong ties with Commonwealth countries in South and Southeast Asia, as well as Africa (Johnson and Kumar 2011). Beyond that, referring to colonization, Banerjee (1982: 54) views India's aid “as a part of the process to undo the injustice of ages." To account for commercial interests, we include India's (log) total exports to a particular recipient country in constant US\$. In addition, we follow Dreher et al. (2011) and use the

\footnotetext{
${ }^{110}$ Note that we also report the results with all votes as a robustness check.
} 
recipient country's (log) depletion of mineral and energy resources as a proxy for a recipient's endowment of natural resources.

Finally, to account for merit as a motive for aid supply, institutional quality in the recipient countries is proxied by both the political rights measure from Freedom House (2009) and the corruption index from Kaufmann et al. (2009). The political rights variable is coded on a scale of 1-7, with higher values representing worse liberties, and lower values reflecting full liberties. As the world's largest democracy, India might reward democratic countries and provide less aid to autocratic countries in comparison. Note that India is the second largest donor in the United Nations Democracy Fund (UNDEF) with cumulative contributions of US\$ 25 million (as of January 5, 2012), which underlines the importance that India attributes to the support of democratization. ${ }^{111}$ Alternatively, India might follow the 'spirit of Bandung' (Lafargue 2006) and follow the principle of non-interference in internal affairs, i.e., its aid allocation might be independent of the institutional characteristics of the recipient country. ${ }^{112}$ If this is the case, we would expect India to be unresponsive to corruption in the recipient countries. The control-of-corruption index ranges from -2.5 to 2.5 , with higher values corresponding to better governance.

For our time-varying explanatory variables, we take lagged values, i.e., the corresponding value in 2007 , to mitigate endogeneity issues. The only exception is the disaster variable since it is reasonable to assume that the occurrence of natural catastrophes is exogenous. Since our export variable and UNGA voting alignment both show relatively high volatility over time, we follow Dreher et al. (2011) and take the average of the respective values in the three years preceding our period of investigation (2005-2007). All definitions and sources of variables are provided in Appendix III.1. For descriptive statistics, please refer to Appendix III.2.

\section{III.4.3 Main Results}

Table III.1 displays our results. While columns 1-3 show the results for the gate-keeping stage, columns 4-6 present the results of the allocation decision. Analyzing the coefficient on GDP per capita in column 1, Indian aid shows some need orientation. The probability that a developing country receives aid from India decreases with a country's stage of development.

\footnotetext{
${ }^{111}$ See UNDEF webpage, available at: http://www.un.org/democracyfund/Donors/donors_index.html (accessed February 11, 2012).

112 The "Bandung conference" was a large meeting of African and Asian states and took place in the Indonesian city of Bandung in 1955. The 29 participating countries agreed to not interfere in the internal affairs of other countries. The meeting is said to have laid the foundations for the Non-Aligned Movement.
} 
The coefficient is statistically significant at the ten-percent level. In turn, both the number of people affected by natural disasters and country size have no significant impact on the probability that a developing country enters India's aid program, at conventional levels of significance. ${ }^{113}$

To test whether India favors countries at a similar developmental stage (hypothesis 1b), we add the developmental distance to India to our regression in column 2. The corresponding coefficient shows the expected negative sign and is statistically significant at the ten-percent level. Note that the coefficient on per-capita GDP loses its statistical significance. Considering that the developmental distance between India and developing countries is correlated with the recipient's income per capita, we drop this latter variable as a next step. As shown in column 3, developmental distance then reaches statistical significance at the five-percent level. This suggests that countries closer to India in terms of economic development are favored by the MEA, in line with hypothesis $1 \mathrm{~b}$. The corresponding marginal effect of a ten-percent decrease in developmental distance increases to 0.01 percentage points.

According to all three specifications (columns 1-3), countries which are geographically closer to India are favored. The probability that a country receives aid from India decreases with distance, at the one-percent level of significance. Holding all other explanatory variables constant at their mean and computing the marginal effects, a ten-percent decrease in bilateral distance leads to an increase in the probability to receive Indian aid by roughly 0.03 percentage points. The political and commercial variables do not have a significant effect on Indian aid in the gate-keeping stage. The coefficient on the UNGA voting alignment on key votes, the Commonwealth dummy, and the variable capturing the extraction of natural resources are all not statistically significant at conventional levels. Note that the Indian exports variable gains statistical significance in column 3, at the five-percent level, but the suggested negative effect is not robust (see columns 1 and 2). The indicators of recipient merit, political rights and control of corruption are not statistically significant at conventional levels in all three specifications. This finding would support the idea that India's aid of today still follows the 'spirit of Bandung', with the principle of non-interference in internal affairs.

\footnotetext{
${ }^{113}$ Note that the coefficient on disasters becomes statistically significant in column 2, at the ten-percent level. The significant negative sign is strong evidence against the hypothesis that disaster-stricken countries are more likely to enter India's aid program.
} 
Table III.1: Allocation of India's aid commitments (2008-2010)

\begin{tabular}{|c|c|c|c|c|c|c|}
\hline & \multicolumn{3}{|c|}{$\begin{array}{c}\text { SELECTION } \\
\text { Probit }\end{array}$} & \multicolumn{3}{|c|}{$\begin{array}{c}\text { ALLOCATION } \\
\text { OLS }\end{array}$} \\
\hline & $(1)$ & $(2)$ & (3) & (4) & (5) & (6) \\
\hline \multirow[t]{2}{*}{ (log) GDP per capita } & $-0.315^{*}$ & -0.244 & & -0.241 & -0.243 & \\
\hline & $(0.060)$ & $(0.182)$ & & $(0.226)$ & $(0.209)$ & \\
\hline \multirow[t]{2}{*}{ (log) Developmental distance } & & $-0.228^{*}$ & $-0.268 * *$ & & 0.012 & -0.015 \\
\hline & & $(0.097)$ & $(0.039)$ & & $(0.936)$ & $(0.924)$ \\
\hline \multirow[t]{2}{*}{ (log) Affected from disasters } & -0.060 & $-0.079 *$ & -0.063 & $0.111^{* *}$ & $0.112^{*}$ & $0.126 * *$ \\
\hline & $(0.137)$ & $(0.059)$ & $(0.126)$ & $(0.037)$ & $(0.055)$ & $(0.015)$ \\
\hline \multirow[t]{2}{*}{ (log) Population } & 0.028 & 0.060 & 0.113 & $-0.526 * * *$ & $-0.530 * * *$ & $-0.451^{* *}$ \\
\hline & $(0.852)$ & $(0.697)$ & $(0.438)$ & $(0.002)$ & $(0.004)$ & $(0.012)$ \\
\hline \multirow[t]{2}{*}{ (log) Distance } & $-0.847 * * *$ & $-0.798 * * *$ & $-0.802 * * *$ & $-1.668 * * *$ & $-1.670 * * *$ & $-1.695^{* * *}$ \\
\hline & $(0.001)$ & $(0.004)$ & $(0.003)$ & $(0.000)$ & $(0.000)$ & $(0.000)$ \\
\hline \multirow[t]{2}{*}{ UN voting (key votes) } & 0.364 & 0.526 & 0.689 & $6.918 * * *$ & $6.911^{* * *}$ & $6.631 * * *$ \\
\hline & $(0.747)$ & $(0.647)$ & $(0.542)$ & $(0.000)$ & $(0.000)$ & $(0.000)$ \\
\hline \multirow[t]{2}{*}{ Commonwealth } & 0.434 & 0.464 & 0.503 & $-1.203^{* * *}$ & $-1.209 * * *$ & $-1.182^{* * *}$ \\
\hline & $(0.146)$ & $(0.132)$ & $(0.101)$ & $(0.001)$ & $(0.001)$ & $(0.001)$ \\
\hline \multirow[t]{2}{*}{ (log) Indian exports } & -0.152 & -0.157 & $-0.197 * *$ & $0.398 * * *$ & $0.400 * * *$ & $0.359 * * *$ \\
\hline & $(0.123)$ & $(0.117)$ & $(0.036)$ & $(0.001)$ & $(0.002)$ & $(0.003)$ \\
\hline \multirow[t]{2}{*}{ (log) Resource depletion } & 0.002 & -0.002 & -0.011 & -0.019 & -0.019 & -0.024 \\
\hline & $(0.924)$ & $(0.895)$ & $(0.488)$ & (0.339) & $(0.355)$ & $(0.217)$ \\
\hline \multirow[t]{2}{*}{ Political rights } & -0.140 & -0.144 & -0.145 & 0.037 & 0.038 & 0.039 \\
\hline & $(0.173)$ & $(0.165)$ & $(0.157)$ & $(0.798)$ & $(0.800)$ & $(0.801)$ \\
\hline \multirow[t]{2}{*}{ Control of corruption } & -0.228 & -0.177 & -0.289 & $1.474^{* * *}$ & $1.469 * * *$ & $1.459 * * *$ \\
\hline & $(0.421)$ & $(0.557)$ & $(0.307)$ & $(0.000)$ & $(0.000)$ & $(0.000)$ \\
\hline \multirow[t]{2}{*}{ Constant } & $12.592 * * *$ & $13.075^{* * *}$ & $11.043^{* * *}$ & $26.284 * * *$ & $26.253^{* * *}$ & $24.308 * * *$ \\
\hline & $(0.000)$ & $(0.000)$ & $(0.001)$ & $(0.000)$ & $(0.000)$ & $(0.000)$ \\
\hline Number of observations & 125 & 125 & 125 & 51 & 51 & 51 \\
\hline Prob $>$ Chi2 / Prob $>F$ & 0.002 & 0.000 & 0.000 & 0.000 & 0.000 & 0.000 \\
\hline (Pseudo) R-squared & 0.17 & 0.19 & 0.18 & 0.83 & 0.82 & 0.82 \\
\hline
\end{tabular}

Note: $*(* *, * * *)$ indicates significance at the ten (five, one) percent level 
Focusing on the sample to India's recipient countries, we analyze the subsequent allocation decision. As can be seen from column 4, we do not find a significant link between a recipient country's stage of development and the amount of aid received. This also holds true if we use the developmental distance between India and the recipient instead of the recipient country's GDP per capita (column 6), or if we include both variables at the same time (column 5).

While this finding questions India's commitment towards recipient need at the allocation stage, we obtain a nuanced picture if we consider the effect of the number of people affected by disasters. While we did not find that disaster-affected countries are more likely to enter India's aid program, countries suffering from more severe natural disasters receive larger aid amounts if they are already among India's aid recipients. If the number of people affected increases by one percent, India's aid commitments increase by about 0.1 percent. Our results also show that larger countries are disfavored as the coefficient on population is negative and statistically significant, at the one-percent level. While this result seems surprising at first, it is in line with empirical evidence for China (see Chapter II) and six other so-called new donors (Dreher et al. 2011). As was the case in the gate-keeping stage, geographic proximity is also an important determinant of aid amounts. A one-percent increase in the distance from India to a particular recipient country decreases India's aid commitments by about 1.6 percent, on average.

Political and commercial motives are also important for India's aid allocation decisions. Recipients with both a closer voting alignment with India in the UNGA and stronger commercial ties (proxied by Indian exports to recipient countries) do in fact receive larger aid flows from the "needy" donor, with both coefficients being significant at the onepercent level. If the voting alignment on key votes increases by ten percentage points, India increases its aid commitments by roughly 0.7 percent, on average. Accordingly, if Indian exports grow by one percent, aid increases by 0.4 percent. These results support hypothesis 2a.

In contrast to our expectations, however, India disfavors countries that are members of the Commonwealth. The coefficient on the Commonwealth dummy shows a surprising negative sign and is statistically significant at the one-percent level. Our results indicate that India donates strategically in order to strengthen ties with developing countries with which it does not already share common ties with through being members of the Commonwealth. In these cases, the marginal benefit of aid giving may be higher compared to aid allocated to Commonwealth members. Moreover, recipient countries' extraction of natural resources does 
not have the expected positive impact on the size of India's aid flows. While we do not find a statistically significant effect of political rights on aid amounts provided by India, aid flows are significantly larger to countries with a relatively low level of corruption, at the onepercent level of significance, and in contrast to our findings at the gate-keeping stage.

Overall, the empirical results lend some support in favor of our "needy" donor hypotheses. In line with hypothesis $1 \mathrm{~b}$, countries at a similar developmental stage are more likely to enter India's aid program (but do not receive larger aid amounts). Moreover, political and commercial interests have an impact on the size of India's aid flows, which is empirical evidence in favor of hypothesis $2 \mathrm{a}$. As a next step, we will compare the role that political and commercial motives play in India's aid allocation decisions with aid flows from richer donors. By doing this, we test whether aid allocation from the "needy" donor India is driven to a higher extent by political and commercial motives than is the case for richer donor countries (hypothesis 2b).

\section{III.4.4 Comparison with DAC and Other Non-DAC Donors}

Finally, we compare India's aid allocation with other donors to evaluate whether aid from the "needy" donor under investigation is special. Dutt (1980: 676) expects India's aid allocation to be closer to that of the big powers than to Scandinavian aid since "Indian elites perceive India as having a role on the world stage," an assessment that became even more evident after the 2003 budget speech. The pattern of India's aid allocation is compared to the largest donors of the DAC, i.e., the United States, Japan and the three largest EU countries (EU-3, i.e., Germany, France and the United Kingdom). We use the so-called 'like-minded donors' or 'good donors' (Canada, Denmark, Netherlands, Norway and Sweden) as a further benchmark. This latter group is said to provide development aid predominantly based on humanitarian motives. ${ }^{114}$ Beyond that, we compare India's aid allocation with two emerging donors for which data are easily accessible. The first donor is South Korea, another large emerging Asian donor, which became a DAC member in 2010. The second one is the United Arab Emirates, which has provided sizable aid amounts since the oil crises of the 1970s.

Data on ODA from these donors again cover the 2008-2010 period, and are obtained from the OECD (2012). Unfortunately, we cannot compare India with China, the largest nonDAC donor, since we lack sufficient data on China's foreign aid after 2005 (see Chapter II for

\footnotetext{
${ }^{114}$ Note that doubts have been raised as to whether the positive image of these donor countries is warranted (see, for example, Neumayer (2003b) with respect to human rights, or Strømmen et al. (2011) with respect to peace and human security). Similarly, in their ranking of aid agency practices, Easterly and Williamson (2011) find that Scandinavian donors perform surprisingly badly.
} 
a discussion). We use a similar set of explanatory variables as in our baseline model in column 1 of Table III.1. Note that we replace the Commonwealth dummy, which is an Indiaspecific variable, with a general dummy variable for common colonial history between donor and recipient. More precisely, the variable takes a value of 1 if donor and recipient had a common colonizer (e.g., the British Crown in the case of India) or if the recipient was a colony of the donor country after 1945 as defined in Mayer and Zignago (2006). Moreover, we now employ the recipient's UNGA voting alignment on key votes with the respective donor (not necessarily India) and, analogously, we take the exports of the respective donor to a recipient economy.

In order to be able to compare the effects between donors, we run nested regressions rather than individual regressions for each donor (see also Berthélemy 2006; Dreher et al. 2011; see also Chapter II). This is done by interacting dummies for each donor country or donor group with each of our explanatory variables. In addition to the coefficients and the corresponding p-value of all explanatory variables for all donors (in parentheses), we compute the p-values of a Wald test for differences in the effect of a variable for a particular country and India (in italics).

Table III.2 displays our results. Analyzing the role of recipient needs as measured by GDP per capita, we find that Indian aid shows the smallest need orientation than of all donors under investigation. The coefficient on GDP per capita for India is the smallest in absolute terms and significantly different from the EU-3 and the "good" donors, at least at the fivepercent level of significance (see p-values of the Wald test in italics). Moreover, India is the only donor for which population size has a negative effect on aid commitments that is statistically significant at conventional levels, which questions India's actual concern for recipient needs. Only with respect to disaster response does India show some need orientation. Apart from Japan, India is the only donor with a statistically significant and positive coefficient on the number of people affected by disasters.

The effect of geographic distance between the donor and recipient is the largest for India compared to all other donors included in the analysis. This can be interpreted as evidence that aid costs matter more for a "needy" donor than for "rich" donors. The p-values of the Wald test in italics show that the distance coefficient for India is significantly different, at least at the five-percent level, from the U.S., the EU-3 and the "good" donors. 
Table III.2: Comparison of India's aid allocation with other donors (2008-2010)

\begin{tabular}{|c|c|c|c|c|c|c|c|}
\hline & India & USA & EU-3 & Good donors & Japan & Korea & UAE \\
\hline \multirow[t]{3}{*}{ (log) GDP per capita } & -0.249 & $-0.646 * *$ & $-0.798 * * *$ & $-1.007 * * *$ & $-0.586 * * *$ & $-0.562 *$ & $-0.926 * * *$ \\
\hline & $(0.165)$ & $(0.021)$ & $(0.000)$ & $(0.000)$ & $(0.000)$ & $(0.067)$ & $(0.007)$ \\
\hline & & 0.211 & 0.016 & 0.002 & 0.163 & 0.344 & 0.092 \\
\hline \multirow[t]{3}{*}{ (log) Affected from disasters } & $0.097 * *$ & 0.039 & -0.044 & 0.054 & $0.103^{* * *}$ & 0.045 & -0.076 \\
\hline & $(0.039)$ & $(0.500)$ & $(0.358)$ & $(0.231)$ & $(0.007)$ & $(0.524)$ & $(0.392)$ \\
\hline & & 0.384 & 0.013 & 0.441 & 0.925 & 0.475 & 0.101 \\
\hline \multirow[t]{3}{*}{ (log) Population } & $-0.483 * * *$ & $0.699 * * *$ & $0.679 * * *$ & $0.462^{* * *}$ & $0.371 * * *$ & $0.524 * * *$ & -0.012 \\
\hline & $(0.001)$ & $(0.000)$ & $(0.000)$ & $(0.000)$ & $(0.000)$ & $(0.004)$ & $(0.960)$ \\
\hline & & 0.000 & 0.000 & 0.000 & 0.000 & 0.000 & 0.108 \\
\hline \multirow[t]{3}{*}{ (log) Distance } & $-1.634 * * *$ & 0.171 & $-0.386^{*}$ & $-0.722 * *$ & $-1.483^{* * *}$ & -0.779 & -0.934 \\
\hline & $(0.000)$ & $(0.740)$ & $(0.081)$ & $(0.021)$ & $(0.000)$ & $(0.115)$ & $(0.168)$ \\
\hline & & 0.002 & 0.000 & 0.033 & 0.681 & 0.123 & 0.321 \\
\hline \multirow[t]{3}{*}{ UN voting (key votes) } & $6.826 * * *$ & $2.009 *$ & $1.873^{*}$ & 0.165 & 0.926 & 1.923 & 2.453 \\
\hline & $(0.000)$ & $(0.077)$ & $(0.085)$ & $(0.906)$ & $(0.506)$ & $(0.627)$ & $(0.424)$ \\
\hline & & 0.006 & 0.005 & 0.001 & 0.002 & 0.236 & 0.229 \\
\hline \multirow[t]{3}{*}{ Common colonial history } & $-1.219 * * *$ & 1.221 & $1.622^{* * *}$ & $4.803^{* * *}$ & & & 0.860 \\
\hline & $(0.000)$ & $(0.465)$ & $(0.000)$ & $(0.000)$ & & & (0.191) \\
\hline & & 0.153 & 0.000 & 0.000 & & & 0.008 \\
\hline \multirow[t]{3}{*}{ (log) Bilateral exports } & $0.401 * * *$ & 0.088 & $0.367^{* * *}$ & 0.121 & 0.068 & $0.285^{* *}$ & $0.187^{* *}$ \\
\hline & $(0.000)$ & $(0.620)$ & $(0.004)$ & $(0.173)$ & $(0.220)$ & $(0.025)$ & $(0.019)$ \\
\hline & & 0.118 & 0.835 & 0.025 & 0.007 & 0.444 & 0.102 \\
\hline \multirow[t]{3}{*}{ (log) Resource depletion } & -0.027 & 0.012 & 0.020 & -0.011 & -0.013 & -0.020 & -0.012 \\
\hline & $(0.115)$ & $(0.563)$ & (0.199) & $(0.591)$ & (0.296) & $(0.473)$ & $(0.723)$ \\
\hline & & 0.133 & 0.017 & 0.514 & 0.498 & 0.816 & 0.691 \\
\hline \multirow[t]{3}{*}{ Political rights } & 0.056 & -0.126 & 0.068 & 0.004 & -0.012 & 0.058 & 0.058 \\
\hline & $(0.676)$ & $(0.306)$ & $(0.340)$ & $(0.967)$ & $(0.888)$ & $(0.744)$ & $(0.752)$ \\
\hline & & 0.333 & 0.939 & 0.780 & 0.677 & 0.992 & 0.993 \\
\hline \multirow[t]{3}{*}{ Control of corruption } & $1.481 * * *$ & -0.572 & 0.202 & 0.433 & $0.467^{* *}$ & -0.273 & -0.032 \\
\hline & $(0.000)$ & (0.188) & $(0.438)$ & $(0.227)$ & $(0.045)$ & $(0.552)$ & $(0.964)$ \\
\hline & & 0.000 & 0.001 & 0.004 & 0.003 & 0.000 & 0.051 \\
\hline Donor country dummies & Yes & Yes & Yes & Yes & Yes & Yes & Yes \\
\hline Number of observations & & & & 1371 & & & \\
\hline Number of recipients & & & & 125 & & & \\
\hline - per donor group & 51 & 124 & 125 & 124 & 125 & 118 & 87 \\
\hline R-squared & & & & 0.58 & & & \\
\hline
\end{tabular}

Notes:

- Estimation technique: Nested OLS model with standard errors clustered by recipient country

- Dependent variable: (log) Aid commitments to recipient country, sum 2008-2010

- We report coefficients of the explanatory variables (corresponding $p$-values in parentheses)

- In italics: p-values of a Wald test of equal marginal effects of the respective donor (group) compared to India

- * $(* *, * * *)$ indicates significance at the ten (five, one) percent level 
Analyzing the impact of the UNGA voting alignment on aid allocation, the coefficient for India is found to be the largest among the donors under investigation. While Indian aid is significantly more motivated by politics than aid from all traditional DAC donors, the difference between the coefficients is not statistically significant with respect to South Korea and the United Arab Emirates. While countries that share a common colonial legacy do not receive higher aid amounts from India and are even receiving less aid on average, the EU-3 and the "good" donors provide significantly more aid to countries which have had a colonial relationship with the respective donor country.

The effect of bilateral exports on aid amounts is larger for India than for any of the other donors under investigation. According to the p-values of the Wald test in italics, Indian aid has a significantly closer link to commercial relationships than aid from the "good" donors and Japan. With regard to its relationship with natural resource endowments, we find that neither of the donors rewards countries extracting natural resources through increased aid flows. Likewise, we do not find evidence that any of the donors under investigation reward countries with greater political rights. Finally, we find that, alongside India, Japan is the only other donor that provides significantly larger amounts of aid to recipients that score better on the control-of-corruption index, at conventional levels of significance.

\section{III.4.5 Robustness Checks}

Next, we examine the robustness of our findings. To begin with, we analyze nine additional variables that might influence India's aid commitments in addition to those included in Tables III.1 and III.2, respectively. First, Indian aid allocation decisions are said to be related to the prevalence of Indian diaspora communities (e.g., Dutt 1980; Banerjee 1982; Lafargue 2006). ${ }^{115}$ The $(\log )$ Indian migrant stock in recipient countries is obtained from two sources, namely the Global Migrant Origin Database (Parsons et al. 2007) and the MEA (2001b). Second, in order to examine whether India targets traditional recipients of aid from China, we include a variable capturing the number of completed Chinese aid projects in recipient countries as a share of China's total aid over the 1996-2005 period (see definition in Chapter II). A positive sign could suggest aid competition between the two emerging Asian powers, as suggested by some scholars (see Cheru and Obi 2011 for instance). Third, we add a recipient country's (logged) infant mortality rate (children under the age of 5) as an alternative measure

\footnotetext{
${ }^{115}$ Lafargue (2006) identifies Indian diaspora as intermediaries for Indian investments in their respective host country.
} 
of India's need orientation. Fourth, we add a dummy for countries which share a border with India to test whether India favors its direct neighbors in addition to the role played by geographic distance.

Fifth, we replace the UNGA voting alignment index covering key votes with an index that covers all votes. Sixth, to allow for an alternative definition of what constitutes a key vote from the Indian perspective, we consider only those votes which show opposite voting behavior to the United States on the one hand, and to the four BRIC countries on the other. More precisely, we construct a voting alignment index based on those votes where Brazil, Russia, India and China vote 'yes' and the United States votes 'no' (or vice versa). ${ }^{116}$ This measure should reflect the one-dimensional voting pattern that continues to exist in the General Assembly after the end of the Cold War, with the United States and its Western allies on one pole and a "counterhegemonic voting bloc," most notably the rising powers, on the other (see Voeten 2000).

Seventh, we replace the Commonwealth dummy with a dummy that takes a value of 1 if India and a recipient country share a common language (i.e., English). Eighth, the Commonwealth dummy is substituted by a dummy variable that takes a value of 1 if the recipient country and India had a common colonizer after 1945 (i.e., the British Crown). Ninth, we replace the political rights measure with a dummy capturing whether a recipient country qualifies as a democracy as defined in Cheibub et al. (2010).

Detailed tables containing the regression results are reported in Appendices III.3 and III.4. In the gate-keeping stage (see Appendix III.3), we do not find any statistical significance for the variables listed above, at conventional levels of significance. For example, neither Indian diaspora communities nor aid projects lead to a significant increase (or decrease) in the probability that a developing country enters India's aid program. The outlined changes in the definition of the various explanatory variables do not change our main conclusions. In the allocation stage, we confirm the large positive significant effect of a country's UNGA voting alignment when we use the two alternative definitions instead. Note that the common colony dummy takes a negative sign, at the one-percent level, in line with our results for the Commonwealth dummy. Apart from these variables, all other variables introduced do not reach statistical significance at conventional levels.

\footnotetext{
${ }^{116}$ We also considered the construction of a voting alignment index based on the instances in which India and Pakistan voted differently. There are, however, only very few instances in which India and Pakistan showed opposite voting behavior during our period of analysis.
} 
Finally, we run a sub-sample analysis by restricting our sample to those countries that receive aid from India (see Appendix III.5). Aware that this approach has its limitations, we intend to control for differences between the sample of India's aid recipients and that of other donors. ${ }^{117}$ As before, we run nested regressions by interacting dummies for each donor country with each of our explanatory variables. By construction, the results for India are exactly the same as those reported in Table III.2. With respect to per-capita GDP, the respective coefficients for the United States, Japan and South Korea lose their statistical significance. When restricting the sample to Indian aid recipients only, Indian aid does not appear to be inferior with respect to need orientation compared to all other donors under investigation (see p-values of the Wald test in italics).

Concerning the UNGA voting alignment, however, our results confirm the high importance of political interests in India's aid allocation. The respective coefficient for India is still larger than for any traditional DAC donor, the difference being statistically significant, at least at the five-percent level (except for the United States). Note that the coefficient on UNGA voting alignment is now larger for South Korea than for India, but the difference is not statistically significant at conventional levels (as indicated by the p-value in italics). Although the EU-3, South Korea and UAE retain the expected sign and level of significance on bilateral exports, "good" donors and Japan are now positive and significantly different from zero, at the one-percent level.

Finally, we also find some changes with respect to the corruption variable. We now find that the coefficients for the EU-3 and the "good" donors (along with India and Japan) become positive and statistically significant, at least at the five-percent level of significance. With respect to population size, mineral and energy depletion, and political rights, our results largely mimic those in Table III.2. Taken together, while commercial interests do not seem to play a significantly larger role for India than for most "rich" donors, according to this robustness check, the sub-sample analysis largely confirms the outstanding importance of political interests compared to most traditional DAC donors.

\footnotetext{
${ }^{117}$ Our sample includes 51 countries that receive aid from India in the 2008-2010 period.
} 


\section{III.5 Conclusions}

Despite having a large amount of its population suffering from underdevelopment, chronic poverty and mal-governance, India has jumped on the bandwagon in the 'business' of development aid. This is puzzling. According to a recent World Bank report on India, about 37 percent of the Indian population lives on less than US\$ 1.25 a day (World Bank 2011). Although India has a large number of anti-poverty schemes and programs to tackle these problems, the progress made in poverty reduction is rather small. Against this background, it is ironic that India provides development aid to other developing countries. Many of India's aid recipients even have a larger income per capita than India. ${ }^{118}$

With the intension of understanding why poor countries such as India provide foreign aid, this paper has empirically analyzed India's aid allocation decisions. We utilized data on aid commitments by the Ministry of External Affairs to 127 developing countries in US dollars, obtained from the AidData database for the 2008-2010 period. To examine whether India is different, we also compared India's aid allocation decisions with those of other donors. Our empirical results show that India's aid allocation is partially in line with our expectations of the behavior of a "needy" donor. Commercial and political self-interests dominate India's aid allocation. We find the importance of political interests, proxied by UNGA voting alignment, to be significantly larger for India than for all traditional DAC donors under investigation. Moreover, India favors countries which are geographically closer, and countries at a similar developmental stage are more likely to enter India's aid program.

From our results, it appears that the "needy" donor India predominantly cares about its own needs rather than the needs of others. Given India's domestic problems, this is understandable. Although India's own interests dominate its aid allocation, it may nevertheless be the case that India's assistance is effective in terms of poverty reduction and other developmental goals with respect to recipient countries. ${ }^{119}$ This merits further investigation. Concerning political self-interest, Agrawal (2007) raises doubts over the longterm political gains resulting from India's engagement. Future research may also evaluate whether Indian aid, officially aimed at the promotion of India's welfare in addition to that of aid recipients, actually supports India's own development.

\footnotetext{
11823 recipients of Indian aid had a larger income per capita than India (based on 2007 values of GDP per capita in international dollars and purchasing power parity): Armenia, Belarus, Bhutan, Botswana, Cape Verde, Cuba, Ecuador, El Salvador, Fiji, Grenada, Indonesia, Jamaica, Maldives, Marshall Islands, Mauritius, Namibia, Samoa, Sao Tome and Principe, Seychelles, Sri Lanka, Tonga and Turkmenistan.

${ }^{119}$ If this is the case, India's aid would differ from DAC aid. Analyzing the effect of aid on growth, empirical evidence in Kilby and Dreher (2010) suggests that donor motives matter for aid effectiveness.
} 
While we find that India's allocation is partially in line with our expectations of a "needy" donor, India itself does not want to be perceived as such. This is made clear by the comments of India's Minister of Finance, Pranab Mukherjee, who characterized British aid to India as a "peanut" compared to India's own development expenditures. ${ }^{120}$ Moreover, India made its ambitions clear by announcing to setup a foreign aid agency, which is said to manage the distribution of aid flows amounting to 11 billion US dollars over the next five to seven years. ${ }^{121}$ If India aspires to be recognized as one of the big aid donors, it would be beneficial from India's point of view to, first, establish clearly outlined aid legislation, and second, increase its aid transparency. Clearly identified goals and the provision of detailed and transparent aid records will not only alleviate India's credibility as an emerging aid donor, but will also enhance the scope for coordination with other aid donors.

120 "India tells Britain: We don't want your aid," The Telegraph, February 4, 2012, available at: http://www.telegraph.co.uk/news/worldnews/asia/india/9061844/India-tells-Britain-We-dont-want-your-aid.html (accessed: May 28, 2012).

121 "Aid 2.0," The Economist, August 13, 2011, available at: http://www.economist.com/node/21525899 (accessed: May 28, 2012). 


\title{
Chapter IV:
}

\section{Emergency Aid 2.0}

\author{
Joint work with Nils-Hendrik Klann ${ }^{\mathrm{a}}$
}

\begin{abstract}
Does the proliferation of aid donors lead to visible changes in the world of foreign assistance? Aid provided by low- and middle-income countries, autocratic regimes and donors operating outside the Development Assistance Committee (DAC) of the OECD is gaining in importance. This article uses data on emergency aid supplied by 105 donor countries to explore the determinants of aid and the differences in allocation patterns between donor groups. Our results show that both the so-called "new" and "traditional" donors provide emergency aid based on humanitarian need and their self-interests, but we find evidence that non-DAC donors attach relatively more importance to political motives. Additionally, autocratic donors seem to favor countries rich in natural resources and to disfavor democracies. Since the timeliness of the aid delivery is crucial for aid effectiveness, we furthermore analyze which factors influence the number of days that pass after a natural disaster before a donor commits herself to provide emergency relief. With regard to aid promptness, we find DAC, developed and democratic countries to be significantly faster than non-DAC, developing and autocratic countries.
\end{abstract}

Acknowledgements: This research is part of the project "Foreign Aid of Emerging Donors and International Politics" supported by the Deutsche Forschungsgemeinschaft (DR 640/4-1). We are grateful for the generous financial support. Excellent research assistance was provided by Clara Brune, Scott Jobson, Katrin Mauch, Jamie Parsons and Jan Paulick. We thank Axel Dreher, Stephan Klasen and Hannes Öhler for helpful comments on earlier drafts of this paper. Furthermore, we thank Paul A. Rashky for sharing data on humanitarian aid flows and disaster severity.

\footnotetext{
${ }^{a}$ Georg-August University Goettingen, Platz der Goettinger Sieben 3, 37073 Goettingen, Germany, e-mail: hhk[at]uni-goettingen.de.
} 
"The old binary division of the world - between rich countries which give aid and poor ones which get it—is gone."

The Economist, Official development assistance: Aid 2.0, August 13, 2011

\section{IV.1 Introduction}

It is commonly anticipated that within donor-recipient relations rich countries, mainly those organized in the OECD Development Assistance Committee (DAC), will assume the role of providers of foreign aid to countries in need. However, this simple breakdown of countries into pure donors and recipients has lost its accuracy, as an increasing number of countries, not just the richest, have taken up responsibilities as donors (see ECOSOC 2008; Dreher et al. 2011). ${ }^{122}$ This new world of foreign assistance is most visible in the provision of humanitarian assistance. Since humanitarian aid requires considerably lower organizational capacities and planning skills than long-term development aid strategies, this type of aid offers a relatively easy way for less affluent nations to graduate from being pure aid recipients to becoming donors of foreign assistance. The Financial Tracking System (FTS) of the United Nations Office for the Coordination of Humanitarian Affairs (OCHA 2011) already lists more than 180 donors as providers of humanitarian aid. Consequently, almost every country in the world provides at least some form of foreign assistance.

The response of the international aid community to the earthquake that hit Haiti in January 2010 is a prime example of this proliferation of donors. In the aftermath of the catastrophe, which is believed to have killed at least 222,570 people (EM-DAT 2012), emergency relief was provided from a total of 175 countries (OCHA 2011). This included all DAC donors, more than 60 autocratic donors, 31 least developed countries and 11 countries that were poorer than Haiti itself. Within one day of the earthquake's occurrence, aid commitments from 30 countries had been registered. 19 non-DAC donors were among these fast-responding donors, including low-income countries like Nicaragua and autocratic countries like China.

Activities of countries whose participation in aid efforts does not fit into the traditional image of an aid donor, are notable for a multitude of emergencies. For example, when a severe flood affected 200,000 people in Australia, India contributed over 90 percent of the total aid amount provided after the disaster. After the 2008 Yemen floods, DAC donors

\footnotetext{
${ }^{122}$ According to data provided by AidData (Tierney et al. 2011), a project-level database, the share in total aid allocations of non-DAC donors increased from 2.5 percent in 2005 to 6.4 percent in 2009. Since many aid agencies and whole countries (e.g., China) are not captured in the dataset, these values provide a lower bound.
} 
including Canada and Germany provided a negligible share of the aid delivery, while autocratic donors such as Kuwait, Saudi Arabia and Singapore contributed over 90 percent of the delivered aid amount. Furthermore, non-DAC donors are not only catching up with traditional DAC donors in terms of contribution scale, but are also often among the first to respond to disasters. For example, in terms of the time period after which a donor commits herself to help, China, together with Canada, was the fastest donor to respond to the devastating 2010 Chile earthquake. Similarly, Russia, together with Germany, was the first donor to provide emergency relief to Iran after the 2006 earthquake.

These examples illustrate that the proliferation of aid donors has led and continues to lead to visible changes in the world of foreign aid, with potential repercussions on aid allocation and aid effectiveness. This paper divides "new" donors from "old" donors in order to analyze these changes. In general, "new" donors are considered to be those donors that operate outside of the institutions of the DAC. ${ }^{123}$ It is important to note, however, that the non-DAC donors constitute a rather heterogeneous set of countries (Manning 2006; Kragelund 2008). Accordingly, we analyze different types of "new" donors. Being aware of the increasing activities of many poor donors, we analyze differences in aid decisions between donors based on their income level. Moreover, to reflect the increased importance of aid from authoritarian countries, we compare aid allocation between democracies and autocracies.

Although emerging economies such as China and India hold a growing stake in the global economy and an increased weight in global decision-making processes, hardly any consensus exists with regards to the motives of these countries as providers of humanitarian aid. This paper builds on the aid allocation literature (e.g., Alesina and Dollar 2000), and in particular, on the strands of the literature that cover aid from "new" donors on the one hand (e.g., Dreher et al. 2011; Neumayer 2003a, 2004) and humanitarian aid on the other (e.g., Eisensee and Strömberg 2007; Fink and Redaelli 2011; Raschky and Schwindt 2012). We combine data on humanitarian aid provided by the Financial Tracking Service covering the 2000-2009 period with a detailed dataset on disaster characteristics from the International Disaster Database (EM-DAT 2012), made available by the Centre for Research on the Epidemiology of Disasters (CRED).

In a first step, we analyze the differences in the determinants of the donor decision to provide emergency aid between "old" and "new" donors as well as between different types of "new" donors. More precisely, we explore how these allocation patterns differ according to disaster type and severity, recipient characteristics and the state and intensity of bilateral

\footnotetext{
${ }^{123}$ Note that we use "new" in quotation marks to take account of the fact that many of the so-called new donors have a long tradition of aid provision to other developing countries.
} 
relations between donor and recipient. While the limited availability of data constrains our analysis to one single type of foreign aid, i.e., humanitarian assistance, we take advantage of FTS data to analyze a huge set of donor countries that are situated at all levels of income, have different political regimes and operate inside and outside the DAC.

In a second step, we analyze the determinants of the number of days following a disaster before a donor commits herself to provide emergency aid. A short response time is crucial for aid to be effective and reflects the donor's commitment to a particular country and disaster episode. Within the DAC, all donor countries endorse the Principles and Practices of Good Humanitarian Donorship (GHD), which emphasize the rapid response of donors after a disaster. Similarly, "new" donors outside the DAC pride themselves with the timeliness of their response to emergencies (Harmer and Martin 2010). An analysis of the determinants of the time a donor takes to commit aid will thus improve our understanding of whether the increased diversity of donors has impacted the promptness of aid provision.

To the best of our knowledge, this is not only the first paper that econometrically analyzes aid allocation by different types of "new" donors, but it is also the first that explicitly looks at the speed of the decision to provide aid in an empirical analysis. ${ }^{124}$ Our results indicate that "new" and "old" donors alike provide aid based on humanitarian need and donor self-interests. Considerable differences emerge with regard to the importance attached to different factors. We find that non-DAC donors attach greater importance to political allies than DAC donors. At the same time, aid from autocratic countries is to a stronger extent motivated by natural resource endowments than disaster relief from democracies. Furthermore, we find autocracies to disfavor democracies. With respect to the timeliness of the decision to help, we find DAC, "rich" and democratic donors to react significantly faster to emergencies than non-DAC, "poor" and autocratic donors.

The remaining paper is structured as follows: Section IV.2 introduces the literature on the determinants of emergency aid. Section IV.3 elaborates our hypotheses with respect to differences in aid decisions between "old" and "new" donors as well as between the different types of "new" donors. The following sections present empirical evidence on aid selection (Section IV.4) and the timeliness of the decision to provide emergency relief (Section IV.5). Finally, Section IV.6 summarizes our paper and concludes.

\footnotetext{
${ }^{124}$ In a different context, Kilby (2011) analyzes the speed of aid disbursements after the initial aid decision was made.
} 


\section{IV.2 Determinants of Emergency Aid}

Natural disasters pose a serious threat to the stability of countries and the well-being and life of many individuals worldwide. ${ }^{125}$ Therefore, disaster-affected countries frequently rely on disaster assistance provided by other countries to tackle the challenges faced in the aftermath of a catastrophe. Although poorer countries do not suffer from more natural disasters than richer ones, poorer countries experience more casualties after catastrophes on average (Kahn 2005; Strömberg 2007). ${ }^{126}$ Thus, the availability of foreign sources of funding is crucial for developing countries, in particular since governments in less affluent countries are more likely to possess insufficient capacities to provide domestic emergency relief. Previous research has analyzed the determinants of the allocation of emergency aid. While one strand of the emergency aid literature focuses on the allocation of disaster relief within countries, ${ }^{127}$ this article is part of the literature that analyzes aid allocation across countries and emergencies (e.g., Drury et al. 2005; Fink and Redaelli 2011).

Emergency aid intends to provide fast relief from humanitarian hardship after a (natural) disaster. Obviously, the more severe a disaster, the more aid is expected to flow to counter its effects. Previous research has shown that both the likelihood that a donor provides aid after a disaster as well as the aid amount provided increase with disaster severity, usually measured by the total number of people affected and the number of casualties (Drury et al. 2005; Strömberg 2007; Fink and Redaelli 2011; Raschky and Schwindt 2012). For humanitarian need to play its role, public awareness of a disaster is required to trigger assistance. In this context, Eisensee and Strömberg (2007) analyze the role of the media on US disaster relief between 1968 and 2002. They find that the likelihood to receive US aid increases with the coverage of the disaster in the television news. ${ }^{128}$

However, media attention and pure humanitarian needs are not the only deciding factors which affect the provision of emergency aid. Within the general aid allocation literature, empirical research has been conducted to reveal whether donor motives that are not directly related to humanitarian concerns determine the allocation of aid. For example, Alesina and Dollar (2000) find in their much-quoted paper that aid flows are driven by past

\footnotetext{
125 See, for example, Nel and Righarts (2008) for an analysis of the link between natural disasters and the occurance of civil war and Neumayer and Plümper (2007) for a study of the effect of natural disasters on life expectancy and gender-specific differences in vulnerability. Luechinger and Raschky (2009) find a sizable reduction of life satisfaction after disasters.

${ }^{126}$ Similarly, disasters lead to fewer victims in countries with better institutions (Raschky 2008).

127 Benini et al. (2009) and Wiesenfarth and Kneib (2010) study relief supply to earthquake-affected communities in Pakistan after the 2005 earthquake. See also Francken et al. (2012) for a study of the political economy of aid allocation inside Madagascar after cyclone Gafilo in 2004.

${ }^{128}$ Potter and Van Belle (2008) find similar results for Japanese disaster aid.
} 
colonial relations between donor and recipient as well as by voting patterns in the United Nations General Assembly (UNGA). ${ }^{129}$ Similarly, empirical research has shown that nonpermanent members of the United Nations Security Council (UNSC) receive a significantly larger amount of aid from the United States (Kuziemko and Werker 2006) and from international organizations (Dreher et al. 2009a, 2009b). With respect to emergency aid, aid giving based on economic, political and strategic considerations - which reflect the donor countries' self-interests rather than humanitarian need - would contradict the guiding principles stated in $\mathrm{UN}$ resolution $\mathrm{A} / \mathrm{RES} / 46 / 182$. According to this resolution, "[h] umanitarian assistance must be provided in accordance with the principles of humanity, neutrality and impartiality." ${ }^{130}$ Despite official claims that the provision of disaster assistance was less prone to political bias or strategic considerations than general development assistance, Drury et al. (2005) find in their study covering the 1964-1995 period that US disaster assistance is influenced by political considerations at the initial "gate-keeping phase," and, to a smaller extent, with regards to the subsequent decision on the amount of aid to be allocated. In particular during the Cold War period, allies of the United States "were almost assured of at least some assistance" (Drury et al. 2005: 466).

However, the motivations for providing humanitarian aid based on political considerations appear ambiguous. On the one hand, donors may rely on disaster aid to express their support of befriended countries or even to ensure the survival of politically-aligned governments in cases where a severe disaster threatens the political stability of an entire country (Drury and Olson 1998; Drury et al. 2005). On the other hand, donors may give aid to persuade adversaries or politically unaligned recipients to make concessions to the donor in the future. This second effect seems to be more likely to influence emergency aid contributions rather than general development assistance. In contrast to emergency aid, the provision of assistance aimed at long-term economic and structural development requires a fair amount of collaboration between donor and recipient and hence at least some goodwill to facilitate negotiations (Fink and Redaelli 2011). Many aid initiatives have long-term goals, such as the alleviation of poverty, which require certain stability in bilateral relations. In contrast to general development aid, emergency aid requires hardly any negotiations and less coordination with a recipient. This type of aid thus provides donors with an opportunity to approach nations in distress, while bypassing potential bilateral conflicts.

\footnotetext{
${ }^{129}$ Empirical results of Höffler and Outram (2011) and Younas (2008) confirm the importance of commercial and political motives. Note that these studies limit their analysis to OECD donors.

${ }^{130}$ The UN Resolution on "Strengthening of the coordination of humanitarian emergency assistance of the United Nations," adopted on December 19, 1991, available at http://www.un.org/documents/ga/res/46/a46r182.htm (accessed: June 1, 2012).
} 
The case of the 2010 Haiti earthquake provides a prime example of these two opposing mechanisms. In the aftermath of the disaster, Taiwan - which currently entertains diplomatic relations with 23 countries including Haiti - engaged in a large-scale humanitarian mission. Moreover, Taiwan restructured Haiti's debt to ease financial pressure on the government. (The People's Republic of) China, which considers Taiwan as being a renegade province and attempts to isolate Taiwan diplomatically, showed similar generosity towards Haiti, despite refusing diplomatic relations with the government in Port-au-Prince as a consequence of Haiti's diplomatic recognition of Taiwan. ${ }^{131}$ Tubilewicz (2012: 6) describes these activities of the two Chinese donors as "aid competition."

In line with the behavior of China in the case of the Haiti earthquake, Fink and Redaelli (2011) find politically less affine countries to be more likely to receive emergency aid from a particular donor. ${ }^{132}$ Political affinity between countries is proxied by their voting alignment in the United Nations General Assembly. Fink and Redaelli also find that donors favor former colonies in their aid allocation decisions. Their study analyzes the disaster response of OECD countries after the occurrence of 270 emergencies worldwide. The authors conclude that donors provide aid out of political and strategic considerations in addition to humanitarian concerns.

Commercial motives could also play a role in the decision to provide emergency relief. ${ }^{133}$ For example, disaster aid can be used as a tool to prevent trade reductions with disaster-struck economies. In line with this idea, Gassebner et al. (2010) find that natural disasters harm trade with countries suffering from a catastrophe. Raschky and Schwindt (2012) confirm that the likelihood that a country receives aid in the aftermath of a disaster increases with its imports from the donor economy. Moreover, the empirical finding of Fink and Redaelli (2011) that oil-exporting countries are, on average, more likely to receive help after a catastrophe can also be explained with donor countries' commercial interests. Many donors have larger strategic interests in oil-rich countries and will therefore seek to secure their access to these markets through aid provision. ${ }^{134}$ According to the findings in Raschky and Schwindt (2012), donors favor only oil exporters with bad institutions, i.e., a low rule of law and a high level of corruption.

\footnotetext{
131 Taiwan's initial aid support amounted to US\$ 5 million, while China has pledged US\$ 4.1 million and provided additional US\$ 2 million worth of medical supplies six days after the earthquake (see http://in.reuters.com/article/2010/01/18/idINIndia-45477020100118, accessed: July 2012).

${ }^{132}$ See also Neumayer (2005) for similar findings with respect to emergency food aid provided by the United States and the European Union.

${ }^{133}$ On the role of development aid for export promotion, see Nowak-Lehmann D. et al. (2009).

${ }^{134}$ Alternatively, larger oil extraction may also be an indicator of need. As argued by Fink and Redaelli (2011), countries rich in natural resources usually show a higher inequality and higher poverty rates.
} 
While most articles analyze the decision to provide aid and the aid amounts attached, Raschky and Schwindt (2012) contribute to a better understanding of the decision-making process underlying the provision of aid. In particular, they investigate the determinants that influence the donors' choice between bilateral and multilateral aid provision (aid channel) and between cash and in-kind contributions (type of aid). They find that politically-aligned countries and important trading partners are more likely to receive bilateral aid rather than assistance channeled via multilateral institutions. At the same time, countries with lower corruption and better institutions have a higher probability to receive cash instead of in-kind disaster aid, while humanitarian need has only a weak impact on the type of aid committed. ${ }^{135}$

The international aid community places growing emphasis on the rapid response of donors after a disaster strikes. The immediate delivery of emergency relief is essential for aid to be effective. Consequently, aid promptness is part of the 23 principles of GHD, according to which donors should "strive to ensure flexible and timely funding, on the basis of the collective obligation of striving to meet humanitarian needs" (principle 5) and "maintain readiness to support the implementation of humanitarian action" (principle 17). ${ }^{136}$ In line with these principles, the commitment to provide quick disaster relief is communicated as a key priority by many donors. For example, Canada claims to assess the need for humanitarian aid within "hours of a natural disaster of significant scale." 137 Similarly, Ireland emphasizes its goal to "respond effectively, efficiently and in a timely manner to the humanitarian needs of crisis affected peoples." "138 Given the importance assigned to a timely response after a disaster, it is necessary to evaluate the effort of donor countries not only based on their monetary dedication, but also by the promptness with which they react to a natural disaster. To date, however, no research exists to our knowledge that empirically investigates which factors lead to a rapid reaction from donor countries after a disaster.

\footnotetext{
${ }^{135}$ Raschky and Schwindt (2012) also split their sample into OECD and non-OECD donors. In contrast to nonOECD countries, OECD countries favor to channel aid to autocracies multilaterally rather than bilaterally. Empirical evidence for commercial motives guiding the channel decision is found for OECD countries only.

${ }^{136}$ The 23 Principles and Good Practice of Humanitarian Donorship are the result of an attempt to "reform and strengthen systems for humanitarian needs, and prioritize and allocate funds more efficiently to meet the needs" (OECD 2005). The DAC endorsed the GHD principles in March 2004 and introduced a regular peer review of the aid activities of DAC members to derive recommendations for improvement. As such, the harmonization of aid practices is at the core of the GHD agenda. See the webpage of the GHD initiative available at http://www.goodhumanitariandonorship.org/gns/principles-good-practice-ghd/overview.aspx (accessed: June 3, 2012).

137 See website of the Department of Foreign Affairs and International Trade, available at http://www.international.gc.ca/humanitarian-humanitaire/faq.aspx?view=d\#q3 (accessed: July 2012).

${ }_{138}$ See policy report by Ireland's Department of Foreign Affairs, available at: http://www.irishaid.gov.ie/Uploads/Humanitarian\%20Relief\%20Policy1.pdf (accessed: July 2012).
} 


\section{IV.3 The New World of Emergency Assistance}

Today, in the area of humanitarian assistance, almost every country in the world acts as a provider of foreign aid. This runs counter to the common belief that being a donor is synonymous with being one of the rich democracies organized in the DAC. In this context, Harmer and Martin (2010: 1) note that "[h]umanitarian action is not the preserve of the rich, industrialised West, but a common pursuit among nations, rich and poor." While the term "new donor" is frequently used in the literature and policy debates to describe donor countries operating outside of the DAC, its usage is misleading (see Manning 2006). Many so-called "new" donors have acted as providers of foreign assistance for decades. China and India, for example, started providing aid to other countries already in the 1950s. In order to take account of this, Kragelund (2010) proposes the use of the term "non-traditional donor" instead. This raises similar concerns, however, since the term implies that long-standing donors like China, India, Saudi Arabia or the United Arab Emirates have no aid traditions. Therefore, we prefer the term "non-DAC donor" for those donor countries operating outside of the aid institutions of the OECD and use the term "new donors" with "new" in quotation marks when referring to them.

The group of non-DAC donors constitutes a heterogeneous set of countries. It includes high-income countries like Poland or Trinidad and Tobago on the one hand as well as lowincome countries like Bangladesh or Tajikistan on the other. It contains democracies like Brazil or Slovenia as well as autocracies like China or Singapore. Appendix IV.1 provides a list of the 21 most important donors of emergency aid according to their number of aid interventions following a disaster. It contains information on their aid agencies, official missions and objectives as well as sectoral and geographic priorities. As can be seen from this list, there are considerable differences in the way humanitarian aid is managed in different non-DAC donor countries as well as in the principles that officially guide donor decisions. For example, the fact that Brazil - like DAC donor countries - adheres to the GHD initiative makes it plausible that the country's behavior as donor of humanitarian aid is to a significant degree comparable to the practices of DAC donors. The aid architecture of Morocco, for example, stands in complete contrast to Brazil's approach as the country's donations are centrally directed by Morocco's ruling monarch. ${ }^{139}$

Although "new" donors deprive the "old" donors of their quasi-monopoly on aid provision, the empirical aid literature, including the strand of the literature that studies

\footnotetext{
${ }^{139}$ Several reports issued by the Government of Morocco, which are available on the ReliefWeb homepage, emphasize that the delivery of humanitarian aid was carried out by "high instructions" of King Mohammed VI, see http://reliefweb.int/node/492950 and http://reliefweb.int/node/488837 (accessed: July 2012).
} 
emergency aid, is largely centered on aid from DAC donors. By analyzing the determinants of Arab aid allocation, Neumayer (2003a) goes beyond the traditional group of donors scrutinized in prior contributions and reveals that Arab aid allocation is not primarily driven by recipient need but rather based on ethnic and religious similarity as well as donor countries' voting alignment in the UNGA. In an investigation of the aid allocation pattern of 16 non-DAC donors, Dreher et al. (2011) find striking similarities in the aid allocation decisions of "old" and "new" donors. The average non-DAC donor, however, shows a weaker poverty orientation, which contradicts the idea that poorer donors should empathize with the problems of the countries which they support.

Rather than grouping all "new" donors together, we refine the approach taken in Dreher et al. (2011) and classify donors according to the following criteria. First, based on aid institutions, we divide donors into DAC members and non-DAC donors. The DAC serves as the major institution to set aid agendas and influence the direction and principles of the majority of global aid flows. Therefore, a "new" donor is a country acting independently from this comprehensive and supranational framework on aid provision. Second, donors may show differences in their aid allocation behavior as a consequence of differences in income level (see also Chapter III of this dissertation). More precisely, we distinguish between highincome countries on the one hand and low- and middle-income countries on the other. Third, based on regime type, we expect to find differences in donor behavior between democratic and authoritarian donors.

A consensus has emerged in the literature that aid follows humanitarian need, rewards recipient countries with good institutions but also follows donor countries' political and commercial self-interests (e.g., Alesina and Dollar 2000; Neumayer 2003b; Höffler and Outram 2011). First, with regard to aid institutions, we expect to find systematic differences in aid allocation behavior between DAC and non-DAC donors. Donors within the DAC have committed themselves to align their aid efforts with principles of impartiality, neutrality and international humanitarian law and accept a regular peer review of their actions by the DAC (OECD 2005). Non-DAC donors on the other hand are less "constrained" by such arrangements. It is therefore more feasible for these countries to align aid flows with their political and economic self-interests and strategic considerations rather than the humanitarian needs of the recipient.

Hypothesis 1a: (independent-donor hypothesis) Non-DAC donors, less constrained by international agreements, provide more aid out of self-interests than DAC donors. 
Second, a donor's income level might have important repercussions on donor motives. Fuchs and Vadlamannati (Chapter III) expect that a "needy" donor puts more emphasis on its own interests rather than on recipient needs. ${ }^{140}$ Given these donors' lower wealth and significant development challenges faced at home, the decision to commit aid based purely on altruism would be a luxury these countries could ill-afford. Therefore, in order to obtain support for the aid program from her own populace, a "needy" donor needs to emphasize the "mutual benefits" of her aid operations. For example, the idea of a mutually beneficial aid relationship has been one of the key characteristics of China's aid efforts since the early days of its aid program (see Bräutigam 2010 for a discussion). Similarly, India considers its aid program to be "about cooperation and partnership for mutual benefit.", "141 Moreover, we expect less affluent donors to minimize costs by predominantly helping recipients located within a closer proximity to their own borders. In line with this idea, the Slovakian Ministry of Foreign Affairs states that its "flexibility in providing in-kind humanitarian aid is limited by the lack of financial resources to cover transport costs in cases of a humanitarian crisis in remote countries." ${ }^{142}$ In summary, we formulate

Hypothesis $1 b$ (needy-donor hypothesis): Poor donors are driven by self-interest insofar as they minimize the economic costs of their commitments while maximizing their political and economic gains.

Third, we expect that a donor's behavior depends on the country's regime type. If emergency aid is provided according to merit, then we would expect that democratic donors support democracies (see Bermeo 2011). Conversely, to the extent that democratic donors want to destabilize an autocratic regime, they may be less likely to support an autocratic country after an emergency. In line with this idea, Bueno de Mesquita and Smith (2010) find that a windfall in free resources - such as aid - provides autocratic recipient governments with additional means to entrench themselves in office. Autocratic donors in turn may be more likely to provide aid to autocracies (see Bermeo 2011). Autocratic recipients, potentially shunned by democratic donors due to bad governance or humanitarian rights abuses, may favor donors with a policy of non-interference in internal affairs. ${ }^{143}$ Furthermore, autocratic

\footnotetext{
${ }^{140}$ This is largely confirmed by their empirical analysis on India's aid efforts with respect to political interests.

141 See website of the Indian Technical and Economic Cooperation (ITEC) Programme, available at: http://itec.mea.gov.in/about\%20itec.html (accessed: June 2012).

${ }^{142}$ See website of the Ministry of Foreign Affairs: http://www.foreign.gov.sk/en/foreign_policy/slovak_aid (accessed: June 2012).

${ }^{143}$ According to Pehnelt (2007: 8), autocratic China faces "higher opportunity costs of morality and governance and human rights oriented policies then the traditional powers" and concludes that China has a "comparative advantage" in providing assistance to "unstable and problematic regions and rogue states."
} 
aid is said to be more focused on donors' self-interests than aid from democratic donor countries. For example, Naím (2007) characterizes development aid from autocratic donors such as China, Venezuela, Iran and Saudi Arabia as "rogue aid" whose allocation is solely guided by international alliances and the extraction of natural resources. By providing some counterexamples, Woods (2008) criticizes Naím's characterization of emerging aid as "rogue aid" as unfounded and points out that evidence for harmful effects of aid from these donors is so far lacking. In line with this, empirical analyses do not find empirical support of the rogueaid hypothesis. Dreher et al. (2011) find that "new" donors do not systematically favor more autocratic and more corrupt recipients. In a similar vein, Dreher and Fuchs (Chapter II) analyze China's allocation of project aid and show that China provides aid regardless of the recipient's regime type and institutional characteristics, which is empirical support of the country's principle of non-interference.

With respect to emergency aid, empirical evidence for the rogue-aid hypothesis is still lacking. We test the following hypothesis:

Hypothesis 1c (rogue-donor hypothesis): Autocratic donors favor countries with bad governance and their aid decisions are predominantly driven by political and commercial interests rather than recipient need.

With respect to the promptness with which DAC and non-DAC donors respond to a natural disaster, donors from both groups emphasize the importance of fast reaction times and claim to be quick providers of relief. ${ }^{144}$ While all DAC donors endorse the GHD framework and thus the associated timely response requirements, non-DAC donors also highlight the rapidity of their response and emphasize their reaction time as being a key point of distinction with their DAC counterparts (Harmer and Martin 2010). Non-DAC donor Israel, for example, claims that " $[\mathrm{n}] \mathrm{o}$ other country can dispatch search and rescue teams and field hospitals as fast and effectively." "145 Similarly, India's government highlights its speedy assistance, which is explained by Meier and Murphy (2011) with the country's striving for international visibility.

While the comparative advantage of DAC donors may lie in their significant experience with aid delivery, non-DAC donors might be able to decide on aid provisions in a

\footnotetext{
${ }^{144}$ In this regard, also refer to the mission statements by South Korea, Turkey, United Arab Emirates, Brazil, and Hungary provided in Appendix IV.1, which emphasize the importance of a quick donor reply.

${ }^{145}$ Israel also claims that its "200-strong relief team was the first on the scene in January 2010 after the earthquake hit Haiti" and that it "was one of the first countries to send aid according to the needs and request of the Japanese government" after the 2011 earthquake. See website of Israel's Ministry of Foreign Affairs, available at: http://www.mfa.gov.il/mfa/humanitarianaid/overview/ (accessed: June 2012).
} 
more flexible manner given their independence from a regulatory aid framework or the need for coordination with other donors (see ECOSOC 2008 for a discussion). India, for example, lacks a common humanitarian aid policy. Meier and Murphy (2011: 11) describe the country's humanitarian aid bureaucracy as "organically grown" with decisions made "in an ad hoc manner" and "on a case-by-case basis." They conclude that "such a flexible set up enables India to [...] provide aid quickly" (pp. 11-12). Since less affluent countries have generally a smaller aid budget, they cannot boast of vast aid contributions, but they can (try to) set themselves apart with a speedy response to emergencies. At the same time, however, most "new" donors do not have dedicated facilities or capacities to quickly disburse funds after a shock. It is thus conceivable that poorer donor countries exhibit a slower response to other countries' needs as both financial means and administrative capacities in poor countries are less abundant on average. ${ }^{146}$

With respect to the regime type of donors, decision-making processes in autocratic donor countries are less constrained by veto players than in democracies where checks and balances may slow down decisions. In Saudi Arabia and Morocco, for example, the king decides whether to provide emergency aid (see Appendix IV.1; also refer to Al-Yahya and Fustier 2011 for an overview on Saudi Arabia's humanitarian aid). At the same time, the need to satisfy veto players and different opinions represented in legislature and government could lead to quicker decision-making processes as different groups lobby for their interests. ${ }^{147}$ Which of these two effects dominates the other is an empirical question. Summarizing these arguments, we formulate two competing hypotheses:

Hypothesis 2: "New" donors, lacking routine and usually working in a less efficient institutional environment, are slower than DAC donors in providing emergency relief.

Hypothesis 2 (alternative): "New" donors, less constrained by bureaucracy, are faster to provide emergency relief.

These hypotheses are tested below. While the existing literature is confined to analyze a maximum of only 16 "new" donors (Dreher et al. 2011) with notable omissions of important donors, we empirically analyze the behavior of 105 donor countries. This is what we turn to next.

\footnotetext{
${ }^{146}$ As can be seen from Appendix IV.1, many "new" donor countries lack a clear assignment of competencies to agencies as well as clear objectives guiding their provision of humanitarian assistance.

${ }^{147}$ See Round and Odedokum (2004) for a discussion of the role of checks and balances on aid effort.
} 


\section{IV.4 Empirical Analysis of Aid Selection}

\section{IV.4.1 Overview}

Our analysis exploits humanitarian aid data obtained from the FTS database (OCHA 2011). ${ }^{148}$ In contrast to the commonly used OECD database maintained by the DAC and the projectlevel database AidData, FTS has the advantage that the dataset is not limited to a relatively small set of donors, but covers virtually every country in the world. Even countries with a low aid transparency like China and Russia are covered by FTS.

While FTS reports humanitarian aid flows pledged, committed and contributed, we exclude pledged funds as these entries represent only a "non-binding announcement of an intended contribution or allocation by the donor" (OCHA 2011). Committed and contributed funds on the other hand constitute either a de facto-payment guaranteed by a signed contract or the actual transfer of funds and in-kind goods from the donor to the recipient. Aid contributions in kind are very heterogeneous and include, for example, medical aid, search and rescue teams, shelter and clothing. Donors send humanitarian assistance either directly to the affected country or channel relief through multilateral institutions or via nongovernmental organizations like the Red Cross.

FTS data is based on self-reported information, which is provided by either donor governments, recipient agencies, collected from donor websites or quoted in pledging conferences. $^{149}$ In addition, FTS invests significant efforts into the cross-validation and reconciliation in cases where donation data stems from various sources. By comparing FTS data with DAC data, Fink and Redaelli (2011) find only minor differences between both databases, which show that FTS has relatively good data coverage. Although data coverage may be worse for non-DAC donors, FTS is the best database available for analyses of all kinds of donors. The database is widely used in policy analysis and academic research (e.g., Fink and Redaelli 2011), including empirical research on non-DAC donors (Raschky and Schwindt 2012).

\footnotetext{
${ }^{148}$ The database is publicly available at: http://fts.unocha.org (accessed: August 2011).

149 For a more detailed description of the data collection and subsequent cross-checking process refer to http://fts.unocha.org/pageloader.aspx?page=showpage\&PageID=61-Data (accessed: July 2012). See Harmer and Cotterrell (2005) for a discussion of strengths and weaknesses of FTS data.
} 
Table IV.1: Disaster types

\begin{tabular}{|l|ccccc|}
\hline Disaster type & $\begin{array}{c}\text { \# of } \\
\text { events }\end{array}$ & $\begin{array}{c}\text { Disaster start } \\
\text { reported (in \%) }\end{array}$ & $\begin{array}{c}\text { Average \# of } \\
\text { people killed }\end{array}$ & $\begin{array}{c}\text { Average \# of } \\
\text { people affected }\end{array}$ & $\begin{array}{c}\text { Average \# of } \\
\text { donors involved }\end{array}$ \\
\hline Drought & 27 & 0.0 & 27 & $15,836,072$ & 6.4 \\
Earthquake & 65 & 100.0 & 7,484 & $1,119,623$ & 13.9 \\
Epidemic & 4 & 25.0 & 92 & 5,153 & 5.0 \\
Extreme Temperature & 7 & 71.4 & 342 & $1,446,904$ & 3.9 \\
Floods & 220 & 91.4 & 124 & $2,620,126$ & 6.0 \\
Insect Infestation & 11 & 9.1 & 0 & 500,000 & 1.7 \\
Mass Movement Wet & 4 & 100.0 & 77 & 77,899 & 1.0 \\
Slides & 7 & 100.0 & 306 & 72,153 & 7.3 \\
Storm & 108 & 87.0 & 1,524 & 843,096 & 6.9 \\
Volcanic eruption & 15 & 100.0 & 8 & 76,649 & 3.9 \\
Wild fires & 4 & 75.0 & 14 & 150,000 & 2.5 \\
\hline
\end{tabular}

Source: Own calculations based on data from OCHA (2011) and EM-DAT (2012)

The UNOCHA defines humanitarian aid as "[a]n intervention to help people who are victims of a natural disaster or conflict meet their basic needs and rights" (OCHA 2011). Definitions of what constitutes humanitarian aid, however, differ across donor countries. To circumvent this caveat, we follow the previous literature and restrict our analysis to official UN appeals issued after emergencies. Consequently, all UN appeals need to be linked to a particular catastrophe. We have therefore updated and cross-validated the dataset used in Raschky and Schwindt (2012). ${ }^{150}$ Data on disaster characteristics are obtained from the emergency database EM-DAT (2012).

Fink and Redaelli (2011) note that measures of humanitarian need, e.g., the number of people killed after a catastrophe, are endogenous to the probability to provide aid. This holds if aid is effective in reducing the number of victims. To mitigate endogeneity issues, we follow their approach and restrict our analysis to cover fast-onset disasters only. These disasters usually take less than one day. Since it is difficult to identify what constitutes a fastonset disaster, we first exclude all disaster types from our sample that lack information on the respective disaster start dates in the majority of emergencies. These are emergencies caused by drought, extreme temperature and insect infestation. Of the remaining disaster types, we keep only those emergencies that have a clearly defined start date. Table IV.1 provides an overview on the share of reported disaster start dates by disaster type. We also report disastertype-specific information on the frequency and severity of disasters as well as on the average number of donor interventions per catastrophe.

\footnotetext{
${ }^{150}$ We thank Paul A. Raschky for generously providing us with the dataset.
} 
The resulting dataset covers 396 fast-onset emergencies over the 2000-2010 period. The non-availability of some of the (lagged) explanatory variables for 2010, however, constrains us to an analysis of 347 emergencies between 2000 and 2009. Since 19 disasters affect more than one country at the same time, as for example the 2004 Indian Ocean Tsunami, we end up with 394 emergency-recipient pairs. We consider every country as a (potential) donor of emergency aid if it has repeatedly (i.e., at least twice) provided emergency assistance after a natural disaster in our sample. By doing so, we investigate the behavior of 105 donor countries. In summary, we obtain $394 \cdot 105=41,370$ observations. Data availability of control variables reduces the final sample size to about 30,000 observations.

Appendix IV.2 lists all donor countries under investigation. The table is sorted by the number of aid interventions, i.e., the number of emergencies for which a donor provided aid to a particular recipient. As can be seen, the most active non-DAC donors are Turkey and South Korea with 54 involvements each. ${ }^{151}$ Thus, Turkey is also the most active donor among the group of low- and middle-income countries. Saudi Arabia tops the list of autocratic donors with 51 involvements.

Figure IV.1 compares the share of "new" donors in disaster relief of the first half of the 2000s (2000-04) with the second half (2005-09). As can be seen, emergency aid provided by "new" donors has gained in importance. Of all aid responses by donors in 2005-09, more than one third came from non-DAC donor countries, compared to only about one fourth in 2000-04. The respective share of poor and autocratic donors, however, was rather stable.

If one compares the share of aid amounts that each country provided, the increasing role of non-DAC donors becomes even more evident. The share of emergency aid funds that non-DAC donors contributed more than tripled from 9.1 to 28.9 percent, the share provided by less developed donors increased from 4.0 to 7.4 percent and the share of autocratic donors almost quadrupled from 5.4 to 23.3 percent over the same time period. This overall increase of aid from autocracies is mainly due to a surge in aid from Saudi Arabia (additional US\$ 415 million), but also caused by substantial increases in aid from Russia and Kazakhstan (additional US\$ 27 million each).

\footnotetext{
${ }^{151}$ In our paper, South Korea is still considered as a non-DAC donor since it joined the OECD's aid organization in 2010 only.
} 
Figure IV.1: Emergency aid over time and by donor group (2000-2009)

Aid interventions

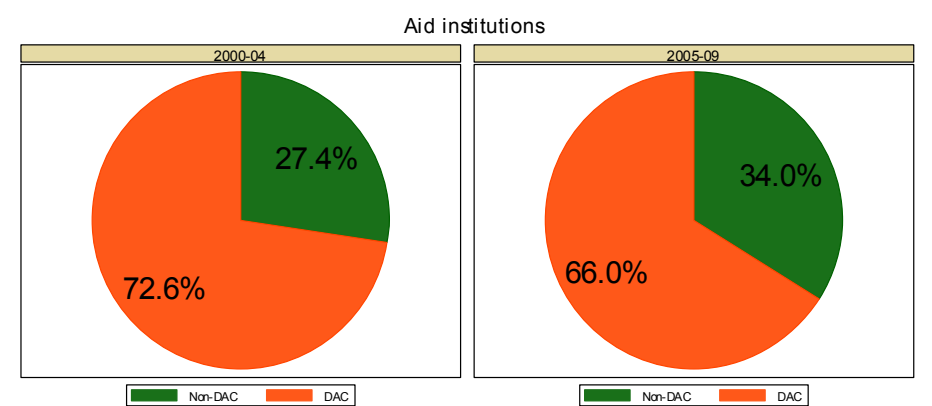

Income level

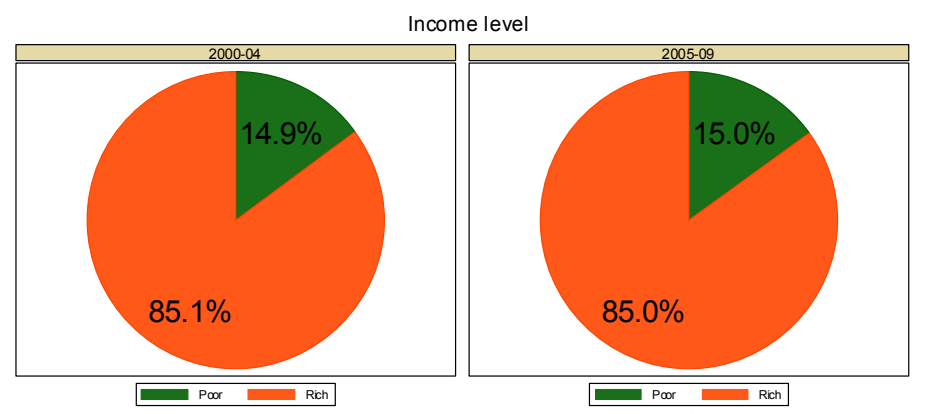

Regime type

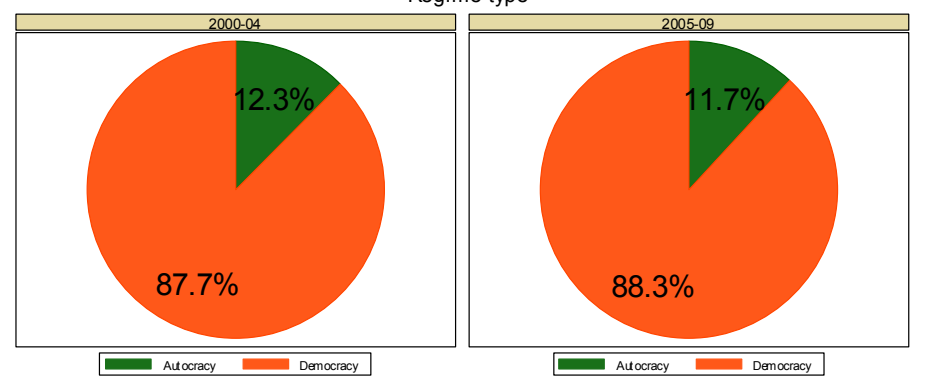

Aid amounts

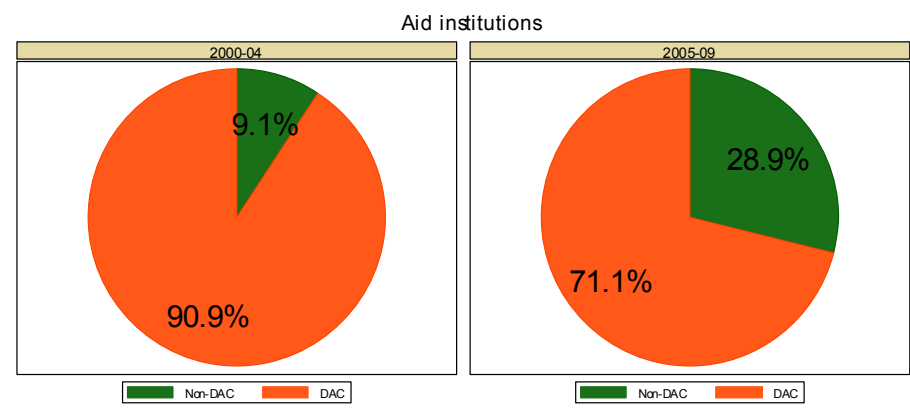

Income level

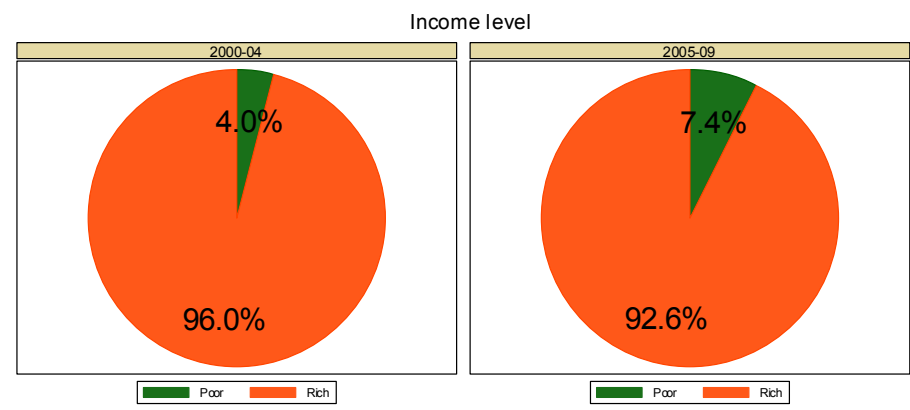

Regime type

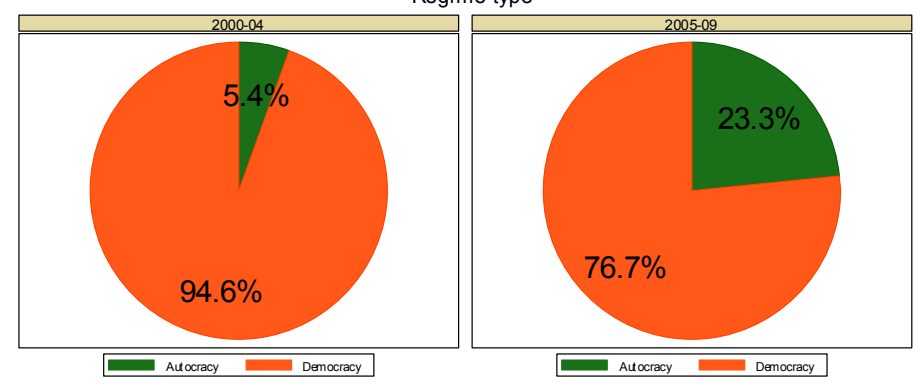




\section{IV.4.2 Empirical Strategy}

We start with estimating the probability that a country provides emergency aid to another country after a natural disaster. Our dependent variable aid is a dummy that takes a value of one if a country $i$ provides emergency assistance to another country $j$ after a natural disaster $k$. The probability to provide emergency assistance can be written as

$$
P\left(\operatorname{aid}_{i j k}=1 \mid x_{i j k}\right)=P\left(x_{i j k} \beta+\varepsilon_{i j k} \mid x_{i j k}\right)
$$

where $x$ is a set of explanatory variables and $\varepsilon$ is a white noise term. For the selection of appropriate explanatory variables, we use the variables employed in the aid allocation literature as guidance, in particular the literature on humanitarian aid (Fink and Redaelli 2011; Raschky and Schwindt 2012) and on "new" donors (Dreher et al. 2011). In line with the previous literature, we include four sets of variables that are said to impact the likelihood that a donor provides emergency relief after a natural disaster, namely disaster severity, donor characteristics, recipient characteristics and variables capturing donor-recipient relations.

First, to control for disaster severity, we employ two indicators that measure humanitarian need after the occurrence of a disaster. The first indicator is the (logged) number of total people affected by the disaster, i.e., the sum of all people injured, left homeless or affected in another way. Our second measure is the number of people killed, which includes all individuals confirmed as dead as well as those missing and presumed dead. Both variables are obtained from EM-DAT (2012). ${ }^{154}$ Moreover, we include disaster-type dummies to account for unobserved characteristics of the different disaster types. With the inclusion of these variables, we control for differences in the measurement of impact through our two measures of disaster severity (see Fink and Redaelli 2011). It is also imaginable that different types of disasters per se trigger different responses from the aid community. In line with this, Eisensee and Strömberg (2007) report that the newsworthiness of emergencies depends on disaster type.

Second, we expect that donor characteristics impact on the likelihood of aid provision. We construct one dummy variable to account for country membership in the DAC and a second one that takes a value of one if a donor country is classified as a democracy (Cheibub et al. 2010). To control for the income of a donor country, we include the (logged) real GDP per capita of a donor country, which is retrieved from the Penn World Tables

\footnotetext{
${ }^{154}$ Data were cross-validated with information from situation reports provided by the Reliefweb, available at

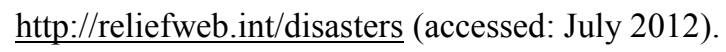


(Heston et al. 2011), as well as a dummy variable that takes a value of one if a donor is classified as a high-income country by the World Bank. ${ }^{155}$ Finally, we rely on the total population size in $\operatorname{logs}$ from the World Development Indicators (WDI) to measure the capacity of donor countries to provide aid.

With regards to recipient characteristics, we control for a country's self-aid capacity by using the (logged) per-capita GDP in constant 2005 international US dollar from the Penn World Tables (Heston et al. 2011) and once again (logged) population size from the WDI. Moreover, we follow Raschky and Schwindt (2012) and use population density as a further control for the socioeconomic environment. Different predictions prevail with regards to the effect of greater population density (see Fink and Redaelli 2011). On the one hand, densely populated areas may be in larger need of assistance as a greater density complicates evacuation of survivors, while fostering the spread of infectious diseases. On the other hand, areas with high population density may possess better networks that facilitate rescue efforts after a disaster.

Moreover, we include a measure of control of corruption from the Governance Matters database (Kaufmann et al. 2009). ${ }^{156}$ There are several reasons to believe that the probability to receive aid depends on a country's institutional characteristics. First, (democratic) donors may reward recipient merit (see Öhler et al. 2012). If this is the case, countries with a low level of corruption should be more likely to receive support after a catastrophe. Second, donor decisions may take account of a lower institutional capacity and thus provide more emergency aid to counteract the recipient's reduced self-aid capacity. More specifically, donors may anticipate that a certain share of their humanitarian aid is embezzled in countries with high levels of corruption and thus donate larger amounts to ensure that a certain amount of aid reaches the needy.

Next, we add a dummy variable indicating whether a disaster-affected country is categorized as democracy (Cheibub et al. 2010). On the one hand, democratic donors may be more likely to provide aid to democracies to support the country's institutions. On the other hand, donors could also favor autocracies if they believe that countries with such a regime are less capable to handle disasters (see Sen 1990). Moreover, aid effectiveness could differ in democracies and autocracies. In line with this, Plümper and Neumayer (2009) find in the context of famines that autocracies need much more aid to reduce mortality. Finally, donors

155 The income classification is based on 2010 GNI per capita data and available at http://data.worldbank.org/about/country-classifications (last accessed: July 2012).

${ }^{156}$ The control of corruption index "[r]eflects perceptions of the extent to which public power is exercised for private gain, including both petty and grand forms of corruption, as well as "capture" of the state by elites and private interests" (Kaufmann et al. 2009). 
guided by commercial interests could provide more support to autocracies to buffer trade reductions. According to empirical results in Gassebner et al. (2010), trade with autocracies suffers more from disasters than commercial relationships of democracies.

To control for commercial interests of donors, we furthermore control for a recipient country's natural resource endowment, which is proxied by the (logged) product of unit resource rents and physical quantities of minerals and energy extracted, which is obtained from the WDI. To capture donor's political interests, we add a dummy variable that takes a value of one if a recipient is a temporary member of the UNSC. In line with Dreher et al. (2009a, 2009b), we expect donors to engage in vote-trading activities and thus to increase aid to UNSC members. Note, however, that a positive coefficient could be simply driven by the fact that disaster-struck UNSC members can communicate their humanitarian needs after a disaster to a greater audience of potential donors and thus mobilize more disaster aid (see also Dreher et al. 2009a, 2009b).

Our fourth set of variables accounts for bilateral relations between donor and recipient. Geographic distance between donor and recipient (in logs) is used as a proxy for transportation costs of aid provided in kind as well as for cultural similarities between countries. ${ }^{157}$ In addition, the contiguity dummy controls for additional support offered to neighboring countries. As past research has shown that having a common colonial history increases the likelihood to receive emergency aid (e.g., Strömberg 2007), we include a dummy variable which takes a value of one if donor and recipient ever had a common colonizer or have been in a colonial relationship before. These variables have been extracted from the CEPII database (Mayer and Zignago 2006).

By including a dummy variable that takes a value of one if donor and recipient country share the same major religion, we control for the fact that some donors might feel more affinity to countries with similar religious orientation (see for example Neumayer 2003a, 2004 on the role of Islamic solidarity). ${ }^{158}$ The propensity of a donor to assist a disasterstruck country might further be influenced by migratory flows between the two countries. On the one hand, donors might be more inclined to assist those countries that host their expatriates. On the other hand, migrants originating from a disaster-affected country could raise the awareness of a disaster in the donor country, thus triggering the donor government to

\footnotetext{
157 The distance variable employed is the distance between major cities of the two countries, weighted by their population size, as defined in Mayer and Zignago (2006).

${ }^{158}$ With respect to India, Meier and Murphy (2011) points out that solidarity with individuals in need are core values within religions such as Hinduism, Buddhism and Islam. Information on countries' major religions is obtained from the World Christian Database (available at http://www.worldchristiandatabase.org/wcd/, accessed: November 2009).
} 
assist the migrants' country of origin. ${ }^{159}$ To test these predictions, we include the (logged) stock of migrants from the donor country in the recipient country and vice versa. The data are retrieved from the Global Migrant Origin Database (Parsons et al. 2007).

Out of self-interest, donors might be more inclined to assist countries with which they maintain close political ties. ${ }^{160}$ As a proxy for bilateral affinity, we include the voting alignment of recipient and donor country in the UNGA (Voeten and Merdzanovic 2009), which is a widely used indicator in the empirical aid literature (e.g., Thacker 1999; Neumayer 2005; Kilby 2009a, 2011). The indicator is the share of total votes in which donor and recipient showed the same voting behavior. ${ }^{161}$ Regarding the measurement of potential economic interest of a donor, we use the (logged) exports of the donor country to the recipient economy as a share of total donor exports. The data are retrieved from the United Nations COMTRADE database. ${ }^{162}$

We follow Fink and Redaelli (2011) and use one-year lags of all time-varying recipient-specific and bilateral variables (except UNSC membership) to mitigate concerns regarding potential feedback effects from aid to the explanatory variables. Appendix IV.3 summarizes all variables and their definitions and sources. Appendix IV.4 provides descriptive statistics.

\section{IV.4.3 Baseline Results}

We start with an analysis of the determinants that influence the decision to allocate aid to disaster-affected countries for our full sample. This setup allows us to evaluate the decision of 94 donors to commit aid to 394 emergency-recipient pairs in our dataset. Relying on Logit regressions, we estimate four model specifications to which we add alternating sets of dummy variables to observe whether our results hinge on the control of unobserved factors. ${ }^{163}$ While Table IV.2 presents our coefficient estimates, Appendix IV.5 adds information on the corresponding average marginal effects. Column 1 of each table shows results based on the

\footnotetext{
${ }^{159}$ With respect to the 2010 Haiti earthquake, for example, some policymakers consider the Haitian diaspora to play a vital role and to help coordinating the work of foreign non-governmental organizations (available at http://www.trust.org/alertnet/news/qa-haitian-diaspora-on-haitis-reconstruction-and-foreign-aid-agencies/, accessed: July 2012).

${ }^{160}$ For example with respect to India, Meier and Murphy (2011) expect humanitarian aid to reflect the quality and importance of bilateral relations as India strives for an improvement of the relationship with the affected country.

${ }^{161}$ Two countries are considered to be voting in line with each other if they jointly vote yes or no, if both abstain, or if both are absent.

${ }_{162}$ As the reporting of trade flows is fragmentary for some countries, we use mirror data to fill missing entries. This implies that export information from a donor is completed with import values as reported by the recipient. We take the mean in those cases, in which a trade flow is reported by both donor and recipient.

${ }^{163}$ Katz (2001) suggests that the bias in unconditional fixed-effects Logit decreases with the number of time periods. Since our "time" dimension reflects 394 emergency episodes, we run unconditional Logit estimations.
} 
inclusion of disaster-type and year dummies. A dummy variable for each emergency-recipient pair is included in the specification shown in column 2. Columns 3 and 4 replicate the specifications in columns 1 and 2 with donor dummies added.

As discussed above, we expect the selection decision of donors to be driven by disaster severity, donor and recipient characteristics as well as bilateral relations between donor and recipient. Our results are largely in line with the previous literature (Fink and Redaelli 2011; Raschky and Schwindt 2012). Regarding humanitarian need as captured by disaster severity, our results reveal a marked need-orientation of donors. In column 1, the coefficients on the number of total individuals affected and people killed are both positive and statistically significant at the one-percent level. The probability that a country receives aid from a particular donor increases by 0.6 percentage points if the number of people affected doubles. ${ }^{164}$ Analogously, a doubling of the number of mortalities causes this likelihood to increase by 1.9 percentage points. Given that the average donor propensity to contribute after a particular disaster is 8.7 percent, these effects are sizable. This finding is virtually unaffected by the inclusion of donor dummies in column 3 .

Turning to donor characteristics, our results show that DAC members are on average more likely to provide emergency aid. The respective coefficient remains significant at the one-percent level when controlling for either the type of disaster (column 1) or the actual emergency-recipient pair (column 2). The propensity to provide relief is on average 3.8 percentage points higher for DAC members than for non-members. Since DAC membership is captured by the donor dummies, this variable is omitted from columns 3 and 4. The coefficients on donor GDP per capita and population size are both positive and significant at the one-percent level in the specifications without donor dummies, implying that richer and larger countries are more likely to help. In contrast, conditional on all other factors, donor regime type has no statistically significant influence on the likelihood to provide disaster relief, at conventional levels of significance. Note, however, that these results should not be overemphasized as they might simply reflect the more complete reporting of these donor groups.

$164=0.008 \cdot \log (2)$ 
Table IV.2: Determinants of aid selection (Logit, 2000-2009)

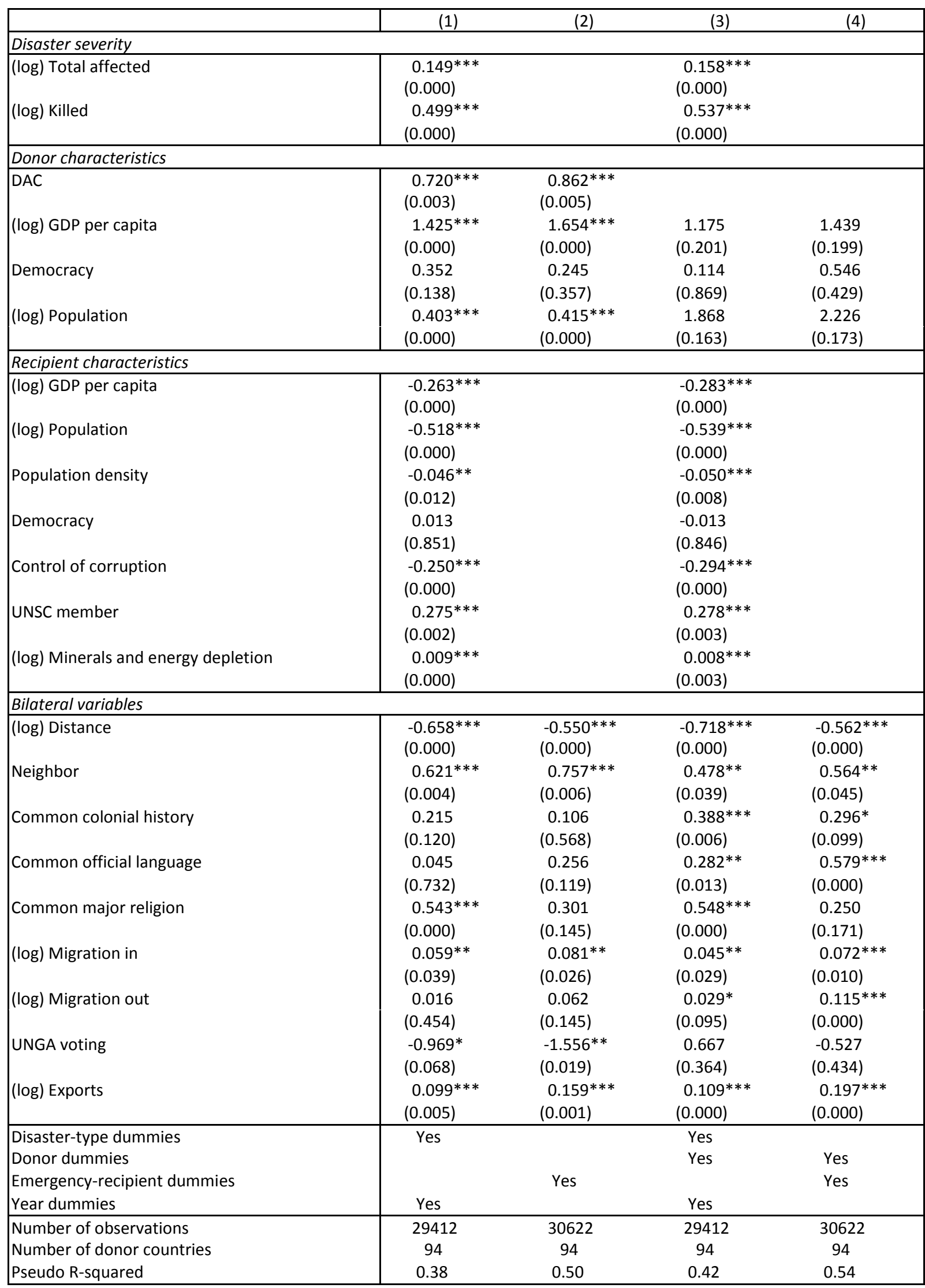

Notes:

- All models are Logit models with standard errors clustered at the donor level

- $p$-values in parentheses $\left(* * * p<0.01,{ }^{* *} p<0.05, * p<0.1\right)$ 
With respect to recipient characteristics, the coefficients on GDP per capita, population size and density are all negative and statistically significant at conventional levels. In line with our expectations, recipients' self-aid capacity thus seems to influence the likelihood that a donor provides emergency aid. In a similar manner, the coefficient on control of corruption has a significantly negative impact on the probability to receive aid. Rather than rewarding countries with a low level of corruption, donors support countries with higher levels of corruption, which should conceivably suffer from a reduced self-aid capacity.

Next, we turn to recipient characteristics that proxy donor countries' self-interests. When a disaster-affected country is a member of the UNSC, it increases the likelihood to receive disaster aid by 1.5 percentage points. The coefficient is significant at the one-percent level in both specifications. This finding could indicate that donors exchange votes at the UNSC for the provision of disaster aid. A greater abundance of natural resources in disasteraffected countries furthermore increases the propensity of donors to help after a natural disaster. The coefficient on recipients' mineral and energy extraction is positive and statistically significant at the one-percent level. Taken together, it seems that donors provide aid with their own political and commercial interests in mind; the results suggest that donors favor potential allies in the UNSC as well as recipients rich in natural resources.

Turning to bilateral variables, the coefficients capturing geographic proximity of donor-recipient pairs, i.e., distance and contiguity, are both statistically significant at conventional levels and show that donors favor geographically close countries. When controlling for unobserved donor characteristics, we find that a common colonial history and linguistic ties increase the likelihood that a donor will provide aid (columns 3 and 4). Aid flows are more likely if donor and recipient share the same major religion (columns 1 and 3), but the respective coefficient does not reach statistical significance at conventional levels when we control for emergency-recipient dummies (columns 2 and 4). Results also indicate that a greater stock of migrants originating from a disaster-affected country makes it more likely that the host country provides help after a disaster. The corresponding coefficient on outward migration is statistically significant at conventional levels in all four specifications. Once we control for donor dummies, we also find that donors are more likely to provide aid to countries which are home to their expatriates (columns 3 and 4).

The extent to which donor and recipient countries vote in line at the UNGA is a proxy for bilateral affinity. According to columns 1 and 2, donors are more likely to help countries less aligned to their agenda at the UNGA. While this appears counterintuitive at first, it seems that donors use humanitarian aid as a measure to improve relations with countries with 
diverging interests, in line with Fink and Redaelli (2011). Note, however, that this does not hold if we control for unobserved donor characteristics (columns 3 and 4). Finally, the coefficient on exports is positive and statistically significant at the one-percent level in all specifications. The average marginal effect of a doubling of the export volume is 0.35 percentage points. On the one hand, this could be an indicator that donors attach importance to the stability of their export destinations and export flows. On the other hand, more intense trade relations could increase the mutual awareness between countries and thus the likelihood of providing humanitarian aid to trading partners. Furthermore, close commercial ties to a disaster-affected country facilitate the provision of aid as donors can use existing logistical networks with the recipient country to disburse humanitarian aid.

In summary, our results indicate that the donors' decision to provide disaster relief is driven by humanitarian need, recipients' self-aid capacity and donor self-interests. Moreover, donors are more inclined to help countries which are geographically or culturally proximate. The results do not only confirm previous findings for an extended time period (2000-09), but confirm the role of factors that have not been tested in the previous literature on emergency aid (e.g., UNSC membership, migratory flows). Since these results only provide evidence for the average donor, it remains unclear whether aid motives of "new" and "old" donors differ. This is what we turn to next.

\section{IV.4.4 Testing for Differences between "New" and "Old" Donors}

In Table IV.3, we investigate whether the determinants of aid selection differ across donor groups. This requires us to apply our estimation strategy to subsamples of our main dataset. Specifically, we run seemingly unrelated regressions (SUR) and re-estimate column 3 of Table IV.2 for each subsample. This enables us to test for statistically significant differences in the coefficients across subsamples with a Wald test (in italics). Accordingly, we divide our sample according to the donor groups introduced above. Column 1 splits our sample into DAC and non-DAC donor countries. The two subsequent models are based on a division of our sample into "rich" and "poor" donors (column 2) as well as democratic and autocratic donors (column 3). Furthermore, we subdivide the group of non-DAC donors into "rich" and "poor" (column 4) as well as democratic and non-democratic donors (column 5). ${ }^{165}$

Turning to our results and starting with the two measures of disaster severity, we find aid decisions of all donor groups to be driven by humanitarian need. According to the pvalues of the Wald test reported in italics, no statistically significant difference emerges

\footnotetext{
${ }^{165}$ Since we split our sample by donor characteristics, we drop the donor variables from the regressions.
} 
between most donor groups. We only find that non-DAC donors have a higher propensity to align their aid efforts to the number of casualties, the difference being significant at the fivepercent level. Recipient characteristics show greater differences in their impact on aid decisions of donor groups. Comparing DAC and non-DAC donors as well as rich and poor donors in columns 1 and 2, statistically significant differences appear in the donor reactions towards recipients' self-aid capacity. While DAC donors as well as "rich" donors account for the income level of disaster-struck countries, this factor is unaccounted for in the considerations of non-DAC and "poor" donors. The Wald test confirms the observed differences in the coefficients to be statistically significant at conventional levels. Interestingly, population size, another measure of recipient self-aid capacity, has a significant influence on the aid allocation decision of all donors, but the coefficient size shows significant differences across donor groups. According to columns 1-3, non-DAC, "poor" and autocratic donors have a significantly lower likelihood to commit aid to more populous recipient countries, at conventional levels of significance.

With regard to democracy, most donor groups provide relief independently from the recipients' regime type. Autocratic donors, however, seem to disfavor democratic recipients (columns $3 \mathrm{~b}$ and $5 \mathrm{~b}$ ). When taking into account the level of corruption in the recipient country, all donor groups except the autocratic donors provide less aid to recipients with stronger control of corruption. As argued above, control of corruption can be interpreted as an indicator for self-help capacity. Although autocracies deviate from this general pattern with an insignificant coefficient, we cannot reject the hypothesis that the coefficient is equal to the one for democracies. Democratic non-DAC donors show the strongest bias towards countries with high levels of corruption. With regard to UNSC membership, no statistically significant differences emerge between donor groups. While resource-abundant recipients are favored by $\mathrm{DAC}$ and non-DAC as well as "rich" and "poor" donors, no statistically significant differences emerge between these groups according to the Wald test. Splitting our sample between democracies and autocracies (columns 3 and 5), however, reveals that recipients' extraction of natural resources has a larger influence on donor decisions taken by autocracies. 
Table IV.3: Determinants of aid selection by donor group (Logit, SUR, 2000-2009)

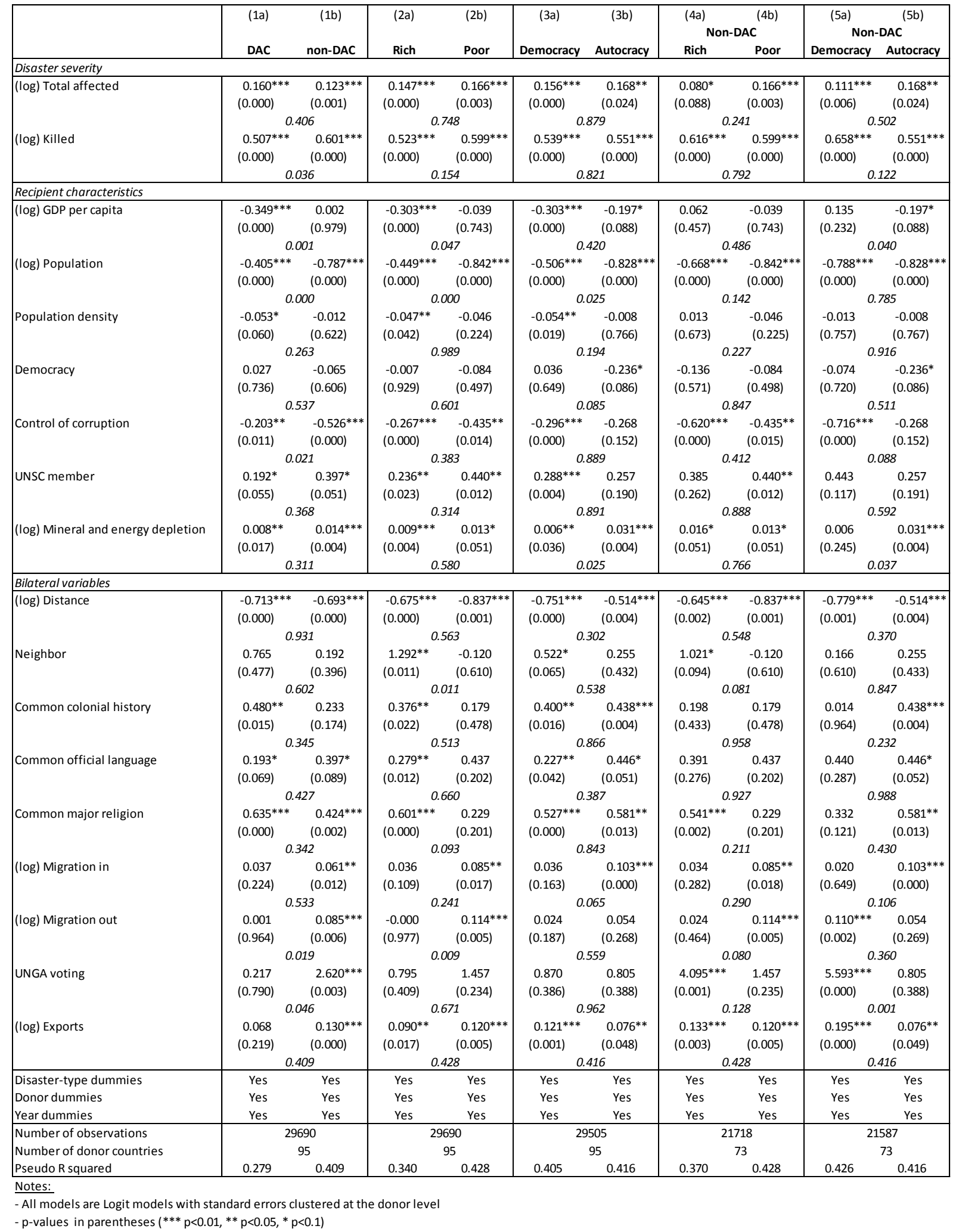


Turning to our bilateral measures, a larger geographic distance between donor and recipient significantly reduces the likelihood of aid provision for each donor group under investigation, at the one-percent level of significance. In contrast to our expectations and previous findings for general development aid, distance is neither more important for nonDAC donors (Dreher et al. 2011) nor poorer donors (Chapter III). The Wald test in italics shows no statistically significant differences between donor groups. While contiguity encourages "rich" and democratic donors to provide disaster aid, "poor" and autocratic donors do not seem to favor neighbors. Cultural ties, as proxied by common colonial history, common language and common major religion, provide incentives to commit disaster aid for "rich" donors but not for "poor" donors. With regard to any systematic differences between the estimated coefficients, results from the Wald test show little support for systematic differences across the donor groups. Inward and outward migration has a statistically significant impact on non-DAC donors and "poor" donors, at conventional levels of significance. Contrasting non-DAC donors by regime type shows that inward migration has a statistically significant effect on aid from autocracies, while the democratic donors' decision to provide aid is influenced by outward migration.

With respect to political and economic self-interests of donor countries, non-DAC countries (column 1b), and within this group the rich and democratic donors (colums 4a and 5a), favor politically-aligned recipients. The coefficient on the UNGA voting alignment between donor and recipient is statistically significant at the one-percent level in these three donor groups. Lastly, with the exception of the DAC donors, all donor groups have a statistically significant greater probability to provide emergency aid to more important trading partners, at conventional levels. Note, however, that there is no indication of statistically significant differences between DAC and non-DAC donors with respect to the role of exports.

In conclusion, some interesting differences emerge from our analysis of differences in aid motives between donor groups. While DAC and non-DAC donors both seem to attach importance to humanitarian need, aid flows from non-DAC donors is guided to a larger extent by deadly disasters. While non-DAC donors attach more importance to the support of small countries, they do not favor poorer countries as DAC donors do. This is evidence that "old" donors are more need-oriented than "new" donors. Finally, non-DAC donors attach a greater importance to political allies, as proxied by their UNGA voting alignment with disasteraffected countries, and autocracies show stronger commercial motives with respect to increased help provided to autocratic recipients and countries rich in natural resources. 


\section{IV.5 Empirical Analysis of Aid Promptness}

\section{IV.5.1 Overview}

We now turn our attention to the determinants of the amount of time that passes between the occurrence of a natural disaster and a donor's decision to commit aid. Analyzing the determinants of this duration in days introduces a novel way of assessing donor behavior in terms of the promptness with which they react to the needs of a recipient in distress. Therefore, we construct a unique measure of the speed of aid responses by combining the information on the date of the onset of a natural disaster, obtained from EM-DAT (2012), with the decision date reported in the FTS aid database. Note that the day on which a disaster started is taken to be Day 1. ${ }^{166}$ The decision date is defined as the "[d]ate on which the donor is reported to have made the funding commitment for that item." ${ }^{167}$ From the resulting measure, we exclude observations with a decision time greater than or equal to 180 days as aid delivered with such a delay hardly aims at urgent needs that require speedy assistance. ${ }^{168}$ Appendix IV.2 provides information on the average decision time for all donor countries.

Figure IV.2 plots the average number of days after which a particular donor commits herself to provide emergency relief to a disaster-affected country as a function of disaster type and donor type. Starting with all disasters, we find that the average decision time is one day shorter for DAC donors (Day 27) than for non-DAC donors (Day 28). Surprisingly, low- and middle-income countries (Day 22) react on average six days earlier to emergencies than highincome countries (Day 28). While democracies respond on average on Day 27 to a catastrophe, autocracies have a slightly longer response time (Day 28). We obtain a more nuanced picture when we split the sample by disaster type. DAC members respond on average more quickly to six of eight disaster types under investigation. Non-DAC donors show a shorter reaction time only with respect to extreme temperature and wild fires. Poorer donors react faster than richer donors to five disaster types. ${ }^{169}$ Taken together, no clear pattern

\footnotetext{
${ }^{166}$ To account for the time difference between donor and recipient as well as for a certain imprecision of the exact day of onset for certain disaster types, we consider all aid decisions taken on the day before the reported disaster-start day as taken on Day 1. In the case of storms, all aid decisions taken in the week before the onset are taken to be taken on Day 1 to account for donors' efforts for disaster preparedness.

167 See FTS webpage available at http://fts.unocha.org/pageloader.aspx?page=showpage\&PageID=62Definitions (accessed June 28, 2012). Ideally, one would use information on the exact day when an aid package reaches the disaster area or when funds are transferred rather than the decision day. Unfortunately, this information is not available. However, committing aid is an important precondition for timely help.

168 The selection of 180 days as cut-off level is in line with the UN's definition of a Flash Appeal, which structures a coordinated humanitarian response for up to six months after the start of an emergency (see http://unocha.org/cap/about-the-cap/faqs, accessed: July 2012).

169 Note that our dataset does not contain any case in which a low- and middle-income country provided emergency aid to help victims suffering from extreme temperature. High-income countries react on average on Day 44 to this disaster type.
} 
emerges whether "new" or "old" donors provide faster relief. Next, we apply econometric techniques that allow us to control for confounding factors.

\section{IV.5.2 Empirical Strategy}

We estimate the following equation:

$$
\operatorname{speed}_{i j k}=\alpha+\beta x_{i j k}+\varepsilon_{i j k}
$$

where speed is the (logged) number of days after a natural disaster by which a donor commits herself to provide emergency aid, $x$ is a set of explanatory variables, and $\varepsilon$ is a white noise term. By definition, our estimation sample only includes information on the decision time if the respective donor has committed aid after a specific disaster. Therefore, we face the problem of incidental truncation of our data. If omitted variables affect both the selection of donors to provide relief (gate-keeping decision) as well as the timing, the use of standard linear regression techniques leads to biased estimates. For example, the (unobservable) intrinsic motivation of a country's government to provide humanitarian aid should determine donor behavior with respect to aid selection and aid promptness.

Therefore, we follow the approach presented in Heckman (1979) and convert our estimation to a two-step procedure. More precisely, we employ a Probit estimation to estimate the decision to provide aid in a first step (see equation IV.1). In a second step, we include the inverse Mills ratio in an OLS estimation of aid promptness (see equation IV.2). It is preferable to add an exclusion variable to the first-step regression, i.e., an explanatory variable that impacts on the likelihood to provide emergency relief after a certain disaster episode but not on the timeliness of the decision to provide aid. Since we lack a suitable exclusion variable, we instead make use of the non-linearity inherent in the underlying Probit estimation of the first step and estimate our Heckman model without an exclusion variable. ${ }^{170}$

\footnotetext{
${ }^{170}$ See Bushway et al. (2007) for a comprehensive discussion of the usage of a Heckman estimation without exclusion variable and its caveats. Note that we included a donor country's debt ratio, fiscal deficit and GDP growth rate as potential exclusion variables. It can be argued that donors are less likely to provide emergency relief in times of tight budgets and economic recession. Given that a donor makes aid funds available, there seems is no reason to believe that these factors impact on the speed of aid. However, none of these variable showed a robust significant effect on aid selection.
} 
Figure IV.2: Aid promptness by disaster type and donor group (2000-2009)
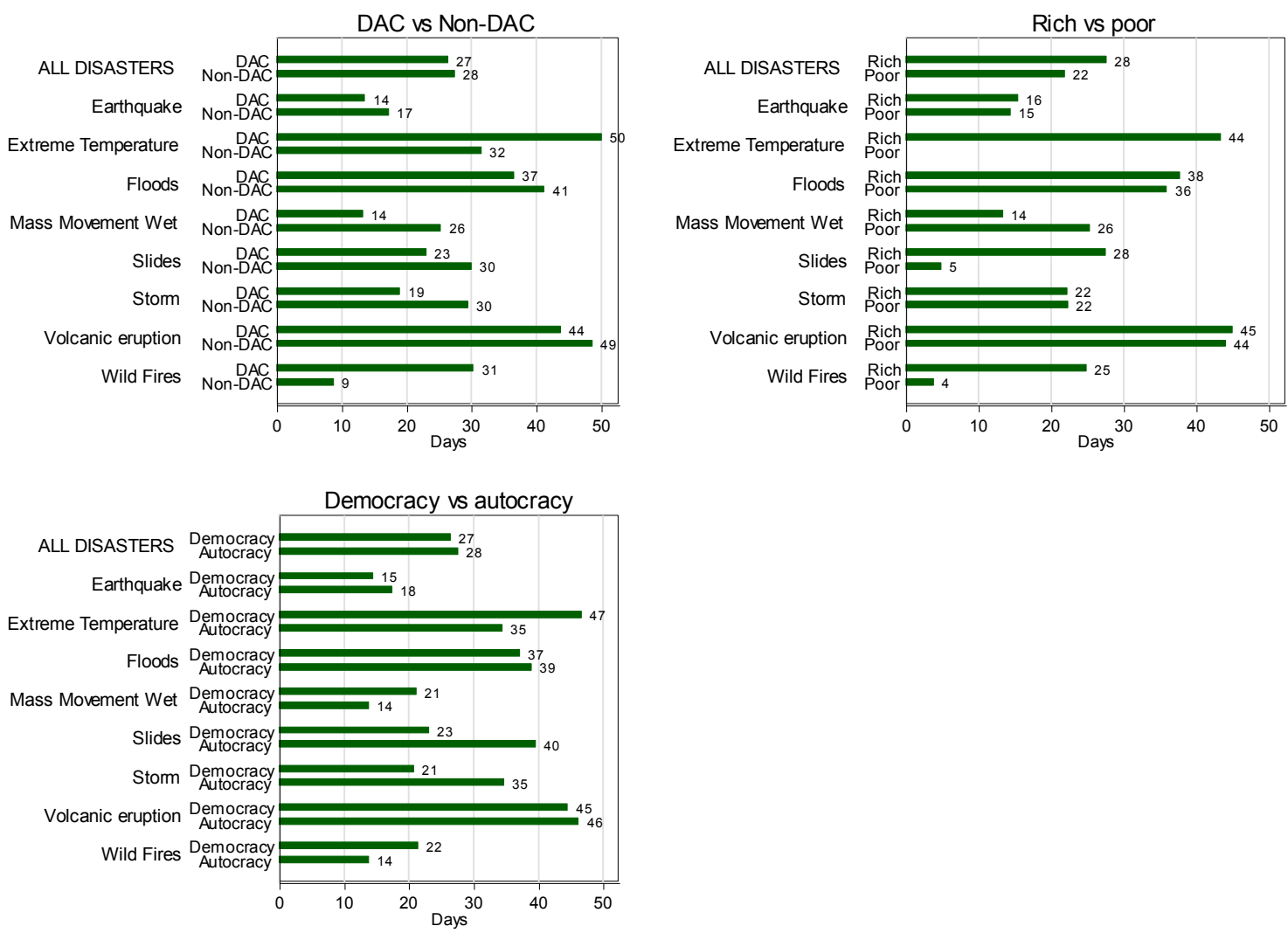

We use the same explanatory variables as for aid selection (see again Section IV.4.2). In most cases, we expect to find the opposite sign in the aid promptness regression compared to aid selection. More precisely, we expect donors to react faster with increasing disaster severity. With respect to donor characteristics, we include the DAC dummy, our income measure and the democracy dummy to test the hypotheses raised in Section IV.3. Donor population size proxies donor countries' aid capacities and we thus expect to find a negative effect on the decision time. Moreover, we anticipate a donor to respond quicker if she has stronger political and commercial interests in the disaster-struck country, as measured by the United Nations variables, export shares and recipients' extraction of natural resources. Conversely, we expect that recipients with a larger self-aid capacity, proxied by GDP per capita, population, population density and control of corruption, receive aid at a later point in time. The stronger the links between donor and recipient, as measured by distance, colonial links, common language, common major religion and migratory flows, the earlier the disasteraffected country should receive the aid commitment. 
All time-varying covariates, with the exception of UNSC membership, are again lagged by one year (see Appendix IV.3 for full details). Standard errors are clustered by donor countries to control for group-wise heterogeneity.

\section{IV.5.3 Results}

Table IV.4 provides the results of the second-stage estimation of aid promptness. ${ }^{171}$ As for aid selection in Section IV.4, we estimate four model specifications. While we include only year and disaster-type dummies in column 1, column 2 presents results of a regression with one dummy variable for each emergency-recipient pair. In column 3 and 4, we add donor dummies to column 1 and 2, respectively. We find that the number of people killed after a disaster has a significantly negative impact on the decision time, at the one-percent level of significance. If the number of mortalities increases by one percent, the decision time is roughly 0.2 percent lower. The total number of people affected, however, does not show a significant impact on aid promptness. A potential explanation could be the role of television news as disasters that involve a high number of casualties are more likely to be covered in the news (Eisensee and Strömberg 2007).

The results on the variables capturing donor characteristics will allow us to draw conclusions with respect to the hypotheses outlined in Section IV.3. While non-DAC donors pride themselves with speedy assistance, we do not find empirical support for this claim. Analyzing differences between donor groups, we find that DAC donors and richer donors, as measured by donor GDP per capita, show a shorter reaction time, at conventional levels of significance. All else being equal, the decision time of DAC members is 33.5 percent shorter than the reaction time of non-DAC donors (column 1). This finding is empirical support of hypothesis 2. Moreover, a ten-percent increase in donor GDP per capita reduces the duration by about three percent, which again supports hypothesis 2 . With regard to regime type, the coefficient on donor democracy is negative in all four specifications, but gains statistical significance at conventional levels only in column 2 (p-value: 0.092). According to this specification, which controls for emergency-recipient characteristics, a democracy's response time is 16.8 percent shorter than that of an autocracy. This is further evidence in favor of hypothesis 2 and against the alternative hypothesis that autocracies take speedier decisions.

\footnotetext{
${ }^{171}$ Results for the first stage deviate from the results described in Section IV.4, but the general picture stays the same. This is because we lose observations due to missing information on the decision time for some emergency-recipient-donor pairs. Most notably, the negative coefficient on democracy and the positive coefficient on UNGA voting become statistically significant at conventional levels in column 3 . The detailed regression table is available upon request.
} 
Table IV.4: Determinants of aid promptness (Heckman, 2000-2009)

\begin{tabular}{|c|c|c|c|c|}
\hline & (1) & $(2)$ & (3) & (4) \\
\hline \multicolumn{5}{|l|}{ Disaster severity } \\
\hline (log) Total affected & $\begin{array}{c}0.012 \\
(0.234)\end{array}$ & & $\begin{array}{c}0.006 \\
(0.564)\end{array}$ & \\
\hline \multirow[t]{2}{*}{ (log) Killed } & $-0.182 * * *$ & & $-0.202 * * *$ & \\
\hline & $(0.000)$ & & $(0.000)$ & \\
\hline \multicolumn{5}{|l|}{ Donor characteristics } \\
\hline DAC & $\begin{array}{l}-0.409 * * * \\
(0.006)\end{array}$ & $\begin{array}{l}-0.410^{* * *} \\
(0.002)\end{array}$ & & \\
\hline \multirow[t]{2}{*}{ (log) GDP per capita } & $-0.313^{* * *}$ & $-0.302 * * *$ & $-1.849 * * *$ & $-1.310^{*}$ \\
\hline & $(0.000)$ & $(0.001)$ & $(0.008)$ & $(0.074)$ \\
\hline \multirow[t]{2}{*}{ Democracy } & -0.104 & $-0.184 *$ & -0.500 & 0.140 \\
\hline & $(0.407)$ & $(0.092)$ & $(0.116)$ & $(0.853)$ \\
\hline \multirow[t]{2}{*}{ (log) Population } & $-0.139 * * *$ & $-0.146 * * *$ & -0.607 & -0.698 \\
\hline & $(0.000)$ & $(0.000)$ & $(0.590)$ & $(0.533)$ \\
\hline \multicolumn{5}{|l|}{ Recipient characteristics } \\
\hline \multirow[t]{3}{*}{ (log) GDP per capita } & $\begin{array}{l}-0.206^{* * *} \\
(0.000)\end{array}$ & & $\begin{array}{l}-0.169^{* * *} \\
(0.000)\end{array}$ & \\
\hline & $0.206^{* * *}$ & & $0.267 * * *$ & \\
\hline & $(0.000)$ & & $(0.000)$ & \\
\hline \multirow[t]{2}{*}{ Population density } & -0.005 & & -0.006 & \\
\hline & $(0.624)$ & & $(0.578)$ & \\
\hline \multirow[t]{2}{*}{ Democracy } & $-0.102 *$ & & -0.061 & \\
\hline & $(0.088)$ & & $(0.367)$ & \\
\hline \multirow[t]{2}{*}{ Control of corruption } & $0.248^{* * *}$ & & $0.260 * * *$ & \\
\hline & $(0.000)$ & & $(0.000)$ & \\
\hline \multirow[t]{2}{*}{ UNSC member } & 0.037 & & 0.035 & \\
\hline & $(0.661)$ & & $(0.679)$ & \\
\hline \multirow[t]{2}{*}{ (log) Minerals and energy depletion } & $-0.005^{* *}$ & & $-0.005^{* *}$ & \\
\hline & $(0.028)$ & & $(0.041)$ & \\
\hline \multicolumn{5}{|l|}{ Bilateral variables } \\
\hline (log) Distance & $\begin{array}{l}0.202^{* * *} \\
(0.000)\end{array}$ & $\begin{array}{l}0.228^{* * *} \\
(0.001)\end{array}$ & $\begin{array}{l}0.190^{* * *} \\
(0.001)\end{array}$ & $\begin{array}{c}0.195^{*} \\
(0.057)\end{array}$ \\
\hline \multirow[t]{2}{*}{ Neighbor } & -0.126 & -0.151 & 0.033 & -0.001 \\
\hline & $(0.343)$ & $(0.166)$ & $(0.817)$ & $(0.992)$ \\
\hline \multirow[t]{2}{*}{ Common colonial history } & -0.048 & -0.022 & -0.049 & -0.073 \\
\hline & $(0.555)$ & $(0.742)$ & $(0.492)$ & $(0.373)$ \\
\hline Common official language & -0.063 & $-0.190 * * *$ & -0.012 & $-0.151^{* *}$ \\
\hline & $(0.450)$ & $(0.002)$ & $(0.880)$ & $(0.019)$ \\
\hline Common major religion & 0.142 & 0.081 & 0.127 & 0.045 \\
\hline & $(0.106)$ & $(0.469)$ & $(0.197)$ & $(0.744)$ \\
\hline (log) Migration in & -0.008 & -0.019 & -0.014 & $-0.030^{*}$ \\
\hline & $(0.658)$ & $(0.244)$ & $(0.481)$ & $(0.091)$ \\
\hline (log) Migration out & $-0.036 * * *$ & -0.014 & $-0.042 * * *$ & -0.034 \\
\hline & $(0.002)$ & $(0.437)$ & $(0.000)$ & $(0.115)$ \\
\hline UNGA voting & -0.008 & 0.133 & -0.480 & 0.045 \\
\hline & $(0.968)$ & $(0.436)$ & $(0.104)$ & $(0.896)$ \\
\hline (log) Exports & $-0.063 * * *$ & $-0.038 * *$ & $-0.101 * * *$ & $-0.057 * *$ \\
\hline & $(0.002)$ & $(0.044)$ & $(0.000)$ & $(0.023)$ \\
\hline Disaster-type dummies & Yes & & Yes & \\
\hline Donor dummies & & & Yes & Yes \\
\hline Emergency-recipient dummies & & Yes & & Yes \\
\hline Year dummies & Yes & & Yes & \\
\hline athrho & $\begin{array}{c}-0.312^{* * *} \\
(0.000)\end{array}$ & $\begin{array}{c}-0.394^{* *} \\
(0.020)\end{array}$ & $\begin{array}{c}-0.406^{* * *} \\
(0.001)\end{array}$ & $\begin{array}{r}-0.497 \\
(0.259)\end{array}$ \\
\hline Insigma & -0.007 & $-0.224^{* * *}$ & -0.041 & $-0.258 * *$ \\
\hline & $(0.806)$ & $(0.001)$ & $(0.318)$ & $(0.042)$ \\
\hline Number of observations & 29049 & 30414 & 29049 & 30414 \\
\hline Number of donor countries & 94 & 94 & 94 & 94 \\
\hline Prob > chi2 & 0.000 & 0.020 & 0.001 & 0.259 \\
\hline
\end{tabular}

Notes:

- All models are Heckman models with standard errors clustered at the donor level

- $\mathrm{p}$-values in parentheses $\left({ }^{* * *} \mathrm{p}<0.01,{ }^{* *} \mathrm{p}<0.05,{ }^{*} \mathrm{p}<0.1\right)$

- Results of first-stage regressions available upon request 
It is not surprising that the democracy variable loses statistical significance once we control for donor dummies (columns 3 and 4) since regime type hardly varies for many countries over a short period of time. Finally, we find that larger countries make faster decisions after emergencies, at the one-percent level of significance (columns 1 and 2). This effect also disappears once we include donor characteristics (columns 3 and 4).

Turning to recipient characteristics, we find that poorer countries receive slower disaster relief, at the one-percent level of significance. From a humanitarian point of view, this is undesirable since less affluent countries possess on average a smaller capacity for selfaid, which puts disaster-affected individuals at greater peril and in larger need of fast assistance. However, we find donor decisions to reflect self-aid capacity as smaller recipients are favored through earlier aid commitments, at the one-percent level of significance. A recipient's population density does not turn out to be a statistically significant predictor of aid promptness, at conventional levels of significance. While column 1 suggests that democracies receive faster relief, once we introduce donor dummies, recipient democracy loses its statistical significance at conventional levels (column 3). Countries with a higher level of corruption receive on average more timely disaster assistance, at the one-percent level of significance. Donors seem to adjust their timeliness of aid provision to counteract the inefficiencies caused by corruption in the recipient country. With regard to the timeliness of the aid decision, members of the UNSC do not receive favorable treatment, which is in contrast to our findings on aid selection in Section IV.4. The coefficient on the UNSC dummy fails to gain statistical significance at conventional levels in column 1 and 3. Disaster-affected countries that are rich in natural resources, however, receive faster aid. The reaction time of donors decreases with increased levels of mineral and energy extraction, at the five-percent level of significance.

Next, we turn to the bilateral variables. Countries that are geographically closer receive timelier aid commitments than more distant disaster-struck countries, at the onepercent level of significance. There is no additional effect stemming from adjacency of donor and recipient. While the results do not show a statistically significant impact of common colonial history and common major religion on aid promptness, donors react on average faster if they share a common official language with a country suffering from a catastrophe. The coefficient is statistically significant at conventional levels in columns 2 and 4 . Reduced communication costs may explain this finding. There is also evidence that migrant networks speed up the aid process. While the coefficients on donor countries' inward and outward migration show the expected negative sign in all four specifications, the coefficient on inward 
migration in column 4 and the coefficients on outward migration in column 1 and 3 gain statistical significance at conventional levels.

Political affinity of donor and recipient, as proxied by their voting alignment in the UNGA, does not to affect the timeliness of the aid commitment. Note, however, that once we control for donor dummies, the p-value of the negative coefficient in column 3 is close to the ten-percent level of significance. Finally, we find robust evidence that countries with strong commercial ties to the donor country receive faster aid commitments following a disaster. The respective coefficients are statistically significant at conventional levels in all four specifications.

In sum, we find that the timeliness of the aid decision depends on similar determinants as does the allocation of aid. The speed with which a country responds to a catastrophe follows a mixture of need-related motives and donor countries' self-interests. All else being equal, we did not find any support for claims that "new" donors respond faster than "old" donors to natural disasters. Identifying "new" donors by their membership in the DAC, income level and regime type, we found "new" donors to be significantly slower than "old" donor countries.

\section{IV.6 Conclusions}

The new world of foreign assistance is most visible in the provision of humanitarian assistance, where virtually every country acts as an aid donor. This proliferation of donors, with increasing aid activities outside the DAC and more aid flows from low- and-middle income countries and authoritarian regimes, is likely to change the international aid architecture. We started by analyzing aid decisions of 105 donor countries and examined differences in allocation behavior between "old" and "new" donors and different types of "new" donors. In a next step, we analyzed whether "new" donors differ from "old" donors with respect to the timeliness of the decision to provide aid.

Our empirical results show that both DAC and non-DAC donors attach great importance to humanitarian need, recipients' self-aid capacity and their political and commercial self-interests. This confirms previous findings on general development aid (e.g., Dreher et al. 2011). Within these broad categories of donor motives, some interesting differences emerged between donor groups. Although non-DAC donors put greater emphasis on the support of small countries, they do not favor poorer countries, a behavior which is in contrast with the decisions of DAC donors. This is can be interpreted as evidence that "old" 
donors are more need-oriented than "new" donors. While self-interests guide aid selection of both "old" and "new" donors alike, non-DAC donors attach greater importance to political allies, as proxied by their UNGA voting alignment, than DAC donors. Autocratic donors put more emphasis on commercial motives than democracies with respect to increased help provided to countries rich in natural resources. This can be seen as evidence that aid allocation of "new" donors is inferior to that of "old" donors from a humanitarian point of view.

To be effective, emergency aid has to be provided in a timely manner. We extended our comparison of "old" and "new" donors to their respective timeliness in providing emergency aid. Our results show that, all else being equal, non-DAC donors, developing countries and autocracies are slower than DAC donors, high-income countries and democracies in their decision to commit to providing emergency aid. This is striking empirical evidence against the claim of many "new" donors that they are faster in their aid responses than the allegedly "bureaucratic" club of DAC donors. We also find that aid promptness - albeit influenced by humanitarian need - suffers, like aid selection, from the strategic motivations of donors.

Finally, it has to be emphasized that our analysis faces some limitations. First, we lack information on the actual delivery date and are confined to an analysis of the timing of aid commitments. Although aid commitments are legally binding, information on the day the aid flow crosses the border would be preferable. Second, donor decisions could be heavily influenced by actual aid requests from disaster-affected countries. The recipient behavior is an important part of the donor decision to provide aid. This is an important topic for future research. Third, although a speedy decision-making process is an important prerequisite for (most types of) disaster aid to be effective, a fast response following a disaster is not the sole objective of emergency assistance. Disaster preparedness, for example, should be an important part of humanitarian aid activities. To the extent to which a long decision time stems from aid coordination between donors that provide fast relief and those who focus on reconstruction and disaster preparedness, donors should not solely be judged on their aid promptness. Beyond the timeliness of the aid decision, future research should evaluate the effectiveness of disaster aid efforts of "new" and "old" donors in greater detail. Domestic and international evaluations of many "new" donors remain widely non-existent (see Harmer and Martin 2010). Although aid efforts by "new" donors are to be welcomed, based on our results, it seems that the "old" providers of aid will remain the important pillars of the emergency aid architecture for the next years to come. 


\title{
Chapter V:
}

\section{Paying a Visit: The Dalai Lama Effect on International Trade}

Joint work with Nils-Hendrik Klann ${ }^{\mathrm{a}}$

\begin{abstract}
Is political compliance a precondition for healthy trade relations with China? The Chinese government frequently threatens that meetings between its trading partners' officials and the Dalai Lama will be met with animosity and ultimately harm trade ties with China. We run a gravity model of exports to China from 159 partner countries between 1991 and 2008 to test the extent to which bilateral tensions affect trade with autocratic China. In particular, we empirically investigate whether countries that receive the Dalai Lama despite China's opposition experience a significant reduction in their exports to China. In order to account for the potential endogeneity of meetings with the Dalai Lama, the number of Tibet Support Groups and the travel pattern of the Tibetan leader are used as instruments. Our empirical results support the idea that countries officially receiving the Dalai Lama at the highest political level are punished through a reduction of their exports to China. However, this 'Dalai Lama Effect' is only observed for the $\mathrm{Hu}$ Jintao era and not for earlier periods. Furthermore, we find that this effect is mainly driven by reduced exports of machinery and transport equipment and that it disappears two years after a meeting took place.
\end{abstract}

\footnotetext{
Acknowledgements: The authors thank Axel Dreher and Stephan Klasen; Christian Bjørnskov, Ron Davies, Jana Friedrichsen, Samuel Kortum, Christoph Moser, Randall E. Newnham and Bernd Süßmuth; seminar participants at presentations at University of Goettingen, Germany, RWTH Aachen University, Germany, and Princeton University, U.S.A.; and conference participants at the Beyond Basic Questions Workshop 2010 at the University of Aarhus, Denmark, the Silvaplana Workshop of Political Economy 2010 in Pontresina, Switzerland, the Annual Conference of the European Trade Study Group 2010 in Lausanne, Switzerland, the CESifo Workshop on Political Economy, Dresden, Germany, the ISA Annual Convention 2011 in Montreal, Canada, and the Meeting of the European Public Choice Society 2011 in Rennes, France, for valuable comments on earlier drafts. Excellent research assistance was provided by Hendrik van Broekhuizen, Juliane Kästner, Karla Henning and Katharina Richert. Finally, I would like to thank my fellow students and friends at Dauphine University Paris for fruitful discussions of Dalai Lama meetings during coffee breaks.

${ }^{a}$ University of Goettingen, Faculty of Economic Sciences, Platz der Goettinger Sieben 3, D-37073 Goettingen, Germany, e-mail: hhk@,uni-goettingen.de
} 
"We will take corresponding measures to make the relevant countries realise their mistakes."

Zhu Weiqun, executive deputy head of the Communist party's United Front Work Department in an official press statement given on February 2nd, 2010, in the forerun of a potential reception of the Dalai Lama by US President Barack Obama

"There is a Tibetan saying: some wounds in the mouth recover by themselves."

Tendzin Gyatsho, $14^{\text {th }}$ Dalai Lama

\section{V.1 Introduction}

Political determinants of trade have received considerable attention in the literature (e.g, Aidt and Gassebner 2010; Méon and Sekkat 2008; Nitsch and Schumacher 2004). Previous research has shown that diplomatic exchanges between trading partners foster bilateral trade through diplomatic representations (Rose 2007) and state visits (Nitsch 2007). However, the importance of economic diplomacy for trade has been questioned recently (Head and Ries 2010). Furthermore, there is mixed evidence on whether the bilateral political climate plays an important role in trade relationships (e.g., Pollins 1989; Gowa and Mansfield 1993; Davis and Meunier 2011). In this regard, Aidt and Gassebner (2010) theoretically and empirically show that a country's involvement in international trade differs between democracies and autocracies. Since China is neither a democracy nor a free market economy, its administration has a greater capacity to influence trading decisions than a government in a democratic freemarket economy. Such significant scope for government intervention opens up the opportunity to utilize trade flows as a foreign policy tool.

Since the leader of the Tibetan community, the $14^{\text {th }}$ Dalai Lama, travels frequently and over long periods of time, his travel pattern offers a valuable case to empirically test the extent to which political relations matter for trade with China. The Chinese government considers the status of Tibet as an internal affair, in which any outside interference is rejected. ${ }^{172}$ Therefore, official receptions of the Dalai Lama regularly lead to severe diplomatic tensions between China and countries hosting him. In addition to purely diplomatic threats, China warns potential host countries that it will respond to such meetings with a deterioration of their trade relationships. The government's decisiveness on this matter is reflected in instances such as the prominent case of France, where the country was crossed off the travel agenda of two Chinese trade delegations in retaliation to a meeting between French President Nicolas Sarkozy and the Dalai Lama in 2008. In an interview conducted in

\footnotetext{
${ }^{172}$ See Goldstein (1997) for a historical overview on the so-called 'Tibet Question', i.e., the long-lasting conflict over the political status of Tibet.
} 
2007, the Dalai Lama himself acknowledged the unwillingness of state officials to receive him, so as not to jeopardize the intense economic ties that their countries have established with China. ${ }^{173}$

To the best of our knowledge, to date no empirical analysis has been conducted unveiling whether China responds to meetings between its trading partners and the Dalai Lama with any systematic economic punishment. This paper aims to fill this gap. Moreover, results may offer valuable insights into the extent to which political relations matter for trade with autocratic emerging economies. We run a gravity model of exports to China from 159 partner countries between 1991 and 2008 to test whether countries that receive the Dalai Lama are economically punished by the Chinese through a reduction in their exports to China. We also test whether the size of the punishment increases with the rank of the highest official receiving the Tibetan leader and how the effect evolves over time. Furthermore, we provide results when controlling for the potential endogeneity of meetings with the Dalai Lama and exploit disaggregated trade data to deepen our understanding of what we call the 'Dalai Lama Effect.'

Does China carry out its threats to sanction non-compliant trading partners or does the emerging economy simply play on its targets' fears? Our empirical results confirm the existence of a negative effect of Dalai Lama receptions at the highest level on exports to China for the Hu Jintao era (2002-2008). Meetings between a head of state or head of government and the Dalai Lama lead to a reduction of exports to China by 8.1 percent or 16.9 percent, on average, depending on the estimation technique used. This effect is mainly driven by reduced exports of machinery and transport equipment and it disappears in the second year after a meeting took place.

The paper is structured as follows: Section V.2 provides a literature overview to gain insights into how meetings with the Dalai Lama might adversely affect exports to China. Moreover, we illustrate how the bilateral climate between China and its trading partners deteriorates after meetings between foreign officials and the Tibetan leader, and develop our hypotheses. Section V.3 presents the empirical approach, the data used and the empirical results. Finally, Section V.4 summarizes our findings and concludes.

\footnotetext{
173 "Dalai Lama Visit Jeopardizes German Business Interests," Spiegel Online, September 17, 2007, available at: http://www.spiegel.de/international/world/0,1518,506166,00.html (accessed: July 12, 2012).
} 


\section{V.2 The Argument}

\section{V.2.1 Political Determinants of Trade and the 'Dalai Lama Effect'}

Trade ties can be exploited as a foreign policy tool by governments to influence the political decisions of trading partners. Research has been devoted to the analysis of the effectiveness of economic sanctions to induce political compliance (e.g., Eaton and Engers 1992; Hufbauer et al. 2007). Our study, however, investigates whether the threats frequently voiced by China's administration are actually carried out to sanction trading partners in response to an official reception of the Dalai Lama. With the rapidly expanding size of the Chinese economy, the asymmetry of trade dependencies between China and its trading partners is shifting in China's favor. This development enables China to enforce political compliance among its trading partners to an ever increasing extent. ${ }^{174}$ Despite the country's growing scope for economic retaliation, the Chinese administration does not communicate in a transparent manner whether, and to what extent, it actually retaliates after a Dalai Lama reception has taken place. $^{175}$

There is a large literature discussing whether politics matter for bilateral trade relationships. While some studies focus on the link between military conflicts and trade (e.g., Martin et al. 2008; Glick and Taylor 2010), conflicts do not need to be militarized in order to influence trade flows. An anticipated conflict alone might trigger reductions of bilateral trade due to "the threat of future government action to restrict trade" (Morrow et al. 1998: 650). Importantly, trade reductions are not necessarily the result of direct government action to sanction a state. While pure economic theory suggests that economic actors base their trading decisions entirely on intrinsic characteristics of goods and services such as price, quantity and quality, political relations exert additional influence on private actors' decisions. In a public choice model of bilateral trade, Pollins (1989) argues that importing decisions of economic agents are influenced by the place of origin of traded goods and services. Based on security concerns, risk-averse importers reward political friends and punish adversaries in order to minimize commercial risks related to potential trade disruptions. ${ }^{176} \mathrm{~A}$ recent study by Davis and Meunier (2011), however, raises doubts over the link between political tensions and

\footnotetext{
${ }^{174}$ The degree of political compliance that can be induced by the dominant country increases with the asymmetry of the trade interdependency between the two trading partners (Keohane and Nye 1977; Richardson and Kegley 1980).

${ }^{175}$ Eaton and Engers (1999) argue that such incomplete information about the threatening country's resolve, as well as about the target's cost of compliance, induces the former to carry out threats to sanction non-compliant countries.

${ }^{176}$ Using bilateral event data on conflict and cooperation for the period 1955-1978, Pollins' (1989) empirical results support the hypothesis that greater amity between trading partners increases trade, while greater hostility has a trade-reducing effect. In a related contribution, Gowa and Mansfield (1993) show that alliances between trading partners foster bilateral trade.
} 
international trade in the era of globalization. They argue that actors that face sunk costs "lack incentives to link political and economic relations" (p. 1). Analyzing trade patterns of the United States and Japan since the end of the Cold War, the authors do not find that political tensions have an impact on bilateral trade.

Economic diplomacy is one of the channels via which the state of political relations might impact on trade. There is mixed evidence whether diplomatic exchanges among trading partners foster bilateral trade. Analyzing export flows from 22 countries for 2002 and 2003, Rose (2007) finds that the size of a country's diplomatic service has a positive impact on its exports: each additional consulate leads to an increase of exports by about six to ten percent. Most relevant to our study, Nitsch (2007) finds empirical evidence that state and official visits have a trade-increasing effect. Estimating export flows from France, Germany and the United States for the 1948-2003 period, he finds that one additional visit is associated with an increase in exports of between eight and ten percent. While Gil-Pareja et al. (2008) find that Spanish regional trade agencies abroad have a positive impact on exports, Head and Ries (2010) do not find empirical evidence that Canadian trade missions have a trade-promoting effect.

Arguably, the effect of politics on trade might depend on a country's regime type. Political relations clearly influence bilateral trade, with the extent of this influence varying between political regimes "since governments in free market economies still set the rules under which firms import and export, while governments in managed economies directly negotiate the terms of trade" (Morrow et al. 1998: 649). In line with this, Mansfield et al. (2000) discuss regime differences in trade policy that emerge as the chief executive does not rely on the approval of a legislative majority in an autocracy. In a related article, Aidt and Gassebner (2010) theoretically and empirically show that autocratic governments exert more influence on trade flows than democratic administrations, which they explain by a lack of political accountability faced by the executive of an autocratic regime.

Taken together, in the case of China, the significant scope of government influence in the Chinese economy provides the country's political leaders with all the means required to manage trade in such a way that it rewards countries that adhere to China's political preferences and punishes those that do not. Since meetings of foreign officials with the Dalai Lama cause a deterioration of the bilateral political climate and a decrease in bilateral diplomatic exchanges, a meeting may subsequently lead to a systematic reduction of exports to China through government influence. For example, countries receiving the Tibetan leader might be punished directly through a reduction of trade missions and, thus, exports of goods 
typically purchased in the ambit of such missions. Also, tariff and non-tariff barriers might be raised and negotiations regarding free trade agreements might be postponed as a response to receptions of the Dalai Lama by foreign officials.

China's political leadership may be willing to bear the economic and political costs that arise from diverting trade away from countries receiving the Dalai Lama if such 'punishment' increases the likelihood of its political survival. By exerting economic pressure on these countries, the Chinese administration seeks to suppress any notion potentially challenging the territorial integrity of China and intends to strengthen the stability of its Communist regime in the multiethnic country. A punishment is imposed if the benefits from maintaining a reputation for toughness outweigh the costs of punishing a certain nation (Eaton and Engers 1999). China might be interested in carrying out a threat to sanction countries receiving the Dalai Lama in order to signal resolve, with the intention being to deter foreign leaders from future receptions of the Tibetan leader. However, any economic punishment mechanism will only prevail as long as the expected political gains from stabilizing the regime outweigh the losses incurred through trade diversion.

Finally, it should also be mentioned that a trade-deteriorating effect of official Dalai Lama receptions may also operate through consumer behavior. Prior empirical research indicates that bilateral opinions (or the affinity between nations) impact on trade as they shift consumer preferences (Disdier and Mayer 2007; Guiso et al. 2009). ${ }^{177}$ Similarly, the state of bilateral political relations between China and its trading partners might have important repercussions for consumer behavior. Since media information on foreign officials meeting with the Dalai Lama may alter public opinions towards countries receiving the Tibetan leader, Dalai Lama receptions can be expected to affect the demand for consumption goods, in particular certain symbolic goods that are characteristic of the country hosting the Dalai Lama. $^{178}$

\footnotetext{
${ }^{177}$ Using Eurobarometer opinion data on the accession of Central and East European countries to the European Union, Disdier and Mayer (2007) show that 'bilateral affinity' has a trade-increasing effect. In a related study, Guiso et al. (2009) find that trade increases significantly with their measure of bilateral trust obtained from Eurobarometer surveys. Beyond its effect on trade via trust, cultural similarities seem to positively impact on trade volumes via other channels.

${ }^{178}$ For example, the disruption of the Olympic torch relay of the 2008 Beijing Olympic Games through the French capital Paris by pro-Tibet activists caused irritation among the Chinese public and subsequently sparked calls for a consumer boycott against French products.
} 


\section{V.2.2 Hypotheses}

Although the Dalai Lama himself emphasizes the non-political nature of his visits, China perceives any meeting of foreign officials with the Buddhist monk as interference with internal affairs. Therefore, Beijing increasingly exerts economic pressure on foreign governments in order to discourage meetings with the Dalai Lama. As early as 1989, when the Dalai Lama was awarded the Nobel Peace Prize in Oslo, China threatened to cut economic ties with Norway if the Norwegian king or government attended the ceremony. ${ }^{179}$ Similarly, the plans of Italy's Prime Minister Silvio Berlusconi to receive the Dalai Lama in 1995 provoked warnings by his Chinese counterpart that "if this [the Italian] government will adopt a policy that could damage a matter of principle [for China], it may also damage trade relations." ${ }^{180}$ In regards to this, Berlusconi openly admitted that the international community was "caught between the importance of maintaining trade relations and protecting human rights."

Similarly, the reception of the Dalai Lama by Germany's head of government Angela Merkel in the chancellery caused tensions between China and Germany in 2007. Before the meeting, China warned that an encounter would severely damage economic ties. After the reception of the Dalai Lama, China responded by cancelling several bilateral meetings with German officials at various political levels. The chancellor's foreign policy was said to come with a "Merkel cost" for business, according to a press article entitled "The Cost of Being Honest." 182 After the announcement of a meeting between French President Nicolas Sarkozy and the Dalai Lama in 2008, China cancelled the $11^{\text {th }}$ annual EU-China summit as well as talks regarding the finalization of a contract to purchase 150 passenger planes from the Franco-German aerospace company Airbus. ${ }^{183}$ After the meeting with the Dalai Lama, China crossed France off the travel agenda of two Chinese trade delegations. Our first hypothesis thus reads as follows:

Hypothesis 1: There is a trade-deteriorating effect caused by foreign officials receiving the Dalai Lama.

\footnotetext{
179 "China Threatens to Cut Ties with Norway over Nobel Award," The Associated Press, October 19, 1989.

180 "Li Peng "diffida" Berlusconi; Il Cavaliere l'aveva promesso a Pannella. Ma Pechino avverte: "Sono in pericolo le relazioni commerciali," La Stampa, June 15, 1994, p. 4, own translation.

181 ""Italia, grazie per il coraggio"; Il leader tibetano a Palazzo Chigi, per la prima volta un governo italiano sfida il veto cinese," La Stampa, June 18, 1994, p. 7, own translation.

182 "Merkel Foreign Policy Is Bad for Business," Spiegel Online, October 23, 2007, available at: http://www.spiegel.de/international/germany/0,1518,513067,00.html (accessed: July 12, 2012).

183 "China tells France Dalai Lama meeting could hurt trade," AFP, December 4, 2008, available at: http://www.google.com/hostednews/afp/article/ALeqM5ifBAQ8quVIihgqVgOrfEUzkzrHWg (accessed: July 12, 2012).
} 
It seems unlikely that this 'Dalai Lama Effect' - if existent - is independent of the rank or the political importance of the dignitary met. Meetings with higher-ranking politicians pose a greater affront to the Chinese, who may then retaliate through a more pronounced reduction in bilateral trade. For example, during his 1995 visit to the United States, the Dalai Lama was formally received by a minister of the Clinton administration only, but President Bill Clinton dropped in during the talks. A related New York Times article suggested that a better treatment of the Dalai Lama "would [have] cost us [the United States] trade with the Chinese." 184

This example illustrates that some leaders prefer to delegate a meeting with the Dalai Lama to lower-ranking government representatives in the hope of reducing the negative effect that such meetings may have on bilateral relations with China. By employing such a strategy, the government still manages to sedate pro-Tibet lobby groups, human rights organizations and other sympathizers of the Dalai Lama. For example, although Dutch Prime Minister Jan Peter Balkenende feared that a personal meeting with the Dalai Lama would bring "unwarranted risk" to Sino-Dutch relations, some members of parliament and the country's foreign minister met with the Tibetan leader during his visit in $2009 .{ }^{185}$ The Dalai Lama himself remarked that most politicians start avoiding meetings with him after they become minister or president. He concluded that "economic relations with China gain the upper hand." 186 Therefore, we derive the following hypothesis:

Hypothesis 2: The detrimental effect of meetings with the Dalai Lama on exports increases with the rank of the dignitary met.

Facing a trade-off between the economic losses incurred from trade diversion and the political gains from stabilizing the regime, it is in China's best interest that trade ties are restored as quickly as possible to reduce the economic losses that arise from the political bias in its importing decisions. At the same time, China's trading partners are also interested in a restoration of trade ties and are likely to direct diplomatic efforts towards restoring these bilateral relations. For example, nine months after the meeting between French President Nicolas Sarkozy and the Dalai Lama, France declared that it recognized Tibet as an integral

\footnotetext{
184 "On My Mind; If He Can, Can I?" The New York Times, September 15, 1995, available at: http://www.nytimes.com/1995/09/15/opinion/on-my-mind-if-he-can-can-i.html (accessed: July 12, 2012).

${ }_{185}$ "Dalai lama meets foreign minister, but not prime minister," NRC Handelsblad, June 5, 2009, available at: http://www.nrc.nl/international/article2262841.ece/Dalai_lama_meets_foreign_minister,_but_not_prime_ministe r (accessed: July 12, 2012).

${ }^{186}$ „Ich will eine echte Autonomie,“ Cicero Magazin für Politische Kultur, January 1, 2008, own translation, available at: http://www.cicero.de/weltbühne/\%3Fich-will-eine-echte-autonomie\%3F/23497 (accessed: July 12, 2012).
} 
part of the Chinese territory and, consequently, went "back on China's shopping list" as reported by China Daily, which refers to the point when France received the first trade delegation after the tensions. ${ }^{187}$ Along these lines, we expect exports to China to recover after a certain period, i.e., the trade-deteriorating effect of Dalai Lama meetings is only of temporary nature:

\section{Hypothesis 3: The trade-deteriorating 'Dalai Lama Effect' disappears as bilateral} relations between China and partner countries recover.

If purchases were only postponed as a signal of temporary Chinese discontent after a Dalai Lama meeting, a positive 'Dalai Lama Effect' may even develop after a while as Chinese imports make up for past cutbacks. For the interested reader, Appendix V.1 offers a more detailed analysis of available anecdotal evidence on how the bilateral climate between China and its trading partners is influenced by meetings of foreign officials with the Dalai Lama.

\section{V.3 Empirical Analysis}

\section{V.3.1 Data and Method}

We estimate econometrically whether and to what extent the diplomatic tensions caused by official receptions of the Dalai Lama impact negatively on the volume of exports to China. Our econometric model builds on the gravity equation of international trade, the workhorse for statistical analyses of trade flows, which translates Newton's 'Law of Universal Gravitation' to economics. The gravity model assumes that bilateral trade is proportional to the product of the trading partners' economic masses, proxied by GDP, and inversely proportional to the geographic distance between them. In order to control for country heterogeneity, we make use of partner country fixed effects. The effect of bilateral distance and other time-invariant factors, such as being landlocked or contiguous, is thus captured by the partner country fixed effects. ${ }^{188}$ In addition to partner country GDP, we add population size and the bilateral exchange rate to our specification, two frequently used variables in the gravity framework. Moreover, we control for time-specific factors by including dummy variables for each time period. We run the following econometric model:

$$
\text { exports }_{i t}=\beta_{1} \text { dalai }_{i t}+\beta_{2} g d p_{i t}+\beta_{3} \text { pop }_{i t}+\beta_{4} \text { exch }_{i t}+\gamma_{t}+\delta_{i}+\varepsilon_{i t}
$$

\footnotetext{
187 "France goes back on China's shopping list," China Daily, October 29, 2009, available at: http://www.chinadaily.com.cn/china/2009-10/29/content_8865307.htm (accessed: July 12, 2012).

${ }^{188}$ The inclusion of a full set of country-by-time effects is not feasible in our model as we estimate bilateral exports to a single country (China).
} 
where exports ex $_{i t}$ is the $\log$ of exports of partner country $i$ to China at time $t$ in US dollars; $g d p_{i t}$ is the log of the partner country's gross domestic product in US dollars; $p o p_{i t}$ is the log of the partner country's population size; $\operatorname{exch}_{i t}$ is a nominal exchange rate index of the partner country's local currency unit in Yuan; $\gamma_{t}$ and $\delta_{i}$ are time and country fixed effects; and $\varepsilon_{i t}$ is a stochastic error. Trade data are obtained from the United Nations COMTRADE database. Data on GDP, population size and exchange rates are drawn from the World Development Indicators (World Bank 2009).

Our variable of interest is the binary dummy variable dalai $_{i t}$, which takes a value of 1 if the Dalai Lama was received by a dignitary in the partner country in year $t$ or $t-1 .{ }^{189}$ Information on the travel pattern of the Buddhist leader is obtained from the Office of His Holiness the 14th Dalai Lama. ${ }^{190}$ The variable is coded in four different ways: In its narrowest definition, we only include Dalai Lama meetings with heads of state or government. Our second definition extends the first by including all meetings between the Dalai Lama and government members. By also adding encounters with speakers of parliament, the third definition produces a dummy variable that accounts for all meetings between the Dalai Lama and national officials. Finally, we construct a variable that incorporates all meetings of the Tibetan leader that are listed by the Office of the Dalai Lama. This definition also includes regional leaders, party leaders, ex-presidents, ambassadors and scientists, among others. Furthermore, we construct a binary dummy variable that takes a value of 1 if the Dalai Lama travelled to a Chinese trading partner country in a given year, irrespective of whether or not the Tibetan leader met with any dignitary there.

Our dataset covers the period 1991 to 2008. Hypothesizing that a potential 'Dalai Lama Effect' might only be observable in more recent years, in which China's economic and political power grew significantly, we further split our dataset into two periods: 1991-2001 and 2002-2008. Two main arguments motivate 2002 as an appropriate point at which to split our sample. First, the leadership change that occurred when Huo Jintao took power of the Communist Party in 2002 may have reoriented China's foreign policy towards a more assertive advocacy of its global interests. Second, China became a WTO member in December 2001, which is likely to have significantly affected China's trading relations. Next, we extend the analysis by restricting our sample to European partner countries to compare the

\footnotetext{
${ }^{189}$ The reason why we also include the lagged value is because it may take some time for the diplomatic tensions to translate into an actual decrease in trade values. Since trade flows are tied to contracts, the 'Dalai Lama Effect' may only become visible in trade statistics with a certain time delay. However, our results do not hinge on this choice. At a later point, we also show results for different definitions of the variable of interest.

${ }^{190}$ Data are available at http://www.dalailama.com/ (accessed: April 2010). Information was cross-checked and completed with information provided on http://www.buddhismtoday.com (accessed: April 2010).
} 
results from previous estimations with those for this more homogenous set of countries. ${ }^{191}$ Europe has been the most important travel destination of the Dalai Lama. Leaving aside his host country India, of the 266 trips that the he made between 1991 and 2008, 160 of them were to European countries.

All models are estimated using two estimation strategies: First, we run Fixed Effects regressions. Standard errors are adjusted for clustering across partner countries since a modified Wald test indicates groupwise heteroskedasticity. ${ }^{192}$ Second, we rerun all models using Feasible Generalized Least Squares (FGLS) to account for cross-sectional heteroskedasticity across panels and autocorrelation. We employ a common AR(1) term since an estimation with a panel-specific AR(1) term would lead to biased results. As noted by Beck and Katz (1995), in contrast to a panel-specific AR(1) term, the use of the FGLS correction for a common $\mathrm{AR}(1)$ is unlikely to lead to inaccurate estimations of the standard errors.

Panel A of Figure V.1 provides a geographical overview of the Dalai Lama's travel pattern in the 1991-2008 period, whereas Panel B and Panel C show a map indicating where and how many times the Dalai Lama was received by a government official or a political leader, respectively. In many cases, the Dalai Lama was not received by any government member during a visit to a country. Russia and Spain, both of which struggle with independence movements, are examples of this. Appendix V.2 lists all the variables employed in the analysis along with their definitions and sources. Appendix V.3 provides descriptive statistics on all variables. Finally, Appendix V.4 lists all countries included in the analysis.

\footnotetext{
${ }^{191}$ Our definition of European countries excludes members of the Community of Independent States (CIS) to create a rather homogeneous group of countries. However, our results do not hinge on this definition.

192 There is an emerging literature on biased estimates caused by the prevalence of zero trade flows in gravity models. In our sample, however, this issue seems to be negligible since the number of zero export flows is very small in our sample (57 of 2,269 observations, i.e., 2.5 percent).
} 
Figure V.1: Travel pattern of the Dalai Lama (1991-2008)

A. Dalai Lama visits

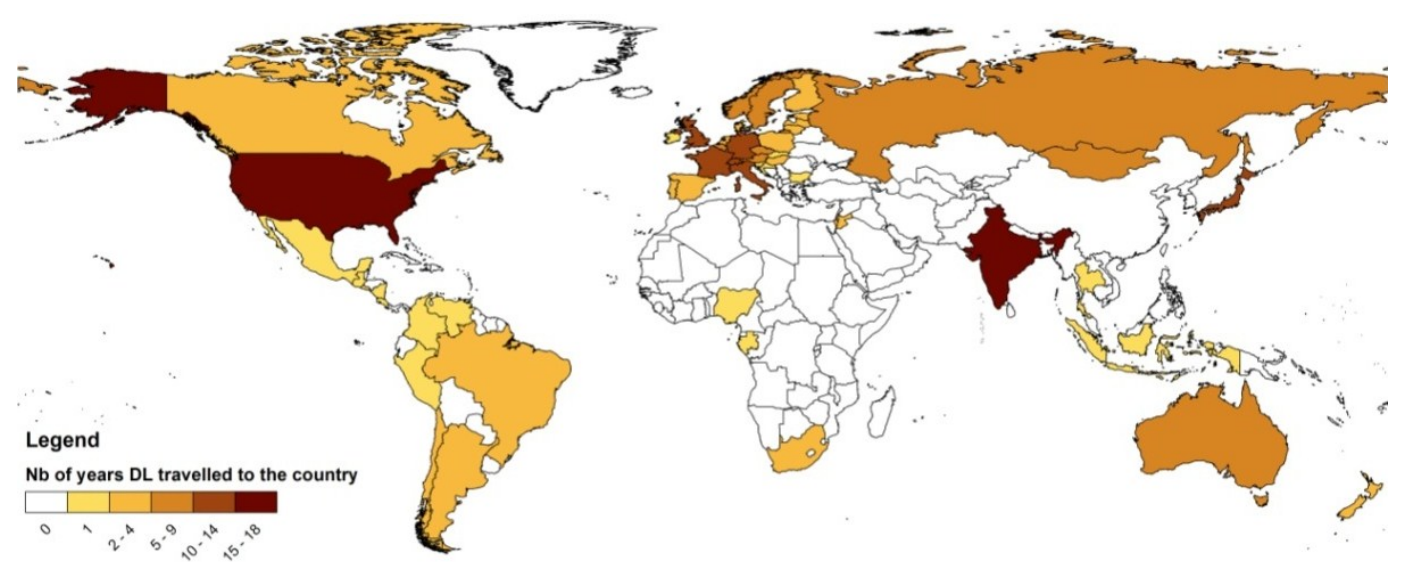

B. Dalai Lama meetings with government members

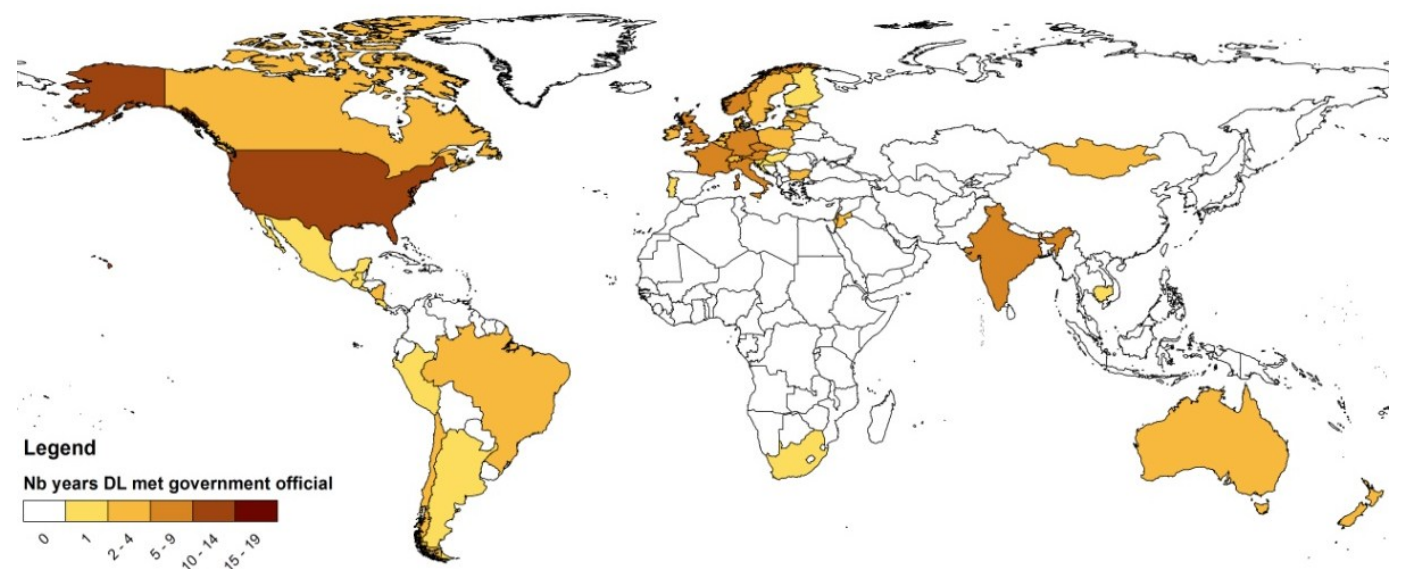

C. Dalai Lama meetings with political leaders

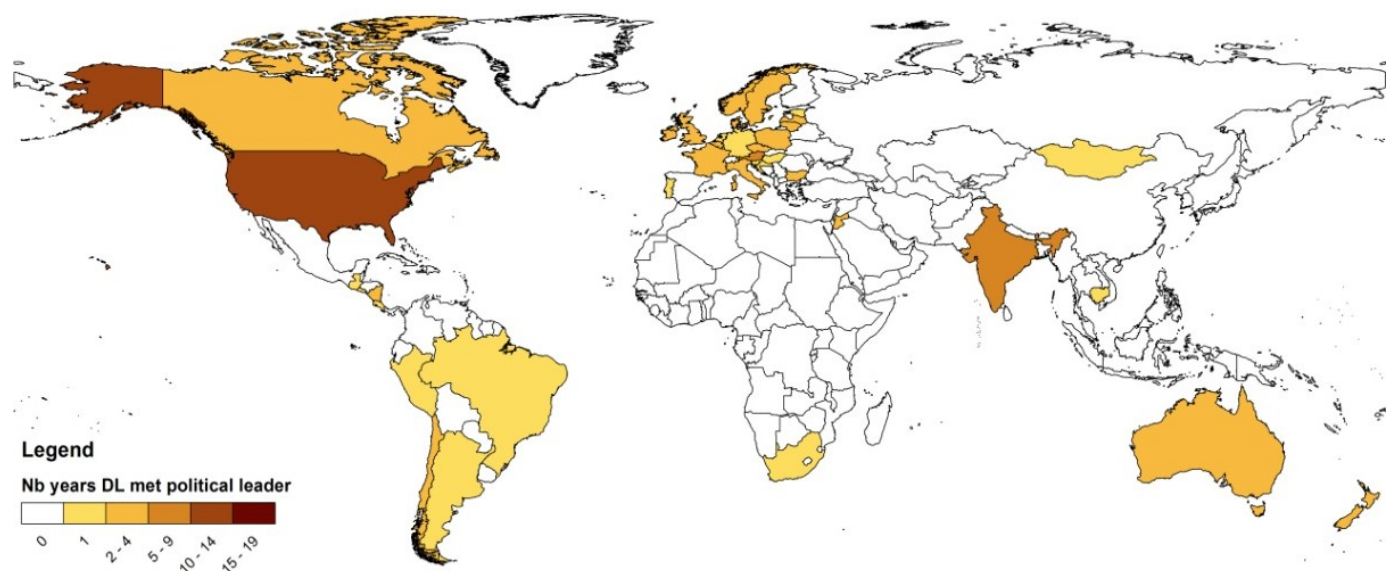


Table V.1.1: Exports to China and Dalai Lama meetings of government members (Hypothesis 1, all countries)

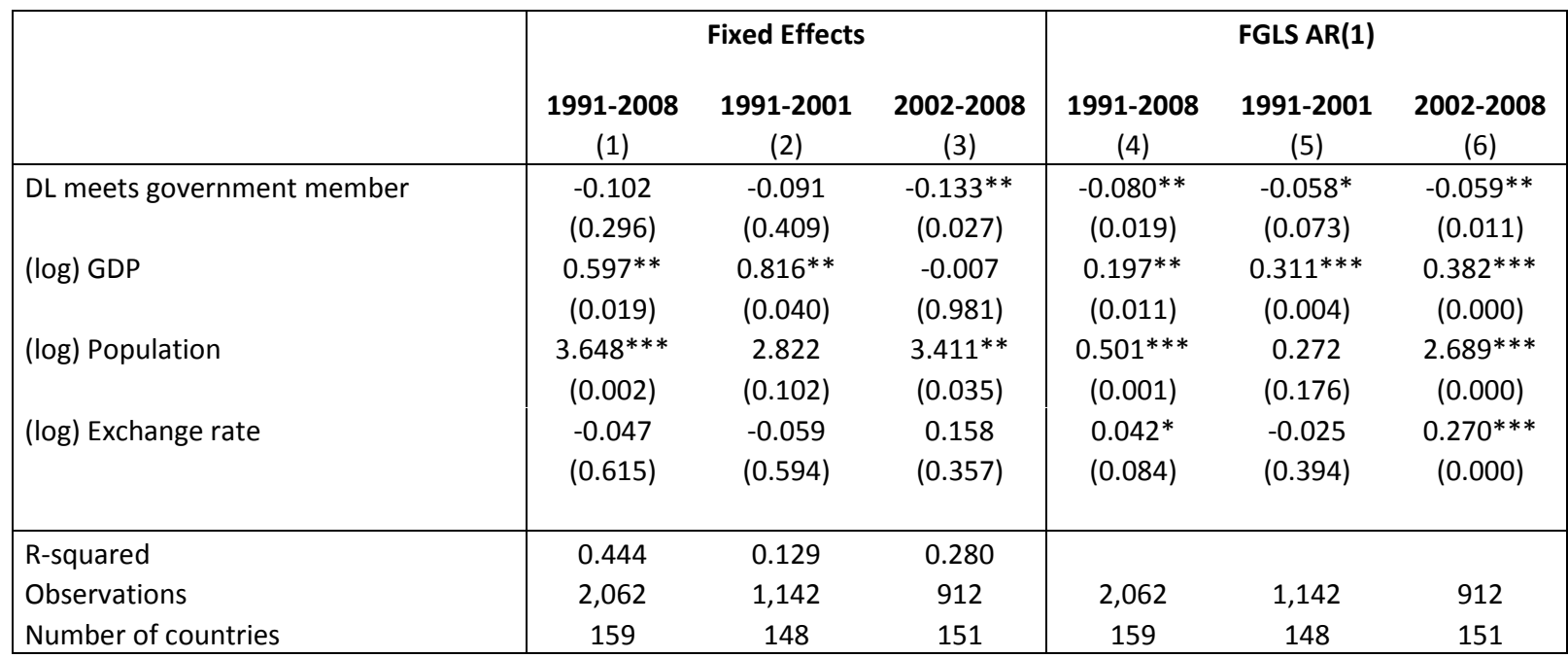

Notes:

- All regressions with country and time fixed effects.

- Robust $p$-values in brackets; * significant at $10 \%$; ${ }^{*}$ significant at $5 \%$; *** significant at $1 \%$

- Standard errors in Fixed Effects regressions are adjusted for clustering across partner countries.

- FGLS regressions are corrected for cross-sectional heteroskedasticity across panels and first order autocorrelation.

\section{V.3.2 Main Results}

Table V.1.1 reports empirical results for the entire sample testing our first hypothesis that meetings between the Dalai Lama and foreign officials have a trade-deteriorating effect. Results are reported for both Fixed Effects and FGLS. Starting with the results from the Fixed Effects regression, we find a negative coefficient on our dummy variable that takes a value of 1 if a government member has received the Tibetan leader in the current or previous year. However, the coefficient is only statistically significant in the second sub-period, which covers the Hu Jintao era (2002-2008). ${ }^{193}$ This result is in line with the increased political and economic power China has acquired in the world in recent years. We find that Dalai Lama meetings with a government member decrease exports to China by 12.5 percent on average. ${ }^{194}$ The coefficient is statistically significant at the five-percent level. This effect is comparable in size to the effect of a state visit in Nitsch (2007) - of course in our case running in the opposite direction. FGLS results confirm the negative effect of Dalai Lama receptions on exports to China in the second sub-period. The expected impact on trade is significant at the five-percent level and, with 5.7 percent, considerably smaller than the effect estimated under

\footnotetext{
${ }^{193}$ As a robustness check, we ran 159 regressions of the same model specification, each time excluding one of China's trading partners. In each case, the coefficient remained negative and statistically significant at conventional levels.

${ }^{194} \exp (-0.133)-1=-12.5 \%$.
} 
Fixed Effects. In addition, the FGLS results unveil a negative effect for the first sub-period as well as for the overall sample. Closer investigation, however, reveals that this finding is driven by product group 9 of the Standard International Trade Classification (SITC), a rather heterogeneous group of products. ${ }^{195}$

In five of the six models in Table V.1.1, the coefficient on GDP is positive and thus in line with the gravity model of trade. It is only in the Fixed Effects model for the second subperiod that we do not find the expected positive coefficient on GDP. However, if we exclude the time dummies, the coefficient becomes positive and significant (results available upon request). Apparently, China's major trading partners were on the same business cycle during the second sub-period. Turning to the effect of the population size of China's trading partners, the corresponding coefficient is positive in all models, but not statistically significant at conventional levels in the first sub-period. This positive coefficient suggests the existence of export-promoting scale effects as a result of a larger population size. The coefficient on the nominal exchange rate is positive in the FGLS estimations for the overall sample and the second sub-period, which shows that a depreciation of the partner country's currency with respect to the Chinese Renminbi has a positive effect on their exports to China. Summing up to this point, empirical results consistently confirm that there is a trade-deteriorating effect caused by foreign officials receiving the Dalai Lama in the 2002- 2008 period (Hu Jintao era). ${ }^{196}$ In what follows, we thus restrict our analysis to this relevant time period.

Column 2 (Fixed Effects) and Column 7 (FGLS) of Table V.1.2 show results for a sample restricted to the more homogenous group of European countries that accounts for roughly half of all Dalai Lama receptions by government members. For the reader's convenience, we show the results of our baseline regressions from Table V.1.1 in column 1 (Fixed Effects) and column 6 (FGLS) of Table V.1.2. We also find evidence in favor of a trade-deteriorating effect in our European subsample. The estimated negative effect of Dalai Lama meetings at government level on European exports to China amounts to 11.5 percent in the Fixed Effects regression and 13.1 percent in the FGLS regression.

\footnotetext{
${ }^{195}$ We ran the same regression at the level of product groups and found results in the first period (1991-2001) to be driven by exports from SITC section 9 ('Commodities and transactions not classified elsewhere in the SITC'). The negative significant effect of Dalai Lama meetings on exports vanishes when we exclude this group from the regression (see Appendix V.5). SITC section 9 consists of 'Postal packages not classified according to kind', 'Special transactions and commodities not classified according to kind', 'Coin (other than gold coin), not being legal tender', and 'Gold, non-monetary (excluding gold ores and concentrates).'

${ }^{196}$ Note that we do not claim that this finding is necessarily due to the personality of Hu Jintao. Alternatively, it may reflect the economic and political rise of China.
} 
Table V.1.2: Exports to China and Dalai Lama meetings of government members (alternative model specifications, 2002-2008)

\begin{tabular}{|c|c|c|c|c|c|c|c|c|c|c|}
\hline & \multicolumn{5}{|c|}{ Fixed Effects } & \multicolumn{5}{|c|}{ FGLS AR(1) } \\
\hline & $\begin{array}{l}\text { World } \\
(1)\end{array}$ & $\begin{array}{c}\text { Europe } \\
\text { (2) }\end{array}$ & $\begin{array}{l}\text { World } \\
\text { (3) }\end{array}$ & $\begin{array}{l}\text { World } \\
\text { (4) }\end{array}$ & $\begin{array}{l}\text { World } \\
\text { (5) }\end{array}$ & $\begin{array}{l}\text { World } \\
(6)\end{array}$ & $\begin{array}{c}\text { Europe } \\
\text { (7) }\end{array}$ & $\begin{array}{c}\text { World } \\
(8)\end{array}$ & $\begin{array}{l}\text { World } \\
\text { (9) }\end{array}$ & $\begin{array}{l}\text { World } \\
(10)\end{array}$ \\
\hline DL meets government member & $\begin{array}{c}-0.133^{* *} \\
(0.027)\end{array}$ & $\begin{array}{l}-0.122^{*} \\
(0.098)\end{array}$ & $\begin{array}{c}-0.136^{* *} \\
(0.023)\end{array}$ & $\begin{array}{c}-0.132^{* *} \\
(0.030)\end{array}$ & $\begin{array}{c}-0.127^{* *} \\
(0.035)\end{array}$ & $\begin{array}{c}-0.059 * * \\
(0.011)\end{array}$ & $\begin{array}{c}-0.140 * * * \\
(0.003)\end{array}$ & $\begin{array}{c}-0.043^{*} \\
(0.084)\end{array}$ & $\begin{array}{c}-0.065 * * \\
(0.011)\end{array}$ & $\begin{array}{c}-0.064 * * * \\
(0.006)\end{array}$ \\
\hline$(\log )$ GDP & $\begin{array}{c}-0.007 \\
(0.981)\end{array}$ & $\begin{array}{c}0.362 \\
(0.587)\end{array}$ & $\begin{array}{l}-0.025 \\
(0.931)\end{array}$ & $\begin{array}{l}-0.147 \\
(0.640)\end{array}$ & $\begin{array}{l}-0.014 \\
(0.962)\end{array}$ & $\begin{array}{c}0.382 * * * \\
(0.000)\end{array}$ & $\begin{array}{c}0.691 * * * \\
(0.000)\end{array}$ & $\begin{array}{c}0.331^{* * *} \\
(0.000)\end{array}$ & $\begin{array}{c}0.240 * * * \\
(0.002)\end{array}$ & $\begin{array}{c}0.359 * * * \\
(0.000)\end{array}$ \\
\hline (log) Population & $\begin{array}{c}3.411^{* *} \\
(0.035)\end{array}$ & $\begin{array}{c}2.208 \\
(0.495)\end{array}$ & $\begin{array}{l}3.250^{*} \\
(0.055)\end{array}$ & $\begin{array}{l}3.075^{*} \\
(0.055)\end{array}$ & $\begin{array}{c}3.325^{* *} \\
(0.032)\end{array}$ & $\begin{array}{c}2.689 * * * \\
(0.000)\end{array}$ & $\begin{array}{c}-0.123 \\
(0.627)\end{array}$ & $\begin{array}{c}3.487 * * * \\
(0.000)\end{array}$ & $\begin{array}{c}2.055^{* * *} \\
(0.000)\end{array}$ & $\begin{array}{c}2.638 * * * \\
(0.000)\end{array}$ \\
\hline (log) Exchange rate & $\begin{array}{c}0.158 \\
(0.357)\end{array}$ & $\begin{array}{l}-1.086 \\
(0.320)\end{array}$ & $\begin{array}{c}0.029 \\
(0.883)\end{array}$ & $\begin{array}{c}0.101 \\
(0.566)\end{array}$ & $\begin{array}{c}0.129 \\
(0.465)\end{array}$ & $\begin{array}{c}0.270^{* * *} \\
(0.000)\end{array}$ & $\begin{array}{l}-0.445 \\
(0.249)\end{array}$ & $\begin{array}{c}0.140^{* *} \\
(0.026)\end{array}$ & $\begin{array}{c}0.186^{* *} \\
(0.015)\end{array}$ & $\begin{array}{c}0.268 * * * \\
(0.000)\end{array}$ \\
\hline Other exports / GDP & & & $\begin{array}{c}2.757 \\
(0.150)\end{array}$ & & & & & $\begin{array}{c}2.098^{* * *} \\
(0.000)\end{array}$ & & \\
\hline (log) Tariff rate & & & & $\begin{array}{l}-0.030 \\
(0.761)\end{array}$ & & & & & $\begin{array}{c}-0.064 * * * \\
(0.000)\end{array}$ & \\
\hline UNGA voting alignment & & & & & $\begin{array}{c}2.020 \\
(0.208)\end{array}$ & & & & & $\begin{array}{c}0.718^{* *} \\
(0.030)\end{array}$ \\
\hline R-squared & 0.280 & 0.502 & 0.294 & 0.296 & 0.283 & & & & & \\
\hline Observations & 912 & 247 & 906 & 887 & 912 & 912 & 247 & 906 & 887 & 912 \\
\hline Number of countries & 151 & 36 & 150 & 148 & 151 & 151 & 36 & 150 & 148 & 151 \\
\hline
\end{tabular}

Notes:

- All regressions with country and time fixed effects.

- Robust p-values in brackets; * significant at $10 \%$; ** significant at $5 \%$; *** significant at $1 \%$

- Standard errors in Fixed Effects regressions are adjusted for clustering across partner countries.

- FGLS regressions are corrected for cross-sectional heteroskedasticity across panels and first order autocorrelation. 
Next, we include three additional control variables to our baseline regression to further test the robustness of our results. In a first step, we assess the effect of partner countries' export orientation on exports to China. While time-invariant country characteristics are captured by the country fixed effects, changes in export orientation across time are not accounted for in our baseline model. We hypothesize that exports to China grow over time when a partner country's export orientation increases. The export orientation of China's trading partners is measured as the total exports to all countries except China as a share of GDP. Trade data are again retrieved from UN COMTRADE and GDP data are obtained from the World Development Indicators (World Bank 2009). The effect of export orientation is not statistically significant at conventional levels in the Fixed Effects regression (column 3). However, in the FGLS estimation, the coefficient is significant at the one-percent level and correctly signed (column 8). Independent of the estimation strategy, the coefficient on our Dalai Lama variable is stable and remains significant at conventional levels.

As a second control variable, we add the log of the trade-weighted bilateral tariff rate to our baseline model in order to account for tariff barriers to trade between each country and China. ${ }^{197}$ Tariff data are taken from the UNCTAD-TRAINS database. In both regression frameworks, the coefficient on the dummy variable for the reception of the Dalai Lama by a government member is robust to the inclusion of tariff rates. While the tariff coefficient is negative, in line with theory, it is only statistically significant at conventional levels in the FGLS estimation. The addition of tariff rates slightly increases the absolute size of the coefficient on the Dalai Lama variable in the FGLS framework (column 9) and leaves the coefficient in the Fixed Effects setting virtually unchanged (column 4). In both cases, the coefficient remains significant at the five-percent level. This finding can be taken as an indication that the trade-reducing 'Dalai Lama Effect' does not operate via an increase of tariff barriers.

The third additional control variable aims to account for the effect of political friendship or hostility on trade with China. A frequently used measure for the extent of bilateral friendship is the degree to which countries vote in line with each other in the United Nations General Assembly (UNGA) (e.g., Richardson and Kegley 1980; Barro and Lee 2005; Dreher and Jensen 2007; Kastner 2007; Dreher and Gassebner 2008). Although this measure has its drawbacks, it also has the advantage that it is available for virtually every country in the world over a long time period. We construct a variable for capturing the voting

\footnotetext{
${ }^{197}$ Arguably, China's import tariffs themselves may be affected by diplomatic tensions caused by meetings of foreign officials with the Tibetan leader. Hence, the estimated coefficient on the Dalai Lama variable has to be attributed to channels other than the bilateral tariff rate.
} 
coincidence at the assembly using the same method as Richardson and Kegley (1980) and Thacker (1999). ${ }^{198}$ Therefore, our indicator of friendship with China is the number of times that a trading partner had the same voting behavior as China as a fraction of all voting instances. Votes in agreement are coded as 1 , votes in disagreement as 0 and abstentions and absences as 0.5 . The regressions in columns 5 and 10 in Table V.1.2 show that greater amity with China seems to promote trade, but that the effect is only statistically significant at conventional levels in the FGLS regression and has a negligible impact on the size of the Dalai Lama dummy variable.

In order to test Hypothesis 2, we run a modified version of the basic regression for the relevant time period (2002-2008), accounting for the different ranks of dignitaries who met with the Dalai Lama. To this end, we include four dummy variables covering an increasingly broader group of people. Furthermore, we include a dummy variable, which takes a value of 1 if the Dalai Lama travelled to the country - regardless of whether he was received by any dignitary. All dummy variables take a value of 1 if an event was registered in the current or previous year.

The regressions in columns 1 to 5 (Fixed Effects) and 10 to 14 (FGLS) in Table V.2 confirm our hypothesis that the trade deteriorations caused by Dalai Lama meetings are associated with the rank of the dignitary that receives the Tibetan leader. We find that meetings between the Dalai Lama and political leaders, defined as head of state or government, have the greatest significant negative impact on exports to China. Dalai Lama meetings at the highest political level reduce exports to China by 16.9 percent according to the Fixed Effects results and by 8.1 percent in our FGLS regression framework. Smaller, but still significant, effects are found when the definition of our variable of interest is extended to include government members and national officials, respectively. The effect is again smaller for the group including all dignitaries listed by the Office of the Dalai Lama. The corresponding coefficient is only significant at the ten-percent level in the FGLS regression and even becomes statistically insignificant at conventional levels in the Fixed Effects regression.

\footnotetext{
${ }^{198}$ The UNGA roll-call voting data are made available by Voeten and Merdzanovic (2009). We thank Axel Dreher for providing us with a Stata do-file to process the data.
} 
Table V.2: Exports to China and Dalai Lama meetings at various political levels (Hypothesis 2, all countries, 2002-2008)

\begin{tabular}{|c|c|c|c|c|c|c|c|c|c|c|c|c|c|c|c|c|c|c|}
\hline & \multicolumn{9}{|c|}{ Fixed Effects } & \multicolumn{9}{|c|}{ FGLS AR(1) } \\
\hline & (1) & (2) & (3) & (4) & (5) & $(6)$ & (7) & (8) & (9) & $(10)$ & (11) & (12) & (13) & (14) & (15) & (16) & (17) & $(18)$ \\
\hline political leader & $\begin{array}{c}-0.185^{* *} \\
(0.011)\end{array}$ & & & & & $\begin{array}{l}-0.193^{*} \\
(0.068)\end{array}$ & $\begin{array}{l}-0.177^{*} \\
(0.083)\end{array}$ & $\begin{array}{c}-0.212^{* *} \\
(0.041)\end{array}$ & $\begin{array}{c}-0.207^{* *} \\
(0.017)\end{array}$ & $\begin{array}{c}-0.084^{* * *} \\
(0.002)\end{array}$ & & & & & $\begin{array}{c}-0.082^{* *} \\
(0.029)\end{array}$ & $\begin{array}{c}-0.069 * * \\
(0.040)\end{array}$ & $\begin{array}{c}-0.079^{* *} \\
(0.017)\end{array}$ & $\begin{array}{c}-0.082^{* * *} \\
(0.006)\end{array}$ \\
\hline$\sum_{\substack{\infty \\
0}}^{E}$ government member & & $\begin{array}{c}-0.133^{* *} \\
(0.027)\end{array}$ & & & & $\begin{array}{c}0.010 \\
(0.906)\end{array}$ & & & & & $\begin{array}{c}-0.059 * * \\
(0.011)\end{array}$ & & & & $\begin{array}{l}-0.003 \\
(0.927)\end{array}$ & & & \\
\hline 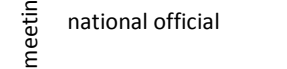 & & & $\begin{array}{c}-0.128^{* *} \\
(0.029)\end{array}$ & & & & $\begin{array}{l}-0.009 \\
(0.904)\end{array}$ & & & & & $\begin{array}{c}-0.057^{* *} \\
(0.013)\end{array}$ & & & & $\begin{array}{l}-0.019 \\
(0.476)\end{array}$ & & \\
\hline$\vec{\Delta} \quad$ all dignitaries & & & & $\begin{array}{l}-0.084 \\
(0.176)\end{array}$ & & & & $\begin{array}{c}0.032 \\
(0.710)\end{array}$ & & & & & $\begin{array}{c}-0.044^{* *} \\
(0.033)\end{array}$ & & & & $\begin{array}{l}-0.009 \\
(0.708)\end{array}$ & \\
\hline DL visits country & & & & & $\begin{array}{l}-0.058 \\
(0.311)\end{array}$ & & & & $\begin{array}{c}0.033 \\
(0.617)\end{array}$ & & & & & $\begin{array}{l}-0.039^{*} \\
(0.062)\end{array}$ & & & & $\begin{array}{l}-0.013 \\
(0.559)\end{array}$ \\
\hline (log) GDP & $\begin{array}{l}-0.031 \\
(0.920)\end{array}$ & $\begin{array}{l}-0.007 \\
(0.981)\end{array}$ & $\begin{array}{l}-0.006 \\
(0.984)\end{array}$ & $\begin{array}{l}-0.004 \\
(0.991)\end{array}$ & $\begin{array}{c}0.009 \\
(0.976)\end{array}$ & $\begin{array}{l}-0.032 \\
(0.919)\end{array}$ & $\begin{array}{l}-0.030 \\
(0.922)\end{array}$ & $\begin{array}{l}-0.032 \\
(0.917)\end{array}$ & $\begin{array}{l}-0.036 \\
(0.908)\end{array}$ & $\begin{array}{c}0.351^{* * *} \\
(0.000)\end{array}$ & $\begin{array}{c}0.382 * * * \\
(0.000)\end{array}$ & $\begin{array}{c}0.386 * * * \\
(0.000)\end{array}$ & $\begin{array}{c}0.388^{* * *} \\
(0.000)\end{array}$ & $\begin{array}{c}0.402 * * * \\
(0.000)\end{array}$ & $\begin{array}{c}0.352^{* * *} \\
(0.000)\end{array}$ & $\begin{array}{c}0.357^{* * *} \\
(0.000)\end{array}$ & $\begin{array}{c}0.353^{* * *} \\
(0.000)\end{array}$ & $\begin{array}{c}0.355 * * * \\
(0.000)\end{array}$ \\
\hline (log) Population & $\begin{array}{l}3.433^{* *} \\
(0.033)\end{array}$ & $\begin{array}{l}3.411^{* *} \\
(0.035)\end{array}$ & $\begin{array}{l}3.403^{* *} \\
(0.035)\end{array}$ & $\begin{array}{l}3.396 * * \\
(0.036)\end{array}$ & $\begin{array}{l}3.369 * * \\
(0.037)\end{array}$ & $\begin{array}{l}3.432^{* *} \\
(0.033)\end{array}$ & $\begin{array}{l}3.434^{* *} \\
(0.033)\end{array}$ & $\begin{array}{l}3.421 * * \\
(0.033)\end{array}$ & $\begin{array}{l}3.421 * * \\
(0.033)\end{array}$ & $\begin{array}{c}2.666 * * * \\
(0.000)\end{array}$ & $\begin{array}{c}2.689 * * * \\
(0.000)\end{array}$ & $\begin{array}{c}2.669 * * * \\
(0.000)\end{array}$ & $\begin{array}{c}2.676 * * * \\
(0.000)\end{array}$ & $\begin{array}{c}2.657^{* * *} \\
(0.000)\end{array}$ & $\begin{array}{c}2.667 * * * \\
(0.000)\end{array}$ & $\begin{array}{c}2.659^{* * *} \\
(0.000)\end{array}$ & $\begin{array}{c}2.687^{* * *} \\
(0.000)\end{array}$ & $\begin{array}{c}2.685^{* * *} \\
(0.000)\end{array}$ \\
\hline (log) Exchange rate & $\begin{array}{c}0.151 \\
(0.380)\end{array}$ & $\begin{array}{c}0.158 \\
(0.357)\end{array}$ & $\begin{array}{c}0.157 \\
(0.359)\end{array}$ & $\begin{array}{c}0.158 \\
(0.358)\end{array}$ & $\begin{array}{c}0.165 \\
(0.337)\end{array}$ & $\begin{array}{c}0.150 \\
(0.380)\end{array}$ & $\begin{array}{c}0.151 \\
(0.380)\end{array}$ & $\begin{array}{c}0.151 \\
(0.379)\end{array}$ & $\begin{array}{c}0.149 \\
(0.386)\end{array}$ & $\begin{array}{c}0.268 * * * \\
(0.000)\end{array}$ & $\begin{array}{c}0.270^{* * *} \\
(0.000)\end{array}$ & $\begin{array}{c}0.269 * * * \\
(0.000)\end{array}$ & $\begin{array}{c}0.269 * * * \\
(0.000)\end{array}$ & $\begin{array}{c}0.281^{* * *} \\
(0.000)\end{array}$ & $\begin{array}{c}0.268 * * * \\
(0.000)\end{array}$ & $\begin{array}{c}0.265 * * * \\
(0.000)\end{array}$ & $\begin{array}{c}0.266 * * * \\
(0.000)\end{array}$ & $\begin{array}{c}0.269 * * * \\
(0.000)\end{array}$ \\
\hline R-squared & 0.280 & 0.280 & 0.280 & 0.279 & 0.279 & 0.280 & 0.280 & 0.280 & 0.280 & & & & & & & & & \\
\hline Observations & 912 & 912 & 912 & 912 & 912 & 912 & 912 & 912 & 912 & 912 & 912 & 912 & 912 & 912 & 912 & 912 & 912 & 912 \\
\hline Number of countries & 151 & 151 & 151 & 151 & 151 & 151 & 151 & 151 & 151 & 151 & 151 & 151 & 151 & 151 & 151 & 151 & 151 & 151 \\
\hline
\end{tabular}

Notes:

- All regressions with country and time fixed effects.
- Robust p-values in brackets; $*$ significant at $10 \% ; * *$ significant at $5 \% ; * * *$ significant at $1 \%$

- Standard errors in Fixed Effects regressions are adjusted for clustering across partner countries.

- FGLS regressions are corrected for cross-sectional heteroskedasticity across panels and first order autocorrelation. 
Since meetings with political leaders seem to have the highest impact, we test whether additional effects occur when the Dalai Lama is also received by lower ranked dignitaries. As shown in columns 6 to 8 (Fixed Effects) and columns 15 to 17 (FGLS), there is no additional effect for lower-ranked dignitaries meeting the Dalai Lama in addition to the effect found for political leaders. When controlling for receptions at the highest political level, each coefficient for meetings at a lower level is not statistically significant at conventional levels. ${ }^{199}$ The coefficient on the dummy indicating the presence of the Dalai Lama in the country - irrespective of whether he was received by a dignitary - is not statistically significant at conventional levels in the Fixed Effects (column 5) and loses its significance in the FGLS regression when controlling for whether an encounter with the Tibetan leader took place (column 18). This underlines that the effect is only caused by a meeting with a foreign leader, whereas the mere presence of the Dalai Lama in the respective country has no effect.

Having shown that the trade-deteriorating effect is driven by meetings with heads of state or government, we focus on these meetings in the following regression analyses. Table V.3 shows how the 'Dalai Lama Effect' evolves over time in a Fixed Effects and in an FGLS regression framework (Hypothesis 3). In order to compare the effect of Dalai Lama meetings over time, we include separate dummy variables that take a value of 1 if the Tibetan leader is received by a political leader in the next year, current year, previous year, two years ago and three years ago, respectively. Starting with the worldwide sample, we find statistically significant negative coefficients on the Dalai Lama dummies for the current and previous years. Both coefficients are similar in size and a t-test does not reject the null hypothesis that the two coefficients are equal in size at the ten-percent level. All other coefficients on the Dalai Lama variables are not statistically significant at conventional levels. We thus conclude that the trade-reducing impact of Dalai Lama meetings disappears after two years, which is in line with Hypothesis 3. Turning to our smaller European sample, we find a similar pattern. The coefficient for Dalai Lama meetings in the current year is statistically significant at the five-percent level, but the coefficient on the dummy for a Dalai Lama reception in the previous year loses significance in the Fixed Effects regression, while retaining significance in the FGLS estimation.

\footnotetext{
${ }^{199}$ When restricting our sample to European countries, a similar pattern emerges. Once more, we find the largest effect for Dalai Lama meetings with political leaders. Again, the coefficients for Dalai Lama meetings with lower-ranked dignitaries are substantially smaller. In the Fixed Effects regression, however, the size of the coefficient for a Dalai Lama meeting with any dignitary outperforms the size of the corresponding dummy restricted to government members or national officials. See Appendix V.6.
} 
Table V.3: Exports to China and Dalai Lama meetings of political leaders

(Hypothesis 3, time-event specification, 2002-2008)

\begin{tabular}{|c|c|c|c|c|}
\hline & \multicolumn{2}{|c|}{ Fixed Effects } & \multicolumn{2}{|c|}{ FGLS AR(1) } \\
\hline & $\begin{array}{l}\text { World } \\
(1) \\
\end{array}$ & $\begin{array}{c}\text { Europe } \\
(2)\end{array}$ & $\begin{array}{l}\text { World } \\
(3)\end{array}$ & $\begin{array}{c}\text { Europe } \\
(4)\end{array}$ \\
\hline DL met political leader in $t+1$ & $\begin{array}{l}-0.113 \\
(0.203)\end{array}$ & $\begin{array}{l}-0.092 \\
(0.276)\end{array}$ & $\begin{array}{l}-0.044 \\
(0.155)\end{array}$ & $\begin{array}{l}-0.037 \\
(0.629)\end{array}$ \\
\hline DL met political leader in $\mathrm{t}$ & $\begin{array}{c}-0.189 * * \\
(0.011)\end{array}$ & $\begin{array}{l}-0.183^{*} \\
(0.065)\end{array}$ & $\begin{array}{c}-0.105^{* * *} \\
(0.001)\end{array}$ & $\begin{array}{l}-0.135^{*} \\
(0.064)\end{array}$ \\
\hline DL met political leader in $\mathrm{t}-1$ & $\begin{array}{c}-0.192 * * \\
(0.031)\end{array}$ & $\begin{array}{l}-0.150 \\
(0.300)\end{array}$ & $\begin{array}{c}-0.087 * * \\
(0.023)\end{array}$ & $\begin{array}{c}-0.318 * * * \\
(0.000)\end{array}$ \\
\hline DL met political leader in t-2 & $\begin{array}{c}0.061 \\
(0.441)\end{array}$ & $\begin{array}{c}0.191 \\
(0.203)\end{array}$ & $\begin{array}{c}0.009 \\
(0.827)\end{array}$ & $\begin{array}{c}0.103 \\
(0.137)\end{array}$ \\
\hline DL met political leader in t-3 & $\begin{array}{l}-0.019 \\
(0.778)\end{array}$ & $\begin{array}{c}0.021 \\
(0.854)\end{array}$ & $\begin{array}{l}-0.016 \\
(0.611)\end{array}$ & $\begin{array}{l}-0.047 \\
(0.433)\end{array}$ \\
\hline$(\log )$ GDP & $\begin{array}{l}-0.033 \\
(0.914)\end{array}$ & $\begin{array}{c}0.303 \\
(0.667)\end{array}$ & $\begin{array}{c}0.341 * * * \\
(0.000)\end{array}$ & $\begin{array}{c}0.559 * * * \\
(0.001)\end{array}$ \\
\hline (log) Population & $\begin{array}{c}3.368 * * \\
(0.042)\end{array}$ & $\begin{array}{c}1.864 \\
(0.547)\end{array}$ & $\begin{array}{c}2.577 * * * \\
(0.000)\end{array}$ & $\begin{array}{c}0.074 \\
(0.782)\end{array}$ \\
\hline (log) Exchange rate & $\begin{array}{c}0.145 \\
(0.399)\end{array}$ & $\begin{array}{l}-1.127 \\
(0.304)\end{array}$ & $\begin{array}{c}0.266 * * * \\
(0.000)\end{array}$ & $\begin{array}{l}-0.435 \\
(0.259)\end{array}$ \\
\hline R-squared & 0.281 & 0.507 & & \\
\hline Observations & 912 & 247 & 912 & 247 \\
\hline Number of countries & 151 & 36 & 151 & 36 \\
\hline
\end{tabular}

Notes:

- All regressions with country and time fixed effects.

- Robust $p$-values in brackets; * significant at $10 \% ;{ }^{* *}$ significant at $5 \% ; * * *$ significant at $1 \%$

- Standard errors in Fixed Effects regressions are adjusted for clustering across partner countries.

- FGLS regressions are corrected for cross-sectional heteroskedasticity across panels and first order autocorrelation.

\section{V.3.3 Endogeneity Concerns}

In analogy to the reverse causal relationship between trade and military conflicts (e.g., Glick and Taylor 2010), the precise nature of the causal link between diplomatic conflicts and trade is unclear. On the one hand, we hypothesize that receiving the Dalai Lama leads to reduced exports to China. On the other hand, stronger commercial ties might also make it less likely that a political leader invites the Dalai Lama in the first place. There are good reasons to believe that a country is more reluctant to receive the Buddhist leader if it has a wellestablished trade relationship with China, which it does not want to jeopardize.

We make use of a Two-Stage-Least-Squares (2SLS) model to account for the potential endogeneity of Dalai Lama meetings. The crucial point in a 2SLS regression framework is the 
choice of an appropriate instrument, which sufficiently explains Dalai Lama meetings with political leaders, but is uncorrelated with the error term in the second stage regression. According to the exclusion restriction, an appropriate instrument should not affect exports to China through channels other than the potentially endogenous variable, i.e., the dummy for Dalai Lama receptions. In other words, an appropriate instrument should have no direct influence on exports to China. In order to find suitable instruments, one needs to gain a better understanding of the Dalai Lama's travel behavior. According to the Dalai Lama himself, most visits abroad follow from invitations from Tibetan and Buddhist communities (Gyatso 1990). During his stays abroad, the Dalai Lama gives lectures and religious speeches and meets local Buddhist communities. While most meetings with lower-ranked dignitaries are scheduled long in advance, it is usually unclear some weeks or even days before the Dalai Lama embarks on a journey, whether he will be received by high-ranked officials. ${ }^{200}$ In some cases, the head of state or government just "drops in" while the Dalai Lama is meeting with a lower-ranked government member. The political leader's decision process of whether or not to meet with the Dalai Lama is usually accompanied by discussions in the media and demands from pro-Tibet lobby groups.

We employ the following three instruments in an attempt to control for endogeneity. The first instrument is the binary dummy variable discussed above, which takes a value of 1 if the Dalai Lama travelled to a partner country in a given year. The underlying idea here is that the Tibetan leader is more likely to meet with officials in those years in which he travels to their respective partner countries. Most meetings with foreign dignitaries take place in the dignitary's own country, although meetings have also occurred in third-party countries such as the 2008 meeting between French President Nicolas Sarkozy and the Dalai Lama in Poland. As outlined above, the Dalai Lama usually fixes his travel itinerary based on invitations from Buddhist or Tibetan communities to give teachings and public talks. Since his travel plans do generally not follow invitations from political leaders, we assume that our instrument is exogenous. Our second instrument is the number of days that the Dalai Lama spent in a partner country. We hypothesize that the longer the duration of the Dalai Lama's stay in a country, the greater will be the public awareness of his presence in the country, the

\footnotetext{
${ }^{200}$ For example, shortly before the Dalai Lama's arrival in Italy in 2003, Prime Minister Silvio Berlusconi left it open whether he would accept the invitation of the Italian Parliamentary Group for Tibet to meet with the Tibetan leader. Finally, he refused the invitation. In the forerun of a trip to Mongolia in 2006, it remained unclear whether or not the Dalai Lama would be received by President Nambaryn Enkhbayar during his stay in the country. In the end, no meeting was scheduled. In a similar manner, the encounter of the Austrian chancellor Alfred Gusenbauer in 2007 was made public only one day before the actual meeting took place.
} 
more intense will be the public discussion regarding his potential official reception, and the greater will be the pressure on political leaders to receive him.

As a third instrument, we use the number of Tibet Support Groups (TSG) in a trading partner country. TSGs are non-governmental organizations (NGOs) formed voluntarily and maintained by private individuals with the aim of rallying regional, national, or international awareness of and support for the Tibet issue. TSGs work independently from the Central Tibetan Administration and act as non-profit organizations that are open to any individuals willing to join the pro-Tibet movement. The larger the pro-Tibetan network in a partner country, the more inclined the political leader might be to receive the Dalai Lama in order to satisfy the demands of these pressure groups. Moreover, the number of TSGs may serve as a proxy for the extent to which a country's population is interested in the Tibet issue.

The dataset on the number of TSGs was established based on a list of pro-Tibet movements that was released by the Central Tibetan Administration in exile. ${ }^{201}$ To account for the evolution of the pro-Tibet movement over time, we construct a time series by collecting information on the year of foundation of each TSG. In order to get information for those TSGs that do not provide this information on their homepage, we contacted them via email and fax. Using this approach, we obtained information on the founding year for about 53.8 percent of all listed 295 organizations. Unfortunately, insufficient information is available on the number of members of each group so that we cannot account for differences in size between Tibet NGOs. With 31 recorded organizations, most TSGs in our sample are located in France, followed by the United States with 20 Tibet NGOs.

The first stage results of our 2SLS estimation approach (see Appendix V.7) are in line with our expectations: the likelihood that a political leader meets the Dalai Lama increases when the Tibetan head of government in exile travels to the leader's country, increases with the duration of the visit and also increases with the number of Tibet Support Groups in the partner country. The Angrist-Pischke test of excluded instruments displayed in Table V.4 underlines the relevance of the instruments selected in the first stage. The null hypothesis of the test is rejected in all specifications. Only in the smaller European sample does the F statistic fall below the critical rule of thumb value of 10 (Staiger and Stock 1997).

\footnotetext{
${ }^{201}$ The list is available at http://www.tibet.net (accessed: June 2009).
} 
Table V.4: Exports to China and Dalai Lama meetings of political leaders (endogeneity, 2002-2008)

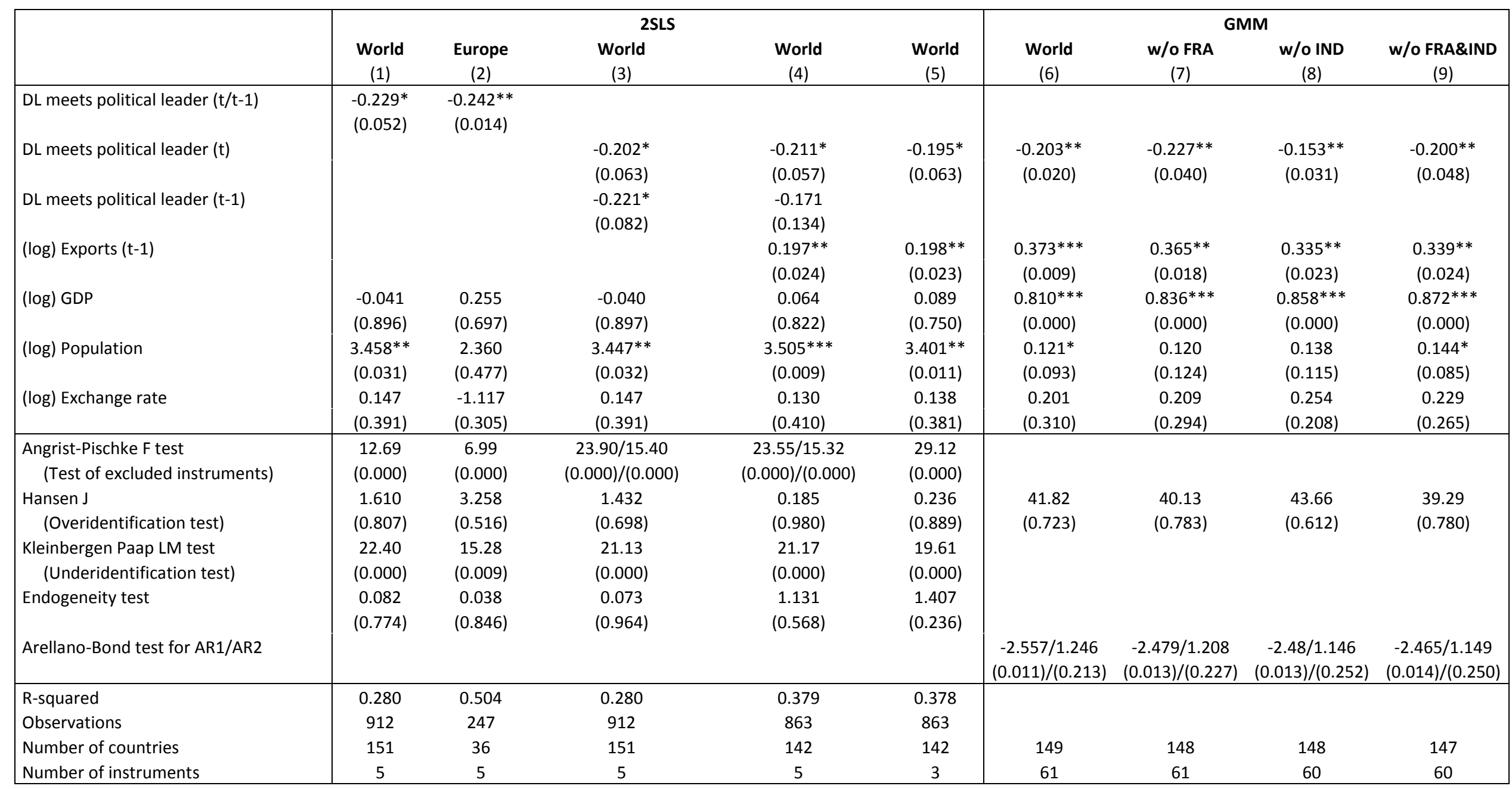

Notes: - ${ }^{*}$ significant at $10 \% ; * *$ significant at $5 \% ; * * *$ significant at $1 \%$

- 2SLS with clustered standard errors, country and time fixed effects. / System GMM with time dummies, Windmeijer finite sample correction and external instruments.

- Instruments (1)-(4): Number of Tibet Support Groups (lagged), Dalai Lama visit dummy (current and lagged) and Duration of Dalai Lama visit (in days, current and lagged).

- Instruments (5)-(9): Number of Tibet Support Groups (lagged), Dalai Lama visit dummy (current) and Duration of Dalai Lama visit (in days, current). 
The regressions in columns 1 to 5 of Table V.4 show the results for the second stage regressions of our 2SLS approach. ${ }^{202}$ Again, we present results for the relevant time period (2002-2008). Starting with the worldwide sample (column 1), the coefficient on the dummy variable indicating whether the Dalai Lama was received by a head of state or head of government in the current or previous year is negative and statistically significant, i.e., we still find that Dalai Lama meetings have a trade-deteriorating effect when controlling for potential endogeneity. The coefficient is somewhat larger than in the Fixed Effects regression (Table V.2, column 1). For the European subsample, displayed in column 2 of Table V.4, the Dalai Lama coefficient is significant at the five-percent level.

In order to shed light on the timing of the 'Dalai Lama Effect', we include two dummy variables, the first taking a value of 1 if a Dalai Lama meeting took place in the current period and the second taking a value of 1 if the Dalai Lama was received in the previous period. The results in column 3 of Table V.4 show that the coefficients for both dummy variables have the expected negative signs, are of similar size, and are significant at the ten-percent level. Tests for overidentification (Hansen $\mathrm{J}$ ) and underidentification (Kleinbergen Paap LM test) also confirm the validity of our instruments. Even though the 2SLS regression results support our previous findings, note that the $\mathrm{C}$ test for endogeneity does not reject the null hypothesis of exogeneity of the Dalai Lama dummy. ${ }^{203}$ Consequently, the Fixed Effects estimates discussed in Section V.4.2 are more efficient than the 2SLS estimates.

Next, we tackle a further endogeneity issue, which stems from the potential endogeneity of lagged export values. Since trade relationships are persistent over time, we include lagged exports as an additional explanatory variable in order to explain current exports to China as a function of past export values. Established commercial ties and signed contracts mean that exports evolve with inertia. It is possible that the lagged exports variable is endogenous in a short panel, which could lead to biased results (Nickell 1981). Unobserved panel level effects may be correlated with lagged exports, thereby making the 2SLS estimator inconsistent. In order to address this issue, we apply the two-step System GMM estimator, which incorporates equations in first differences and in levels (Arellano and Bover 1995; Blundell and Bond 1998). Since we have a small $\mathrm{T}$ in our setting $(\mathrm{T}=7)$, we employ the Windmeijer correction to obtain standard errors which are larger and more reliable in finite samples (Windmeijer 2005). Meetings with the Dalai Lama and lagged exports are treated as

\footnotetext{
${ }^{202}$ All results are based on the user-written Stata command xtivreg2 (Schaffer 2005).

${ }^{203}$ Under conditional homoskedasticity, the $\mathrm{C}$ statistic is numerically equal to the Durbin-Wu-Hausman test. However, its main advantage is that it is robust to violations of conditional homoskedasticity (see Hayashi 2000: 232-234).
} 
endogenous and all additional covariates as strictly exogenous. Furthermore, we include time fixed effects and employ the same external instruments as in the 2SLS regression framework discussed above. To limit the number of instruments, the matrix of instruments is collapsed as proposed in Roodman (2009).

Before proceeding to the GMM estimation results, column 4 of Table V.4 reports for comparison the 2SLS results when lagged exports are included as an additional control variable. The coefficient on lagged exports to China is statistically significant at the fivepercent level. Interestingly, the Dalai Lama dummy indicating a meeting with a political leader in the previous period becomes insignificant once we include the lagged exports variable. Arguably, the 'Dalai Lama Effect' of meetings in the previous period is already (partially) captured in the lagged export variable. However, the dummy variable indicating a reception of the Tibetan leader in the current period remains statistically significant at conventional levels as expected. In column 5, we therefore exclude the dummy variable indicating a Dalai Lama meeting in the previous period. The coefficients on the remaining variables remain virtually unchanged.

Column 6 shows our GMM regression results for the worldwide sample. ${ }^{204}$ The estimated coefficient on Dalai Lama meetings is negative, statistically significant at the fivepercent level, and of similar size as the corresponding value in the 2SLS setting. The coefficient on the lagged exports variable has the expected positive sign and is statistically significant at the five-percent level. The Hansen test on the validity of the instruments used does not reject the exogeneity of the covariates. The Arellano-Bond test does not reject the hypothesis of no second-order autocorrelation in the data, which needs to be absent in order for the estimator to be consistent. As a final robustness check, we exclude France in column 7 and India in column 8 from our sample, since both countries show extreme values in the distribution of our instrumental variables. France is the country with by far the most Tibet Support Groups (31 in our sample). India, in turn, is the country that experiences the longest Dalai Lama visits (up to 124 days per year). Nevertheless, when separately or jointly excluding the two countries from the GMM regression, our variable of interest remains statistically significant at the five-percent level (columns 7-9). We therefore conclude that our results are not driven by these outliers.

\footnotetext{
${ }^{204}$ All results are based on the user-written Stata command xtabond2 (Roodman 2009).
} 


\section{V.3.4 Results by Product Group}

Finally, we investigate which product groups drive the trade-deteriorating 'Dalai Lama Effect.' As indicated in the first column of Table V.5.1, the value of exports to China is especially concentrated among the following SITC product groups: 'Machinery and transport equipment' (41.0 percent of total exports to China), 'Manufactured goods classified chiefly by material' (13.3 percent), 'Chemicals and related products' (12.4 percent) and 'Crude materials, inedible, except fuels' (12.1 percent). Exports of goods of the most important product group, 'Machinery and transport equipment', are expected to be closely associated with the state of political relations between countries as negotiations over the purchase of such goods are commonly carried out during the course of high-rank trade talks between national representatives and trade delegations. Running separate regressions for each SITC product group, Table V.5.1 reports the full-sample results for the period 2002 to 2008. With the exception of 'Beverages and tobacco', the coefficients for all subgroups exhibit the expected negative sign in the Fixed Effects and FGLS regressions. However, only SITC group 7, which incorporates 'Machinery and transport equipment', the most important product group, turns out to be statistically significant in both regression frameworks. Furthermore, in the FGLS setting, we find a statistically significant and negative coefficient for 'Food, live animals', 'Crude materials' and 'Mineral fuels.'

Table V.5.2 reports our results when the regressions are repeated for European countries. Results are found to be more diverse in the European sample. In the Fixed Effects regressions, we find negative and statistically significant results for the group of 'Food, live animals' and, once again, 'Machinery and transport equipment.' The coefficients on Dalai Lama meetings for the remaining groups are not statistically significant at conventional levels. In the FGLS regressions, statistically significant effects at conventional levels are found for 'Crude materials', 'Mineral fuels', 'Chemicals', and 'Machinery and transport equipment.'

Therefore, the only product group for which we find a statistically significant negative effect at conventional levels for both samples and both estimation techniques is 'Machinery and transport equipment.' This result suggests that the 'Dalai Lama Effect' exists predominantly for those goods that are commonly sold in the course of state visits and trade missions. Our results lend at least weak support in favor of a 'Dalai Lama Effect' operating through consumer opinions since negative coefficients on Dalai Lama meetings are found for consumption goods, namely 'Food, live animals' and 'Miscellaneous manufactured articles.' Finally, there is at least some evidence indicating that strategic goods such as 'Crude materials' and 'Mineral fuels' are not free from political influences. This contradicts Polachek 
(1980), who argues that oil exports show a low export elasticity to conflict between trading partners, as oil-dependent economies have little choice but to continue importing the product regardless of any bilateral conflicts with an oil-exporting country.

Table V.5.1: Exports to China and Dalai Lama meetings of political leaders

(by product groups, all countries, 2002-2008)

\begin{tabular}{|c|c|c|c|c|c|c|c|}
\hline \multirow{2}{*}{$\begin{array}{l}\text { Product Group (SITC) } \\
\text { Food, live animals (0) }\end{array}$} & \multirow{2}{*}{$\begin{array}{c}\% \text { trade } \\
1.7\end{array}$} & \multicolumn{6}{|c|}{ World 2002-2008 } \\
\hline & & -0.197 & $(0.283)$ & $-0.107 *$ & (0.075) & \begin{tabular}{|l} 
Obs. \\
710
\end{tabular} & $\frac{\text { Countries }}{124}$ \\
\hline Beverages and Tobacco (1) & 0.2 & 0.181 & $(0.545)$ & 0.115 & (0.319) & 467 & 91 \\
\hline Crude materials, inedible, except fuels (2) & 12.1 & -0.140 & $(0.328)$ & $-0.116 * * *$ & $(0.003)$ & 840 & 140 \\
\hline Mineral fuels, lubricants and related materials (3) & 7.8 & -0.432 & $(0.275)$ & $-0.352 * * *$ & $(0.000)$ & 481 & 84 \\
\hline Animal and vegetable oils, fats and waxes (4) & 1.0 & -0.206 & (0.661) & -0.046 & $(0.620)$ & 349 & 69 \\
\hline Chemicals and related products, n.e.s. (5) & 12.4 & -0.096 & $(0.593)$ & -0.049 & (0.194) & 722 & 125 \\
\hline Manufactured goods classified chiefly by material (6) & 13.3 & -0.031 & $(0.874)$ & -0.032 & (0.499) & 800 & 132 \\
\hline Machinery and transport equipment (7) & 41.0 & $-0.605 * * *$ & $(0.000)$ & $-0.359 * * *$ & $(0.000)$ & 756 & 129 \\
\hline Miscellaneous manufactured articles (8) & 7.3 & -0.232 & $(0.291)$ & $-0.105^{*}$ & $(0.054)$ & 754 & 128 \\
\hline Not classified elsewhere (9) & 2.2 & -0.294 & $(0.324)$ & -0.037 & (0.675) & 504 & 100 \\
\hline
\end{tabular}

Notes:

- All regressions with country and time fixed effects.

- Robust-p values in brackets; * significant at $10 \%$; ** significant at $5 \%$; *** significant at $1 \%$

- Standard errors in Fixed Effects regressions are adjusted for clustering across partner countries.

- FGLS regressions are corrected for cross-sectional heteroskedasticity across panels and first order autocorrelation.

- \% trade denotes the average share of each SITC product group in total exports to China.

Table V.5.2: Exports to China and Dalai Lama meetings of political leaders (by product groups, European countries, 2002-2008)

\begin{tabular}{|l|c|cc|cc|cc|}
\hline & & \multicolumn{4}{|c|}{ Europe 2002-2008 } \\
Product Group (SITC) & \% trade & \multicolumn{2}{|c|}{ Fixed Effects } & \multicolumn{2}{|c|}{ FGLS AR(1) } & Obs. Countries \\
\hline Food, live animals (0) & 1.3 & $-0.539^{* *}$ & $(0.029)$ & -0.160 & $(0.110)$ & 213 & 33 \\
Beverages and Tobacco (1) & 0.4 & 0.126 & $(0.784)$ & 0.279 & $(0.177)$ & 190 & 32 \\
Crude materials, inedible, except fuels (2) & 5.7 & -0.052 & $(0.742)$ & $-0.114^{*}$ & $(0.084)$ & 242 & 36 \\
Mineral fuels, lubricants and related materials (3) & 1.0 & -0.132 & $(0.695)$ & $-0.228^{*}$ & $(0.087)$ & 191 & 29 \\
Animal and vegetable oils, fats and waxes (4) & 0.1 & -0.280 & $(0.715)$ & 0.100 & $(0.668)$ & 142 & 26 \\
Chemicals and related products, n.e.s. (5) & 9.5 & -0.004 & $(0.985)$ & $-0.143^{* *}$ & $(0.011)$ & 237 & 36 \\
Manufactured goods classified chiefly by material (6) & 12.5 & -0.306 & $(0.187)$ & -0.103 & $(0.171)$ & 241 & 36 \\
Machinery and transport equipment (7) & 58.3 & $-0.396^{* *}$ & $(0.025)$ & $-0.286^{* * *}$ & $(0.000)$ & 246 & 36 \\
Miscellaneous manufactured articles (8) & 7.0 & -0.191 & $(0.304)$ & -0.059 & $(0.262)$ & 245 & 36 \\
Not classified elsewhere (9) & 3.6 & 0.060 & $(0.820)$ & 0.074 & $(0.610)$ & 177 & 30 \\
& & & & & & \\
\hline
\end{tabular}

Notes:

- All regressions with country and time fixed effects.

- Robust $\mathrm{p}$-values in brackets; ${ }^{*}$ significant at $10 \%{ }^{* *}$ significant at $5 \%$; ${ }^{* * *}$ significant at $1 \%$

- Standard errors in Fixed Effects regressions are adjusted for clustering across partner countries.

- FGLS regressions are corrected for cross-sectional heteroskedasticity across panels and first order autocorrelation.

- \% trade denotes the average share of each SITC product group in total exports to China. 


\section{V.4 Conclusions}

Our article contributes to the literature on the political determinants of trade through an assessment of the importance of the state of bilateral relations for trade with China. The Chinese administration frequently threatens, in a more-or-less open manner, that meetings between its trading partners' officials and the Dalai Lama will be met with animosity and lead to a subsequent deterioration in their trade relationships. Using data on the travel pattern of the Dalai Lama, we run a gravity model of exports to China from 159 partner countries in the 1991-2008 period to test for political influences on China's trading decisions. All models are estimated using Fixed Effects with clustered standard errors and Feasible Generalized Least Squares (FGLS) with a common AR(1) term. In order to account for the potential endogeneity of meetings with the Dalai Lama, the number of Tibet Support Groups and the travel pattern of the Buddhist leader are used as instruments in 2SLS and GMM regressions.

Empirical evidence confirms the existence of a trade-deteriorating effect of meetings with the Dalai Lama for the Hu Jintao era (2002-2008). However, we find at best weak evidence to support the existence of such an effect in earlier years. While our results suggest that systematic trade reductions are only caused by meetings with heads of state or government, we find no additional impact for meetings between the Dalai Lama and lowerranking officials. As a consequence of a political leader's reception of the Dalai Lama in the current or previous period, exports to China decrease by 8.1 percent or 16.9 percent on average, depending on the estimation technique used. Furthermore, we find that this effect will have disappeared two years after a meeting took place. Analyzing disaggregated export data, 'Machinery and transport equipment' is found to be the only product group with a robust negative effect of Dalai Lama meetings on exports across samples and estimation techniques.

To sum up, this is strong evidence that bilateral political relations are of large importance for trade with China. Chinese trade relations are not free of political biases and the country seems to exploit trade ties as a foreign policy tool. While political leaders should be aware of potential export losses as a consequence of receiving the Dalai Lama, not meeting with him is not necessarily the conclusion to be drawn from our findings. Despite the possible deterioration in trade, state leaders can see receiving the Dalai Lama as a means to project their stance on human rights and democracy. Therefore, the willingness to bear the costs of trade reductions in conjunction with bilateral disagreements lends credible resolve to the political position of such a country (see also Morrow 2003; Gartzke et al. 2001).

Beyond that, internationally coordinated receptions of the Dalai Lama by political leaders, or even joint meetings, are a possibility to reconcile commercial interests with 
domestic demands to receive the Tibetan leader. Such a strategy may reduce China's scope to play one trading partner off against another. As sanctions imposed on one country can generate rents to third countries through trade deviation, coordination among countries receiving the Dalai Lama can prevent the problem of one country avoiding the Dalai Lama to strengthen its commercial links with China at the expense of the others. Nonetheless, with the increasing economic power of China and other (autocratic) emerging countries, the (ab)use of trade ties as a foreign policy tool is likely to grow in importance. 


\section{References}

Abadie, Alberto, 2006, Poverty, Political Freedom, and the Roots of Terrorism, American Economic Review 96, 2: 50-56.

Agrawal, Subhash, 2007, Emerging Donors in International Development Assistance: The India Case, Partnership and Business Development Division, International Development Research Centre, Ottawa, ON.

Ai, Chunrong and Edward C. Norton, 2003, Interaction Terms in Logit and Probit Models, Economics Letters 80, 1: 123-129.

Aidt, Toke S. and Martin Gassebner, 2010, Do Autocratic States Trade Less? World Bank Economic Review 24, 1: 38-76.

Alden, Chris, 2005, Red Star, Black Gold, Review of African Political Economy 32, 104/5: 415-419.

Alesina, Alberto and David Dollar, 2000, Who Gives Foreign Aid to Whom and Why? Journal of Economic Growth 5, 1: 33-63.

Alesina, Alberto and Beatrice Weder, 2002, Do Corrupt Governments Receive Less Foreign Aid? American Economic Review 92, 4: 1126-1137.

Al-Yahya, Khalid and Nathalie Fustier, 2011, Saudi Arabia as a Humanitarian Donor: High Potential, Little Institutionalization, GPPi Research Paper No. 14, Global Public Policy Institute, Berlin, Germany.

Arellano, Manuel and Olympia Bover, 1995, Another Look at the Instrumental Variable Estimation of Error-Components Models, Journal of Econometrics 68, 1: 29-51.

AusAID, 2003, Counter-Terrorism and Australian Aid, AusAID Public Affairs Group, available at: http://www.ausaid.gov.au/Publications/Documents/counterterrorism.pdf (accessed: July 2012).

Azam, Jean-Paul and Alexandra Delacroix, 2006, Aid and the Delegated Fight Against Terrorism, Review of Development Economics 10, 2: 330-344.

Azam, Jean-Paul and Véronique Thelen, 2008, The Roles of Foreign Aid and Education in the War on Terror, Public Choice 135, 3-4: 375-397.

Azam, Jean-Paul and Véronique Thelen, 2010, Foreign Aid vs. Military Intervention in the War on Terror, Journal of Conflict Resolution 54, 2: 237-261.

Azam, Jean-Paul and Véronique Thelen, 2011, Where to Spend Foreign Aid to Counter Terrorism, Paper presented at the EPCS, Rennes, France, 2011. 
Bandyopadhyay, Subhayu, Todd Sandler and Javed Younas, 2011, Foreign Aid as Counterterrorism Policy, Oxford Economic Papers 63, 3: 423-447.

Banerjee, Brojendra Nath, 1982, India's Aid to Its Neighbouring Countries, New Delhi, India: Select Books.

Banerjee, Kaustav, 2010, Social Development Index, Social Development Report 2010, New Delhi, India: Oxford University Press.

Bapat, Navin A., 2011, Transnational Terrorism, US Military Aid, and the Incentive to Misrepresent, Journal of Peace Research 48, 3: 303-318.

Barbieri, Katherine, Omar Keshk and Brian Pollins, 2008, Correlates of War Project Trade Data Set Codebook, Version 2.0, available at: http://correlatesofwar.org (accessed: October 2010).

Barro, Robert J. and Jong-Wha Lee, 2005, IMF Programs: Who Is Chosen and What Are the Effects? Journal of Monetary Economics 52, 7: 1245-1269.

Bartke, Wolfgang, 1989, The Economic Aid of the PR China to Developing and Socialist Countries, 2nd ed., Munich, Germany: K. G. Saur.

Basu, Kaushik, 2008, The Enigma of India's Arrival: A Review of Arvind Virmani's Propelling India: From Socialist Stagnation to Global Power, Journal of Economic Literature 46, 2: 396-406.

Basu, Kaushik and Annemie Maertens, 2007, The Pattern and Causes of Economic Growth in India, Oxford Review of Economic Policy 23, 2: 143-167.

Beck, Nathaniel and Jonathon N. Katz, 1995, What To Do (and Not To Do) with Time-Series Cross-Section Data, American Political Science Review 89, 3: 634-647.

Benini, Aldo, Charles Conley, Brody Dittemore and Zachary Waksman, 2009, Survivor Needs or Logistical Convenience? Factors Shaping Decisions to Deliver Relief to Earthquake-affected Communities, Pakistan 2005-06, Disasters 33, 1: 110-131.

Bermeo, Sarah Blodgett, 2011, Foreign Aid and Regime Change: A Role for Donor Intent, World Development 39, 11: 2021-2031.

Berthélemy, Jean-Claude, 2006, Bilateral Donors' Interests vs. Recipients' Development Motives in Aid Allocation: Do All Donors Behave the Same? Review of Development Economics 10, 2: 179-194.

Berthélemy, Jean-Claude, 2009, Impact of China's Engagement on the Sectoral Allocation of Resources and Aid Effectiveness in Africa, Paper presented at the African Economic Conference 2009, Addis Adaba, Ethiopia. 
Bertoli, Simone, Giovanni A. Cornia and Francesco Manaresi, 2008, Aid Effort and Its Determinants: A Comparison of the Italian Performance with other OECD Donors, Dipartimento di Scienze Economiche Working Paper 11/2008, Universita' degli Studi di Firenze, Florence, Italy.

Bjørnskov, Christian, 2010, Do Elites Benefit from Democracy and Foreign Aid in Developing Countries? Journal of Development Economics 92, 2: 115-124.

Blomberg, Brock, Khusrav Gaibulloev and Todd Sandler, 2011, Terrorist Group Survival: Ideology, Tactics, and Base of Operations, Public Choice 149, 3-4: 441-463.

Blundell, Richard and Stephen Bond, 1998, Initial Conditions and Moment Restrictions in Dynamic Panel Data Models, Journal of Econometrics 87, 1: 115-143.

BP, 2010, BP Statistical Review of World Energy, available at: http://www.bp.com/statisticalreview (accessed: December 2010).

Bräutigam, Deborah, 2008, China's African Aid - Transatlantic Challenges, International Development Program, School of International Service, American University, Washington, DC.

Bräutigam, Deborah, 2010, The Dragon's Gift: The Real Story of China in Africa, Oxford, UK: Oxford University Press.

Bräutigam, Deborah, 2011, Aid 'With Chinese Characteristics': Chinese Foreign Aid and Development Finance Meet the OECD-DAC Regime, Journal of International Development 23, 5: 752-764.

Bueno de Mesquita, Bruce Bueno and Alastair Smith, 2010, Leader Survival, Revolutions, and the Nature of Government Finance, American Journal of Political Science 54, 4: 936-950.

Burnside, Craig and David Dollar, 2000, Aid, Policies, and Growth, American Economic Review 90, 4: 847- 868.

Bushway, Shawn, Brian D. Johnson and Lee Ann Slocum, 2007, Is the Magic Still There? The Use of the Heckman Two-Step Correction for Selection Bias in Criminology, Journal of Quantitative Criminology 23, 2:151-178.

Busse, Matthias and Steffen Gröning, 2009, Does Foreign Aid Improve Governance? Economics Letters 104, 2: 76-78.

Campos, Nauro and Martin Gassebner, 2009, International Terrorism, Political Instability and the Escalation Effect, CEPR Discussion Paper No. 7226, Centre for Economic Policy Research, London, UK. 
Chanana, Dweepa, 2009, India as an Emerging Donor, Economic and Political Weekly XLIV, 12: 11-14.

Chaturvedi, Sachin, 2008, Emerging Patterns in Architecture for Management of Economic Assistance and Development Cooperation: Implications and Challenges for India, RIS Discussion Paper 139, Research and Information System for Developing Countries, New Dehli, India.

Cheibub, José A., Jennifer Gandhi and James R. Vreeland, 2010, Democracy and Dictatorship Revisited, Public Choice 143, 1-2: 67-101.

Cheru, Fantu and Cyril Obi, 2011, Genuine Partnership or a Marriage of Convenience? IndiaAfrica Relations in the 21st Century, Pambazuka News, available at: http://www.pambazuka.org/en/category/features/74100 (accessed: February 2012).

CIA, 1975-1976, Communist Aid to Less Developed Countries of the Free World, CIA Intelligence Handbook, available at: http:/www.foia.cia.gov/ (accessed: October 2010).

CIA, 1980, Communist Aid to Non-Communist Less Developed Countries, Intelligence Handbook, available at: http://www.foia.cia.gov/ (accessed: October 2010).

CIA, 1981-1984, Communist Aid to Less Developed Countries of the Free World, CIA Intelligence Handbook, available at: http://www.foia.cia.gov/ (accessed: October 2010).

Council of the European Union, 2004, EU-US Declaration on Combating Terrorism,

Dromoland Castle, June 26, 10760/04 (Presse 205), available at: http://www.eurunion.org/partner/summit/Summit0406/2004SumTerror.pdf (accessed: May 2011).

Cyprusaid, 2009, The Development Cooperation Service of the Republic of Cyprus, Planning Bureau of the Republic of Cyprus, Nikosia, Cyprus, available at: http://www.planning.gov.cy/planning/planning.nsf/AttachmentArchive/1D6633BC475 7FC74C2257599003BAF12/\$file/CyprusAid\%20Brochure\%20Eng.pdf?openelement (accessed: July 2012).

Davies, Penny, 2007, China and the End of Poverty in Africa - towards Mutual Benefit? Diakonia, Alfaprint, Sundyberg, Sweden.

Davis, Christina L. and Sophie Meunier, 2011, Business as Usual? Economic Responses to Political Tensions, American Journal of Political Science 55, 3: 628-646. 
DFA, 2001, EU Development Ministers Respond to Humanitarian Crisis in Afghanistan, Press releases, Department of Foreign Affairs, Republic of Ireland, available at: http://www.dfa.ie/home/index.aspx?id=26383 (accessed: May 27, 2011).

Disdier, Anne-Celia and Thierry Mayer, 2007, Je t'aime, moi non plus: Bilateral Opinions and International Trade, European Journal of Political Economy 23, 4: 1140-1159.

Doucouliagos, Hristos and Martin Paldam, 2008, Aid Effectiveness on Growth: A Meta Study, European Journal of Political Economy 24, 1: 1-24.

Doucouliagos, Hristos and Martin Paldam, 2010, Conditional Aid Effectiveness: A MetaStudy, Journal of International Development 22, 4: 391-410.

Dreher, Axel and Martin Gassebner, 2008, Does Political Proximity to the U.S. Cause Terror? Economics Letters 99, 1: 27-29.

Dreher, Axel and Nathan M. Jensen, 2007, Independent Actor or Agent? An Empirical Analysis of US Interests on IMF Conditions, Journal of Law \& Economics 50, 1: 105124.

Dreher, Axel, Stephan Klasen, James Raymond Vreeland and Eric Werker, forthcoming, The Costs of Favoritism: Is Politically-driven Aid Less Effective? Economic Development and Cultural Change.

Dreher, Axel, Rainer Thiele and Peter Nunnenkamp, 2008, Does Aid for Education Educate Children? Evidence from Panel Data, World Bank Economic Review 22, 2: 291-314.

Dreher, Axel, Peter Nunnenkamp and Rainer Thiele, 2011, Are 'New' Donors Different? Comparing the Allocation of Bilateral Aid between Non-DAC and DAC Donor Countries, World Development 39, 11: 1950-1968.

Dreher, Axel, Jan-Egbert Sturm and James Raymond Vreeland, 2009a, Development Aid and International Politics: Does Membership on the UN Security Council Influence World Bank Decisions? Journal of Development Economics 88, 7: 1-18.

Dreher, Axel, Jan-Egbert Sturm and James Raymond Vreeland, 2009b, Global Horse Trading: IMF Loans for Votes in the United Nations Security Council, European Economic Review 53, 1: 742-757.

Drèze, Jean and Amartya Sen, 2011, Putting Growth in Its Place, Outlook, November 14, available at: http://www.outlookindia.com/article.aspx?278843 (accessed: June 2012).

Drury, A. Cooper and Richard Stuart Olson, 1998, Disasters and Political Unrest: An Empirical Investigation, Journal of Contingencies and Crisis Management 6, 3: 153161. 
Drury, A. Cooper, Richard Stuart Olson and Douglas A. Van Belle, 2005, The Politics of Humanitarian Aid: U.S. Foreign Disaster Assistance, 1964-1995, Journal of Politics 67, 2: 454-473.

Dutt, Srikant, 1980, Indian Aid to Co-Developing Countries, Economic and Political Weekly 15, 5: 672-678.

Easterly, William, Ross Levine and David Roodman, 2004, Aid, Policies, and Growth: Comment, American Economic Review 94, 3: 774-780.

Easterly, William and Claudia Williamson, 2011, Rhetoric versus Reality: The Best and Worst of Aid Agency Practices, World Development 39, 11: 1930-1949.

Eaton, Jonathon and Maxim Engers, 1992, Sanctions, Journal of Political Economy 100, 5: 899-928.

Eaton, Jonathon and Maxim Engers, 1999, Sanctions: Some Simple Analytics, American Economic Review 89, 2: 409-414.

ECOSOC, 2008, Trends in South-South and Triangular Development Cooperation, Background Study for the Development Cooperation Forum, United Nations Economic and Social Council (ECOSOC), available at: http://www.un.org/en/ecosoc/docs/pdfs/south-south_cooperation.pdf (last accessed: July 2012).

Eisensee, Thomas and David Strömberg, 2007, News Droughts, News Floods, and U.S. Disaster Relief, Quarterly Journal of Economics 122, 2: 693-728.

EM-DAT, 2010, The OFDA/CRED International Disaster Database, Université Catholique de Louvain, Brussels, Belgium, available at: http://www.emdat.be (accessed: October 2010).

EM-DAT, 2012, The OFDA/CRED International Disaster Database, Université Catholique de Louvain, Brussels, Belgium, available at: http://www.emdat.be (last accessed: May 2012).

Fink, Günther and Silvia Redaelli, 2011, Determinants of International Emergency Aid Humanitarian Need Only? World Development 39, 5: 741-757.

Fleck, Robert K. and Christopher Kilby, 2010, Changing Aid Regimes? U.S. Foreign Aid from the Cold War to the War on Terror, Journal of Development Economics 91, 2: 185-197.

Francken, Nathalie, Bart Minten and Johan F.M. Swinnen, 2012, The Political Economy of Relief Aid Allocation: Evidence from Madagascar, World Development 40, 3: 486500 . 
Freedom House, 2009, Freedom in the World 2009, Freedom House, available at: http://www.freedomhouse.org (accessed: February 12, 2011).

Gartzke, Eric, Quan Li and Charles Boehmer, 2001, Investing in the Peace: Economic Interdependence and International Conflict, International Organization 55, 2: 391-438.

Gassebner, Martin, Richard Jong-A-Pin and Jochen Mierau, 2008, Terrorism and Electoral Accountability: One Strike, You're out! Economics Letters 100, 1: 126-129.

Gassebner, Martin, Richard Jong-A-Pin and Jochen Mierau, 2012, Terrorism and Cabinet Duration, International Economic Review 52, 4: 1253-1270.

Gassebner, Martin, Alexander Keck and Robert Teh, 2010, Shaken, Not Stirred: The Impact of Disasters on International Trade, Review of International Economics 18, 2: 351368.

Gil-Pareja, Salvador, Rafael Llorca and Jose A. Martínez Serrano, 2008, Measuring the Impact of Regional Export Promotion: The Spanish Case, Papers in Regional Science 87, 1: 139-146.

Glick, Reuven and Alan Taylor, 2010, Collateral Damage: Trade Disruption and the Economic Impact of War, Review of Economics and Statistics 92, 1: 102-127.

Goldstein, Melvyn C., 1997, The Snow Lion and the Dragon: China, Tibet, and the Dalai Lama, Berkeley, CA: University of California Press.

Goldstein, Melvyn C., 1998, The Dalai Lama's Dilemma, Foreign Affairs 77, 1: 83-97.

Gowa, Joanne and Edward Mansfield, 1993, Power Politics and International Trade, American Political Science Review 87, 2: 408-420.

Guiso, Luigi, Paola Sapienza and Luigi Zingales, 2009, Cultural Biases in Economic Exchange? Quarterly Journal of Economics 124, 3: 1095-1131.

Gupta, Sanjeev, Catherine Pattillo and Smita Wagh, 2006, Are Donor Countries Giving More or Less Aid? Review of Development Economics 10, 3: 535-552.

Gwartney, James and Robert Lawson with Herbert Grubel, Jakob de Haan, Jan-Egbert Sturm and Eelco Zandberg, 2009, Economic Freedom of the World: 2009 Annual Report, Vancouver, BC: The Fraser Institute, available at: http://www.freetheworld.com (accessed: February 2010).

Gyatso, Tenzin, 1990, Freedom in Exile: The Autobiography of the Dalai Lama, New York, NY: Harper Perennial.

Halper, Stefan, 2010, The Beijing Consensus: How China's Authoritarian Model Will Dominate the Twenty-first Century, New York, NY: Basic Books. 
Harmer, Adele and Lin Cotterrell, 2005, Diversity in Donorship: The Changing Landscape of Official Humanitarian Aid, Humanitarian Policy Group Research Report 20, Overseas Development Institute, London, UK.

Harmer, Adele and Ellen Martin, 2010, Diversity in Donorship: Field Lessons, Humanitarian Policy Group Research Report 30, Overseas Development Institute, London, UK.

Hawkins, Darren, Dan Nielson, Anna Bergevin, Ashley Hearn and Becky Perry, 2010, Codebook for Assembling Data on China's Development Finance, College of William and Mary, Brigham Young University, Provo, UT, available at: http://www.aiddata.org/research/china (accessed: September 2010).

Hayashi, Fumio, 2000, Econometrics, Princeton, NJ: Princeton University Press.

He, Wenping, 2006, China-Africa Relations Moving into an Era of Rapid Development, Inside Asia 3-4, Oct/Dec: 2-6.

Head, Keith and John Ries, 2010, Do Trade Missions Increase Trade? Canadian Journal of Economics 43, 3: 754-775.

Heckman, James J., 1979, Sample Selection Bias as a Specification Error, Econometrica 47, 1: 153-161.

Heston, Alan, Robert Summers and Bettina Aten, 2009, Penn World Table, Version 6.3, Center for International Comparisons of Production, Income and Prices at the University of Pennsylvania, Philadelphia, PA.

Heston, Alan, Robert Summers and Bettina Aten, 2011, Penn World Table, Version 7.0, Center for International Comparisons of Production, Income and Prices at the University of Pennsylvania, Philadelphia, PA.

Hilsum, Lindsey, 2006, China, Africa and the G8 - or why Bob Geldof Needs to Wake up, in: Wild, Leni and Mepham, David, Editors, The New Sinosphere: China in Africa, Institute for Public Policy Research (IPPR), London, UK.

Hodler, Roland and Axel Dreher, 2012, Development (Paradigm) Failures, mimeo.

Höffler, Anke and Verity Outram, 2011, Need, Merit, or Self-Interest-What Determines the Allocation of Aid? Review of Development Economics 15, 2: 237-250.

Hsu, Sara, 2008, The Effect of Political Regimes on Inequality, 1963-2002, Inequality Project Working Paper 53, University of Texas, Austin, TX.

Hufbauer, Gary, Jeffrey Schott, Kimberly Elliott and Barbara Oegg, 2007, Economic Sanctions Reconsidered (3rd edition), Washington, DC: Institute for International Economics. 
Humphreys, Macartan, 2005, Natural Resources, Conflict, and Conflict Resolution: Uncovering the Mechanisms, Journal of Conflict Resolution 49, 4: 508-537.

IFPRI, 2011, Global Hunger Index, International Food Policy Research Institute (IFPRI), Washington, DC, available at: http://www.ifpri.org/publication/2011-global-hungerindex (accessed: December 2011).

Isopi, Alessia and Fabrizio Mattesini, 2010, Aid and Corruption: Do Donors Use Development Assistance to Provide the "Right" Incentives? Paper presented at the AidData Conference, University College, Oxford, UK, March 22-25.

ITEC, 2011, Official Website of Technical Cooperation Division, Ministry of External Affairs, Government of India, available at: http://itec.mea.gov.in/ (accessed: October 11, 2011).

Johnson, Jo and Rajiv Kumar, 2011, Reconnecting Britain and India: Ideas for an Enhanced Partnership, New Dehli, India: Academic Foundation.

Kahn, Matthew E., 2005, The Death Toll from Natural Disasters: The Role of Income, Geography, and Institutions, Review of Economics and Statistics 87, 2: 271-284.

Kaplinsky, Raphael, Dorothy McCormick and Mike Morris, 2007, The Impact of China on Subsaharan Africa, IDS Working Paper $\mathrm{n}^{\circ}$ 291, Institute of Development Studies, Brighton, UK.

Kastner, Scott L., 2007, When Do Conflicting Political Relations Affect International Trade? Journal of Conflict Resolution 51, 4: 664-688.

Katti, Vijaya, Tatjana Chahoud and Atul Kaushik, 2009, India's Development Cooperation Opportunities and Challenges for International Development Cooperation, Briefing Paper No. 3, German Development Institute (DIE), Bonn, Germany.

Katz, Ethan, 2001, Bias in Conditional and Unconditional Fixed Effects Logit Estimation, Political Analysis 9, 4: 379-384.

Kaufmann, Daniel, Aart Kraay and Massimo Mastruzzi, 2009, Governance Matters VIII, Governance Indicators for 1996-2008, available at: http://info.worldbank.org/governance/wgi/pdf/wgicharts.xls (accessed: February 13, 2010).

Keohane, Robert O. and Joseph S. Nye, 1977, Power and Interdependence: World Politics in Transition, Boston, MA: Little, Brown.

Kilby, Christopher, 2009a, The Political Economy of Conditionality: an Empirical Analysis of World Bank Loan Disbursements, Journal of Development Economics 89, 1: 51-61. 
Kilby, Christopher, 2009b, Donor Influence in International Financial Institutions: Deciphering What Alignment Measures Measure, Paper presented at the Political Economy of International Organizations Meeting, Geneva, Switzerland.

Kilby, Christopher, 2011, Informal Influence in the Asian Development Bank, Review of International Organizations 6, 3-4: 223-257.

Kilby, Christopher, forthcoming, An Empirical Assessment of Informal Influence in the World Bank, Economic Development and Cultural Change.

Kilby, Christopher and Axel Dreher, 2010, The Impact of Aid on Growth Revisited: Do Donor Motives Matter? Economics Letters 107, 3: 338-340.

Knack, Stephen, 2004, Does Foreign Aid Promote Democracy? International Studies Quarterly 48, 1: 251-266.

Knack, Stephen, F. Halsey Rogers and Nicolas Eubank, 2011, Aid Quality and Donor Rankings, World Development 39, 11: 1907-1917.

Kobayashi, Takaaki, 2008, Evolution of China's Aid Policy, JBICI Working Paper 27, Japan Bank for International Cooperation, Tokyo, Japan.

Kragelund, Peter, 2008, The Return of Non-DAC Donors to Africa: New Prospects for African Development? Development Policy Review 26, 5: 555-584.

Kragelund, Peter, 2010, The Potential Role of Non-Traditional Donors' Aid in Africa, ICTSD Issue Paper No. 11, International Centre for Trade and Sustainable Development, Geneva, Switzerland.

Krueger, Alan B. and Jitka Maleckova, 2003, Education, Poverty and Terrorism: Is There a Causal Connection? Journal of Economic Perspectives 17, 4: 119-144.

Kurlantzick, Joshua, 2006, Beijing's Safari: China's Move Into Africa and Its Implications for Aid, Development, and Governance, Carnegie Endowment for International Peace, Policy Outlook, November.

Kuziemko, Ilyana and Eric Werker, 2006, How Much is a Seat on the Security Council Worth? Foreign Aid and Bribery at the United Nations, Journal of Political Economy 114, 5: 905-930.

Lafargue, François, 2006, L'Inde en Afrique: Logiques et limites d'une Politique, Afrique contemporaine 219, 3: 137-148.

Lammers, Ellen, 2007, How Will the Beijing Consensus Benefit Africa? The Broker, available at: http://www.thebrokeronline.eu/en/Magazine/articles/How-will-theBeijing-Consensus-benefit-Africa (accessed: June 2010). 
Lancaster, Carol, 2007, The Chinese Aid System, Center for Global Development Essay, Center for Global Development, Washington, DC.

Lin, The-chang, 1995, Problems in the Study of Beijing's Foreign Aid, Issues \& Studies 31, 7: 66-78.

Luechinger, Simon and Paul A. Raschky, 2009, Valuing Flood Disasters Using the Life Satisfaction Approach, Journal of Public Economics 93, 3-4: 620-633.

Manning, Richard, 2006, Will 'Emerging Donors' Change the Face of International Cooperation? Development Policy Review 24, 4: 371-385.

Manning, Richard, 2007, Notes from Visit to Beijing 9-12 February 2007.

Mansfield, Edward D., 2011, Rising Powers in the Global Economy: Issues and Questions, Paper presented at the workshop on "The Transatlantic Community and Economic Engagement of the Rising Powers," Free University of Berlin, Germany.

Mansfield, Edward D., Helen Milner and Peter Rosendorff, 2000, Free to Trade: Democracies, Autocracies, and International Trade, American Political Science Review 94, 2: 305-322.

Martin, Philippe, Thierry Mayer and Mathias Thoenig, 2008, Make Trade Not War? Review of Economic Studies 75, 3: 865-900.

Mayer, Thierry and Soledad Zignago, 2006, Notes on CEPII's Distances Measures, available at: http://www.cepii.fr/anglaisgraph/bdd/distances.htm (accessed: May 2009).

MEA, 1967-2011, Annual Report, Ministry of External Affairs, Government of India, available at: http://www.meaindia.nic.in and http://mealib.nic.in/ (accessed: October $25,2010)$.

MEA, 2001b, Estimated Size of Overseas Indian Community: Country-wise, Non Resident Indians \& Persons of Indian Origin Division, Ministry of External Affairs, Government of India, available at: http://indiandiaspora.nic.in/diasporapdf/part1est.pdf (accessed: February 14, 2011).

Meier, Claudia and C. S. R. Murphy, 2011, India's Growing Involvement in Humanitarian Assistance, GPPi Research Paper No. 13, Global Public Policy Institute, Berlin, Germany.

Méon, Pierre-Guillaume and Khalid Sekkat, 2008, Institutional Quality and Trade: Which Institutions? Which Trade? Economic Inquiry 46, 2: 227-240.

Mickolus, Edward F., 1980, Transnational Terrorism, Westport, CT: Greenwood Press. 
Mickolus, Edward F., Todd Sandler, Jean M. Murdock and Peter A. Flemming, 2009, International Terrorism: Attributes of Terrorist Events (ITERATE 5): 1968-2008, Vinyard Software, Inc., Dunn Loring, VA.

Minfin, 2007, Russia's Participation in International Development Assistance, Concept approved by the President of the Russian Federation, June 14th, available at: http://www1.minfin.ru/en/financial_affairs/Dev_Assis/concept_rus/ (accessed: June 2012).

Ministry of Commerce, 1984-2001, Almanac of China's Foreign Economic Relations and Trade, Hong Kong: China Foreign Economic Relations and Trade Publishing House.

Ministry of Commerce, 2002-2003, Yearbook of China's Foreign Economic Relations and Trade, Hong Kong: China Foreign Economic Relations and Trade Publishing House.

Ministry of Commerce, 2004-2009, China Commerce Yearbook, Beijing, China: China Commerce and Trade Press.

Morrow, James D., 2003, Assessing the Role of Trade as a Source of Costly Signals, in: Edward D. Mansfield and Brian M. Pollins (eds.), Economic Interdependence and International Conflict: New Perspectives on an Enduring Debate, Ann Arbor, MI: University of Michigan Press.

Morrow, James D., Randolph. M. Siverson and Tressa Tabares, 1998, The Political Determinants of International Trade: The Major Powers, 1907-1990, American Political Science Review 92, 4: 649-661.

Moss, Todd J., Scott Standley and David Roodman, 2005, The Global War on Terror and U.S. Development Assistance: USAID Allocation by Country, 1998-2005, CGD Working Paper No. 62, Washington, DC.

Naím, Moisés, 2007, Rogue Aid, Foreign Policy 159, March/April: 95-96.

Nel, Philip and Marjolein Righarts, 2008, Natural Disasters and the Risk of Violent Civil Conflict, International Studies Quarterly 52, 1: 159-185.

Neumayer, Eric, 2002, Is Good Governance Rewarded? A Cross-National Analysis of Debt Forgiveness, World Development 30, 6: 913-930.

Neumayer, Eric, 2003a, What Factors Determine the Allocation of Aid by Arab Countries and Multilateral Agencies? Journal of Development Studies 39, 4: 134-147.

Neumayer, Eric, 2003b, Do Human Rights Matter in Bilateral Aid Allocation? A Quantitative Analysis of 21 Donor Countries, Social Science Quarterly 84, 3: 650-666.

Neumayer, Eric, 2004, Arab-related Bilateral and Multilateral Sources of Development Finance: Issues, Trends, and the Way Forward, World Economy 27, 2: 281-300. 
Neumayer, Eric, 2005, Is the Allocation of Food Aid Free from Donor Interest Bias? Journal of Development Studies 41, 3: 394-411.

Neumayer, Eric and Thomas Plümper, 2007, The Gendered Nature of Natural Disasters: The Impact of Catastrophic Events on the Gender Gap in Life Expectancy, 1981-2002, Annals of the Association of American Geographers 97, 3: 551-566.

Nickell, Stephen J., 1981, Biases in Dynamic Models with Fixed Effects, Econometrica 49, 6: 1417-1426.

Nitsch, Volker, 2007, State Visits and International Trade, World Economy 30, 12: 1797 1816.

Nitsch, Volker and Dieter Schumacher, 2004, Terrorism and International Trade: An Empirical Investigation, European Journal of Political Economy 20, 2: 423-433.

Nowak-Lehmann D., Felicitas, Inmaculada Martínez-Zarzoso, Stephan Klasen and Dierk Herzer, 2009, Aid and Trade - A Donor's Perspective, Journal of Development Studies 45, 7: 1184-1202.

OCHA, 2011, Financial Tracking System, United Nations Office for the Coordination of Humanitarian Affairs, available at: http://fts.unocha.org/ (accessed: August 2011).

OECD, 1987, The Aid Programme of China, Organisation for Economic Co-operation and Development, Paris, France.

OECD, 2003, A Development Co-operation Lens on Terrorism Prevention, DAC Guidelines and Reference Series, Organisation for Economic Co-operation and Development, Paris, France, available at: http://www.oecd.org/dataoecd/17/4/16085708.pdf (last accessed: July 2012).

OECD, 2005, Assessment Framework for Coverage of Humanitarian Actions in DAC Peer Reviews, available at: http://www.oecd.org/dataoecd/59/59/35374051.pdf (accessed: July 2012).

OECD, 2012, Creditor Reporting System Aid Activities Database, available at: http://stats.oecd.org/Index.aspx (accessed: March 21, 2012).

Öhler, Hannes, Peter Nunnenkamp and Axel Dreher, 2012, Does Conditionality Work? A Test for an Innovative US Aid Scheme, European Economic Review 56, 1: 138-153.

O’Neill, Jim, 2001, Building Better Economic BRICs, Goldman Sachs Global Economics Paper No: 66, Goldman Sachs Economic Research Group, London, UK.

Panagariya, Arvind, 2010, India: The Emerging Giant, USA: Oxford University Press. 
Papke, Leslie E. and Jeffrey M. Wooldridge, 1996, Econometric Methods for Fractional Response Variables with an Application to 401(k) Plan Participation Rates, Journal of Applied Econometrics 11, 6: 619-632.

Parsons, Christopher R., Ronald Skeldon, Terrie L. Walmsley and L. Alan Winters, 2007, Quantifying International Migration: A Database of Bilateral Migrant Stocks, World Bank Policy Research Working Paper 4165, The World Bank, Washington, DC.

Pehnelt, Gernot, 2007, The Political Economy of China's Aid Policy in Africa, Jena Economic Research Paper 51, University of Jena, Jena, Germany.

Plümper, Thomas and Eric Neumayer, 2009, Famine Mortality, Rational Political Inactivity, and International Food Aid, World Development 37, 1: 50-61.

Polachek, Solomon W., 1980, Conflict and Trade, Journal of Conflict Resolution 24, 1: 55-78. Pollins, Brian M., 1989, Does Trade Still Follow the Flag? American Political Science Review 83, 2: 465-480.

Potter, David M. and Douglas A. Van Belle, 2008, News Coverage and Japanese Foreign Disaster Aid: A Comparative Example of Bureaucratic Responsiveness to the News Media, International Relations of the Asia-Pacific 9, 2: 295-315.

Price, Gareth, 2004, India’s Aid Dynamics: From Recipient to Donor? Asia Program Working Paper, Chatham House, London, UK.

Price, Gareth, 2005, Diversity in Donorship: The Changing Landscape of Official Humanitarian Aid - India's Official Aid Programme, Overseas Development Institute (ODI), London, UK.

Qi, Guoqiang, 2007, China's Foreign Aid: Policies, Structure, Practice and Trend.

Raschky, Paul A., 2008, Institutions and the Losses from Natural Disasters, Natural Hazards and Earth System Sciences 8, 4: 627-634.

Raschky, Paul A. and Manijeh Schwindt, 2012, On the Channel and Type of Aid: The Case of International Disaster Assistance, European Journal of Political Economy 28, 1: 119131.

Reynaud, Julien and Julien Vauday, 2009, Geopolitics and International Organizations: An Empirical Study on IMF Facilities, Journal of Development Economics 89, 1: 139162.

Rich, Timothy S., 2009, Status for Sale: Taiwan and the Competition for Diplomatic Recognition, Issues \& Studies 45, 4: 159-188.

Richardson, Neil and Charles Kegley, 1980, Trade Dependence and Foreign Policy Compliance, International Studies Quarterly 24, 2: 191-222. 
Roodman, David, 2009, How to Do xtabond2: An Introduction to "Difference" and "System" GMM in Stata, Stata Journal 9, 1: 86-136.

Rose, Andrew, 2007, The Foreign Service and Foreign Trade: Embassies as Export Promotion, World Economy 30, 1: 22-38.

Round, Jeffery I. and Matthew Odedokun, 2004, Aid Effort and Its Determinants, International Review of Economics \& Finance 13, 3: 293-309.

Schaffer, Mark E., 2005, XTIVREG2: Stata Module to Perform Extended IV/2SLS, GMM and AC/HAC, LIML and k-Class Regression for Panel Data Models, Statistical Software Components S456501, Boston College Department of Economics, revised 28 June 2010.

Schüller, Margot, Magnus Brod, Daniel Neff and Marco Bünte, 2010, China's Emergence within Southeast Asia's Aid Architecture: New Kid on the Block? Paper presented at the AidData Conference, University College, Oxford, UK, March 22-25.

Sen, Amartya, 1990, Public Action to Remedy Hunger, Arturo Tanco Memorial Lecture, August 2, London, UK.

Sharma, Swati, Zach Davis and Mike Findley, 2009, Deadly Gift? The Effect of Foreign Aid on Terrorism, mimeo, Brigham Young University, Provo, UT.

Shinn, David, 2006, Africa, China and Health Care, Inside Asia 3-4, Oct/Dec: 14-16.

Sinha, Pranay and Michael Hubbard, 2011, DAC (Traditional) \& Non DAC (Emerging) Donors at the Crossroads: The Problem of Export Credits, Paper presented at the EADI-DSA 2011 Conference, University of York, York, UK, available at: http://www.bhamlive3.bham.ac.uk/Documents/college-social-sciences/governmentsociety/idd/research/aid-data/problem-export-credits.pdf (last accessed: July 2012).

Staiger, Douglas and James H. Stock, 1997, Instrumental Variables Regression with Weak Instruments, Econometrica 65, 3: 557-586.

State Council, 2011, White Paper on China's Foreign Aid, Xinhua/China's Information Office of the State Council, available at: http://www.gov.cn/english/official/201104/21/content 1849913.htm (accessed: August 2011).

Strömberg, David, 2007, Natural Disasters, Economic Development, and Humanitarian Aid, Journal of Economic Perspectives 21, 3: 199-222.

Strømmen, Marthe A., Indra de Soysa and Krishna Chaitanya Vadlamannati, 2011, How Kind the Good Samaritan? An Empirical Test of Scandinavian Aid and the Promotion of Peace and Human Rights, 1960-2009, ISS working paper, Norwegian University of Science and Technology, Trondheim, Norway. 
Taylor, Ian, 1998, China's Foreign Policy towards Africa in the 1990s, Journal of Modern African Studies 6, 3: 443-460.

Thacker, Strom C., 1999, The High Politics of IMF Lending, World Politics 52: 38-75.

Tierney, Michael J., Daniel L. Nielson, Darren G. Hawkins, J. Timmons Roberts, Michael G.

Findley, Ryan M. Powers, Bradley Parks, Sven E. Wilson and Robert L. Hicks, 2011, More Dollars than Sense: Refining Our Knowledge of Development Finance Using AidData, World Development 39, 11: 1891-1906.

Tingley, Dustin, 2010, Donors and Domestic Politics: Political Influences on Foreign Aid Effort, Quarterly Review of Economics and Finance 50, 2: 40-49.

Tubilewicz, Czeslaw, 2012, The Politics of Compassion: Examining a Divided China's Humanitarian Assistance to Haiti, International Relations of the Asia-Pacific, first published online May 2, 2012.

Tull, Denis M., 2006, China's Engagement in Africa: Scope, Significance and Consequences, Journal of Modern African Studies 44, 3: 459-479.

UNCTAD, 2010, World Investment Report 2010, United Nations Conference on Trade and Development, available at: http://www.unctad.org (accessed: January 26, 2011).

UNESCO, 2011, Education Statistics, UNESCO Institute for Statistics, available at: http://stats.uis.unesco.org/ (accessed: December 20, 2011).

Union of International Associations (1984-2007), Yearbook of International Organizations, Munich, Germany: K. G. Saur.

Villanger, Espen, 2007, Arab Foreign Aid: Disbursement Patterns, Aid Policies and Motives, Forum for Development Studies 34, 2: 223-256.

Voeten, Erik, 2000, Clashes in the Assembly, International Organization 54, 2: 185-215.

Voeten, Erik and Adis Merdzanovic, 2009, United Nations General Assembly Voting Data, Georgetown College, Washington, DC, available at: http://hdl.handle.net/1902.1/12379 (accessed: June 2010).

Vreeland, James Raymond, 2010, G20 Revisited: ASK IT SAM! the vreelander, 12 November 2010, available at: http://vreelander.blogspot.co.uk/ (accessed: July 2012).

Wiesenfarth, Manuel and Thomas Kneib, 2010, Bayesian Geoadditive Sample Selection Models, Journal of the Royal Statistical Society: Series C (Applied Statistics) 59, 3: 381-404.

Windmeijer, Frank, 2005, A Finite Sample Correction for the Variance of Linear Efficient Two-step GMM Estimators, Journal of Econometrics 126, 1: 25-51. 
Woods, Ngaire, 2005, The Shifting Politics of Foreign Aid, International Affairs 81, 2: 393409.

Woods, Ngaire, 2008, Whose Aid? Whose Influence? China, Emerging Donors and the Silent Revolution in Development Assistance, International Affairs 84, 6: 1205-1221.

World Bank, 2009, World Development Indicators, CD-Rom, Washington, DC.

World Bank, 2010, The Changing Wealth of Nations, World Bank, Washington, DC, available at: http://data.worldbank.org/data-catalog/wealth-of-nations (accessed: August 2011).

World Bank, 2011, Social Protection for Changing India: Volume 1, The World Bank, Washington, DC, available at: http://go.worldbank.org/OMQD3XEWJ0 (accessed: June 10, 2011).

World Food Programme, 2011, Food Aid Information System, available at http://www.wfp.org/fais/ (accessed: February 2011).

Younas, Javed, 2008, Motivation for Bilateral Aid Allocation: Altruism or Trade Benefits, European Journal of Political Economy 24, 3: 661-674.

Young, Joseph K. and Michael G. Findley, 2011, Can Peace Be Bought? A Sectoral-Level Analysis of Aid's Influence on Transnational Terrorism, Public Choice 149, 3-4: 365381. 
Appendices 
Appendix I.1: Variables and sources

\begin{tabular}{|c|c|c|}
\hline Variable & Description & Source \\
\hline \multicolumn{3}{|l|}{ Aid effort regressions } \\
\hline Aid effort & Total Official Development Assistance as a share of GNI (commitments, in \%) & OECD DAC (http://stats.oecd.org) \\
\hline Debt & General government gross financial liabilities of donor country as a percentage of GDP (in \%) & OECD Economic Outlook (http://stats.oecd.org) \\
\hline (log) GDP per capita & (log) GDP of donor country divided by population (constant 2000 US\$) & WDI (http://databank.worldbank.org) \\
\hline (log) Population & (log) Total population size of donor country & WDI (http://databank.worldbank.org) \\
\hline Government size & Total disbursements of the general government as a share of GDP (in \%) & OECD Economic Outlook (http://stats.oecd.org) \\
\hline Cold War & 1 if Cold War period (1971-1990) & - \\
\hline War on Terror & 1 if War on Terror period (2002-2008) & - \\
\hline Terror worldwide & Number of terror incidents worldwide (4-year average) & ITERATE (Mickolus et al. 2009) \\
\hline Terror DAC & Number of terror incidents with victims from DAC countries (4-year average) & ITERATE (Mickolus et al. 2009) \\
\hline Terror donor & Number of terror incidents with victims from donor country (4-year average) & ITERATE (Mickolus et al. 2009) \\
\hline Aid for education & Aid to education sector (CRS Purpose Code $110, \%$ of total aid commitments) & OECD DAC (http://stats.oecd.org) \\
\hline Aid for GCS & Aid to government and civil society sector (CRS Purpose Code $150, \%$ of total aid commitments) & OECD DAC (http://stats.oecd.org) \\
\hline$(\log ) \mathrm{NGOs}$ & (log) Number of international NGOs operating in donor country (per 100,000 inhabitants) & Union of International Associations (1984-2007) \\
\hline (log) Tertiary school enrollment & (log) Gross enrollment ratio to tertiary education in donor country & WDI (http://databank.worldbank.org) \\
\hline Civil liberties & Civil liberties rated on a seven-point scale, with 1 representing the most free and 7 the least free & Freedom House (2009) \\
\hline \multicolumn{3}{|l|}{ Aid allocation regressions } \\
\hline ODA $>0$ & 1 if aid is commited to recipient country by donor country & OECD DAC (http://stats.oecd.org) \\
\hline$(\log )$ ODA & (log) Total aid commitments to recipient country (constant 2000 US\$) & OECD DAC (http://stats.oecd.org) \\
\hline (log) GDP per capita & (log) GDP of recipient country divided by population (constant 2000 US\$) & WDI (http://databank.worldbank.org) \\
\hline (log) Population & (log) Total population of recipient country & WDI (http://databank.worldbank.org) \\
\hline (log) Disaster & (log) Number of people affected by disasters in recipient country & EM-DAT $(2010)$ \\
\hline Democracy & 1 if the recipient regime qualifies as democratic & Cheibub, Gandhi and Vreeland (2009) \\
\hline UNGA voting & UNGA voting alignment between donor and recipient & Voeten and Merdzanovic (2009) \\
\hline (log) Bilateral exports & (log) Donor exports to recipient country (constant 2000 US\$) & COW (Barberini, Keshk and Pollins 2008) \\
\hline (log) Oil production & (log) Oil production in recipient country in millions of barrels per day & Humphreys (2005), BP (2010) \\
\hline (log) Donor total commitments & (log) Total aid commitments of donor country (constant 2000 US\$) & OECD DAC (http://stats.oecd.org) \\
\hline Bilateral terror donor & Number of terror incidents with victims from donor country conducted by recipient citizens (4-year average) & ITERATE (Mickolus et al. 2009) \\
\hline Bilateral terror DAC & Number of terror incidents with victims from DAC countries conducted by recipient citizens (4-year average) & ITERATE (Mickolus et al. 2009) \\
\hline State sponsor of terror & 1 if a recipient country is classified by the US Secretary of State as a state sponsor of terror & U.S. Department of State \\
\hline Aid for education & Aid to education sector (CRS Purpose Code $110, \%$ of total aid allocated to recipient) & OECD DAC (http://stats.oecd.org) \\
\hline Aid for GCS & Aid to government and civil society sector (CRS Purpose Code $150, \%$ of total aid allocated to recipient) & OECD DAC (http://stats.oecd.org) \\
\hline (log) Primary school enrollment & $(\log )$ Gross enrollment ratio to primary education in recipient country & WDI (http://databank.worldbank.org) \\
\hline (log) Tertiary school enrollment & $(\log )$ Gross enrollment ratio to tertiary education in recipient country & WDI (http://databank.worldbank.org) \\
\hline$(\log ) \mathrm{NGOs}$ & (log) Number of international NGOs operating in recipient country (per 100,000 inhabitants) & Union of International Associations (1984-2007) \\
\hline Donor aid for education & Total aid to education sector (CRS Purpose Code $110, \%$ of donor's total aid commitments) & OECD DAC (http://stats.oecd.org) \\
\hline Donor aid for GCS & Total aid to government and civil society sector (CRS Purpose Code $150, \%$ of donor's total aid commitments) & OECD DAC (http://stats.oecd.org) \\
\hline
\end{tabular}

Notes:

- Values that were only available in current US dollars have been transformed to constant 2000 US dollars using US Consumer Price Indices obtained from the World Development Indicators

- The value of 1 has been added to Bilateral exports, Oil production and Disaster before taking logarithms 
Appendix I.2: Descriptive statistics

\begin{tabular}{|c|c|c|c|c|c|}
\hline Variable & \# obs & Mean & Std. Dev. & Min & Max \\
\hline \multicolumn{6}{|l|}{ Aid effort regressions } \\
\hline Aid effort & 614 & 0.51 & 0.28 & 0.10 & 1.78 \\
\hline Debt & 614 & 60.04 & 29.39 & 7.65 & 175.27 \\
\hline (log) GDP per capita & 614 & 9.93 & 0.34 & 9.13 & 10.94 \\
\hline (log) Population & 614 & 16.74 & 1.34 & 12.92 & 19.52 \\
\hline Government size & 614 & 45.59 & 8.27 & 20.45 & 70.93 \\
\hline Cold War & 614 & 0.40 & 0.49 & 0.00 & 1.00 \\
\hline War on Terror & 614 & 0.25 & 0.43 & 0.00 & 1.00 \\
\hline Terror worldwide & 603 & 126.44 & 42.56 & 57.25 & 207.50 \\
\hline Terror DAC & 603 & 87.79 & 30.02 & 34.75 & 148.75 \\
\hline Terror donor & 603 & 5.14 & 12.83 & 0.00 & 69.00 \\
\hline Aid for education & 601 & 11.34 & 8.89 & 0.49 & 50.86 \\
\hline Aid for GCS & 582 & 5.98 & 7.63 & 0.01 & 60.20 \\
\hline (log) NGOs & 614 & 2.40 & 1.37 & -1.08 & 5.69 \\
\hline (log) Tertiary school enrollment & 554 & 3.70 & 0.48 & 2.26 & 4.58 \\
\hline Civil liberties & 592 & 1.23 & 0.45 & 1.00 & 3.00 \\
\hline \multicolumn{6}{|l|}{ Aid allocation regressions } \\
\hline$O D A>0$ & 71279 & 0.66 & 0.47 & 0.00 & 1.00 \\
\hline (log) ODA & 47132 & 14.67 & 2.53 & 8.99 & 23.43 \\
\hline (log) GDP per capita & 71279 & 6.91 & 1.23 & 4.13 & 10.81 \\
\hline (log) Population & 71279 & 15.53 & 1.89 & 9.85 & 20.99 \\
\hline (log) Disaster & 71279 & 5.22 & 5.59 & 0.00 & 19.65 \\
\hline Democracy & 71279 & 0.38 & 0.49 & 0.00 & 1.00 \\
\hline UNGA voting & 71279 & 0.66 & 0.12 & 0.01 & 0.97 \\
\hline (log) Bilateral exports & 71279 & 15.69 & 4.39 & 0.00 & 25.67 \\
\hline (log) Oil production & 71279 & 4.45 & 5.94 & 0.00 & 16.22 \\
\hline (log) Donor total commitments & 71279 & 21.33 & 1.38 & 17.25 & 24.08 \\
\hline Bilateral terror donor & 68082 & 0.03 & 0.33 & 0.00 & 26.25 \\
\hline Bilateral terror DAC & 71279 & 0.52 & 1.91 & 0.00 & 31.75 \\
\hline State sponsor of terror & 60439 & 0.02 & 0.15 & 0.00 & 1.00 \\
\hline Aid for education & 16908 & 26.18 & 31.70 & 0.00 & 100.00 \\
\hline Aid for GCS & 14885 & 21.12 & 28.44 & 0.00 & 100.00 \\
\hline (log) Primary school enrollment & 57212 & 4.48 & 0.37 & 2.43 & 5.15 \\
\hline (log) Tertiary school enrollment & 42573 & 1.64 & 1.39 & -4.36 & 4.29 \\
\hline$(\log )$ NGOs & 60771 & 1.79 & 1.51 & -3.60 & 5.87 \\
\hline Donor aid for education & 65760 & 11.77 & 8.90 & 0.39 & 52.62 \\
\hline Donor aid for GCS & 63782 & 5.55 & 7.23 & 0.01 & 60.20 \\
\hline
\end{tabular}

Notes:

- Aid effort regressions: statistics for estimation sample as in Table 1 (column 1)

- Aid allocation regressions: statistics for estimation sample as in Table 2 (column 1) 
Appendix I.3: Aid allocation and interactions (OLS, 1971-2008)

\begin{tabular}{|c|c|c|c|c|c|c|c|c|}
\hline & $\begin{array}{c}\text { (1) } \\
\mathrm{ODA}>0\end{array}$ & $\begin{array}{c}(2) \\
O D A>0\end{array}$ & $\begin{array}{c}\text { (3) } \\
O D A>0\end{array}$ & $\begin{array}{c}\text { (4) } \\
O D A>0\end{array}$ & $\begin{array}{c}(5) \\
O D A>0 \\
\end{array}$ & $\begin{array}{c}(6) \\
O D A>0\end{array}$ & $\begin{array}{c}(7) \\
O D A>0\end{array}$ & $\begin{array}{c}(8) \\
O D A>0 \\
\end{array}$ \\
\hline (log) GDP per capita (t-1) & $\begin{array}{c}-0.0644^{* * *} \\
(0.00)\end{array}$ & $\begin{array}{c}-0.0646 * * * \\
(0.00)\end{array}$ & $\begin{array}{c}-0.0640^{* * *} \\
(0.00)\end{array}$ & $\begin{array}{c}-0.0702^{* * *} \\
(0.00)\end{array}$ & $\begin{array}{c}-0.0590^{* * *} \\
(0.00)\end{array}$ & $\begin{array}{c}-0.0597^{* * *} \\
(0.00)\end{array}$ & $\begin{array}{c}-0.0583^{* * *} \\
(0.00)\end{array}$ & $\begin{array}{c}-0.0636^{* * *} \\
(0.00)\end{array}$ \\
\hline (log) Population (t-1) & $\begin{array}{c}0.2148^{* * *} \\
(0.00)\end{array}$ & $\begin{array}{c}0.2148^{* * *} \\
(0.00)\end{array}$ & $\begin{array}{c}0.2143^{* * *} \\
(0.00)\end{array}$ & $\begin{array}{c}0.1784^{* * *} \\
(0.00)\end{array}$ & $\begin{array}{c}0.2217^{* * *} \\
(0.00)\end{array}$ & $\begin{array}{c}0.2207^{* * *} \\
(0.00)\end{array}$ & $\begin{array}{c}0.2178^{* * *} \\
(0.00)\end{array}$ & $\begin{array}{c}0.1493^{* * *} \\
(0.00)\end{array}$ \\
\hline$(\log )$ Disaster (t-1) & $\begin{array}{c}0.0020^{* * *} \\
(0.00)\end{array}$ & $\begin{array}{c}0.0020^{* * * *} \\
(0.00)\end{array}$ & $\begin{array}{c}0.0020^{* * *} \\
(0.00)\end{array}$ & $\begin{array}{c}0.0015^{* * *} \\
(0.00)\end{array}$ & $\begin{array}{c}0.0021 * * * \\
(0.00)\end{array}$ & $\begin{array}{c}0.0021 * * * \\
(0.00)\end{array}$ & $\begin{array}{c}0.0022 * * * \\
(0.00)\end{array}$ & $\begin{array}{c}0.0016^{* * *} \\
(0.00)\end{array}$ \\
\hline Democracy (t-1) & $\begin{array}{c}0.0519 * * * \\
(0.00)\end{array}$ & $\begin{array}{c}0.0510 * * * \\
(0.00)\end{array}$ & $\begin{array}{c}0.0521 * * * \\
(0.00)\end{array}$ & $\begin{array}{c}0.0305^{* * *} \\
(0.00)\end{array}$ & $\begin{array}{c}0.0589 * * * \\
(0.00)\end{array}$ & $\begin{array}{c}0.0518^{* * *} \\
(0.00)\end{array}$ & $\begin{array}{c}0.0582^{* * *} \\
(0.00)\end{array}$ & $\begin{array}{c}0.0387^{* * *} \\
(0.00)\end{array}$ \\
\hline UNGA voting (t-1) & $\begin{array}{c}0.0018 \\
(0.95)\end{array}$ & $\begin{array}{l}0.0011 \\
(0.97)\end{array}$ & $\begin{array}{c}-0.0026 \\
(0.93)\end{array}$ & $\begin{array}{c}-0.0335 \\
(0.32)\end{array}$ & $\begin{array}{c}0.0604^{* *} \\
(0.03)\end{array}$ & $\begin{array}{c}0.0630^{* *} \\
(0.03)\end{array}$ & $\begin{array}{c}0.0484^{*} \\
(0.09)\end{array}$ & $\begin{array}{c}0.0304 \\
(0.31)\end{array}$ \\
\hline$(\log )$ Bilateral exports (t-1) & $\begin{array}{c}0.0195^{* * *} \\
(0.00)\end{array}$ & $\begin{array}{c}0.0195^{* * *} \\
(0.00)\end{array}$ & $\begin{array}{c}0.0195^{* * *} \\
(0.00)\end{array}$ & $\begin{array}{c}0.0201^{* * *} \\
(0.00)\end{array}$ & $\begin{array}{c}0.0195 * * * \\
(0.00)\end{array}$ & $\begin{array}{c}0.0195 * * * \\
(0.00)\end{array}$ & $\begin{array}{c}0.0194^{* * *} \\
(0.00)\end{array}$ & $\begin{array}{c}0.0203 * * * \\
(0.00)\end{array}$ \\
\hline$(\log )$ Oil production (t-1) & $\begin{array}{c}-0.0004 \\
(0.74)\end{array}$ & $\begin{array}{c}-0.0004 \\
(0.72)\end{array}$ & $\begin{array}{c}-0.0004 \\
(0.72)\end{array}$ & $\begin{array}{c}-0.0019 \\
(0.11)\end{array}$ & $\begin{array}{c}-0.0009 \\
(0.41)\end{array}$ & $\begin{array}{c}-0.0014 \\
(0.23)\end{array}$ & $\begin{array}{c}-0.0012 \\
(0.29)\end{array}$ & $\begin{array}{c}-0.0034^{* * *} \\
(0.00)\end{array}$ \\
\hline (log) Donor total commitments (t-1) & $\begin{array}{c}0.1044^{* * *} \\
(0.00)\end{array}$ & $\begin{array}{c}0.1043^{* * * *} \\
(0.00)\end{array}$ & $\begin{array}{c}0.1041^{* * *} \\
(0.00)\end{array}$ & $\begin{array}{c}0.1264^{* * *} \\
(0.00)\end{array}$ & $\begin{array}{c}0.1117 * * * \\
(0.00)\end{array}$ & $\begin{array}{c}0.1116^{* * *} \\
(0.00)\end{array}$ & $\begin{array}{c}0.1117^{* * * *} \\
(0.00)\end{array}$ & $\begin{array}{c}0.1326^{* * *} \\
(0.00)\end{array}$ \\
\hline Cold War & $\begin{array}{c}0.0310^{* * *} \\
(0.00)\end{array}$ & $\begin{array}{c}0.0302^{* * *} \\
(0.00)\end{array}$ & $\begin{array}{c}0.0301^{* * *} \\
(0.00)\end{array}$ & $\begin{array}{c}0.0334^{* * * *} \\
(0.00)\end{array}$ & $\begin{array}{c}0.0385^{* * *} \\
(0.00)\end{array}$ & $\begin{array}{c}0.0319 * * * \\
(0.00)\end{array}$ & $\begin{array}{c}0.0320^{* * *} \\
(0.00)\end{array}$ & $\begin{array}{c}0.0312^{* * *} \\
(0.00)\end{array}$ \\
\hline War on Terror & $\begin{array}{c}0.0150^{* *} \\
(0.02)\end{array}$ & $\begin{array}{c}0.0149 * * \\
(0.02)\end{array}$ & $\begin{array}{c}0.0151^{* *} \\
(0.02)\end{array}$ & $\begin{array}{c}0.0133^{* *} \\
(0.04)\end{array}$ & $\begin{array}{c}0.0150 * * \\
(0.02)\end{array}$ & $\begin{array}{c}0.0173^{* * *} \\
(0.01)\end{array}$ & $\begin{array}{c}0.0175^{* * *} \\
(0.01)\end{array}$ & $\begin{array}{c}0.0201 * * * \\
(0.00)\end{array}$ \\
\hline Bilateral terror donor ( $\mathrm{t}-1)$ & $\begin{array}{c}-0.0046 \\
(0.37)\end{array}$ & $\begin{array}{c}-0.0266 \\
(0.12)\end{array}$ & $\begin{array}{c}-0.0295 \\
(0.19)\end{array}$ & $\begin{array}{c}-0.0043 \\
(0.34)\end{array}$ & & & & \\
\hline Bilateral terror DAC (t-1) & & & & & $\begin{array}{c}-0.0018 \\
(0.28)\end{array}$ & $\begin{array}{c}-0.0087 * * * \\
(0.00)\end{array}$ & $\begin{array}{c}-0.0228^{* *} \\
(0.02)\end{array}$ & $\begin{array}{c}-0.0017 \\
(0.22)\end{array}$ \\
\hline State sponsor of terror $(\mathrm{t}-1)$ & & & & $\begin{array}{c}0.0594 \\
(0.18)\end{array}$ & & & & $\begin{array}{c}0.0956^{* *} \\
(0.04)\end{array}$ \\
\hline Interaction of terror with: & $\begin{array}{c}\text { War on Terror } \\
-0.0017 \\
(0.75)\end{array}$ & $\begin{array}{c}\text { Democracy } \\
0.0199 \\
(0.23)\end{array}$ & $\begin{array}{c}\text { UNGA voting } \\
0.0473 \\
(0.40)\end{array}$ & $\begin{array}{c}\text { State Terror } \\
-0.077 \\
(0.18)\end{array}$ & $\begin{array}{c}\text { War on Terror } \\
0.0071^{* * *} \\
(0.00)\end{array}$ & $\begin{array}{c}\text { Democracy } \\
0.0078^{* * *} \\
(0.00)\end{array}$ & $\begin{array}{c}\text { UNGA voting } \\
0.0277^{* *} \\
(0.05)\end{array}$ & $\begin{array}{c}\text { State Terror } \\
-0.0124^{*} \\
(0.05)\end{array}$ \\
\hline & $\begin{array}{c}\text { Cold War } \\
-0.0198 \\
(0.11)\end{array}$ & & & & $\begin{array}{c}\text { Cold War } \\
-0.0084^{* * *} \\
(0.00)\end{array}$ & & & \\
\hline Donor dummies & Yes & Yes & Yes & Yes & Yes & Yes & Yes & Yes \\
\hline Recipient dummies & Yes & Yes & Yes & Yes & Yes & Yes & Yes & Yes \\
\hline R-squared & 0.37 & 0.37 & 0.37 & 0.37 & 0.37 & 0.37 & 0.37 & 0.37 \\
\hline Number of observations & 68082 & 68082 & 68082 & 58730 & 71279 & 71279 & 71279 & 60439 \\
\hline Number of country-pairs & 2794 & 2794 & 2794 & 2794 & 2856 & 2856 & 2856 & 2856 \\
\hline
\end{tabular}

Note: Robust $p$-values in parentheses $\left({ }^{* * *} p<0.01,{ }^{* *} p<0.05,{ }^{*} p<0.1\right)$. 
Appendix I.4: Aid effort and aid allocation by donor (selected results, 1971-2008)

\begin{tabular}{|c|c|c|c|c|}
\hline & $\begin{array}{c}\text { (1) } \\
\text { OLS } \\
\text { Aid effort }\end{array}$ & $\begin{array}{c}\text { (2) } \\
\text { OLS } \\
\text { Aid effort }\end{array}$ & $\begin{array}{c}\text { (3) } \\
\text { Heckman } \\
\text { (log) ODA }\end{array}$ & $\begin{array}{c}(4) \\
\text { Heckman } \\
(\log ) \text { ODA }\end{array}$ \\
\hline \multicolumn{5}{|l|}{ War on Terror } \\
\hline \multirow[t]{2}{*}{ Canada } & 0.0612 & $0.0881^{*}$ & -0.1774 & -0.1412 \\
\hline & $(0.18)[0.66]$ & $(0.06)[0.60]$ & $(0.10)[0.01]$ & $(0.21)[0.01]$ \\
\hline \multirow[t]{2}{*}{ Germany } & 0.0332 & 0.0258 & $-0.3998 * * *$ & $-0.4417^{* * *}$ \\
\hline & (0.47) [0.37] & $(0.57)[0.56]$ & $(0.00)[0.00]$ & $(0.00)[0.00]$ \\
\hline \multirow[t]{2}{*}{ Denmark } & 0.0420 & -0.0341 & 0.0003 & -0.0095 \\
\hline & (0.71) [0.71] & $(0.72)[0.36]$ & $(1.00)[0.21]$ & (0.96) [0.17] \\
\hline \multirow[t]{2}{*}{ France } & $0.1122 * *$ & $0.2051 * * *$ & 0.1083 & 0.0739 \\
\hline & (0.01) [0.67] & $(0.00)$ [0.03] & $(0.15)[0.25]$ & $(0.31)[0.13]$ \\
\hline \multirow[t]{2}{*}{ United Kingdom } & 0.0861 & 0.0541 & 0.0537 & 0.0186 \\
\hline & (0.11) [0.99] & $(0.27)[0.94]$ & $(0.72)[0.25]$ & $(0.90)[0.15]$ \\
\hline \multirow[t]{2}{*}{ Italy } & -0.0477 & -0.0507 & -0.2123 & -0.1961 \\
\hline & $(0.36)[0.04]$ & $(0.23)[0.03]$ & $(0.10)[0.01]$ & (0.13) [0.01] \\
\hline \multirow[t]{2}{*}{ Japan } & -0.0085 & -0.0080 & $-0.2475^{*}$ & $-0.3457 * * *$ \\
\hline & (0.89) [0.17] & $(0.89)[0.32]$ & $(0.05)[0.00]$ & $(0.00)[0.00]$ \\
\hline \multirow[t]{2}{*}{ Netherlands } & -0.0434 & -0.0308 & $-0.3874 * * *$ & $-0.3867^{* * *}$ \\
\hline & (0.78) [0.41] & $(0.90)[0.72]$ & $(0.01)[0.00]$ & (0.01) [0.00] \\
\hline \multirow[t]{2}{*}{ Norway } & -0.0328 & 0.0034 & $0.2941 * *$ & $0.3281 * *$ \\
\hline & (0.78) [0.33] & (0.98) [0.69] & $(0.05)$ [0.98] & (0.03) [0.92] \\
\hline \multirow[t]{2}{*}{ Sweden } & -0.0083 & 0.0547 & $0.4007^{* * *}$ & $0.4093 * * *$ \\
\hline & (0.95) [0.48] & $(0.70)[0.98]$ & $(0.00)[0.56]$ & $(0.00)$ [0.59] \\
\hline \multirow[t]{2}{*}{ United States } & $0.0871^{* *}$ & $0.0583^{*}$ & $0.2901 * *$ & $0.3089 * *$ \\
\hline & $(0.02)$ & $(0.09)$ & $(0.04)$ & $(0.03)$ \\
\hline \multicolumn{5}{|l|}{ Terror donor (t-1) } \\
\hline \multirow[t]{2}{*}{ Canada } & & 0.0267 & & 0.7430 \\
\hline & & $(0.46)[0.45]$ & & (0.17) [0.24] \\
\hline \multirow[t]{2}{*}{ Germany } & & -0.0025 & & -0.0273 \\
\hline & & $(0.88)[0.88]$ & & $(0.90)[0.57]$ \\
\hline \multirow[t]{2}{*}{ Denmark } & & 0.1823 & & -0.1613 \\
\hline & & (0.18) [0.18] & & (0.84) [0.74] \\
\hline \multirow[t]{2}{*}{ France } & & 0.0059 & & $-0.1014^{* * *}$ \\
\hline & & $(0.21)[0.21]$ & & $(0.00)[0.00]$ \\
\hline \multirow[t]{2}{*}{ United Kingdom } & & $-0.0177^{*}$ & & -0.1107 \\
\hline & & $(0.06)[0.06]$ & & $(0.40)[0.11]$ \\
\hline \multirow[t]{2}{*}{ Italy } & & -0.0118 & & $-0.3156 * *$ \\
\hline & & $(0.24)[0.25]$ & & $(0.04)[0.01]$ \\
\hline \multirow[t]{2}{*}{ Japan } & & 0.0085 & & -0.0891 \\
\hline & & $(0.34)[0.34]$ & & $(0.80)$ [0.59] \\
\hline \multirow[t]{2}{*}{ Netherlands } & & 0.0650 & & 0.2080 \\
\hline & & (0.10) [0.10] & & $(0.46)[0.70]$ \\
\hline Norway & & -0.0703 & & 3.0461 \\
\hline & & $(0.54)[0.54]$ & & (0.18) [0.20] \\
\hline Sweden & & 0.0432 & & $-3.9207^{* *}$ \\
\hline & & $(0.72)[0.72]$ & & $(0.03)[0.03]$ \\
\hline United States & & -0.0001 & & $0.1002^{* * *}$ \\
\hline & & $(0.92)$ & & $(0.00)$ \\
\hline Control variables & Yes & Yes & Yes & Yes \\
\hline Donor dummies & Yes & Yes & & \\
\hline Pair effects & & & Yes & Yes \\
\hline Observations & 387 & 378 & 32325 & 31589 \\
\hline
\end{tabular}

Notes: The control variables of Table 1 (colums 1 and 2) or Table 2 (columns 3 and 4) are included but not shown. Columns 3 and 4 report the results of the Heckman allocation equation. Robust $p$-values indicating the significance of the coefficients are shown in parentheses $(* * * p<0.01, * * p<0.05, * p<0.1)$, while the squared brackets report $p$-values indicating whether the respective coefficient is different compared to the United States according to a Wald test. 
Appendix I.5: Share of aid for education (\% of aid budget, OLS, 1971-2008)

\begin{tabular}{|c|c|c|c|c|c|}
\hline & $(1)$ & $(2)$ & (3) & (4) & (5) \\
\hline Aid for education (t-1) & $\begin{array}{l}0.5258^{* * *} \\
\quad(0.00)\end{array}$ & $\begin{array}{l}0.5290^{* * *} \\
(0.00)\end{array}$ & $\begin{array}{l}0.5285^{* * *} \\
\quad(0.00)\end{array}$ & $\begin{array}{l}0.5257^{* * *} \\
\quad(0.00)\end{array}$ & $\begin{array}{l}0.5264^{* * *} \\
\quad(0.00)\end{array}$ \\
\hline (log) GDP per capita (t-1) & $\begin{array}{c}-6.1521^{*} \\
(0.07)\end{array}$ & $\begin{array}{c}-5.6129 * \\
(0.07)\end{array}$ & $\begin{array}{c}-5.8025^{*} \\
(0.07)\end{array}$ & $\begin{array}{l}-6.1525^{*} \\
(0.07)\end{array}$ & $\begin{array}{l}-6.3575^{*} \\
(0.07)\end{array}$ \\
\hline$(\log )$ NGOs (t-1) & $\begin{array}{c}5.5604^{*} \\
(0.06)\end{array}$ & $\begin{array}{l}3.5903 \\
(0.10)\end{array}$ & $\begin{array}{c}4.0712^{*} \\
(0.07)\end{array}$ & $\begin{array}{c}5.5642^{*} \\
(0.06)\end{array}$ & $\begin{array}{c}5.6723^{*} \\
(0.05)\end{array}$ \\
\hline (log) Tertiary school enrollment (t-1) & $\begin{array}{l}0.1149 \\
(0.92)\end{array}$ & $\begin{array}{c}0.2246 \\
(0.85)\end{array}$ & $\begin{array}{c}0.2916 \\
(0.81)\end{array}$ & $\begin{array}{l}0.133 \\
(0.92)\end{array}$ & $\begin{array}{l}0.2213 \\
(0.87)\end{array}$ \\
\hline Cold War & $\begin{array}{l}1.2539 \\
(0.20)\end{array}$ & $\begin{array}{c}0.2629 \\
(0.76)\end{array}$ & $\begin{array}{c}0.4508 \\
(0.64)\end{array}$ & $\begin{array}{l}1.2693 \\
(0.21)\end{array}$ & $\begin{array}{l}1.3456 \\
(0.22)\end{array}$ \\
\hline War on Terror & $\begin{array}{c}-0.4843 \\
(0.46)\end{array}$ & $\begin{array}{r}0.5724 \\
(0.46)\end{array}$ & $\begin{array}{r}0.3043 \\
(0.68)\end{array}$ & $\begin{array}{c}-0.4982 \\
(0.49)\end{array}$ & $\begin{array}{c}-0.5488 \\
(0.48)\end{array}$ \\
\hline Terror worldwide (t-1) & & $\begin{array}{r}0.0147 \\
(0.11)\end{array}$ & & & \\
\hline Terror DAC (t-1) & & & $\begin{array}{c}0.0176 \\
(0.16)\end{array}$ & & \\
\hline Terror donor $(\mathrm{t}-1)$ & & & & $\begin{array}{c}-0.0040 \\
(0.88)\end{array}$ & $\begin{array}{c}0.0081 \\
(0.75)\end{array}$ \\
\hline Cold War * Terror donor (t-1) & & & & & $\begin{array}{c}-0.0049 \\
(0.77)\end{array}$ \\
\hline War on Terror * Terror donor ( $\mathrm{t}-1)$ & & & & & $\begin{array}{c}0.0253 \\
(0.50) \\
\end{array}$ \\
\hline Number of observations & 606 & 606 & 606 & 606 & 606 \\
\hline Number of countries & 22 & 22 & 22 & 22 & 22 \\
\hline Adjusted R-squared & 0.35 & 0.35 & 0.35 & 0.35 & 0.35 \\
\hline
\end{tabular}

Note: Robust $p$-values in parentheses $\left(* * * p<0.01,{ }^{* *} p<0.05, * p<0.1\right)$. 
Appendix I.6: Share of aid for government and civil society (\% of aid budget, OLS, 1971-2008)

\begin{tabular}{|c|c|c|c|c|c|}
\hline & (1) & (2) & (3) & (4) & (5) \\
\hline Aid for GCS (t-1) & $\begin{array}{c}0.6585^{* * *} \\
(0.00)\end{array}$ & $\begin{array}{c}0.6433^{* * *} \\
(0.00)\end{array}$ & $\begin{array}{c}0.6484^{* * *} \\
(0.00)\end{array}$ & $\begin{array}{c}0.6585^{* * *} \\
(0.00)\end{array}$ & $\begin{array}{c}0.6579 * * * \\
(0.00)\end{array}$ \\
\hline (log) GDP per capita (t-1) & $\begin{array}{c}5.0342^{*} \\
(0.05)\end{array}$ & $\begin{array}{c}4.2099 \\
(0.15)\end{array}$ & $\begin{array}{c}4.3013 \\
(0.13)\end{array}$ & $\begin{array}{c}5.0357^{*} \\
(0.05)\end{array}$ & $\begin{array}{c}4.8531^{*} \\
(0.06)\end{array}$ \\
\hline$(\log ) \mathrm{NGOs}(\mathrm{t}-1)$ & $\begin{array}{c}-0.5150 \\
(0.71)\end{array}$ & $\begin{array}{c}1.7484 \\
(0.42)\end{array}$ & $\begin{array}{c}1.2377 \\
(0.52)\end{array}$ & $\begin{array}{c}-0.5123 \\
(0.71)\end{array}$ & $\begin{array}{l}-0.352 \\
(0.81)\end{array}$ \\
\hline Civil liberties (t-1) & $\begin{array}{c}0.7722 \\
(0.52)\end{array}$ & $\begin{array}{c}0.7563 \\
(0.53)\end{array}$ & $\begin{array}{c}0.7324 \\
(0.54)\end{array}$ & $\begin{array}{c}0.7731 \\
(0.52)\end{array}$ & $\begin{array}{c}0.7613 \\
(0.52)\end{array}$ \\
\hline Cold War & $\begin{array}{c}-0.6012 \\
(0.17)\end{array}$ & $\begin{array}{c}0.6075 \\
(0.34)\end{array}$ & $\begin{array}{c}0.4708 \\
(0.39)\end{array}$ & $\begin{array}{c}-0.5986 \\
(0.16)\end{array}$ & $\begin{array}{c}-0.6156 \\
(0.17)\end{array}$ \\
\hline War on Terror & $\begin{array}{l}0.889 \\
(0.10)\end{array}$ & $\begin{array}{c}-0.3869 \\
(0.62)\end{array}$ & $\begin{array}{c}-0.1404 \\
(0.85)\end{array}$ & $\begin{array}{c}0.8869 \\
(0.11)\end{array}$ & $\begin{array}{c}0.7878 \\
(0.18)\end{array}$ \\
\hline Terror worldwide (t-1) & & $\begin{array}{c}-0.0196^{* *} \\
(0.01)\end{array}$ & & & \\
\hline Terror DAC (t-1) & & & $\begin{array}{c}-0.0251^{* * *} \\
(0.01)\end{array}$ & & \\
\hline Terror donor $(\mathrm{t}-1)$ & & & & $\begin{array}{c}-0.0009 \\
(0.97)\end{array}$ & $\begin{array}{c}0.0024 \\
(0.91)\end{array}$ \\
\hline Cold War * Terror donor (t-1) & & & & & $\begin{array}{c}0.0076 \\
(0.72)\end{array}$ \\
\hline War on Terror * Terror donor ( $\mathrm{t}-1)$ & & & & & $\begin{array}{c}0.0418 \\
(0.30)\end{array}$ \\
\hline Number of observations & 617 & 617 & 617 & 617 & 617 \\
\hline Number of countries & 22 & 22 & 22 & 22 & 22 \\
\hline Adjusted R-squared & 0.67 & 0.68 & 0.67 & 0.67 & 0.67 \\
\hline
\end{tabular}

Note: Robust $p$-values in parentheses $(* * * p<0.01, * * p<0.05, * p<0.1)$. 
Appendix I.7: Share of aid for education and government and civil society

(\% of total aid allocated to recipient, OLS, 1971-2008)

\begin{tabular}{|c|c|c|c|c|c|c|}
\hline & (1) & $\begin{array}{c}\text { (2) } \\
\text { Aid for educatior }\end{array}$ & (3) & (4) & $\begin{array}{c}\text { (5) } \\
\text { Aid for GCS }\end{array}$ & (6) \\
\hline (log) GDP per capita (t-1) & $\begin{array}{c}6.6539 * * * \\
(0.01)\end{array}$ & $\begin{array}{c}6.9416^{* * *} \\
(0.01)\end{array}$ & $\begin{array}{c}6.5250^{* * *} \\
(0.01)\end{array}$ & $\begin{array}{l}1.8423 \\
(0.36)\end{array}$ & $\begin{array}{l}0.616 \\
(0.77)\end{array}$ & $\begin{array}{l}1.6712 \\
(0.41)\end{array}$ \\
\hline Democracy $(t-1)$ & $\begin{array}{l}-2.3438 \\
(0.14)\end{array}$ & $\begin{array}{l}-2.368 \\
(0.13)\end{array}$ & $\begin{array}{l}-2.3313 \\
(0.14)\end{array}$ & $\begin{array}{c}-0.1745 \\
(0.85)\end{array}$ & $\begin{array}{c}-0.6705 \\
(0.48)\end{array}$ & $\begin{array}{l}-0.163 \\
(0.86)\end{array}$ \\
\hline (log) Primary school enrollment (t-1) & $\begin{array}{c}3.4211 \\
(0.29)\end{array}$ & $\begin{array}{c}3.5475 \\
(0.27)\end{array}$ & $\begin{array}{c}3.4709 \\
(0.28)\end{array}$ & & & \\
\hline (log) Tertiary school enrollment (t-1) & $\begin{array}{c}-6.0532^{* * *} \\
(0.00)\end{array}$ & $\begin{array}{c}-6.1107^{* * *} \\
(0.00)\end{array}$ & $\begin{array}{c}-6.0433^{* * *} \\
(0.00)\end{array}$ & & & \\
\hline Donor aid for education ( $t-1)$ & $\begin{array}{r}0.1097 \\
(0.15)\end{array}$ & $\begin{array}{c}0.1128 \\
(0.14)\end{array}$ & $\begin{array}{c}0.1123 \\
(0.14)\end{array}$ & & & \\
\hline (log) NGOs (t-1) & & & & $\begin{array}{c}-0.3385 \\
(0.84)\end{array}$ & $\begin{array}{l}16,808 \\
(0.40)\end{array}$ & $\begin{array}{c}-0.2921 \\
(0.86)\end{array}$ \\
\hline Donor aid for GCS (t-1) & & & & $\begin{array}{l}0.3003^{* * *} \\
(0.00)\end{array}$ & $\begin{array}{l}0.3075^{* * *} \\
(0.00)\end{array}$ & $\begin{array}{l}0.2996^{* * *} \\
(0.00)\end{array}$ \\
\hline Cold War & $\begin{array}{l}4.7978^{* * *} \\
(0.00)\end{array}$ & $\begin{array}{c}4.7007^{* * *} \\
(0.00)\end{array}$ & $\begin{array}{l}4.7455^{* * *} \\
(0.00)\end{array}$ & $\begin{array}{c}1.8434^{*} \\
(0.07)\end{array}$ & $\begin{array}{c}2.0826 * * \\
(0.04)\end{array}$ & $\begin{array}{c}1.8173^{*} \\
(0.07)\end{array}$ \\
\hline War on Terror & $\begin{array}{c}-0.8434 \\
(0.37)\end{array}$ & $\begin{array}{c}-0.8482 \\
(0.37)\end{array}$ & $\begin{array}{c}-0.9254 \\
(0.33)\end{array}$ & $\begin{array}{c}0.4244 \\
(0.47)\end{array}$ & $\begin{array}{l}0.438 \\
(0.46)\end{array}$ & $\begin{array}{l}0.3785 \\
(0.52)\end{array}$ \\
\hline Bilateral terror donor ( $\mathrm{t}-1)$ & & $\begin{array}{c}-1.2459 \\
(0.14)\end{array}$ & & & $\begin{array}{c}-0.8614 \\
(0.20)\end{array}$ & \\
\hline Bilateral terror DAC $(\mathrm{t}-1)$ & & & $\begin{array}{c}-0.2157 \\
(0.11) \\
\end{array}$ & & & $\begin{array}{c}-0.2348^{* *} \\
(0.03) \\
\end{array}$ \\
\hline Number of observations & 11124 & 10970 & 11124 & 16854 & 16455 & 16854 \\
\hline Number of countries & 1851 & 1791 & 1851 & 2046 & 1979 & 2046 \\
\hline R-Squared & 0.02 & 0.02 & 0.02 & 0.01 & 0.01 & 0.01 \\
\hline
\end{tabular}

Note: Robust $p$-values in parentheses $(* * * p<0.01, * * p<0.05, * p<0.1)$. 
Appendix I.8: Number of terror attacks targeted at countries (1967-2007)

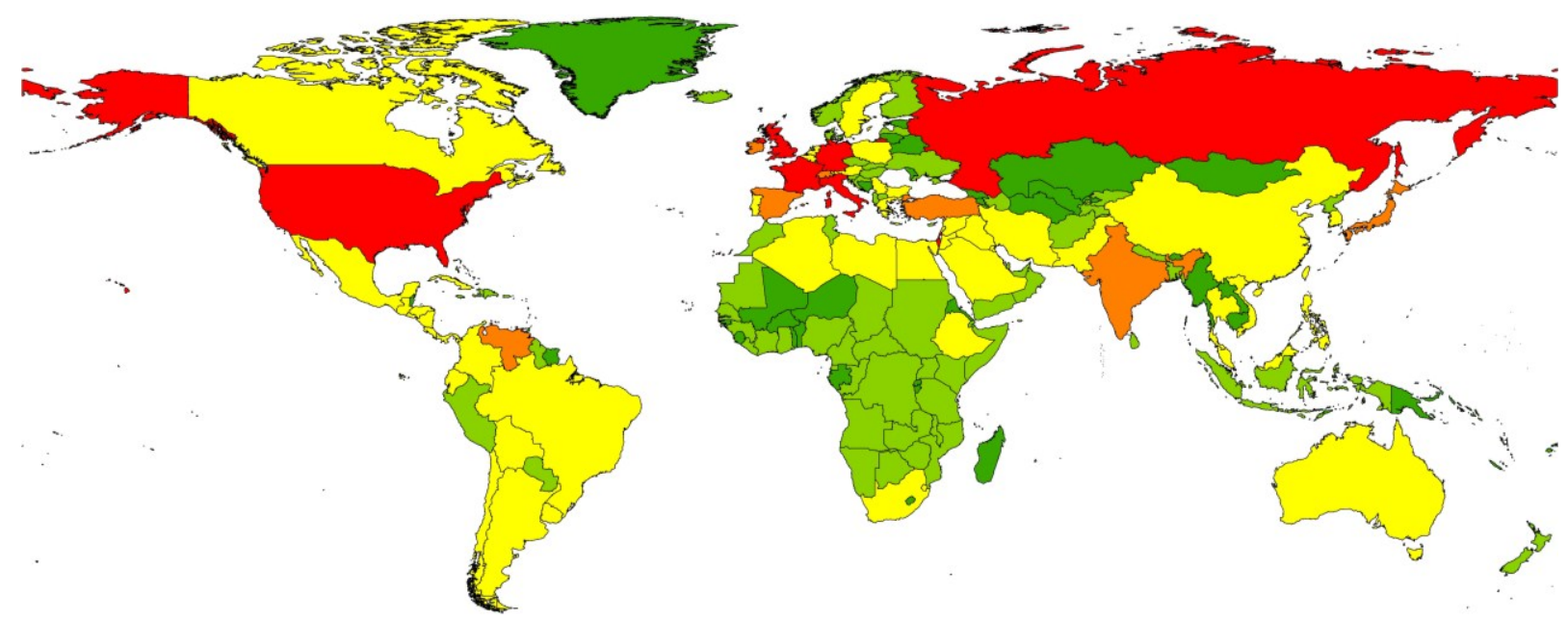

Note: Colors indicate the number of terrorist attacks against citizens of the respective country - dark green: 0 incidents, light green: 1-10 incidents, yellow: 11-50 incidents, orange: 51-100 incidents, red: >100 incidents

Appendix I.9: Number of terror attacks originating from countries (1967-2007)

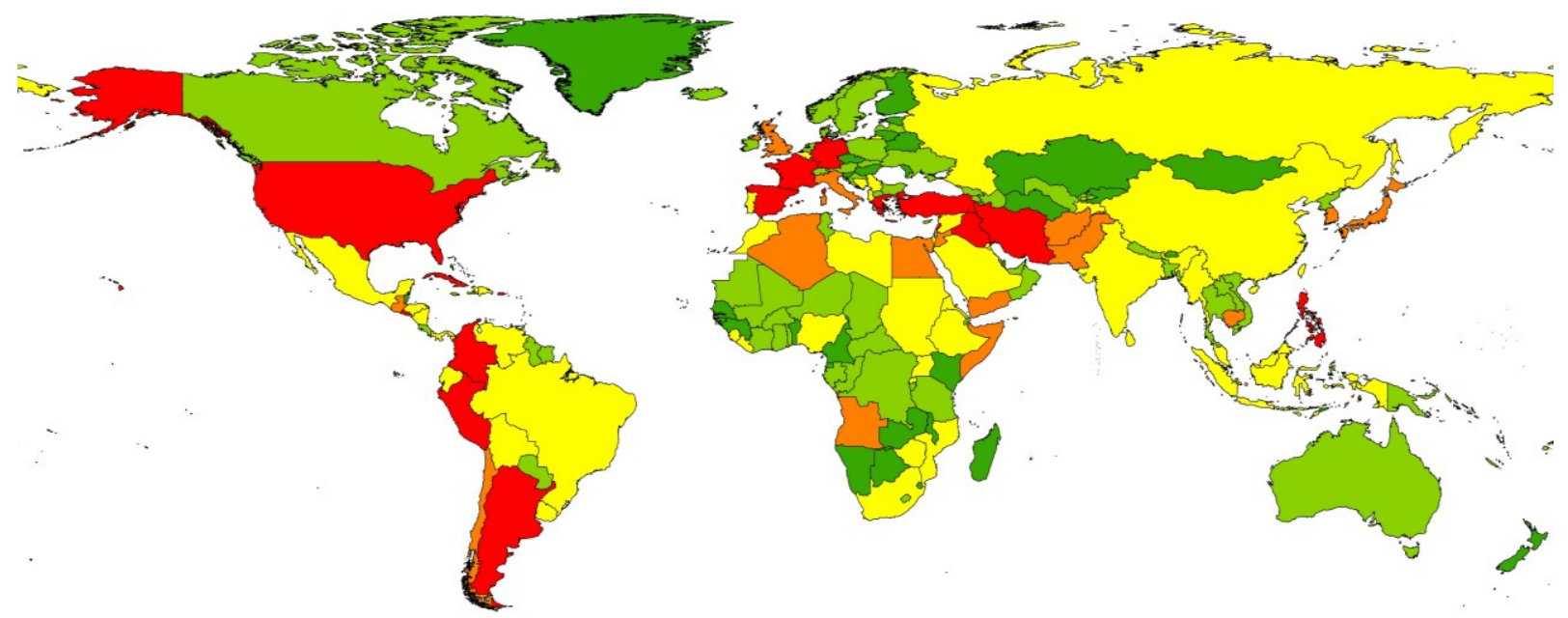

Note: Colors indicate the number of terrorist attacks originating from citizens of the respective country - dark green: 0 incidents, light green: 1-10 incidents, yellow: 11-50 incidents, orange: 51-100 incidents, red: >100 incidents 
Appendix II.1: Sources and definitions

\begin{tabular}{|c|c|c|}
\hline Variable & Description & Source \\
\hline \multicolumn{3}{|l|}{ Dependent variables } \\
\hline Aid projects (Bartke/CCY) & Number of aid projects completed in recipient country (\% of total number of aid projects provided by donor), $1990-2005$ & Bartke (1989), Ministry of Commerce (1984-2009), Hawkins et al. (2010) \\
\hline Aid amount (Bartke) & Aid provided to recipient country in constant 2000 US\$ (\% of total aid provided by donor), $1956-1987$ & Bartke (1989) \\
\hline Aid amount (CIA) & Aid provided to recipient country in constant 2000 US\$ (\% of total aid provided by donor), $1956-1984$ & CIA (1975-1984) \\
\hline Aid amount (OECD) & Aid provided to recipient country in constant 2000 US\$ (\% of total aid provided by donor), $1970-1985$ & OECD (1987) \\
\hline Medical staff (CCY) & Number of medical staff dispatched to recipient country by the end of the year (\% of total medical personnel provided by donor), 1983-1994 & Ministry of Commerce (1984-2009) \\
\hline Food aid (FAIS) & Food aid provided to recipient country in tons of grain equivalent (\% of total food aid provided by donor), 1988-2006 & Food Aid Information System (World Food Programme 2011) \\
\hline \multicolumn{3}{|l|}{ Control variables } \\
\hline Distance & (log) Bilateral distance (weighted by populations of major cities) & CEPII (Mayer and Zignago 2006) \\
\hline Population & (log) Total population, average & Penn World Tables (Heston et al. 2009) \\
\hline GDP per capita & (log) GDP per capita (constant 2005 I\$), average & Penn World Tables (Heston et al. 2009) \\
\hline Disaster & (log) Number of people affected by disasters, average & EM-DAT (2010) \\
\hline Taiwan recognition & 1 if recipient country recognizes Taiwan, average & Rich (2009) \\
\hline UNGA voting & UNGA voting alignment between donor and recipient, average & Voeten and Merdzanovic (2009) \\
\hline Exports & (log) Exports to recipient country (constant 2000 US\$), average & Correlates of War (Barberini et al. 2008) \\
\hline \multicolumn{3}{|c|}{ Governance and institutions } \\
\hline Democracy & 1 if the regime qualifies as democratic, average & Cheibub et al. (2010) \\
\hline Voice & Index ranging from -2.5 to 2.5 with higher values corresponding to better governance, average & Kaufmann et al. (2009) \\
\hline Political stability & Index ranging from -2.5 to 2.5 with higher values corresponding to better governance, average & Kaufmann et al. (2009) \\
\hline Government effectiveness & Index ranging from -2.5 to 2.5 with higher values corresponding to better governance, average & Kaufmann et al. (2009) \\
\hline Regulatory quality & Index ranging from -2.5 to 2.5 with higher values corresponding to better governance, average & Kaufmann et al. (2009) \\
\hline Control of corruption & Index ranging from -2.5 to 2.5 with higher values corresponding to better governance, average & Kaufmann et al. (2009) \\
\hline Economic freedom & Index ranging from 0 (not free) to 10 (free), average & Gwartney et al. (2000) \\
\hline Military dictatorship & 1 if political regime of the recipient country is classified as a military dictatorship, average & UTIP (Hsu 2008) \\
\hline \multicolumn{3}{|c|}{ Natural resource endowment } \\
\hline Oil production & (log) Oil production in millions of barrels per day, average & Humphreys (2005), BP (2010) \\
\hline Oil production (BP only) & (log) Oil production in tonnes, average & BP (2010) \\
\hline Oil dummy & 1 if oil is produced in recipient country, average & BP (2010) \\
\hline Oil reserves & (log) Oil reserves in barrels, average & $\mathrm{BP}(2010)$ \\
\hline Gas production & (log) Gas production in tonnes oil equivalent, average & $\mathrm{BP}(2010)$ \\
\hline Coal production & (log) Coal production in tonnes oil equivalent, average & BP (2010) \\
\hline Diamond production & (log) Diamonds production in metric carats, average & Humphreys (2005) \\
\hline Energy depletion & (log) Product of unit resource rents and physical quanitites of energy extracted, average & World Bank (http://data.worldbank.org/indicator) \\
\hline Mineral depletion & (log) Product of unit resource rents and physical quanitites of minerals extracted, average & World Bank (http://data.worldbank.org/indicator) \\
\hline Total fuel exports & $\begin{array}{l}\text { (log) Total fuels exports of recipient country in constant } 2000 \text { US\$, average } \\
\text { (a) }\end{array}$ & World Bank (http://data.worldbank.org/indicator) \\
\hline Total OM exports & (log) Total ores and metals exports of recipient country in constant 2000 US\$, average & World Bank (http://data.worldbank.org/indicator) \\
\hline Total ARM exports & (log) Total agricultural raw materials exports of recipient country in constant 2000 US\$, average & World Bank (http://data.worldbank.org/indicator) \\
\hline Bilateral fuel imports & (log) Bilateral fuels imports of donor country from recipient country in constant 2000 US\$, average & UN Comtrade via WITS (http://wits.worldbank.org) \\
\hline Bilateral OM imports & (log) Bilateral ores and metals imports of donor country from recipient country in constant 2000 US\$\$, average & UN Comtrade via WITS (http://wits.worldbank.org) \\
\hline Bilateral ARM imports & (log) Bilateral agricultural raw materials imports of donor country from recipient country in constant 2000 US\$, average & UN Comtrade via WITS (http://wits. worldbank.org) \\
\hline Natural capital & (log) Natural capital in constant 2000 US\$, average (values for 2000 and 2005) & World Bank (2010) \\
\hline
\end{tabular}

- Values in current US\$ have been transformed to constant 2000 US\$ using US Consumer Price Indices from the World Bank (http://data.worldbank.org/indicator) and the Bureau of Labor Statistics (http://www.bls.gov/cpi/\#tables)

- The value of 1 has been added to all trade and natural resource variables as well as to the number of people affected by disasters before taking logarithms 
Appendix II.2: Descriptive statistics

\begin{tabular}{|c|c|c|c|c|c|}
\hline Variable & \# obs & Mean & Std. Dev. & Min & Max \\
\hline \multicolumn{6}{|l|}{ Dependent variables } \\
\hline Aid projects (Bartke/CCY) & 528 & 0.751 & 1.265 & 0.000 & 12.222 \\
\hline Aid amount (Bartke) & 267 & 0.876 & 1.762 & 0.000 & 13.898 \\
\hline Aid amount (CIA) & 263 & 0.890 & 1.957 & 0.000 & 14.522 \\
\hline Aid amount (OECD) & 200 & 0.878 & 1.700 & 0.000 & 10.126 \\
\hline Medical staff (CCY) & 233 & 0.742 & 2.126 & 0.000 & 17.940 \\
\hline Food aid (FAIS) & 261 & 0.394 & 2.436 & 0.000 & 29.551 \\
\hline \multicolumn{6}{|l|}{ Control variables } \\
\hline Distance & 528 & 9.151 & 0.488 & 7.486 & 9.858 \\
\hline Population & 528 & 15.371 & 1.871 & 9.870 & 20.737 \\
\hline GDP per capita & 528 & 8.031 & 0.892 & 5.721 & 10.663 \\
\hline Disaster & 528 & 8.672 & 4.374 & 0.000 & 18.011 \\
\hline Taiwan recognition & 528 & 0.224 & 0.382 & 0.000 & 1.000 \\
\hline UNGA voting & 528 & 0.700 & 0.193 & 0.183 & 0.920 \\
\hline Exports & 528 & 15.803 & 3.969 & 0.000 & 22.548 \\
\hline \multicolumn{6}{|l|}{ Governance and institutions } \\
\hline Democracy & 528 & 0.339 & 0.442 & 0.000 & 1.000 \\
\hline Voice & 130 & -0.425 & 0.791 & -1.842 & 1.267 \\
\hline Political stability & 130 & -0.406 & 0.875 & -2.556 & 1.365 \\
\hline Government effectiveness & 130 & -0.479 & 0.603 & -1.987 & 1.283 \\
\hline Regulatory quality & 130 & -0.454 & 0.713 & -2.402 & 1.397 \\
\hline Control of corruption & 130 & -0.464 & 0.620 & -1.673 & 1.362 \\
\hline Economic freedom & 277 & 5.505 & 0.925 & 3.051 & 7.494 \\
\hline Military dictatorship & 432 & 0.160 & 0.327 & 0.000 & 1.000 \\
\hline \multicolumn{6}{|l|}{ Natural resource endowment } \\
\hline Oil production & 528 & 4.467 & 5.782 & 0.000 & 16.070 \\
\hline Oil production (BP only) & 528 & 4.383 & 7.390 & 0.000 & 19.951 \\
\hline Oil dummy & 528 & 0.263 & 0.441 & 0.000 & 1.000 \\
\hline Oil reserves & 361 & 5.461 & 9.602 & 0.000 & 26.294 \\
\hline Gas production & 461 & 3.187 & 6.346 & 0.000 & 18.083 \\
\hline Coal production & 365 & 1.649 & 4.875 & 0.000 & 18.736 \\
\hline Diamond production & 442 & 2.010 & 4.848 & 0.000 & 16.889 \\
\hline Energy depletion & 429 & 9.734 & 9.871 & 0.000 & 24.643 \\
\hline Mineral depletion & 429 & 8.662 & 8.630 & 0.000 & 22.226 \\
\hline Total fuel exports & 417 & 20.392 & 6.427 & 0.000 & 30.381 \\
\hline Total OM exports & 426 & 21.202 & 3.941 & 0.000 & 27.636 \\
\hline Total ARM exports & 429 & 21.769 & 3.062 & 0.000 & 27.162 \\
\hline Bilateral fuel imports & 119 & 21.845 & 4.121 & 11.791 & 28.611 \\
\hline Bilateral OM imports & 234 & 13.751 & 3.420 & 0.693 & 21.135 \\
\hline Bilateral ARM imports & 274 & 12.735 & 4.897 & 0.000 & 20.447 \\
\hline Natural capital & 197 & 24.232 & 2.222 & 13.915 & 28.788 \\
\hline
\end{tabular}

Note:

- Descriptive statistics for sample as in Table 1, column 1 (phase 1-5) 
Appendix II.3: Construction of the dataset on China's project aid

We constructed our dataset on the number of China's aid projects completed based on two primary datasets: Bartke (1989) and Ministry of Commerce (1984-2007). The first source is Wolfgang Bartke's book “The Economic Aid of the PR China to Developing and Socialist Countries." It contains information on aid projects completed between 1956 and 1987 with detailed project descriptions. The author "feels certain that no important project [in noncommunist countries] has been excluded, especially since it was part of the PR China's promotion of its own image up until 1978 to draw full attention of its economic aid" (Bartke 1989: 5). However, concerning the coverage of certain communist recipient countries, the information on China's foreign aid in Bartke (1989) is incomplete. Therefore, we exclude Albania, Cuba, Mongolia, North Korea and Vietnam from the dataset. Medical groups (including acupuncture medical teams) were also excluded from the Bartke (1989) dataset to achieve better comparability with data from the China Commerce Yearbook discussed below.

In those cases where no year of completion was registered, we estimate the year of completion by adding four years to the starting year of a project (48 cases) or by adding five years to the year of signature (6 cases). These values correspond to the average duration of a project after its signature or start. 8 of 528 projects had to be excluded from the analysis as information was neither provided on the year of signature, the start year, nor the year of completion of the project. We keep 35 projects that were under construction at the time the book was published. Projects in the planning stage, in turn, were not included in our combined dataset. The construction of the Tanzania-Zambia Railway is counted twice, as one project in Tanzania and one project in Zambia.

Second, we employ data on China's project aid from the Ministry of Commerce (1984-2009), which provides this information in the China Commerce Yearbook and its predecessors - the Yearbook of China's Foreign Economic Relations and Trade, and the Almanac of China's Foreign Economic Relations and Trade. Data are collected by Hawkins et al. (2010) and available on the AidData webpage (http://www.aiddata.org/research/china). The data cover the 1990-2005 period with the exception of 2002. For the 1983-1989 period, as well as the year 2006, the Ministry of Commerce (1984-2009) only provides information on whether or not an aid project was completed in a recipient country, without the possibility of deriving information on the number of projects per country. Altogether, the dataset consists of 304 aid projects provided to 97 developing countries (and Malta). 
Appendix II.4: China's foreign aid to recipient countries ( $\%$ of total)

\begin{tabular}{|c|c|c|c|c|c|c|c|c|c|c|c|c|c|c|c|c|c|}
\hline \multirow{2}{*}{$\begin{array}{r}\begin{array}{r}\text { Variable } \\
\text { Source }\end{array} \\
\text { Time period }\end{array}$} & \multicolumn{5}{|c|}{$\begin{array}{l}\text { Completed aid projects } \\
\text { (Bartke/CCY) }\end{array}$} & \multicolumn{3}{|c|}{$\begin{array}{l}\text { Amount } \\
\text { (Bartke) }\end{array}$} & \multicolumn{3}{|c|}{$\begin{array}{l}\text { Amount } \\
\text { (CIA) }\end{array}$} & \multicolumn{2}{|c|}{$\begin{array}{l}\text { Amount } \\
\text { (OECD) }\end{array}$} & \multicolumn{2}{|c|}{$\begin{array}{l}\text { MedStaff } \\
\text { (CCY) }\end{array}$} & \multicolumn{2}{|c|}{$\begin{array}{l}\text { Food aid } \\
\text { (FAIS) }\end{array}$} \\
\hline & 1 & 2 & 3 & 4 & 5 & 1 & 2 & 3 & 1 & 2 & 3 & 2 & 3 & 3 & 4 & 4 & 5 \\
\hline Afghanistan & 1.1 & 3.3 & 0.5 & 0.0 & 0.0 & 2.8 & 3.3 & 0.0 & 2.8 & 1.5 & 0.0 & 1.9 & 0.0 & 0.0 & 0.0 & 0.0 & 0.0 \\
\hline Albania & . & . & . & 0.0 & 0.6 & . & . & . & 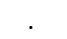 & . & . & 0.0 & 0.0 & 0.0 & 0.0 & 0.0 & 0.0 \\
\hline Algeria & 3.3 & 2.8 & 0.0 & 0.0 & 0.3 & 6.5 & 2.4 & 0.0 & 5.1 & 1.3 & 0.0 & 1.2 & 0.0 & 17.5 & 17.5 & 0.0 & 0.0 \\
\hline Angola & . & 0.0 & 0.5 & 0.0 & 0.6 & & 0.0 & 0.1 & & 0.0 & 1.4 & 0.0 & 1.8 & 0.0 & 0.0 & 0.0 & 0.0 \\
\hline Anguilla & 0.0 & 0.0 & 0.0 & 0.0 & 0.0 & 0.0 & 0.0 & 0.0 & 0.0 & 0.0 & 0.0 & 0.0 & 0.0 & 0.0 & 0.0 & 0.0 & 0.0 \\
\hline Antigua and Barbuda & 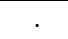 & . & 0.9 & 0.6 & 0.6 & 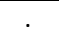 & & 0.3 & & & $<0.1$ & & 0.2 & 0.0 & 0.0 & 0.0 & 0.0 \\
\hline Argentina & 0.0 & 0.0 & 0.0 & 0.0 & 0.0 & 0.0 & 0.0 & 0.0 & 0.0 & 0.0 & 0.0 & 0.0 & 0.0 & 0.0 & 0.0 & 0.0 & 0.0 \\
\hline Armenia & . & . & . & 0.0 & 0.3 & . & . & . & . & . & . & . & . & . & 0.0 & 0.0 & 0.0 \\
\hline Azerbaijan & . & . & . & 0.0 & 0.0 & . & . & . & . & 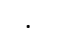 & . & . & . & 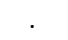 & 0.0 & 0.0 & 0.0 \\
\hline Bangladesh & 1.1 & 1.1 & 1.4 & 2.3 & 1.2 & 0.0 & 1.2 & 7.9 & 1.1 & 1.3 & 3.0 & 1.2 & 5.6 & 0.0 & 0.0 & 0.0 & $<0.1$ \\
\hline Barbados & 0.0 & 0.0 & 0.5 & 1.1 & 0.6 & 0.0 & 0.0 & 0.1 & 0.0 & 0.0 & 0.0 & 0.0 & 0.0 & 0.0 & 0.0 & 0.0 & 0.0 \\
\hline Belarus & $\cdot$ & . & . & 0.0 & 0.3 & . & . & . & . & . & . & . & . & . & 0.0 & 0.0 & 0.0 \\
\hline Belize & . & . & 0.0 & 0.0 & 0.0 & . & . & 0.6 & . & . & 0.0 & . & 0.0 & 0.0 & 0.0 & 0.0 & 0.0 \\
\hline Benin & 0.0 & 1.1 & 1.8 & 2.8 & 3.4 & 0.0 & 1.7 & 2.0 & 0.0 & 1.3 & 0.7 & 1.4 & $<0.1$ & 1.8 & 1.6 & 0.0 & $<0.1$ \\
\hline Bhutan & & 0.0 & 0.0 & 0.0 & 0.0 & . & 0.0 & 0.0 & . & 0.0 & 0.0 & 0.0 & 0.0 & 0.0 & 0.0 & 0.0 & $<0.1$ \\
\hline Bolivia & 0.0 & 0.0 & 0.0 & 2.3 & 1.5 & 0.0 & 0.0 & 0.0 & 0.0 & 0.0 & 0.0 & 0.0 & 0.0 & 0.0 & 0.0 & 0.0 & 0.0 \\
\hline Bosnia and Herzegovina & . & . & $\cdot$ & 0.0 & 0.0 & . & . & . & . & . & . & . & & . & 0.0 & 0.0 & 0.0 \\
\hline Botswana & 0.0 & 0.0 & 1.4 & 1.1 & 0.0 & 0.0 & 0.3 & 0.0 & 0.0 & 0.4 & 1.7 & 0.1 & 0.8 & 1.4 & 1.7 & 9.3 & 0.0 \\
\hline Brazil & 0.0 & 0.0 & 0.0 & 0.0 & 0.0 & 0.0 & 0.0 & 0.0 & 0.0 & 0.0 & 0.0 & 0.0 & 0.0 & 0.0 & 0.0 & 0.0 & 0.0 \\
\hline Burkina Faso & 0.0 & 1.7 & 2.8 & 2.3 & 0.0 & 0.0 & 0.3 & 2.1 & 0.0 & 1.5 & 0.5 & 1.6 & 1.3 & 1.3 & 1.3 & 1.6 & 0.0 \\
\hline Burundi & 0.0 & 0.0 & 1.4 & 2.8 & 0.3 & 0.0 & 0.7 & 0.9 & 0.0 & 0.6 & 3.0 & 0.6 & 5.7 & 0.5 & 1.3 & 0.0 & 0.0 \\
\hline Cambodia & 23.3 & 1.7 & 0.0 & 0.0 & 3.4 & 4.8 & 0.3 & 0.0 & 9.1 & . & . & 5.0 & 0.0 & 0.0 & 0.0 & 0.0 & 0.0 \\
\hline Cameroon & 0.0 & 0.0 & 0.9 & 2.8 & 1.8 & 0.0 & 2.8 & 0.8 & 0.0 & 2.7 & 0.0 & 2.4 & 0.0 & 1.5 & 2.4 & 0.0 & 0.0 \\
\hline Cape Verde & . & 0.0 & 0.9 & 0.6 & 1.2 & . & 0.8 & 0.0 & . & 0.4 & $<0.1$ & $<0.1$ & 1.9 & 0.4 & 0.5 & 0.9 & $<0.1$ \\
\hline Central African Republic & 0.0 & 0.0 & 0.5 & 0.0 & 0.3 & 0.4 & 0.3 & 0.1 & 0.4 & 0.2 & 0.9 & 0.0 & 1.3 & 1.4 & 0.4 & 0.0 & $<0.1$ \\
\hline Chad & 0.0 & 0.0 & 0.0 & 1.7 & 0.0 & 0.0 & 1.9 & 0.0 & 0.0 & 1.9 & 0.0 & 1.6 & $<0.1$ & 0.1 & 0.8 & 0.0 & $<0.1$ \\
\hline Chile & 0.0 & 0.0 & 0.0 & 0.0 & 0.0 & 0.0 & 0.0 & 0.0 & 0.0 & 2.0 & 0.0 & 2.1 & 0.0 & 0.0 & 0.0 & 0.0 & 0.0 \\
\hline Colombia & 0.0 & 0.0 & 0.5 & 0.0 & 0.6 & 0.0 & 0.0 & 0.5 & 0.0 & 0.0 & 2.9 & 0.0 & 0.0 & 0.0 & 0.0 & 0.0 & 0.0 \\
\hline Comoros & . & 0.0 & 0.9 & 1.7 & 1.2 & . & 0.1 & 0.8 & . & 0.3 & 0.0 & 0.2 & 0.0 & 0.0 & 0.0 & 0.0 & 0.0 \\
\hline Congo & 3.3 & 3.3 & 0.9 & 1.1 & 0.9 & 4.8 & 2.5 & 3.4 & 2.5 & 1.5 & 6.4 & 1.1 & 2.4 & 3.0 & 2.8 & 0.0 & $<0.1$ \\
\hline Cook Islands & 0.0 & 0.0 & 0.0 & 0.0 & 0.3 & 0.0 & 0.0 & 0.0 & 0.0 & 0.0 & 0.0 & 0.0 & 0.0 & 0.0 & 0.0 & 0.0 & 0.0 \\
\hline Costa Rica & 0.0 & 0.0 & 0.0 & 0.0 & 0.0 & 0.0 & 0.0 & 0.0 & 0.0 & 0.0 & 0.0 & 0.0 & 0.0 & 0.0 & 0.0 & 0.0 & 0.0 \\
\hline Croatia & $\cdot$ & . & . & 0.0 & 0.0 & . & . & . & . & . & . & . & . & & 0.0 & 0.0 & 0.0 \\
\hline Cuba & $\cdot$ & $\cdot$ & $\cdot$ & 1.7 & 1.5 & $\cdot$ & $\cdot$ & $\cdot$ & $\cdot$ & $\cdot$ & $\cdot$ & 0.0 & 0.0 & 0.0 & 0.0 & 0.0 & $<0.1$ \\
\hline Dem. Rep. of the Congo & 0.0 & 1.7 & 2.3 & 0.6 & 1.8 & 0.0 & 0.0 & 0.0 & 0.0 & 2.9 & $<0.1$ & 3.1 & 0.0 & 2.6 & 2.4 & 0.0 & 0.0 \\
\hline Djibouti & . & 0.0 & 0.9 & 0.6 & 3.1 & . & 0.0 & 1.5 & . & 0.0 & 2.1 & 0.0 & 1.5 & 0.4 & 0.4 & 0.0 & 0.0 \\
\hline Dominica & . & 0.0 & 0.0 & 0.0 & 0.0 & . & 0.0 & 0.0 & . & 0.0 & 0.0 & 0.0 & 0.0 & 0.0 & 0.0 & 0.0 & 0.0 \\
\hline Dominican Republic & 0.0 & 0.0 & 0.0 & 0.0 & 0.0 & 0.0 & 0.0 & 0.0 & 0.0 & 0.0 & 0.0 & 0.0 & 0.0 & 0.0 & 0.0 & 0.0 & 0.0 \\
\hline East Timor & . & . & $\cdot$ & . & 0.0 & . & . & . & . & $\cdot$ & . & . & $\cdot$ & . & . & . & 0.0 \\
\hline Ecuador & 0.0 & 0.0 & 0.0 & 2.8 & 0.3 & 0.0 & 0.0 & 0.1 & 0.0 & 0.0 & 0.4 & 0.0 & 0.6 & 0.0 & 0.0 & 0.0 & 0.0 \\
\hline Egypt & 0.0 & 0.0 & 0.9 & 0.0 & 0.6 & 0.6 & 3.0 & 0.0 & 10.2 & 0.8 & 6.7 & 0.8 & 4.2 & 0.0 & 0.0 & 0.0 & 0.0 \\
\hline El Salvador & 0.0 & 0.0 & 0.0 & 0.0 & 0.0 & 0.0 & 0.0 & 0.0 & 0.0 & 0.0 & 0.0 & 0.0 & 0.0 & 0.0 & 0.0 & 0.0 & 0.0 \\
\hline Equatorial Guinea & 0.0 & 2.2 & 1.4 & 2.8 & 0.6 & 0.0 & 0.4 & 1.0 & 0.0 & 1.0 & 0.7 & 0.3 & 0.7 & 1.7 & 1.7 & 0.0 & 0.0 \\
\hline Eritrea & . & . & . & 0.0 & 1.2 & . & . & . & . & $\cdot$ & . & . & $\cdot$ & . & 0.0 & 0.0 & $<0.1$ \\
\hline Ethiopia & 0.0 & 1.7 & 1.8 & 1.7 & 0.6 & 0.0 & 4.1 & 1.1 & 0.0 & 2.7 & 2.5 & 2.7 & 0.2 & 0.9 & 1.1 & 0.3 & 0.2 \\
\hline Fiji & $\cdot$ & 0.0 & 0.9 & 1.7 & 0.9 &. & 0.0 & 0.1 & & 0.0 & 0.0 & 0.0 & 0.0 & 0.0 & 0.0 & 0.0 & 0.0 \\
\hline Gabon & 0.0 & 0.6 & 0.5 & 0.6 & 1.2 & 0.0 & 0.3 & 0.8 & 0.0 & 0.6 & 0.0 & 0.8 & 0.0 & 1.5 & 2.0 & 0.0 & 0.0 \\
\hline Gambia & 0.0 & 0.6 & 1.4 & 2.8 & 0.0 & 0.0 & 0.4 & 1.6 & 0.0 & 0.4 & 0.0 & 0.5 & $<0.1$ & 1.8 & 1.9 & 0.0 & 0.0 \\
\hline Georgia & . & . & & 0.0 & 0.0 & . & . & . & . & . & . & . & . & . & 0.0 & 0.0 & 0.0 \\
\hline Ghana & 1.1 & 1.1 & 1.8 & 2.3 & 0.9 & 4.4 & 0.0 & 1.0 & 4.1 & 0.0 & 0.0 & 0.0 & 1.2 & 0.0 & 0.0 & 0.0 & 0.0 \\
\hline Grenada &. & 0.0 & 0.0 & 0.0 & 0.0 &. & 0.0 & $<0.1$ & & 0.0 & 0.0 & 0.0 & 0.0 & 0.0 & 0.0 & 0.0 & 0.0 \\
\hline Guatemala & 0.0 & 0.0 & 0.0 & 0.0 & 0.0 & 0.0 & 0.0 & 0.0 & 0.0 & 0.0 & 0.0 & 0.0 & 0.0 & 0.0 & 0.0 & 0.0 & $<0.1$ \\
\hline Guinea & 6.7 & 3.9 & 1.4 & 2.8 & 2.2 & 6.7 & 1.1 & 2.7 & 6.6 & 0.4 & 3.0 & 1.6 & 3.7 & 2.2 & 1.6 & 0.0 & 0.1 \\
\hline Guinea-Bissau & . & 0.0 & 0.0 & 0.0 & 0.6 & . & 0.1 & 0.3 & . & 0.4 & 0.0 & 0.5 & 0.0 & 1.5 & 0.0 & 29.6 & 0.5 \\
\hline Guyana & 0.0 & 1.7 & 0.5 & 0.6 & 0.9 & 0.0 & 2.2 & 0.6 & 0.0 & 1.0 & 0.2 & 1.1 & 0.2 & 0.0 & 0.2 & 0.0 & 0.0 \\
\hline Haiti & 0.0 & 0.0 & 0.0 & 0.0 & 0.0 & 0.0 & 0.0 & 0.0 & 0.0 & 0.0 & 0.0 & 0.0 & 0.0 & 0.0 & 0.0 & 0.0 & 0.0 \\
\hline Honduras & 0.0 & 0.0 & 0.0 & 0.0 & 0.0 & 0.0 & 0.0 & 0.0 & 0.0 & 0.0 & 0.0 & $<0.1$ & 0.0 & 0.0 & 0.0 & 0.0 & 0.0 \\
\hline India & 0.0 & 0.0 & 0.0 & 0.0 & 0.0 & 0.0 & 0.0 & 0.0 & 0.0 & 0.0 & 0.0 & 0.0 & 0.0 & 0.0 & 0.0 & 0.0 & 0.0 \\
\hline Indonesia & 0.0 & 0.0 & 0.0 & 0.0 & 0.3 & 1.3 & 0.0 & 0.0 & 4.7 & 0.0 & 0.0 & 0.0 & 0.0 & 0.0 & 0.0 & 0.0 & 0.0 \\
\hline Iran & 0.0 & 0.0 & 0.0 & 0.0 & 0.0 & 0.0 & 0.0 & $<0.1$ & 0.0 & 0.0 & 0.0 & $<0.1$ & 0.0 & 0.0 & 0.0 & 0.0 & 0.0 \\
\hline
\end{tabular}


Appendix II.4 (continued): China's foreign aid to recipient countries ( $\%$ of total)

\begin{tabular}{|c|c|c|c|c|c|c|c|c|c|c|c|c|c|c|c|c|c|}
\hline \multirow{2}{*}{$\begin{array}{r}\begin{array}{r}\text { Variable } \\
\text { Source }\end{array} \\
\text { Time period }\end{array}$} & \multicolumn{5}{|c|}{$\begin{array}{l}\text { Completed aid projects } \\
\text { (Bartke/CCY) }\end{array}$} & \multicolumn{3}{|c|}{$\begin{array}{l}\text { Amount } \\
\text { (Bartke) }\end{array}$} & \multicolumn{3}{|c|}{$\begin{array}{l}\text { Amount } \\
\text { (CIA) }\end{array}$} & \multicolumn{2}{|c|}{$\begin{array}{l}\text { Amount } \\
\text { (OECD) }\end{array}$} & \multicolumn{2}{|c|}{$\begin{array}{l}\text { MedStaff } \\
\text { (CCY) }\end{array}$} & \multicolumn{2}{|c|}{$\begin{array}{l}\text { Food aid } \\
\text { (FAIS) }\end{array}$} \\
\hline & 1 & 2 & 3 & 4 & 5 & 1 & 2 & 3 & 1 & 2 & 3 & 2 & 3 & 3 & 4 & 4 & 5 \\
\hline Iraq & 0.0 & 0.6 & 1.8 & 0.0 & 0.0 & 0.0 & 1.4 & 6.3 & 0.0 & 1.4 & 0.0 & 1.3 & 0.0 & 0.0 & 0.0 & 0.0 & 0.0 \\
\hline Ivory Coast & 0.0 & 0.0 & 0.0 & 0.0 & 0.9 & 0.0 & 0.0 & 0.0 & 0.0 & 0.0 & 0.0 & 0.0 & 0.0 & 0.0 & 0.0 & 0.0 & 0.0 \\
\hline Jamaica & 0.0 & 0.0 & 0.0 & 0.0 & 0.3 & 0.0 & 0.3 & 0.0 & 0.0 & 0.3 & 0.0 & 0.3 & 0.0 & 0.0 & 0.0 & 0.0 & 0.0 \\
\hline Jordan & 0.0 & 0.0 & 0.5 & 0.6 & 0.9 & 0.0 & 0.0 & 0.8 & 0.0 & 0.0 & 2.3 & 0.0 & 0.0 & 0.0 & 0.0 & 0.0 & 0.0 \\
\hline Kazakhstan & . & . & . & 0.0 & 0.6 & . & . & . & . & . & . & . & . & . & 0.0 & 0.0 & 0.0 \\
\hline Kenya & 1.1 & 0.0 & 1.4 & 1.1 & 0.3 & 1.9 & 0.0 & 2.7 & 1.8 & 0.0 & 3.2 & $<0.1$ & 5.1 & 0.0 & 0.0 & 0.0 & 0.0 \\
\hline Kiribati & . & . & . & . & 0.0 & . & . & . & . & . & . & . & . & 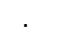 & . & . & 0.0 \\
\hline Korea, Dem. Rep. & . & . & . & 0.6 & 0.6 & . & . & . & . & . & . & . & . & 0.0 & 0.0 & 0.0 & 96.8 \\
\hline Kyrgyzstan & . & . & . & 0.0 & 0.0 & . & . & . & . & . & . & . & . & . & 0.0 & 0.0 & 0.0 \\
\hline Laos & 1.1 & 5.6 & 0.5 & 0.6 & 1.5 & 1.1 & 1.7 & 0.0 & 0.0 & . & . & 0.8 & 0.0 & 0.0 & 0.0 & 0.0 & $<0.1$ \\
\hline Lebanon & 0.0 & 0.0 & 0.0 & 0.0 & 0.6 & 0.0 & 0.0 & 0.0 & 0.0 & 0.0 & 0.0 & 0.0 & $<0.1$ & 0.0 & 0.0 & 0.0 & 0.0 \\
\hline Lesotho & 0.0 & 0.0 & 0.9 & 0.0 & 0.9 & 0.0 & 0.0 & 0.1 & 0.0 & 0.0 & 0.5 & 0.0 & 0.5 & 0.0 & 0.0 & 3.1 & 0.0 \\
\hline Liberia & 0.0 & 0.6 & 2.3 & 0.0 & 0.0 & 0.0 & 0.9 & 2.7 & 0.0 & 0.5 & 2.8 & 0.5 & 4.9 & 1.0 & 0.0 & 0.0 & 1.1 \\
\hline Libya & 0.0 & 0.0 & 0.5 & 0.0 & 0.0 & 0.0 & 0.0 & 1.0 & 0.0 & 0.0 & 0.0 & 0.0 & 0.0 & 1.6 & 0.0 & 0.0 & 0.0 \\
\hline Macedonia & . & . & . & 0.0 & 0.3 & . & . & . & . & . & . & . & . & . & 0.0 & 0.0 & 0.0 \\
\hline Madagascar & 0.0 & 1.7 & 3.2 & 0.0 & 1.5 & 0.0 & 1.2 & 3.1 & 0.0 & 2.2 & 0.0 & 1.9 & 4.0 & 2.4 & 2.5 & 0.0 & $<0.1$ \\
\hline Malawi & 0.0 & 0.0 & 0.0 & 0.0 & 0.0 & 0.0 & 0.0 & 0.0 & 0.0 & 0.0 & 0.0 & 0.0 & 0.0 & 0.0 & 0.0 & 0.0 & $<0.1$ \\
\hline Malaysia & 0.0 & 0.0 & 0.0 & 0.0 & 0.0 & 0.0 & 0.0 & 0.0 & 0.0 & 0.0 & 0.0 & $<0.1$ & 0.0 & 0.0 & 0.0 & 0.0 & 0.0 \\
\hline Maldives & 0.0 & 0.6 & 0.0 & 1.1 & 0.6 & 0.0 & 0.0 & 0.5 & 0.0 & 0.0 & 0.0 & 0.0 & 0.0 & 0.0 & 0.0 & 0.0 & 0.0 \\
\hline Mali & 12.2 & 5.0 & 2.3 & 0.6 & 1.8 & 3.7 & 1.1 & 3.2 & 5.2 & 0.6 & 0.4 & 1.5 & 1.7 & 2.6 & 2.8 & 0.0 & $<0.1$ \\
\hline Marshall Islands & & & & 1.1 & 0.0 & & & $\cdot$ & & & & & & & 0.0 & 0.0 & 0.0 \\
\hline Mauritania & 1.1 & 5.0 & 3.2 & 3.4 & 1.2 & 0.4 & 1.4 & 3.6 & 0.4 & 2.2 & 1.1 & 2.3 & 3.8 & 2.9 & 2.4 & 7.6 & 0.1 \\
\hline Mauritius & 0.0 & 0.6 & 0.9 & 2.3 & 0.6 & 0.0 & 1.2 & 1.2 & 0.0 & 1.1 & 0.0 & 1.1 & 1.0 & 0.0 & 0.0 & 0.0 & 0.0 \\
\hline Mayotte & 0.0 & 0.0 & 0.0 & 0.0 & 0.0 & 0.0 & 0.0 & 0.0 & 0.0 & 0.0 & 0.0 & 0.0 & 0.0 & 0.0 & 0.0 & 0.0 & 0.0 \\
\hline Mexico & 0.0 & 0.0 & 0.0 & 0.0 & 0.0 & 0.0 & 0.0 & 0.0 & 0.0 & 0.0 & 0.0 & 0.0 & $<0.1$ & 0.0 & 0.0 & 0.0 & 0.0 \\
\hline Micronesia &. & . &. & 0.0 & 0.0 & . & . &. &. & . & . &. &. & . & 0.0 & 0.0 & 0.0 \\
\hline Moldova & . & . & . & 0.0 & 0.6 & . & . & . & . & . & . & . & . & . & 0.0 & 0.0 & 0.0 \\
\hline Mongolia & . & . & . & 0.0 & 3.7 & . & . & . & . & . & . & 0.0 & 0.0 & 0.0 & 0.0 & 13.7 & $<0.1$ \\
\hline Montserrat & 0.0 & 0.0 & 0.0 & 0.0 & 0.0 & 0.0 & 0.0 & 0.0 & 0.0 & 0.0 & 0.0 & 0.0 & 0.0 & 0.0 & 0.0 & 0.0 & 0.0 \\
\hline Morocco & 0.0 & 0.0 & 0.9 & 0.6 & 0.3 & 0.0 & 0.9 & 0.0 & 0.0 & 1.2 & $<0.1$ & 0.8 & 0.0 & 5.1 & 6.8 & 0.0 & $<0.1$ \\
\hline Mozambique & & 0.0 & 1.4 & 1.1 & 1.2 & & 0.4 & 0.3 & & 0.3 & 1.4 & 1.9 & 1.4 & 1.3 & 0.8 & 9.3 & $<0.1$ \\
\hline Myanmar & 5.6 & 1.1 & 1.8 & 1.1 & 0.9 & 16.2 & 0.0 & 6.7 & 2.7 & 2.5 & 8.9 & $<0.1$ & 10.2 & 0.0 & 0.0 & 0.0 & 0.3 \\
\hline Namibia & . & 0.0 & 0.0 & 1.7 & 1.8 & . & 0.0 & 0.0 & . & 0.0 & 0.0 & 0.0 & 0.0 & 0.0 & 0.0 & 0.0 & 0.0 \\
\hline Nauru & . & . & . & . & 0.0 & . & . & . & . & . & . & . & . & . & . & . & 0.0 \\
\hline Nepal & 5.6 & 4.4 & 4.6 & 2.3 & 2.5 & 7.0 & 1.3 & 1.0 & 6.4 & 3.7 & 3.4 & 4.3 & 2.8 & 0.0 & 0.0 & 0.0 & $<0.1$ \\
\hline Nicaragua & 0.0 & 0.0 & 0.0 & 0.0 & 0.0 & 0.0 & 0.0 & 0.0 & 0.0 & 0.0 & 0.0 & 0.0 & 0.8 & 0.0 & 0.0 & 0.0 & 0.0 \\
\hline Niger & 0.0 & 0.6 & 2.8 & 0.6 & 3.4 & 0.0 & 0.9 & 0.5 & 0.0 & 1.4 & 0.3 & 1.7 & 0.7 & 2.3 & 1.3 & 0.0 & $<0.1$ \\
\hline Nigeria & 0.0 & 0.6 & 1.8 & 0.0 & 0.0 & 0.0 & 0.1 & 1.1 & 0.0 & 0.0 & 0.0 & $<0.1$ & 0.0 & 0.0 & 0.0 & 0.0 & 0.0 \\
\hline Niue & 0.0 & 0.0 & 0.0 & 0.0 & 0.3 & 0.0 & 0.0 & 0.0 & 0.0 & 0.0 & 0.0 & 0.0 & 0.0 & 0.0 & 0.0 & 0.0 & 0.0 \\
\hline Oman & . & 0.0 & 0.0 & 1.1 & 0.0 & . & 0.0 & 0.0 & . & 0.0 & 0.0 & 0.0 & 0.0 & 0.0 & 0.0 & 0.0 & 0.0 \\
\hline Pakistan & 2.2 & 5.0 & 4.1 & 0.0 & 0.9 & 13.9 & 12.4 & 2.5 & 14.5 & 11.9 & 9.5 & 9.8 & 2.4 & 0.0 & 0.0 & 1.5 & $<0.1$ \\
\hline Palau & . & . & . & 0.0 & 0.0 & 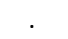 & . & . & . & . & . & . & . & . & 0.0 & 0.0 & 0.0 \\
\hline Palestinian territories & . & . & . & 0.0 & 0.3 & . & . & . & . & . & . & . & . & . & 0.0 & 0.0 & 0.0 \\
\hline Panama & 0.0 & 0.0 & 0.0 & 0.0 & 0.0 & 0.0 & 0.0 & 0.0 & 0.0 & 0.0 & 0.0 & 0.0 & 0.0 & 0.0 & 0.0 & 0.0 & 0.0 \\
\hline Papua New Guinea & (2) & 0.0 & 0.0 & 1.1 & 1.2 & . & 0.0 & 0.9 & . & 0.0 & 0.0 & 0.0 & 0.0 & 0.0 & 0.0 & 0.0 & 0.0 \\
\hline Paraguay & 0.0 & 0.0 & 0.0 & 0.0 & 0.0 & 0.0 & 0.0 & 0.0 & 0.0 & 0.0 & 0.0 & 0.0 & 0.0 & 0.0 & 0.0 & 0.0 & 0.0 \\
\hline Peru & 0.0 & 0.0 & 0.0 & 0.6 & 0.6 & 0.0 & 1.6 & 0.9 & 0.0 & 1.3 & 0.0 & 1.3 & 0.0 & 0.0 & 0.0 & 0.0 & 0.0 \\
\hline Philippines & 0.0 & 0.0 & 0.5 & 0.0 & 0.3 & 0.0 & 0.0 & 0.8 & 0.0 & 0.0 & 2.1 & $<0.1$ & 0.0 & 0.0 & 0.0 & 0.0 & 0.0 \\
\hline Rwanda & 0.0 & 1.7 & 2.8 & 0.0 & 3.1 & 0.0 & 1.3 & 0.0 & 0.0 & 1.3 & 0.0 & 0.7 & 0.0 & 0.7 & 0.9 & 0.0 & $<0.1$ \\
\hline Saint Kitts and Nevis & . & . & 0.0 & 0.0 & 0.0 & . & . & 0.0 & . & . & 0.0 & . & 0.0 & 0.0 & 0.0 & 0.0 & 0.0 \\
\hline Saint Lucia & . & . & 0.0 & 0.0 & 0.0 & . & . & 0.0 & . & . & 0.0 & . & 0.0 & 0.0 & 0.0 & 0.0 & 0.0 \\
\hline Saint Vincent and the Gr. & . & . & 0.0 & 0.0 & 0.0 & . & . & 0.0 & . & . & 0.0 & . & 0.0 & 0.0 & 0.0 & 0.0 & 0.0 \\
\hline Samoa & . & 0.0 & 0.5 & 1.1 & 0.9 & . & 0.4 & 0.0 & . & 0.2 & 0.0 & 0.0 & 0.6 & 0.0 & 0.0 & 0.0 & 0.0 \\
\hline Sao Tome and Principe & . & 0.6 & 0.0 & 1.1 & 0.0 & . & 0.3 & 1.2 & . & 0.4 & $<0.1$ & 0.3 & 0.0 & 1.1 & 1.4 & 0.0 & $<0.1$ \\
\hline Saudi Arabia & 0.0 & 0.0 & 0.0 & 0.0 & 0.0 & 0.0 & 0.0 & 0.0 & 0.0 & 0.0 & 0.0 & 0.0 & 0.0 & 0.0 & 0.0 & 0.0 & 0.0 \\
\hline Senegal & 0.0 & 0.6 & 3.7 & 2.3 & 0.0 & 0.0 & 0.7 & 0.7 & 0.0 & 1.5 & $<0.1$ & 1.5 & $<0.1$ & 1.6 & 1.6 & 0.0 & $<0.1$ \\
\hline Serbia / Yugoslavia & 0.0 & 0.0 & 0.0 & 0.0 & 0.3 & 0.0 & 0.0 & 0.0 & . & . & . & 0.0 & 0.0 & 0.0 & 0.0 & 0.0 & 0.0 \\
\hline Seychelles & . & 0.0 & 0.5 & 1.7 & 1.5 & $\cdot$ & 0.1 & 0.7 & . & $<0.1$ & 0.0 & $<0.1$ & 0.4 & 0.3 & 0.5 & 0.0 & 0.0 \\
\hline Sierra Leone & 0.0 & 7.8 & 2.8 & 4.0 & 0.9 & 0.0 & 0.8 & 3.3 & 0.0 & 1.3 & 1.0 & 0.9 & 1.3 & 1.3 & 0.9 & 0.0 & 0.0 \\
\hline Solomon Islands & . & 0.0 & 0.0 & 0.0 & 0.0 & . & 0.0 & 0.0 & . & 0.0 & 0.0 & 0.0 & 0.0 & 0.0 & 0.0 & 0.0 & 0.0 \\
\hline
\end{tabular}


Appendix II.4 (continued): China's foreign aid to recipient countries ( $\%$ of total)

\begin{tabular}{|c|c|c|c|c|c|c|c|c|c|c|c|c|c|c|c|c|c|}
\hline \multirow{2}{*}{$\begin{array}{r}\begin{array}{r}\text { Variable } \\
\text { Source }\end{array} \\
\text { Time period }\end{array}$} & \multicolumn{5}{|c|}{$\begin{array}{c}\text { Completed aid projects } \\
\text { (Bartke/CCY) }\end{array}$} & \multicolumn{3}{|c|}{$\begin{array}{l}\text { Amount } \\
\text { (Bartke) }\end{array}$} & \multicolumn{3}{|c|}{$\begin{array}{l}\text { Amount } \\
\text { (CIA) }\end{array}$} & \multicolumn{2}{|c|}{$\begin{array}{l}\text { Amount } \\
\text { (OECD) }\end{array}$} & \multicolumn{2}{|c|}{$\begin{array}{l}\text { MedStaff } \\
\text { (CCY) }\end{array}$} & \multicolumn{2}{|c|}{$\begin{array}{l}\text { Food aid } \\
\text { (FAIS) }\end{array}$} \\
\hline & 1 & 2 & 3 & 4 & 5 & 1 & 2 & 3 & 1 & 2 & 3 & 2 & 3 & 3 & 4 & 4 & 5 \\
\hline Somalia & 2.2 & 2.8 & 5.1 & 0.0 & 0.0 & 2.4 & 5.1 & 1.3 & 2.3 & 3.8 & 0.9 & 4.3 & 0.0 & 2.5 & 0.4 & 0.0 & 0.0 \\
\hline South Africa & 0.0 & 0.0 & 0.0 & 0.0 & 0.6 & 0.0 & 0.0 & 0.0 & . & . & . & 0.0 & 0.0 & 0.0 & 0.0 & 0.0 & 0.0 \\
\hline Sri Lanka & 2.2 & 2.8 & 2.3 & 4.0 & 1.5 & 4.6 & 3.0 & 2.3 & 4.0 & 4.8 & $<0.1$ & 4.3 & 3.0 & 0.0 & 0.0 & 0.0 & $<0.1$ \\
\hline St Helens & 0.0 & 0.0 & 0.0 & 0.0 & 0.0 & 0.0 & 0.0 & 0.0 & 0.0 & 0.0 & 0.0 & 0.0 & 0.0 & 0.0 & 0.0 & 0.0 & 0.0 \\
\hline Sudan & 0.0 & 2.2 & 1.8 & 5.1 & 2.5 & 0.0 & 4.3 & 2.4 & 0.0 & 2.6 & 5.6 & 2.5 & 10.1 & 2.7 & 2.7 & 0.0 & $<0.1$ \\
\hline Suriname & & 0.0 & 0.0 & 0.6 & 0.6 & & 0.0 & 1.4 & & 0.0 & 0.7 & 0.0 & 0.0 & 0.0 & 0.0 & 0.0 & 0.0 \\
\hline Swaziland & 0.0 & 0.0 & 0.0 & 0.0 & 0.0 & 0.0 & 0.0 & 0.0 & 0.0 & 0.0 & 0.0 & 0.0 & 0.0 & 0.0 & 0.0 & 0.2 & 0.0 \\
\hline Syria & 0.0 & 1.1 & 0.0 & 1.1 & 1.2 & 1.7 & 3.1 & 0.0 & 1.6 & 1.6 & 0.0 & 1.4 & 0.0 & 0.0 & 0.0 & 0.0 & $<0.1$ \\
\hline Tajikistan & . & . & . & 0.0 & 0.6 & . & . & . & . & . & . & . & . & . & 0.0 & 0.0 & 0.0 \\
\hline Tanzania & 18.9 & 12.8 & 2.8 & 4.5 & 4.6 & 5.6 & 12.9 & 5.7 & 5.6 & 9.2 & 13.7 & 9.2 & 2.7 & 5.3 & 6.7 & 0.0 & 0.0 \\
\hline Thailand & 0.0 & 0.0 & 0.0 & 0.6 & 0.0 & 0.0 & 0.0 & 0.0 & 0.0 & 0.0 & 0.0 & 0.0 & 0.0 & 0.0 & 0.0 & 0.0 & 0.0 \\
\hline Togo & 0.0 & 1.7 & 1.4 & 0.6 & 1.2 & 0.0 & 1.7 & 1.0 & 0.0 & 1.4 & 0.0 & 1.4 & 0.0 & 1.7 & 1.9 & 0.0 & 0.0 \\
\hline Tokelau & 0.0 & 0.0 & 0.0 & 0.0 & 0.0 & 0.0 & 0.0 & 0.0 & 0.0 & 0.0 & 0.0 & 0.0 & 0.0 & 0.0 & 0.0 & 0.0 & 0.0 \\
\hline Tonga & . & & . & . & 0.6 & & . & . & . & & . & . & . & . & & . & 0.0 \\
\hline Trinidad and Tobago & 0.0 & 0.0 & 0.0 & 0.0 & 0.3 & 0.0 & 0.0 & 0.0 & 0.0 & 0.0 & 0.0 & 0.0 & 0.0 & 0.0 & 0.0 & 0.0 & 0.0 \\
\hline Tunisia & 0.0 & 0.0 & 1.4 & 1.1 & 0.6 & 0.0 & 1.3 & 2.2 & 0.0 & 2.4 & 0.0 & 1.5 & 0.0 & 3.0 & 4.6 & 0.0 & 0.0 \\
\hline Turkey & 0.0 & 0.0 & 0.0 & 0.0 & 0.0 & 0.0 & 0.0 & 0.3 & 0.0 & 0.0 & 0.0 & $<0.1$ & 0.0 & 0.0 & 0.0 & 0.0 & 0.0 \\
\hline Turkmenistan & . & . & . & 0.0 & 0.9 & 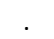 & . & . & . & . & . & . & . & . & 0.0 & 0.0 & 0.0 \\
\hline Turks and Caicos Islands & 0.0 & 0.0 & 0.0 & 0.0 & 0.0 & 0.0 & 0.0 & 0.0 & 0.0 & 0.0 & 0.0 & 0.0 & 0.0 & 0.0 & 0.0 & 0.0 & 0.0 \\
\hline Tuvalu & & 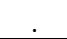 & . & . & 0.0 & & & & . & & & & & & & . & 0.0 \\
\hline Uganda & 0.0 & 2.2 & 1.4 & 0.6 & 1.2 & 1.5 & 0.0 & 1.3 & 1.5 & 0.5 & 0.0 & 0.0 & 0.1 & 1.2 & 1.1 & 0.0 & $<0.1$ \\
\hline Ukraine & . & . & . & 0.0 & 0.0 & $\cdot$ & . & . & . & . & . & . & . & . & 0.0 & 0.0 & 0.0 \\
\hline Uruguay & 0.0 & 0.0 & 0.0 & 0.0 & 0.0 & 0.0 & 0.0 & 0.0 & 0.0 & 0.0 & 0.0 & $<0.1$ & 0.0 & 0.0 & 0.0 & 0.0 & 0.0 \\
\hline Uzbekistan & . & . & . & 0.0 & 1.5 & . & . & . & . & . & . & . & . & . & 0.0 & 0.0 & 0.0 \\
\hline Vanuatu & . & . & 0.0 & 0.6 & 1.8 & . & . & 0.3 & . & . & 0.6 & . & 0.0 & 0.0 & 0.0 & 0.0 & 0.0 \\
\hline Venezuela & 0.0 & 0.0 & 0.0 & 0.0 & 0.0 & 0.0 & 0.0 & 0.0 & 0.0 & 0.0 & 0.0 & 0.0 & 0.0 & 0.0 & 0.0 & 0.0 & 0.0 \\
\hline Vietnam & . & . & . & 0.0 & 0.6 & $\cdot$ & $\cdot$ & . & . & $\cdot$ & . & . & . & 0.0 & 0.0 & 0.0 & 0.0 \\
\hline Wallis and Futuna & 0.0 & 0.0 & 0.0 & 0.0 & 0.0 & 0.0 & 0.0 & 0.0 & 0.0 & 0.0 & 0.0 & 0.0 & 0.0 & 0.0 & 0.0 & 0.0 & 0.0 \\
\hline Yemen & 7.8 & 2.8 & 4.6 & 1.7 & 0.6 & 5.3 & 1.9 & 0.6 & 5.8 & 1.7 & 0.0 & 1.8 & 0.0 & 14.8 & 15.9 & 0.0 & $<0.1$ \\
\hline Zambia & 0.0 & 1.7 & 2.8 & 1.7 & 2.8 & 2.3 & 6.3 & 1.3 & 1.6 & 8.9 & 0.9 & 8.7 & 1.4 & 2.1 & 2.1 & 9.4 & $<0.1$ \\
\hline Zimbabwe & 0.0 & 0.0 & 1.4 & 1.1 & 1.5 & 0.0 & 0.0 & 3.5 & 0.0 & 0.0 & 4.6 & 0.0 & 7.6 & 0.9 & 0.8 & 13.6 & 0.0 \\
\hline
\end{tabular}


Appendix III.1: Definitions and sources

\begin{tabular}{|c|c|c|}
\hline Variable & Description & Source \\
\hline \multicolumn{3}{|l|}{ Explained variables } \\
\hline $\begin{array}{l}1 \text { if aid commitment } \\
\text { (log) Aid commitment }\end{array}$ & $\begin{array}{l}1 \text { if aid commited to recipient country, 2008-2010 } \\
\text { (log) Aid commitments to recipient country (constant } 2000 \text { US\$), sum, 2008-2010 }\end{array}$ & $\begin{array}{l}\text { AidData (Tierney et al. 2011) } \\
\text { AidData (Tierney et al. 2011) }\end{array}$ \\
\hline \multicolumn{3}{|c|}{ Explanatory variables: Main results } \\
\hline $\begin{array}{l}\text { (log) GDP per capita } \\
\text { (log) Developmental distance } \\
\text { (log) Affected from disasters } \\
\text { (log) Population } \\
\text { (log) Distance } \\
\text { UN voting (key votes) } \\
\text { Commonwealth } \\
\text { Common colonial history } \\
\text { (log) Indian/Bilateral exports } \\
\text { (log) Resource depletion } \\
\text { Political rights } \\
\text { Control of corruption }\end{array}$ & $\begin{array}{l}\text { (log) GDP per capita (constant } 2005 \text { I\$), lag } \\
(\log ) \text { Absolute difference between the per-capita GDP of donor and recipient, lag } \\
(\log ) \text { Number of people affected by disasters, average } \\
(\log ) \text { Total population, lag } \\
(\log ) \text { Bilateral distance (weighted by populations of major cities) } \\
\text { UNGA voting alignment between donor and recipient (key votes), lag } \\
1 \text { if recipient is a non-suspended member of the Commonwealth, lag } \\
1 \text { if donor and recipient have had a colonial relationship or a common colonizer after } 1945 \\
(\log ) \text { Total exports from donor to recipient country, lag } \\
(\log ) \text { Product of unit resource rents and physical quantities of energy and minerals extracted, lag } \\
\text { Index of political rights rated on a seven-point scale (1: most free), lag } \\
\text { Index ranging from - } 2.5 \text { to } 2.5 \text { with higher values corresponding to better governance, lag }\end{array}$ & $\begin{array}{l}\text { Penn World Tables (Heston et al. 2009) } \\
\text { Own construction based on Penn World Tables } \\
\text { EM-DAT (2010) } \\
\text { Penn World Tables (Heston et al. 2009) } \\
\text { CEPII (Mayer and Zignago 2006) } \\
\text { Voeten and Merdzanovic (2009), Kilby (2009b) } \\
\text { www.thecommonwealth.org, internet research } \\
\text { CEPII (Mayer and Zignago 2006) } \\
\text { UN Comtrade via WITS (http://wits.worldbank.org) } \\
\text { World Bank (http://data.worldbank.org/indicator) } \\
\text { Freedom House (2009) } \\
\text { Kaufmann et al. (2009) }\end{array}$ \\
\hline \multicolumn{3}{|c|}{ Explanatory variables: Robustness checks } \\
\hline $\begin{array}{l}\text { (log) Indian migrants (def. 1) } \\
\text { (log) Indian migrants (def. 2) } \\
\text { Chinese aid projects } \\
\text { (log) Under-5 mortality rate } \\
\text { Neighbor } \\
\text { UN voting } \\
\text { UN voting (BRIC vs USA) } \\
\text { Common language } \\
\text { Democracy }\end{array}$ & $\begin{array}{l}\text { (log) Indian migrant stock in recipient country, } 2000 \text { round of population censuses } \\
\text { (log) Estimated size of Indian community in recipient country, } 2001 \\
\text { Number of Chinese aid projects completed in recipient country (\% of total), 1996-2005 } \\
\text { (log) Mortality rate, under } 5 \text { years (per 1000), lag } \\
1 \text { if donor and recipient share a border } \\
\text { UNGA voting alignment between donor and recipient, lag } \\
\text { UNGA voting alignment between donor and recipient (disagreement between BRIC and USA), lag } \\
1 \text { if a language is spoken by at least } 9 \% \text { of the population in donor and recipient country } \\
1 \text { if the regime qualifies as democratic, lag }\end{array}$ & $\begin{array}{l}\text { Global Migrant Origin Database (Parsons et al. 2007) } \\
\text { MEA (2001b) } \\
\text { Dreher and Fuchs (2011) } \\
\text { World Bank (http://data.worldbank.org/indicator) } \\
\text { CEPII (Mayer and Zignago 2006) } \\
\text { Voeten and Merdzanovic (2009), Kilby (2009b) } \\
\text { Voeten and Merdzanovic (2009), Kilby (2009b) } \\
\text { CEPII (Mayer and Zignago 2006) } \\
\text { Cheibub et al. (2010) }\end{array}$ \\
\hline
\end{tabular}

\section{Notes:}

- Values in current US\$ have been transformed to constant 2000 US\$ using US Consumer Price Indices from the World Bank (http://data.worldbank.org/indicator)

- The value of 1 has been added to exports and natural resource variables as well as to the number of people affected by disasters before taking logarithms 
Appendix III.2: Descriptive statistics

\begin{tabular}{|c|c|c|c|c|c|}
\hline & Obs & Mean & Std. Dev. & Min & Max \\
\hline 1 if aid commitment & 125 & 0.41 & 0.49 & 0.00 & 1.00 \\
\hline (log) Aid commitment & 51 & 13.28 & 2.45 & 9.02 & 20.07 \\
\hline (log) GDP per capita & 125 & 8.37 & 0.97 & 5.95 & 10.16 \\
\hline (log) Developmental distance & 125 & 7.86 & 1.09 & 3.83 & 10.00 \\
\hline (log) Affected from disasters & 125 & 9.21 & 4.34 & 0.00 & 18.71 \\
\hline (log) Population & 125 & 15.62 & 2.02 & 10.59 & 21.00 \\
\hline (log) Distance & 125 & 8.83 & 0.64 & 7.04 & 9.74 \\
\hline UN voting (key votes) & 125 & 0.74 & 0.14 & 0.25 & 0.93 \\
\hline Commonwealth & 125 & 0.30 & 0.46 & 0.00 & 1.00 \\
\hline Common colonial history & 125 & 0.30 & 0.46 & 0.00 & 1.00 \\
\hline (log) Exports & 125 & 17.36 & 2.42 & 10.32 & 22.66 \\
\hline (log) Resource depletion & 125 & 13.16 & 10.22 & 0.00 & 25.82 \\
\hline Political rights & 125 & 3.94 & 1.95 & 1.00 & 7.00 \\
\hline Control of corruption & 125 & -0.47 & 0.59 & -1.38 & 1.34 \\
\hline (log) Indian migrants (def. 1) & 125 & 6.17 & 2.99 & 0.00 & 13.86 \\
\hline (log) Indian migrants (def. 2) & 125 & 4.73 & 4.24 & 0.00 & 14.33 \\
\hline Chinese project aid & 124 & 0.75 & 0.94 & 0.00 & 4.62 \\
\hline (log) Under-5 mortality rate & 125 & 3.84 & 0.90 & 1.76 & 5.57 \\
\hline Neighbor & 125 & 0.04 & 0.20 & 0.00 & 1.00 \\
\hline UN voting & 125 & 0.79 & 0.10 & 0.38 & 0.89 \\
\hline UN voting (BRIC vs USA) & 125 & 0.92 & 0.12 & 0.37 & 1.00 \\
\hline Common language & 125 & 0.31 & 0.47 & 0.00 & 1.00 \\
\hline Democracy & 125 & 0.52 & 0.50 & 0.00 & 1.00 \\
\hline
\end{tabular}

Note: Descriptive statistics for sample as in Table III.1, column 1 
Appendix III.3: Allocation of India's aid commitments (Probit, 2008-2010): Robustness checks

\begin{tabular}{|c|c|c|c|c|c|c|c|c|c|c|c|}
\hline & baseline & (1a) & (1b) & (2) & (3) & (4) & (5) & (6) & (7) & (8) & (9) \\
\hline \multirow[t]{2}{*}{ (log) GDP per capita } & $-0.315^{*}$ & $-0.308^{*}$ & $-0.313^{*}$ & -0.247 & $-0.469^{* *}$ & $-0.315^{*}$ & $-0.316^{*}$ & $-0.321 *$ & $-0.331 *$ & $-0.320^{*}$ & $-0.319 *$ \\
\hline & $(0.060)$ & $(0.067)$ & $(0.061)$ & $(0.165)$ & $(0.037)$ & $(0.059)$ & $(0.057)$ & $(0.053)$ & $(0.052)$ & $(0.059)$ & $(0.054)$ \\
\hline \multirow[t]{2}{*}{ (log) Affected from disasters } & -0.060 & -0.057 & -0.060 & -0.066 & -0.058 & -0.060 & -0.062 & -0.060 & -0.058 & -0.058 & -0.053 \\
\hline & $(0.137)$ & $(0.170)$ & (0.139) & $(0.102)$ & $(0.145)$ & $(0.134)$ & $(0.128)$ & $(0.139)$ & $(0.151)$ & $(0.152)$ & $(0.177)$ \\
\hline \multirow[t]{2}{*}{ (log) Population } & 0.028 & 0.015 & 0.031 & 0.062 & 0.007 & 0.028 & 0.022 & 0.028 & -0.027 & -0.009 & 0.016 \\
\hline & $(0.852)$ & $(0.924)$ & $(0.837)$ & $(0.681)$ & $(0.963)$ & $(0.852)$ & $(0.883)$ & $(0.850)$ & $(0.854)$ & $(0.950)$ & $(0.914)$ \\
\hline \multirow[t]{2}{*}{ (log) Distance } & $-0.847 * * *$ & $-0.806^{* * *}$ & $-0.847^{* * *}$ & $-0.783^{* * *}$ & $-0.825 * * *$ & $-0.841^{* * *}$ & $-0.873^{* * *}$ & $-0.850^{* * *}$ & $-0.852^{* * *}$ & $-0.852^{* * *}$ & $-0.797^{* * *}$ \\
\hline & $(0.001)$ & $(0.004)$ & $(0.001)$ & $(0.003)$ & $(0.002)$ & $(0.003)$ & $(0.001)$ & $(0.001)$ & $(0.001)$ & $(0.001)$ & $(0.001)$ \\
\hline \multirow[t]{2}{*}{ UN voting (key votes) } & 0.364 & 0.375 & 0.337 & 0.157 & 0.610 & 0.365 & & & 0.602 & 0.530 & 0.380 \\
\hline & $(0.747)$ & $(0.738)$ & $(0.767)$ & $(0.889)$ & $(0.590)$ & $(0.746)$ & & & $(0.590)$ & $(0.641)$ & $(0.727)$ \\
\hline \multirow[t]{2}{*}{ Commonwealth } & 0.434 & 0.408 & 0.424 & 0.432 & 0.494 & 0.432 & 0.436 & 0.448 & & & $0.549 *$ \\
\hline & $(0.146)$ & $(0.169)$ & $(0.162)$ & $(0.150)$ & $(0.100)$ & $(0.146)$ & $(0.140)$ & $(0.128)$ & & & $(0.061)$ \\
\hline \multirow[t]{2}{*}{ (log) Indian exports } & -0.152 & -0.166 & -0.157 & $-0.165 *$ & -0.148 & -0.152 & -0.162 & -0.144 & -0.126 & -0.136 & -0.152 \\
\hline & $(0.123)$ & $(0.102)$ & $(0.128)$ & $(0.092)$ & $(0.135)$ & $(0.124)$ & $(0.101)$ & $(0.137)$ & $(0.197)$ & $(0.166)$ & $(0.121)$ \\
\hline \multirow[t]{2}{*}{ (log) Resource depletion } & 0.002 & 0.002 & 0.001 & 0.001 & 0.003 & 0.002 & 0.002 & 0.002 & 0.003 & 0.003 & 0.003 \\
\hline & $(0.924)$ & $(0.908)$ & $(0.948)$ & $(0.940)$ & $(0.885)$ & $(0.923)$ & $(0.896)$ & $(0.920)$ & $(0.877)$ & $(0.864)$ & $(0.852)$ \\
\hline \multirow[t]{2}{*}{ Political rights } & -0.140 & -0.136 & -0.139 & -0.133 & -0.135 & -0.140 & -0.142 & -0.131 & -0.163 & -0.162 & \\
\hline & $(0.173)$ & $(0.184)$ & $(0.175)$ & $(0.201)$ & $(0.190)$ & $(0.173)$ & $(0.153)$ & $(0.171)$ & $(0.124)$ & $(0.116)$ & \\
\hline \multirow[t]{2}{*}{ Control of corruption } & -0.228 & -0.237 & -0.231 & -0.211 & -0.315 & -0.230 & -0.250 & -0.212 & -0.205 & -0.219 & -0.114 \\
\hline & $(0.421)$ & $(0.404)$ & $(0.415)$ & $(0.452)$ & $(0.291)$ & $(0.423)$ & $(0.378)$ & $(0.450)$ & $(0.467)$ & $(0.440)$ & $(0.670)$ \\
\hline (log) Indian migrants (def. 1) & & $\begin{array}{c}0.026 \\
(0.662)\end{array}$ & & & & & & & & & \\
\hline (log) Indian migrants (def. 2) & & & $\begin{array}{c}0.005 \\
(0.883)\end{array}$ & & & & & & & & \\
\hline Chinese project aid & & & & $\begin{array}{c}0.190 \\
(0.174)\end{array}$ & & & & & & & \\
\hline (log) Under-5 mortality rate & & & & & $\begin{array}{l}-0.246 \\
(0.291)\end{array}$ & & & & & & \\
\hline Neighbor & & & & & & $\begin{array}{c}0.035 \\
(0.961)\end{array}$ & & & & & \\
\hline UN voting & & & & & & & $\begin{array}{c}0.978 \\
(0.492)\end{array}$ & & & & \\
\hline UN voting (BRIC vs USA) & & & & & & & & $\begin{array}{c}0.073 \\
(0.950)\end{array}$ & & & \\
\hline Common language & & & & & & & & & $\begin{array}{c}0.039 \\
(0.894)\end{array}$ & & \\
\hline Colonial relationship & & & & & & & & & & $\begin{array}{c}0.148 \\
(0.624)\end{array}$ & \\
\hline Democracy & & & & & & & & & & & $\begin{array}{c}0.442 \\
(0.133)\end{array}$ \\
\hline Constant & $\begin{array}{l}12.592^{* * *} \\
(0.000)\end{array}$ & $\begin{array}{l}12.416^{* * *} \\
(0.000)\end{array}$ & $\begin{array}{l}12.632^{* * *} \\
(0.000) \\
\end{array}$ & $\begin{array}{l}11.210^{* * *} \\
(0.002) \\
\end{array}$ & $\begin{array}{l}14.607^{* * *} \\
(0.000)\end{array}$ & $\begin{array}{l}12.546^{* * *} \\
(0.000)\end{array}$ & $\begin{array}{l}12.617^{* * *} \\
(0.000)\end{array}$ & $\begin{array}{l}12.704^{* * *} \\
(0.000)\end{array}$ & $\begin{array}{l}13.218^{* * *} \\
(0.000) \\
\end{array}$ & $\begin{array}{l}13.031^{* * *} \\
(0.000)\end{array}$ & $\begin{array}{l}11.524^{* * *} \\
(0.000) \\
\end{array}$ \\
\hline Number of observations & 125 & 125 & 125 & 124 & 125 & 125 & 125 & 125 & 125 & 125 & 125 \\
\hline Prob>Chi2 & 0.002 & 0.003 & 0.003 & 0.003 & 0.001 & 0.003 & 0.002 & 0.002 & 0.002 & 0.002 & 0.002 \\
\hline Pseudo R-Squared & 0.17 & 0.17 & 0.17 & 0.18 & 0.18 & 0.17 & 0.17 & 0.17 & 0.16 & 0.16 & 0.17 \\
\hline
\end{tabular}

Notes: Dependent variable: Dummy that takes a value of one if aid was commited to a recipient country during the 2008-2010 period / * $\left({ }^{* *},{ }^{* * *}\right.$ ) indicates significance at the ten (five, one) percent level 
Appendix III.4: Allocation of India's aid commitments (OLS, 2008-2010): Robustness checks

\begin{tabular}{|c|c|c|c|c|c|c|c|c|c|c|c|}
\hline & baseline & (1a) & (1b) & (2) & (3) & (4) & (5) & (6) & (7) & (8) & (9) \\
\hline \multirow[t]{2}{*}{ (log) GDP per capita } & -0.241 & -0.235 & -0.240 & -0.214 & -0.047 & -0.230 & -0.317 & -0.286 & -0.233 & -0.249 & -0.251 \\
\hline & $(0.226)$ & $(0.251)$ & $(0.233)$ & $(0.292)$ & $(0.880)$ & $(0.246)$ & $(0.126)$ & $(0.175)$ & $(0.340)$ & $(0.208)$ & $(0.201)$ \\
\hline \multirow[t]{2}{*}{ (log) Affected from disasters } & $0.111^{* *}$ & $0.112^{* *}$ & $0.111^{* *}$ & $0.109 * *$ & $0.106^{* *}$ & $0.108^{* *}$ & 0.077 & 0.075 & $0.101 *$ & $0.097 *$ & $0.110^{* *}$ \\
\hline & $(0.037)$ & $(0.041)$ & $(0.040)$ & $(0.042)$ & $(0.034)$ & $(0.043)$ & $(0.162)$ & $(0.173)$ & $(0.060)$ & $(0.063)$ & $(0.036)$ \\
\hline \multirow[t]{2}{*}{ (log) Population } & $-0.526^{* * *}$ & $-0.533^{* * *}$ & $-0.526^{* * *}$ & $-0.531 * * *$ & $-0.532^{* * *}$ & $-0.522 * * *$ & $-0.502^{* * *}$ & $-0.465^{* * *}$ & $-0.363^{* *}$ & $-0.483^{* * *}$ & $-0.542^{* * *}$ \\
\hline & $(0.002)$ & $(0.004)$ & $(0.002)$ & $(0.003)$ & $(0.003)$ & $(0.002)$ & $(0.003)$ & $(0.008)$ & $(0.037)$ & $(0.004)$ & $(0.003)$ \\
\hline \multirow[t]{2}{*}{ (log) Distance } & $-1.668^{* * *}$ & $-1.646^{* * *}$ & $-1.669 * * *$ & $-1.630^{* * *}$ & $-1.660^{* * *}$ & $-1.529^{* * *}$ & $-1.997^{* * *}$ & $-2.053^{* * *}$ & $-1.857^{* * *}$ & $-1.634^{* * *}$ & $-1.635^{* * *}$ \\
\hline & $(0.000)$ & $(0.000)$ & $(0.000)$ & $(0.000)$ & $(0.000)$ & $(0.000)$ & $(0.000)$ & $(0.000)$ & $(0.000)$ & $(0.000)$ & $(0.000)$ \\
\hline \multirow[t]{2}{*}{ UN voting (key votes) } & $6.918^{* * *}$ & $6.968^{* * *}$ & $6.907^{* * *}$ & $6.933^{* * *}$ & $6.858^{* * *}$ & $7.215^{* * *}$ & & & $5.926^{* * *}$ & $6.826^{* * *}$ & $6.941^{* * *}$ \\
\hline & $(0.000)$ & $(0.000)$ & $(0.000)$ & $(0.000)$ & $(0.000)$ & $(0.000)$ & & & $(0.000)$ & $(0.000)$ & $(0.000)$ \\
\hline \multirow[t]{2}{*}{ Commonwealth } & $-1.203^{* * *}$ & $-1.214^{* * *}$ & $-1.210^{* * *}$ & $-1.210^{* * *}$ & $-1.236^{* * *}$ & $-1.199 * * *$ & $-1.050^{* * *}$ & $-1.000^{* * *}$ & & & $-1.292^{* * *}$ \\
\hline & $(0.001)$ & $(0.002)$ & $(0.002)$ & $(0.001)$ & $(0.001)$ & $(0.001)$ & $(0.003)$ & $(0.006)$ & & & $(0.000)$ \\
\hline \multirow[t]{2}{*}{ (log) Indian exports } & $0.398^{* * *}$ & $0.394^{* * *}$ & $0.395^{* * *}$ & $0.398^{* * *}$ & $0.413^{* * *}$ & $0.383^{* * *}$ & $0.365^{* * *}$ & $0.378^{* * *}$ & $0.292^{* *}$ & $0.401^{* * *}$ & $0.412^{* * *}$ \\
\hline & $(0.001)$ & $(0.001)$ & $(0.001)$ & $(0.001)$ & $(0.001)$ & $(0.002)$ & $(0.003)$ & $(0.003)$ & $(0.015)$ & $(0.001)$ & $(0.002)$ \\
\hline \multirow[t]{2}{*}{ (log) Resource depletion } & -0.019 & -0.019 & -0.019 & -0.019 & -0.019 & -0.019 & -0.010 & -0.011 & -0.014 & -0.027 & -0.020 \\
\hline & $(0.339)$ & $(0.325)$ & $(0.316)$ & $(0.350)$ & $(0.349)$ & $(0.347)$ & $(0.625)$ & $(0.622)$ & $(0.534)$ & $(0.153)$ & $(0.303)$ \\
\hline \multirow[t]{2}{*}{ Political rights } & 0.037 & 0.038 & 0.037 & 0.039 & 0.030 & 0.035 & 0.072 & 0.096 & 0.052 & 0.056 & \\
\hline & $\begin{array}{l}(0.798) \\
1.474^{* * *}\end{array}$ & $\begin{array}{l}(0.797) \\
1.473^{* * *}\end{array}$ & $\begin{array}{l}(0.802) \\
1.470^{* * *}\end{array}$ & $\begin{array}{l}(0.788) \\
1.465^{* * *}\end{array}$ & $\begin{array}{l}(0.849) \\
1.426^{* * *}\end{array}$ & $\begin{array}{l}(0.812) \\
1.403^{* * *}\end{array}$ & $\begin{array}{l}(0.568) \\
1.508^{* * *}\end{array}$ & $\begin{array}{l}(0.447) \\
1.587^{* * *}\end{array}$ & $\begin{array}{l}(0.750) \\
1.505^{* * *}\end{array}$ & $\begin{array}{l}(0.703) \\
1.881 * * *\end{array}$ & \\
\hline Control of corruption & $\begin{array}{l}1.474^{* 7 *} \\
(0.000)\end{array}$ & $\begin{array}{l}1.473 \text { (0.000) } \\
(0.00)\end{array}$ & $(0.000)$ & $(0.000)$ & $\begin{array}{l}1.426 \text { * } \\
(0.000)\end{array}$ & $\begin{array}{l}1.405 \\
(0.000) \\
\end{array}$ & $\begin{array}{r}1.500 \\
(0.000) \\
\end{array}$ & $\begin{array}{l}1.587 \text { ath } \\
(0.000)\end{array}$ & $\begin{array}{l}1.505^{* * *} \\
(0.000)\end{array}$ & $\begin{array}{l}1.481^{\text {*** }} \\
(0.000) \\
\end{array}$ & $\begin{array}{l}1.461^{\text {*** }} \\
(0.000) \\
\end{array}$ \\
\hline (log) Indian migrants (def. 1) & & $\begin{array}{c}0.011 \\
(0.892)\end{array}$ & & & & & & & & & \\
\hline (log) Indian migrants (def. 2) & & & $\begin{array}{c}0.004 \\
(0.920)\end{array}$ & & & & & & & & \\
\hline Chinese project aid & & & & $\begin{array}{c}0.080 \\
(0.551)\end{array}$ & & & & & & & \\
\hline (log) Under-5 mortality rate & & & & & $\begin{array}{c}0.341 \\
(0.267)\end{array}$ & & & & & & \\
\hline Neighbor & & & & & & $\begin{array}{c}0.682 \\
(0.268)\end{array}$ & & & & & \\
\hline UN voting & & & & & & & $\begin{array}{l}8.478^{* * *} \\
(0.000)\end{array}$ & & & & \\
\hline UN voting (BRIC vs USA) & & & & & & & & $\begin{array}{l}5.854^{* * *} \\
(0.000)\end{array}$ & & & \\
\hline Common language & & & & & & & & & $\begin{array}{l}-0.239 \\
(0.486)\end{array}$ & & \\
\hline Common colonial history & & & & & & & & & & $\begin{array}{l}-1.219^{* * *} \\
(0.001)\end{array}$ & \\
\hline Democracy & & & & & & & & & & & $\begin{array}{l}-0.259 \\
(0.498)\end{array}$ \\
\hline Constant & $\begin{array}{l}26.284^{* * *} \\
(0.000)\end{array}$ & $\begin{array}{l}26.111^{* * *} \\
(0.000) \\
\end{array}$ & $\begin{array}{l}26.321^{* * *} \\
(0.000) \\
\end{array}$ & $\begin{array}{l}25.727^{* * *} \\
(0.000) \\
\end{array}$ & $\begin{array}{l}23.238^{* * *} \\
(0.000)\end{array}$ & $\begin{array}{l}24.922^{* * *} \\
(0.000)\end{array}$ & $\begin{array}{l}28.461^{* * *} \\
(0.000) \\
\end{array}$ & $\begin{array}{l}29.206^{* * *} \\
(0.000)\end{array}$ & $\begin{array}{l}27.486^{* * *} \\
(0.000)\end{array}$ & $\begin{array}{l}25.511^{* * *} \\
(0.000) \\
\end{array}$ & $\begin{array}{l}26.396^{* * *} \\
(0.000) \\
\end{array}$ \\
\hline Number of observations & 51 & 51 & 51 & 51 & 51 & 51 & 51 & 51 & 51 & 51 & 51 \\
\hline Prob $>F$ & 0.000 & 0.000 & 0.000 & 0.000 & 0.000 & 0.000 & 0.000 & 0.000 & 0.000 & 0.000 & 0.000 \\
\hline R-Squared & 0.83 & 0.82 & 0.82 & 0.82 & 0.83 & 0.83 & 0.84 & 0.84 & 0.77 & 0.83 & 0.83 \\
\hline
\end{tabular}

Notes: Dependent variable: (log) Aid commitments to recipient country, sum 2008-2010/ * $\left(^{* *},{ }^{* * *}\right)$ indicates significance at the ten (five, one) percent level 
Appendix III.5: Comparison of India's aid allocation with other donors (Indian aid recipients only, 2008-2010)

\begin{tabular}{|c|c|c|c|c|c|c|c|}
\hline & India & USA & EU-3 & Good donors & Japan & Korea & UAE \\
\hline \multirow[t]{3}{*}{ (log) GDP per capita } & -0.249 & 0.003 & $-0.628^{* *}$ & $-0.647^{* *}$ & -0.314 & -0.237 & $-1.174 * *$ \\
\hline & (0.191) & (0.994) & $(0.035)$ & $(0.011)$ & $(0.108)$ & $(0.429)$ & $(0.027)$ \\
\hline & & 0.552 & 0.203 & 0.154 & 0.823 & 0.970 & 0.119 \\
\hline \multirow[t]{3}{*}{ (log) Affected from disasters } & $0.097^{*}$ & $0.131^{*}$ & 0.025 & 0.062 & $0.083^{*}$ & 0.099 & -0.213 \\
\hline & $(0.053)$ & $(0.083)$ & $(0.705)$ & $(0.342)$ & $(0.056)$ & $(0.278)$ & $(0.188)$ \\
\hline & & 0.696 & 0.244 & 0.595 & 0.844 & 0.979 & 0.073 \\
\hline \multirow[t]{3}{*}{ (log) Population } & $-0.483 * * *$ & $0.868 * * *$ & $0.543^{* *}$ & $0.567 * * *$ & $0.312^{* *}$ & $0.841 * * *$ & -0.256 \\
\hline & $(0.002)$ & $(0.005)$ & $(0.013)$ & $(0.001)$ & $(0.020)$ & $(0.000)$ & $(0.507)$ \\
\hline & & 0.000 & 0.000 & 0.000 & 0.000 & 0.000 & 0.601 \\
\hline \multirow[t]{3}{*}{ (log) Distance } & $-1.634 * * *$ & 0.184 & -0.535 & $-1.139 * *$ & $-1.467^{* * *}$ & $-1.336^{* * *}$ & $-2.001^{*}$ \\
\hline & $(0.000)$ & $(0.798)$ & $(0.317)$ & $(0.022)$ & $(0.000)$ & $(0.002)$ & $(0.072)$ \\
\hline & & 0.025 & 0.041 & 0.394 & 0.618 & 0.544 & 0.739 \\
\hline \multirow[t]{3}{*}{ UN voting (key votes) } & $6.826 * * *$ & 4.023 & -0.383 & 0.717 & -0.076 & $10.602^{* *}$ & -1.883 \\
\hline & $(0.000)$ & $(0.165)$ & $(0.880)$ & $(0.766)$ & $(0.964)$ & $(0.016)$ & $(0.678)$ \\
\hline & & 0.389 & 0.021 & 0.030 & 0.001 & 0.388 & 0.097 \\
\hline \multirow[t]{3}{*}{ Common colonial history } & $-1.219 * * *$ & $4.189 * * *$ & $1.039 * *$ & $2.681 * * *$ & & & 0.606 \\
\hline & $(0.000)$ & $(0.007)$ & $(0.050)$ & $(0.000)$ & & & (0.519) \\
\hline & & 0.001 & 0.000 & 0.000 & & & 0.092 \\
\hline \multirow[t]{3}{*}{ (log) Bilateral exports } & $0.401 * * *$ & 0.043 & $0.506^{* * *}$ & $0.311^{* * *}$ & $0.220 * * *$ & $0.217^{*}$ & $0.231 * *$ \\
\hline & $(0.001)$ & $(0.858)$ & $(0.009)$ & $(0.002)$ & $(0.003)$ & $(0.074)$ & $(0.014)$ \\
\hline & & 0.136 & 0.616 & 0.468 & 0.179 & 0.184 & 0.226 \\
\hline \multirow[t]{3}{*}{ (log) Resource depletion } & -0.027 & 0.037 & 0.012 & -0.030 & -0.019 & -0.031 & 0.020 \\
\hline & $(0.137)$ & $(0.253)$ & $(0.630)$ & $(0.291)$ & $(0.164)$ & $(0.222)$ & $(0.618)$ \\
\hline & & 0.066 & 0.084 & 0.926 & 0.716 & 0.914 & 0.301 \\
\hline \multirow[t]{3}{*}{ Political rights } & 0.056 & -0.026 & 0.083 & 0.141 & -0.052 & 0.186 & -0.499 \\
\hline & (0.692) & $(0.897)$ & $(0.410)$ & $(0.251)$ & $(0.474)$ & $(0.177)$ & $(0.190)$ \\
\hline & & 0.756 & 0.881 & 0.697 & 0.491 & 0.468 & 0.200 \\
\hline \multirow[t]{3}{*}{ Control of corruption } & $1.481 * * *$ & 0.175 & $0.972^{* *}$ & $1.321 * * *$ & $0.573^{* *}$ & -0.267 & -1.157 \\
\hline & $(0.000)$ & $(0.805)$ & $(0.021)$ & $(0.005)$ & $(0.048)$ & $(0.607)$ & (0.398) \\
\hline & & 0.094 & 0.314 & 0.707 & 0.025 & 0.001 & 0.064 \\
\hline Donor country dummies & Yes & Yes & Yes & Yes & Yes & Yes & Yes \\
\hline Number of observations & & & & 574 & & & \\
\hline Number of recipients & & & & 51 & & & \\
\hline - per donor group & 51 & 51 & 51 & 50 & 51 & 49 & 33 \\
\hline R-Squared & & & & 0.65 & & & \\
\hline
\end{tabular}

\section{Notes:}

- Estimation technique: Nested OLS with standard errors clustered by recipient country

- Dependent variable: (log) Aid commitments to recipient country, sum 2008-2010

- We report coefficients of the explanatory variables (corresponding $\mathrm{p}$-values in parentheses)

- In italics: p-values of a Wald test of equal marginal effects of the respective donor (group) compared to India

$-*(* *, * * *)$ indicates significance at the ten (five, one) percent level 
Appendix IV.1: Humanitarian aid and disaster relief of "new" donors

\begin{tabular}{|l|l|}
\hline Turkey & Ministry of Foreign Affairs \\
\hline Responsible agency & $\begin{array}{l}\text { Channel humanitarian assistance rapidly to those countries in dire straits and support } \\
\text { international efforts to this end indiscriminate of race, religion, language and gender; } \\
\text { build a safer world, save human lives and protect the environment; build on own } \\
\text { experiences as a disaster-prone country }\end{array}$ \\
\hline Priorities & N/A \\
\hline Sources & www.mfa.gov.tr/humanitarian-assistance-by-turkey.en.mfa \\
\hline
\end{tabular}

\begin{tabular}{|l|l|}
\hline South Korea & $\begin{array}{l}\text { Korean International Cooperation Agency (KOICA) } \\
\text { Ministry of Foreign Affairs and Trade } \\
\text { Other ministries and governmental agencies }\end{array}$ \\
\hline Objectives / Mission & $\begin{array}{l}\text { Provide immediate relief to refugees and the victims of natural disasters and war; } \\
\text { stabilize food supplies; repair and reconstruct health and education facilities; rebuild } \\
\text { economic and social infrastructure; facilitate industrial rehabilitation }\end{array}$ \\
\hline Priorities & Infrastructure support; aid in kind; emergency relief; training; focus on Asia \\
\hline Sources & www.koica.go.kr/english/aid/disaster/index.html \\
\hline http://en.rescue.go.kr/
\end{tabular}

\begin{tabular}{|l|l|}
\hline Saudi Arabia \\
\hline Responsible agency & No central agency \\
\hline Objectives / Mission & Spread aid to who needs it; “Kingdom of Humanity” \\
\hline Priorities & Initiation of donation campaigns; focus on Arabic and Muslim countries \\
\hline Sources & www.saudiembassy.pl/The,Kingdom,of,Saudi,Arabia,and,Humanitarian,aids,281.html \\
\hline
\end{tabular}

\begin{tabular}{|l|l|}
\hline United Arab Emirates \\
\hline Responsible agency & $\begin{array}{l}\text { UAE Office for the Coordination of Foreign Aid (OCFA) } \\
\text { Several government ministries, departments and agencies }\end{array}$ \\
\hline Objectives / Mission & $\begin{array}{l}\text { Provide urgent relief to those suffering the effects of natural disasters and man-made } \\
\text { crises; dictated by an Islamic belief that helping those in need is a primary duty and } \\
\text { that part of the country's wealth from oil and gas should be devoted to assisting less } \\
\text { fortunate countries and individuals; lead the way in responding to regional and } \\
\text { international emergencies }\end{array}$ \\
\hline Priorities & $\begin{array}{l}\text { Middle East; Sub-Saharan Africa; Central and South Asia; difficult regions; high risk } \\
\text { areas }\end{array}$ \\
\hline Sources & $\begin{array}{l}\text { http://www.uaeinteract.com/government/development aid.asp } \\
\text { http://www.ocfa.gov.ae }\end{array}$ \\
\hline
\end{tabular}

\begin{tabular}{|l|l|}
\hline Czech Republic & $\begin{array}{l}\text { Ministry for Foreign Affairs } \\
\text { Ministry of the Interior }\end{array}$ \\
\hline Objectives / Mission & $\begin{array}{l}\text { Save lives; alleviating human suffering; build resilience; prevent new disasters; operate } \\
\text { out of common human solidarity and independent of particular political or other } \\
\text { interests; regular annual humanitarian budget since 1995 }\end{array}$ \\
\hline Priorities & $\begin{array}{l}\text { Development priority partner countries (e.g., Afghanistan and Ethiopia); countries that } \\
\text { receive little aid (e.g., Zimbabwe, Myanmar, Sri Lanka and DR Congo); floods response } \\
\text { (high-capacity water pumps); decontamination; urban search and rescue assistance; } \\
\text { disaster risk reduction; early recovery in the local communities }\end{array}$ \\
\hline Sources & $\begin{array}{l}\text { E-mail from Ministry of Foreign Affairs } \\
\text { www.mzv.cz/aid }\end{array}$ \\
\hline
\end{tabular}


Appendix IV.1 (continued): Humanitarian aid and disaster relief of "new" donors

\begin{tabular}{|l|l|}
\hline Singapore & \multicolumn{2}{|l|}{$\begin{array}{l}\text { Singaporean Civil Defence Force } \\
\text { Ministry of Foreign Affairs }\end{array}$} \\
\hline Objectives / Mission & $\begin{array}{l}\text { Being a responsible member of the international community; does not aspire to being a } \\
\text { major donor; being part of an overall international contribution }\end{array}$ \\
\hline Priorities & $\begin{array}{l}\text { Decisions taken under consideration of the value added to the general relief efforts and } \\
\text { of the nature of Singapore's relations with the affected country; emphasis on } \\
\text { neighboring countries }\end{array}$ \\
\hline Sources & E-mail from Ministry of Foreign Affairs \\
\hline
\end{tabular}

\begin{tabular}{|l|l|}
\hline Russian Federation & \\
\hline Responsible agency & $\begin{array}{l}\text { Ministry of Foreign Affairs } \\
\text { Ministry of Finance } \\
\text { Ministry for Emergencies }\end{array}$ \\
\hline Objectives / Mission & $\begin{array}{l}\text { Eliminate the consequences of humanitarian, natural, environmental, and industrial } \\
\text { disasters and other emergencies }\end{array}$ \\
\hline Priorities & N/A \\
\hline Sources & $\begin{array}{l}\text { Minfin (2007) } \\
\text { www.mchs.gov.ru/eng }\end{array}$ \\
\hline
\end{tabular}

\begin{tabular}{|l|l|}
\hline China & \multicolumn{1}{|l|}{$\begin{array}{l}\text { Ministry of Foreign Affairs } \\
\text { Ministry of Commerce } \\
\text { Ministry of Health } \\
\text { Ministry of Civil Affairs } \\
\text { China Earthquake Administration }\end{array}$} \\
\hline Objectives / Mission & $\begin{array}{l}\text { Reduce losses of life and property in disaster-stricken areas; help the victim country } \\
\text { tackle difficulties caused by the disaster; fulfill duty of a responsible member of } \\
\text { international society; humanitarian spirit of "People first" }\end{array}$ \\
\hline Priorities & N/A \\
\hline Sources & $\begin{array}{l}\text { State Council (2011) } \\
\text { www.gov.cn/misc/2006-01/18/content 163087.htm }\end{array}$ \\
\hline
\end{tabular}

\begin{tabular}{|l|l|}
\hline Brazil & Ministry of Foreign Affairs \\
\hline Objectives / Mission & $\begin{array}{l}\text { Respond quickly to humanitarian emergencies caused by social and environmental } \\
\text { disasters; promote both food security and nutritional status of vulnerable populations; } \\
\text { implement measures to prevent and reduce disaster risks; sustainable post-disaster } \\
\text { early recovery; bring world nations and peoples closer }\end{array}$ \\
\hline Priorities & $\begin{array}{l}\text { Priority to projects capable of igniting changes in the structural causes beneath the } \\
\text { situation of food insecurity; gifts of food, materials for temporary shelter and health } \\
\text { supplies; Latin American, Caribbean, African and Asian countries }\end{array}$ \\
\hline Sources & cooperacaohumanitaria.itamaraty.gov.br \\
\hline
\end{tabular}

\begin{tabular}{|l|l|}
\hline \multicolumn{2}{|l|}{ Poland } \\
\hline Responsible agency & Ministry of Foreign Affairs \\
\hline Objectives / Mission & Save lives and protect during disasters and crises \\
\hline Priorities & $\begin{array}{l}\text { Partner countries (e.g., Afghanistan, Georgia, Moldova, Palestinian Territory and } \\
\text { Ukraine); in difficult humanitarian situations (Sudan, Chad and Iraq) }\end{array}$ \\
\hline Sources & www.polishaid.gov.pl \\
\hline
\end{tabular}


Appendix IV.1 (continued): Humanitarian aid and disaster relief of "new" donors

\begin{tabular}{|l|l|}
\hline Hungary & \multicolumn{2}{|l|}{$\begin{array}{l}\text { Ministry of Foreign Affairs } \\
\text { Other ministries } \\
\text { National Directorate for Disaster Management }\end{array}$} \\
\hline Objectives / Mission & $\begin{array}{l}\text { Give the victims of conflicts and disasters speedy assistance; focus also on } \\
\text { rehabilitation and reconstruction }\end{array}$ \\
\hline Priorities & $\begin{array}{l}\text { Support in the sectors of health, water and sanitation; restoration of livelihoods; focus } \\
\text { on Central and South-East European region }\end{array}$ \\
\hline Sources & www.mfa.gov.hu/kum/en/bal/foreign_policy/international development \\
\hline
\end{tabular}

\begin{tabular}{|l|l|}
\hline Cyprus & \multicolumn{2}{|l|}{$\begin{array}{l}\text { Minister of Foreign Affairs } \\
\text { CyprusAid (Planning Bureau) }\end{array}$} \\
\hline Objectives / Mission & $\begin{array}{l}\text { Assist countries and people in dire situations; motivated by own experience after the } \\
\text { Turkish invasion of 1974; facilitator in emergency response situations; active since 1994 }\end{array}$ \\
\hline Priorities & $\begin{array}{l}\text { Funds or in kind (pharmaceuticals, food and clothing); countries that are close and } \\
\text { enjoy good relations with Cyprus }\end{array}$ \\
\hline Sources & $\begin{array}{l}\text { E-mail from Ministry of Foreign Affairs } \\
\text { CyprusAid (2009) } \\
\text { http://www.planning.gov.cy/planning/planning.nsf/dmlcyactivities en/dmlcyactivities } \\
\text { en?OpenDocument }\end{array}$ \\
\hline
\end{tabular}

\begin{tabular}{|c|c|}
\hline \multicolumn{2}{|l|}{ Slovakia } \\
\hline Responsible agency & $\begin{array}{l}\text { Ministry of Foreign Affairs } \\
\text { Ministry of Interior }\end{array}$ \\
\hline Objectives / Mission & $\begin{array}{l}\text { Expression of solidarity with people in need; prevent the loss of lives; mitigate the } \\
\text { suffering of people affected by exceptional events like natural disasters, armed } \\
\text { conflicts or similar emergency situations; active since about } 2002\end{array}$ \\
\hline Priorities & Urgency; availability of resources; no pre-defined regional or sectoral priorities \\
\hline Sources & $\begin{array}{l}\text { E-Mail from Ministry of Foreign Affairs } \\
\text { www.foreign.gov.sk/en/foreign policy/slovak aid }\end{array}$ \\
\hline
\end{tabular}

\begin{tabular}{|l|l|}
\hline \multicolumn{2}{|l|}{ Israel } \\
\hline Responsible agency & $\begin{array}{l}\text { Ministry of Foreign Affairs } \\
\text { Agency for International Development Cooperation (MASHAV) }\end{array}$ \\
\hline Objectives / Mission & $\begin{array}{l}\text { Respond in the wake of natural or man-made disasters; "by tragic circumstance, Israel } \\
\text { is a world leader in handling mass casualties;" active since } 1957 \text { (disaster relief since } \\
\text { the 1980s) }\end{array}$ \\
\hline Priorities & Emergency and disaster medicine; Gaza Strip; West Bank \\
\hline Sources & $\begin{array}{l}\text { www.mfa.gov.il/mfa/humanitarianaid/overview } \\
\text { mashav.mfa.gov.il } \\
\text { E-Mail from MASHAV }\end{array}$ \\
\hline
\end{tabular}

\begin{tabular}{|l|l|}
\hline Monaco & Ministry of Foreign Affairs (Department of International Cooperation) \\
\hline Objectives / Mission & $\begin{array}{l}\text { Support people affected by natural disasters or food shortage without any political } \\
\text { considerations; active since 2007 }\end{array}$ \\
\hline Priorities & No geographic priorities \\
\hline Sources & www.gouv.mc/Action-Gouvernementale/Monaco-dans-le-Monde/L-Aide-Publique-au- \\
& Developpement-et-la-Cooperation-Internationale \\
\hline
\end{tabular}


Appendix IV.1 (continued): Humanitarian aid and disaster relief of "new" donors

\begin{tabular}{|l|l|}
\hline Argentina & Ministry of Foreign Affairs and Worship (Comisión Cascos Blancos) \\
\hline Responsible agency & $\begin{array}{l}\text { Search for new proposals to reduce risks, prevent disasters, preparing responses and } \\
\text { minimize their impact; development of participatory and preventive tools; } \\
\text { incorporation of communities in risk reduction processes }\end{array}$ \\
\hline Priorities & Focus on the Americas \\
\hline Sources & www.cascosblancos.gov.ar \\
\hline
\end{tabular}

\begin{tabular}{|l|}
\hline Venezuela \\
\hline No information available \\
\hline
\end{tabular}

\begin{tabular}{|c|c|}
\hline \multicolumn{2}{|l|}{ Estonia } \\
\hline Responsible agency & $\begin{array}{l}\text { Ministry of Foreign Affairs } \\
\text { Ministry of the Interior (Estonian Disaster Relief Team ) }\end{array}$ \\
\hline Objectives / Mission & $\begin{array}{l}\text { Save human lives and render help to the victims; pay attention first and foremost to } \\
\text { most vulnerable groups of the population; most genuine form of solidarity between } \\
\text { people and countries; active since } 1998\end{array}$ \\
\hline Priorities & Earthquakes; floods; war refugees \\
\hline Sources & $\begin{array}{l}\text { www.vm.ee } \\
\text { www.rescue.ee }\end{array}$ \\
\hline
\end{tabular}

\begin{tabular}{|l|l|}
\hline Malaysia & No unified procedure (case-by-case basis) \\
\hline Responsible agency & Strive and support efforts in the area of international disaster relief \\
\hline Objectives / Mission & $\begin{array}{l}\text { Availability of technical expertise and technical equipment; language and culture; focus } \\
\text { on Malaysia's own natural disasters (flooding, sporadic peat soil fire and forest } \\
\text { fire/haze) }\end{array}$ \\
\hline Sources & E-mail from the Embassy of Malaysia in Berlin \\
\hline
\end{tabular}

\begin{tabular}{|l|}
\hline Thailand \\
\hline No information available \\
\hline
\end{tabular}

\begin{tabular}{|l|l|}
\hline Slovenia & $\begin{array}{l}\text { Ministry of Foreign Affairs } \\
\text { Ministry of Defence } \\
\text { Administration for Civil Protection and Disaster Relief }\end{array}$ \\
\hline Objectives / Mission & $\begin{array}{l}\text { Prevent or alleviate human suffering; non-discriminatory and not linked to foreign } \\
\text { policy objectives }\end{array}$ \\
\hline Priorities & $\begin{array}{l}\text { Reduction of poverty and hunger; mine action; assistance to children in post-conflict } \\
\text { situations; Western Balkans; Eastern Europe, the Caucasus and Central Asia; Africa }\end{array}$ \\
\hline Sources & www.mzz.gov.si/en/foreign policy/foreign policy/ \\
\hline
\end{tabular}


Appendix IV.2: List of donor countries by definition of "new" donors

\begin{tabular}{|c|c|c|c|c|c|c|}
\hline Donor country & \# aid & Aid (mill. US\$) & Decision time & Non-DAC & Poor & Autocracy \\
\hline United States of America & 269 & 832 & 21 & & & \\
\hline Germany & 168 & 247 & 26 & & & \\
\hline Norway & 134 & 187 & 33 & & & \\
\hline Sweden & 132 & 192 & 30 & & & \\
\hline Japan & 131 & 516 & 13 & & & \\
\hline Italy & 102 & 124 & 27 & & & \\
\hline France & 101 & 72 & 20 & & & \\
\hline Switzerland & 95 & 78 & 45 & & & \\
\hline Canada & 93 & 192 & 24 & & & \\
\hline United Kingdom & 91 & 450 & 29 & & & \\
\hline Spain & 83 & 113 & 22 & & & \\
\hline Australia & 75 & 136 & 21 & & & \\
\hline Ireland & 75 & 60 & 30 & & & \\
\hline Denmark & 72 & 85 & 25 & & & \\
\hline Luxembourg & 70 & 22 & 37 & & & \\
\hline Netherlands & 69 & 153 & 27 & & & \\
\hline Turkey & 54 & 84 & 41 & $\mathrm{x}$ & $\mathrm{x}$ & \\
\hline Korea, Republic of & 54 & 25 & 21 & $x$ & & \\
\hline Belgium & 52 & 71 & 35 & & & \\
\hline Saudi Arabia (Kingdom of) & 51 & 482 & 42 & $x$ & & $x$ \\
\hline New Zealand & 50 & 36 & 23 & & & \\
\hline United Arab Emirates & 47 & 46 & 51 & $X$ & & $x$ \\
\hline Czech Republic & 44 & 9 & 29 & $x$ & & \\
\hline Austria & 41 & 18 & 47 & & & \\
\hline Finland & 39 & 39 & 30 & & & \\
\hline Singapore & 37 & 12 & 34 & $\mathrm{X}$ & & $\mathrm{x}$ \\
\hline Greece & 35 & 35 & 28 & & & \\
\hline Russian Federation & 30 & 35 & 18 & $x$ & $x$ & $x$ \\
\hline China & 30 & 21 & 15 & $x$ & $x$ & $x$ \\
\hline Brazil & 26 & 5 & 30 & $x$ & $x$ & \\
\hline Poland & 24 & 10 & 17 & $x$ & & \\
\hline Hungary & 23 & 2 & 26 & $x$ & & \\
\hline Portugal & 19 & 11 & 26 & & & \\
\hline Cyprus & 19 & 1 & 61 & $x$ & & \\
\hline Slovakia & 18 & 8 & 20 & $x$ & & \\
\hline Israel & 18 & 4 & 20 & $x$ & & \\
\hline Monaco & 18 & 2 & 44 & $x$ & & $\mathrm{~N} / \mathrm{A}$ \\
\hline Argentina & 18 & 0 & 25 & $x$ & $x$ & \\
\hline Venezuela & 16 & 0 & 18 & $x$ & $x$ & \\
\hline Estonia & 15 & 1 & 20 & $x$ & & \\
\hline Malaysia & 14 & 9 & 9 & $x$ & $x$ & $x$ \\
\hline Thailand & 13 & 30 & 19 & $x$ & $x$ & $(X)$ \\
\hline Slovenia & 13 & 1 & 15 & $x$ & & \\
\hline Qatar & 12 & 25 & 16 & $x$ & & $x$ \\
\hline Iceland & 12 & 1 & 29 & $x$ & & \\
\hline Liechtenstein & 12 & 1 & 60 & $x$ & & \\
\hline Colombia & 12 & 0 & 23 & $x$ & $x$ & \\
\hline South Africa & 11 & 2 & 24 & $x$ & $x$ & $x$ \\
\hline Latvia & 11 & 1 & 19 & $x$ & $x$ & \\
\hline Andorra & 11 & 0 & 72 & $x$ & & \\
\hline Chile & 11 & 0 & 12 & $\mathrm{X}$ & $x$ & \\
\hline Morocco & 10 & 1 & 24 & $x$ & $x$ & $x$ \\
\hline Peru & 10 & 0 & 35 & $x$ & $x$ & $(X)$ \\
\hline India & 9 & 31 & 6 & $x$ & $x$ & \\
\hline Kuwait & 9 & 21 & 11 & $x$ & & $x$ \\
\hline
\end{tabular}

Note: N/A - not available; $(X)$ - true in some years 
Appendix IV.2 (continued): List of donor countries by definition of "new" donors

\begin{tabular}{|c|c|c|c|c|c|c|}
\hline Donor country & \# aid & Aid (mill. US\$) & Decision time & Non-DAC & Poor & Autocracy \\
\hline Kazakhstan & 9 & 7 & 39 & $x$ & $x$ & $\mathrm{X}$ \\
\hline Mexico & 9 & 4 & 33 & $x$ & $x$ & $(X)$ \\
\hline Cuba & 9 & 0 & 11 & $x$ & $x$ & $x$ \\
\hline Hong Kong & 7 & 7 & 24 & $x$ & & $\mathrm{~N} / \mathrm{A}$ \\
\hline Trinidad and Tobago & 7 & 3 & 14 & $\mathrm{x}$ & & \\
\hline Romania & 7 & 3 & 27 & $x$ & $x$ & \\
\hline Lithuania & 6 & 0 & 24 & $x$ & $x$ & \\
\hline Laos & 6 & 0 & 17 & $x$ & $x$ & $x$ \\
\hline Pakistan & 6 & 0 & 12 & $x$ & $x$ & $(X)$ \\
\hline Korea, Dem. Rep. & 6 & 0 & 11 & $x$ & $x$ & $x$ \\
\hline Libya & 5 & 2 & 21 & $x$ & $x$ & $x$ \\
\hline Moldova & 5 & 0 & 27 & $x$ & $x$ & \\
\hline Sri Lanka & 4 & 1 & 8 & $x$ & $x$ & \\
\hline Nigeria & 4 & 1 & 11 & $x$ & $x$ & \\
\hline Iran & 4 & 1 & 15 & $x$ & $x$ & $x$ \\
\hline Mauritius & 4 & 0 & 10 & $x$ & $x$ & \\
\hline Bulgaria & 4 & 0 & 26 & $x$ & $x$ & \\
\hline Tunisia & 4 & 0 & 18 & $x$ & $x$ & $x$ \\
\hline Nicaragua & 4 & 0 & 9 & $x$ & $x$ & \\
\hline Ecuador & 4 & 0 & 8 & $x$ & $x$ & $(X)$ \\
\hline Jordan & 4 & 0 & 12 & $x$ & $x$ & $x$ \\
\hline Malta & 3 & 11 & 47 & $x$ & & \\
\hline Indonesia & 3 & 1 & 5 & $x$ & $x$ & \\
\hline Algeria & 3 & 1 & 19 & $x$ & $x$ & $x$ \\
\hline Azerbaijan & 3 & 1 & 19 & $x$ & $x$ & $x$ \\
\hline Botswana & 3 & 1 & 26 & $x$ & $x$ & $x$ \\
\hline Mauritania & 3 & 0 & 17 & $x$ & $x$ & (X) \\
\hline Belarus & 3 & 0 & 29 & $x$ & $x$ & $x$ \\
\hline Oman & 3 & 0 & 5 & $x$ & & $x$ \\
\hline Bangladesh & 3 & 0 & 13 & $x$ & $x$ & $(X)$ \\
\hline Panama & 3 & 0 & 8 & $x$ & $x$ & \\
\hline Kyrgyzstan & 2 & 27 & 14 & $x$ & $x$ & $(X)$ \\
\hline Gabon & 2 & 1 & 12 & $x$ & $x$ & $x$ \\
\hline Reunion & 2 & 0 & 23 & $x$ & N/A & N/A \\
\hline Philippines & 2 & 0 & 15 & $x$ & $x$ & \\
\hline Vietnam & 2 & 0 & 25 & $x$ & $x$ & $x$ \\
\hline Faeroe Islands & 2 & 0 & 44 & $x$ & & N/A \\
\hline Nepal & 2 & 0 & 2 & $x$ & $x$ & $(X)$ \\
\hline Dominican Republic & 2 & 0 & & $x$ & $x$ & \\
\hline Swaziland & 2 & 0 & 14 & $x$ & $x$ & $x$ \\
\hline San Marino & 2 & 0 & & $x$ & & \\
\hline Guatemala & 2 & 0 & 3 & $x$ & $x$ & \\
\hline Fiji & 2 & 0 & 48 & $x$ & $x$ & $(X)$ \\
\hline Cook Islands & 2 & 0 & 55 & $x$ & $\mathrm{~N} / \mathrm{A}$ & N/A \\
\hline Bahamas & 2 & 0 & 31 & $x$ & & \\
\hline Ukraine & 2 & 0 & 10 & $x$ & $x$ & \\
\hline El Salvador & 2 & 0 & 12 & $x$ & $x$ & \\
\hline Bolivia & 2 & 0 & 4 & $x$ & $x$ & \\
\hline Syrian Arab Republic & 2 & 0 & 4 & $x$ & $x$ & $x$ \\
\hline Tajikistan & 2 & 0 & 12 & $x$ & $x$ & $x$ \\
\hline
\end{tabular}

Note: N/A - not available; $(X)$ - true in some years 
Appendix IV.3: Sources and definitions

\begin{tabular}{|c|c|c|}
\hline Variable & Description & Source \\
\hline \multicolumn{3}{|l|}{ Dependent variables } \\
\hline $\begin{array}{l}\text { Aid dummy } \\
\text { (log) Decision time }\end{array}$ & $\begin{array}{l}1 \text { if donor provides emergency assistance to recipient after a natural disaster } \\
\text { (log) Number of days following a disaster before a donor commits herself to provide emergency aid }\end{array}$ & $\begin{array}{l}\text { OCHA (2011) } \\
\text { OCHA (2011) }\end{array}$ \\
\hline \multicolumn{3}{|l|}{ Disaster characteristics } \\
\hline $\begin{array}{l}\text { (log) Total affected } \\
\text { (log) Killed }\end{array}$ & $\begin{array}{l}\text { (log) Number of people that have been injured, affected and left homeless after a disaster } \\
\text { (log) Number of persons confirmed as dead and persons missing and presumed dead }\end{array}$ & $\begin{array}{l}\text { EM-DAT (2012) } \\
\text { EM-DAT (2012) }\end{array}$ \\
\hline \multicolumn{3}{|l|}{ Donor characteristics } \\
\hline $\begin{array}{l}\text { DAC } \\
\text { (log) GDP per capita } \\
\text { High income } \\
\text { Democracy } \\
\text { (log) Population }\end{array}$ & $\begin{array}{l}1 \text { if donor country is a member of the OECD Development Assistance Committee } \\
\text { (log) Real GDP per capita (Constant Prices: Laspeyres), derived from growth rate, lag } \\
1 \text { if donor country is classified as high-income country according to } 2010 \text { GNI per capita } \\
1 \text { if the regime qualifies as democratic, lag } \\
\text { (log) Total population, lag }\end{array}$ & $\begin{array}{l}\text { Own construction } \\
\text { Penn World Tables (Heston et al. 2009) } \\
\text { World Bank (http://data.worldbank.org/) } \\
\text { Cheibub et al. (2010) } \\
\text { World Bank (http://data.worldbank.org/indicator/) } \\
\end{array}$ \\
\hline \multicolumn{3}{|l|}{ Recipient characteristics } \\
\hline $\begin{array}{l}\text { (log) GDP per capita } \\
\text { (log) Population } \\
\text { Population density } \\
\text { Democracy } \\
\text { Control of corruption } \\
\text { UNSC member } \\
\text { (log) Mineral and energy }\end{array}$ & $\begin{array}{l}\text { (log) Real GDP per capita (constant } 2005 \text { Prices: Laspeyres), derived from growth rate, lag } \\
\text { (log) Total population, lag } \\
\text { Total population divided by area in hectare, lag } \\
1 \text { if the regime qualifies as democratic, lag } \\
\text { Index ranging from }-2.5 \text { to } 2.5 \text { (higher values: better governance), interpolated, lag } \\
1 \text { if a country is a temporary member of the United Nations Security Council, current year } \\
\text { (log) Product of unit resource rents and physical quanitites of minerals and energy extracted, lag }\end{array}$ & $\begin{array}{l}\text { Penn World Tables (Heston et al. 2011) } \\
\text { World Bank (http://data.worldbank.org/indicator/) } \\
\text { Own construction based on CEPII and World Bank data } \\
\text { Cheibub et al. (2010) } \\
\text { Kaufmann et al. (2009) } \\
\text { Dreher et al. (2009b) } \\
\text { World Bank (http://data.worldbank.org/indicator/) } \\
\end{array}$ \\
\hline \multicolumn{3}{|l|}{ Bilateral variables } \\
\hline $\begin{array}{l}\text { (log) Distance } \\
\text { Neighbor } \\
\text { Common colonial history } \\
\text { Common official language } \\
\text { Common major religion } \\
\text { (log) Migration in } \\
\text { (log) Migration out } \\
\text { UNGA voting } \\
\text { (log) Exports }\end{array}$ & $\begin{array}{l}\text { (log) Bilateral distance (weighted by populations of major cities) } \\
1 \text { if donor and recipient share a common border } \\
1 \text { if countries ever had a common colonizer or have ever been in a colonial relationship } \\
1 \text { if countries share a common official language } \\
1 \text { if countries have the same major religion } \\
\text { (log) Stock of migrants from recipient country in donor country, } 2000 \text { round of population censuses } \\
\text { (log) Stock of migrants from donor country in recipient country, } 2000 \text { round of population censuses } \\
\text { UNGA voting alignment between donor and recipient, lag } \\
\text { (log) Exports to recipient country (\% of total exports of donor country), mirror data used, lag }\end{array}$ & $\begin{array}{l}\text { CEPII (Mayer and Zignago 2006) } \\
\text { CEPII (Mayer and Zignago 2006) } \\
\text { CEPII (Mayer and Zignago 2006) } \\
\text { CEPII (Mayer and Zignago 2006) } \\
\text { WCD (http://www.worldchristiandatabase.org/wcd/) } \\
\text { Global Migrant Origin Database (Parsons et al. 2007) } \\
\text { Global Migrant Origin Database (Parsons et al. 2007) } \\
\text { Voeten and Merdzanovic (2009) } \\
\text { UN Comtrade via WITS (http://wits.worldbank.org/) }\end{array}$ \\
\hline
\end{tabular}

Notes:

- The value of 1 has been added to "Total affected," "Killed" and "Mineral and energy depletion" before taking logarithms 
Appendix IV.4: Descriptive statistics

\begin{tabular}{|c|c|c|c|c|c|}
\hline Variable & Obs & Mean & Std. Dev. & Min & Max \\
\hline \multicolumn{6}{|l|}{ Dependent variables } \\
\hline Aid dummy & 29412 & 0.09 & 0.28 & 0.00 & 1.00 \\
\hline (log) Decision time & 2194 & 2.62 & 1.20 & 0.00 & 5.18 \\
\hline \multicolumn{6}{|l|}{ Disaster severity } \\
\hline (log) Total affected & 29412 & 11.23 & 2.78 & 0.00 & 18.83 \\
\hline (log) Killed & 29412 & 3.56 & 2.30 & 0.00 & 12.02 \\
\hline \multicolumn{6}{|l|}{ Donor characteristics } \\
\hline DAC & 29412 & 0.27 & 0.44 & 0.00 & 1.00 \\
\hline (log) GDP per capita & 29412 & 9.35 & 1.04 & 6.80 & 11.92 \\
\hline High income & 29412 & 0.46 & 0.50 & 0.00 & 1.00 \\
\hline Democracy & 29412 & 0.70 & 0.46 & 0.00 & 1.00 \\
\hline (log) Population & 29412 & 16.47 & 1.73 & 12.53 & 21.00 \\
\hline \multicolumn{6}{|l|}{ Recipient characteristics } \\
\hline (log) GDP per capita & 29412 & 8.07 & 0.91 & 4.77 & 10.35 \\
\hline (log) Population & 29412 & 17.02 & 1.99 & 11.14 & 21.00 \\
\hline Population density & 29412 & 1.38 & 1.74 & 0.02 & 10.10 \\
\hline Democracy & 29412 & 0.65 & 0.48 & 0.00 & 1.00 \\
\hline Control of corruption & 29412 & -0.51 & 0.53 & -1.73 & 1.50 \\
\hline UNSC member & 29412 & 0.11 & 0.31 & 0.00 & 1.00 \\
\hline (log) Mineral and energy depletion & 29412 & 33.89 & 15.46 & 0.00 & 51.12 \\
\hline \multicolumn{6}{|l|}{ Bilateral variables } \\
\hline (log) Distance & 29412 & 8.84 & 0.71 & 5.25 & 9.89 \\
\hline Neighbor & 29412 & 0.02 & 0.15 & 0.00 & 1.00 \\
\hline Common colonial history & 29412 & 0.15 & 0.36 & 0.00 & 1.00 \\
\hline Common official language & 29412 & 0.11 & 0.31 & 0.00 & 1.00 \\
\hline Common major religion & 29412 & 0.43 & 0.50 & 0.00 & 1.00 \\
\hline (log) Migration in & 29412 & 5.31 & 3.14 & 0.00 & 16.05 \\
\hline (log) Migration out & 29412 & 4.63 & 2.74 & 0.00 & 15.40 \\
\hline UNGA voting & 29412 & 0.77 & 0.14 & 0.01 & 0.99 \\
\hline (log) Exports & 29412 & -4.24 & 3.13 & -17.66 & 4.05 \\
\hline
\end{tabular}

Note: Descriptive statistics for sample as in Table IV.2, column 1. 
Appendix IV.5: Determinants of aid selection (Logit, marginal effects, 2000-09)

\begin{tabular}{|c|c|c|c|c|}
\hline & (1) & $(2)$ & (3) & (4) \\
\hline \multicolumn{5}{|l|}{ Disaster severity } \\
\hline (log) Total affected & $\begin{array}{l}0.0079 * * * \\
(0.000)\end{array}$ & & $\begin{array}{l}0.0079 * * * \\
(0.000)\end{array}$ & \\
\hline \multirow[t]{2}{*}{ (log) Killed } & $0.0266 * * *$ & & $0.0269 * * *$ & \\
\hline & $(0.000)$ & & $(0.000)$ & \\
\hline \multicolumn{5}{|l|}{ Donor characteristics } \\
\hline DAC & $\begin{array}{l}0.0384 * * * \\
(0.003)\end{array}$ & $\begin{array}{l}0.0381^{* * *} \\
(0.006)\end{array}$ & & \\
\hline (log) GDP per capita & $\begin{array}{l}0.0759 * * * \\
(0.000)\end{array}$ & $\begin{array}{l}0.0730^{* * *} \\
(0.000)\end{array}$ & $\begin{array}{r}0.0589 \\
(0.201)\end{array}$ & $\begin{array}{c}0.0578 \\
(0.198)\end{array}$ \\
\hline Democracy & $\begin{array}{c}0.0188 \\
(0.140)\end{array}$ & $\begin{array}{l}0.0108 \\
(0.361)\end{array}$ & $\begin{array}{c}0.0057 \\
(0.869)\end{array}$ & $\begin{array}{c}0.0219 \\
(0.429)\end{array}$ \\
\hline (log) Population & $\begin{array}{l}0.0215^{* * *} \\
(0.000)\end{array}$ & $\begin{array}{l}0.0183^{* * *} \\
(0.000)\end{array}$ & $\begin{array}{r}0.0935 \\
(0.163) \\
\end{array}$ & $\begin{array}{r}0.0895 \\
(0.175) \\
\end{array}$ \\
\hline \multicolumn{5}{|l|}{ Recipient characteristics } \\
\hline (log) GDP per capita & $\begin{array}{l}-0.0140 * * * \\
(0.000)\end{array}$ & & $\begin{array}{l}-0.0142 * * * \\
(0.000)\end{array}$ & \\
\hline (log) Population & $\begin{array}{l}-0.0276^{* * *} \\
(0.000)\end{array}$ & & $\begin{array}{l}-0.0270 * * * \\
(0.000)\end{array}$ & \\
\hline Population density & $\begin{array}{l}-0.0025^{* *} \\
(0.012)\end{array}$ & & $\begin{array}{l}-0.0025^{* * *} \\
(0.009)\end{array}$ & \\
\hline Democracy & $\begin{array}{l}0.0007 \\
(0.851)\end{array}$ & & $\begin{array}{l}-0.0007 \\
(0.846)\end{array}$ & \\
\hline Control of corruption & $\begin{array}{l}-0.0133^{* * *} \\
(0.000)\end{array}$ & & $\begin{array}{l}-0.0147^{* * *} \\
(0.000)\end{array}$ & \\
\hline UNSC member & $\begin{array}{l}0.0147^{* * *} \\
(0.002)\end{array}$ & & $\begin{array}{l}0.0139 * * * \\
(0.003)\end{array}$ & \\
\hline (log) Mineral and energy depletion & $\begin{array}{l}0.0005^{* * *} \\
(0.001)\end{array}$ & & $\begin{array}{l}0.0004 * * * \\
(0.003)\end{array}$ & \\
\hline \multicolumn{5}{|l|}{ Bilateral variables } \\
\hline (log) Distance & $\begin{array}{l}-0.0350 * * * \\
(0.000)\end{array}$ & $\begin{array}{l}-0.0243^{* * *} \\
(0.000)\end{array}$ & $\begin{array}{l}-0.0360 * * * \\
(0.000)\end{array}$ & $\begin{array}{l}-0.0226^{* * *} \\
(0.000)\end{array}$ \\
\hline Neighbor & $\begin{array}{l}0.0331^{* * *} \\
(0.005)\end{array}$ & $\begin{array}{l}0.0334^{* * *} \\
(0.006)\end{array}$ & $\begin{array}{l}0.0239 * * \\
(0.039)\end{array}$ & $\begin{array}{l}0.0227^{* *} \\
(0.045)\end{array}$ \\
\hline Common colonial history & $\begin{array}{c}0.0114 \\
(0.113)\end{array}$ & $\begin{array}{r}0.0047 \\
(0.564)\end{array}$ & $\begin{array}{l}0.0195^{* * *} \\
(0.005)\end{array}$ & $\begin{array}{l}0.0119 * \\
(0.098)\end{array}$ \\
\hline Common official language & $\begin{array}{c}0.0024 \\
(0.732)\end{array}$ & $\begin{array}{r}0.0113 \\
(0.115)\end{array}$ & $\begin{array}{l}0.0141^{* *} \\
(0.013)\end{array}$ & $\begin{array}{l}0.0233^{* * *} \\
(0.000)\end{array}$ \\
\hline Common major religion & $\begin{array}{l}0.0289 * * * \\
(0.000)\end{array}$ & $\begin{array}{c}0.0133 \\
(0.147)\end{array}$ & $\begin{array}{l}0.0275^{* * *} \\
(0.000)\end{array}$ & $\begin{array}{r}0.0100 \\
(0.172)\end{array}$ \\
\hline (log) Migration in & $\begin{array}{l}0.0032^{* *} \\
(0.043)\end{array}$ & $\begin{array}{l}0.0036^{* *} \\
(0.030)\end{array}$ & $\begin{array}{l}0.0023^{* *} \\
(0.028)\end{array}$ & $\begin{array}{l}0.0029 * * * \\
(0.010)\end{array}$ \\
\hline (log) Migration out & $\begin{array}{c}0.0009 \\
(0.451)\end{array}$ & $\begin{array}{c}0.0027 \\
(0.141)\end{array}$ & $\begin{array}{l}0.0015^{*} \\
(0.096)\end{array}$ & $\begin{array}{l}0.0046^{* * *} \\
(0.000)\end{array}$ \\
\hline UNGA voting & $\begin{array}{l}-0.0516^{*} \\
(0.066)\end{array}$ & $\begin{array}{l}-0.0687^{* *} \\
(0.017)\end{array}$ & $\begin{array}{l}0.0334 \\
(0.365)\end{array}$ & $\begin{array}{l}-0.0212 \\
(0.434)\end{array}$ \\
\hline (log) Exports & $\begin{array}{l}0.0053^{* * *} \\
(0.004)\end{array}$ & $\begin{array}{l}0.0070^{* * *} \\
(0.000)\end{array}$ & $\begin{array}{l}0.0055^{* * *} \\
(0.000)\end{array}$ & $\begin{array}{l}0.0079 * * * \\
(0.000)\end{array}$ \\
\hline Disaster-type dummies & Yes & & Yes & \\
\hline Donor dummies & & & Yes & Yes \\
\hline Emergency-recipient dummies & & Yes & & Yes \\
\hline Year dummies & Yes & & Yes & \\
\hline Number of observations & 29412 & 30622 & 29412 & 30622 \\
\hline
\end{tabular}

Notes:

- All models show marginal effects of Logit models with standard errors clustered at the donor level 
Appendix V.1: Anecdotal evidence

Tibet's political status represents a long-run cause of conflict both in China and in international relations that revolves around the question of whether the incorporation of Tibet into China was in accordance with international law. In light of this, the Chinese administration has recognized that its position on Tibet's status not only needs to be enforced domestically, but also internationally. ${ }^{1}$ By opposing any notion from abroad that might challenge the status quo of the region, China not only aims to contain the spread of unrest inside Tibet, but also seeks to weaken the worldwide Tibetan independence movement. ${ }^{2}$ Within this context, the Dalai Lama, in his position as leader of the Tibetan community, is seen as a threat to the integrity of the Chinese nation. Consequently, meetings between foreign officials and the Dalai Lama are a constant source of bilateral diplomatic tensions with China.

Since going into exile in 1959 until the end of 2009, the Tibetan leader visited 62 countries on all continents. ${ }^{3}$ The Dalai Lama himself emphasizes the non-political nature of his visits and uses his travels as an opportunity to meet foreign politicians in order to discuss - among other issues - the situation in Tibet. The Chinese administration emphasizes that Tibet forms an integral part of China and sees the Dalai Lama as a pretentious state leader with a separatist agenda regarding Tibet. Therefore, any meeting of foreign officials with the Buddhist monk is perceived by Beijing as interference with internal affairs. Despite Chinese opposition, many countries have, to an increasing extent, recognized the Dalai Lama as a notable religious leader, subsequently granting him considerable attention. At the same time, China has increased pressure on other countries to not receive the exiled Tibetan leader in any form.

In this appendix, we study anecdotal evidence on how the bilateral climate between China and its trading partners is influenced by meetings between foreign officials and the Dalai Lama and derive our hypotheses. Of course, the incidents involving diplomatic threats listed below are not exhaustive, but provide some illustrative examples. Moreover, many diplomatic threats occur outside of the public spotlight, as can be seen in the example of a

\footnotetext{
${ }^{1}$ According to an official government bulletin, China identifies the issue of Tibet as one of the "most important and sensitive" core issues to be respected by China's partners, available at: http://www.gov.cn/misc/200905/27/content 1326253.htm (accessed: July 12, 2012).

${ }^{2}$ As Goldstein (1998: 83) notes, international opinion plays an important role in conflicts over regional independence since "the ambiguity about when entities have the right to seek self-determination has made international opinion an important dimension of such disputes".

${ }^{3}$ In 1967, the Dalai Lama travelled outside India for the first time in order to visit Japan and Thailand. His first trip to Europe was in 1973 where he visited 12 countries in 75 days. In 1979, he travelled to the United States and Canada for the first time.
} 
letter written by China's ambassador Zhang Yun to the Dutch chairman of the Standing Committee on Foreign Affairs, Henk Jan Ormel. In the text, which to the surprise of the ambassador was made public, the Chinese embassy warned that Sino-Dutch relations might be negatively affected by a planned meeting between Dutch members of parliament and the Dalai Lama. ${ }^{4}$

\section{Hypothesis 1: Trade-deteriorating effect of Dalai Lama meetings}

In addition to purely diplomatic threats, China increasingly exerts economic pressure on foreign governments to discourage them from meeting with the Dalai Lama. The growing assertiveness of the Chinese administration towards meetings of foreign dignitaries with the Tibetan leader reflects China's rising economic power. As such, this growing economic power provides China with the leverage needed to advance its political interests.

The Dalai Lama was officially invited to the White House for the first time in 1991 by President George Bush senior. The reception marked a pronounced change from the policy of former US presidents and sparked immediate protest from the Chinese. ${ }^{5}$ During the subsequent two Clinton and Bush presidencies, the Dalai Lama has been a visitor to the White House a further nine times, provoking regular protest from Beijing. In 2007, the US Congress awarded the Congressional Gold Medal, the highest civil honor conferred in the United States, to the Dalai Lama. The act was compounded by the fact that the US president personally attended the award ceremony. In a statement issued one day later by the Chinese Ministry of Foreign Affairs, Spokesperson Liu Jianchao emphasized that the award "ha[d] severely hurt the feelings of the Chinese people and gravely undermined the relationship between China and the US," a wording that is characteristic of the Chinese reaction to countries officially receiving the Dalai Lama. Furthermore, he "urge[d] the US to take effective measures immediately to undo the severe adverse impact of its erroneous act." ${ }^{\prime 6}$ In 2009, President Barack Obama decided not to receive the Dalai Lama. The media deemed the decision "unprecedented" and surmised that the president had strategically delayed the reception until after his state visit to Beijing. The meeting finally took place in February 2010 and caused considerable discontent in Beijing. Chinese authorities emphasized that the move

\footnotetext{
4 "We are clear: no dalai lama visits," NRC Handelsblad, May 7, 2009, available at: http://www.nrc.nl/international/Features/article2234645.ece/We are_clear_no dalai_lama_visits (accessed: July 12, 2012).

5 "On my mind; Beijing Heart Attack," The New York Times, April 19, 1991, p. A27, available at: http://www.nytimes.com/1991/04/19/opinion/on-my-mind-beijing-heart-attack.html (accessed: July 12, 2012).

6 "Foreign Ministry Spokesperson Liu Jianchao's Regular Press Conference," Ministry of Foreign Affairs of the People's Republic of China, October 18, 2007, available at: http://www.fmprc.gov.cn/eng/xwfw/s2510/2511/t373809.htm (accessed: July 12, 2012).
} 
damaged US-Chinese relations, which, in turn, would undermine the United States' recovery from the current economic crisis. $^{7}$

Before Italian Prime Minister Silvio Berlusconi's reception of the Dalai Lama in 1995, the Chinese prime minister warned his Italian counterpart that "if this [the Italian] government will adopt a policy that could damage a matter of principle [for China], it may also damage trade relations." ${ }^{\prime 2}$ Facing potential trade retaliations by the Chinese, Berlusconi openly admitted to the Dalai Lama that the international community was facing a dilemma, "caught between the importance of maintaining trade relations and protecting human rights." 9 The decision to meet the Tibetan leader, despite Chinese threats, was judged as "courageous" by both the Italian media and the Dalai Lama himself.

In contrast, Germany's political leaders refrained for a long time from meeting with the Dalai Lama. In this regard, a 1995 New York Times article critically assessed that German foreign policy was aimed at avoiding political conflict over human rights issues with China, so as not to endanger lucrative trade ties with the emerging economy. ${ }^{10}$ Bilateral discontent emerged between China and Germany when Chancellor Angela Merkel deviated from this general practice by receiving the Dalai Lama in the chancellery in 2007. Merkel's predecessor Gerhard Schröder, known for his keenness for good economic relations with China, criticized the decision as a mistake, bearing in mind the detrimental effect the meeting may have on bilateral relations with Beijing. In the lead up to the Dalai Lama's announced visit to Berlin, Chinese politicians warned that the meeting would severely damage economic ties. In the aftermath of this meeting, several bilateral meetings at various political levels were cancelled. An article entitled "The Cost of Being Honest," published in the German weekly "Der Spiegel," concluded that the chancellor's foreign policy comes with a "Merkel cost" for business. $^{11}$

Sino-French relations worsened as French government sources announced a meeting between Nicolas Sarkozy and the Dalai Lama. Chinese officials promptly insinuated that trade ties with France could suffer unless the meeting was cancelled. China sent a strong message to France, which held the EU presidency at the time, by cancelling the 11th annual

\footnotetext{
7 "Destiny of Tibet 'in hands of people," China Daily, February 3, 2010, available at: http://www.chinadaily.com.cn/china/2010-02/03/content 9417649 2.htm (accessed: July 12, 2012).

8 "Li Peng "diffida" Berlusconi; Il Cavaliere l'aveva promesso a Pannella. Ma Pechino avverte: "Sono in pericolo le relazioni commerciali,"” La Stampa, June 15, 1994, p. 4, own translation.

9 “"Italia, grazie per il coraggio"; Il leader tibetano a Palazzo Chigi, per la prima volta un governo italiano sfida il veto cinese," La Stampa, June 18, 1994, p. 7, own translation.

10 “Seeking China Deal, Bonn Shuns Rights Issue," The New York Times, July 13, 1995, available at: http://www.nytimes.com/1995/07/13/world/seeking-china-deal-bonn-shuns-rights-issue.html (accessed: July 12, 2012).

11 "Merkel Foreign Policy Is Bad for Business," Spiegel Online, October 23, 2007, available at: http://www.spiegel.de/international/germany/0,1518,513067,00.html (accessed: July 12, 2012).
} 
EU-China summit at rather short notice. ${ }^{12}$ In addition, the media reported that the finalization of a contract to purchase 150 passenger planes from Airbus was suddenly postponed without further explanation. ${ }^{13}$ After the actual meeting took place, Vice Foreign Minister He Yafei emphasized that it had "sabotage[d] the political basis of China-France and China-EU relations" and furthermore warned of "serious consequences" which France alone would have to bear. ${ }^{14}$ In early 2009, France was crossed off the travel agenda of two Chinese trade delegations. The first delegation alone signed 15 billion US dollars' worth of trade deals in other European countries. Furthermore, Chinese Prime Minister Wen Jiabao did not pay any state visit to France during his trip to Europe in January 2009. When asked to comment on the itinerary of his European tour, he was cited saying: "I looked at a map of Europe on the plane. My trip goes around France. [...] We all know why." 15

The case of Mongolia serves as a further illustration of China's antagonism towards countries receiving the Dalai Lama. The Dalai Lama has visited the country on several occasions since 1979 as the country has strong historical and cultural links with Tibet. As reported by media sources in 2002, China imposed a temporary ban on imports from Mongolia and blocked the only railway link between the two countries in response to the reception of the Tibetan leader by the Mongolian Prime Minister Nambaryn Enkhbayar. The import ban was lifted after only one day and no further official receptions of the Dalai Lama took place in Mongolia - despite him visiting the country again in 2006.

We thus hypothesize that a deterioration of the bilateral political climate and a decrease in bilateral diplomatic exchanges, as a result of foreign officials meeting the Dalai Lama, leads to a significant reduction in exports to China. Our first hypothesis reads as follows:

\section{Hypothesis 1: There is a trade-deteriorating effect caused by foreign officials receiving the Dalai Lama.}

\footnotetext{
${ }^{12}$ The meeting had originally been scheduled to take place on December $1^{\text {st }}$ in France where over a hundred high-ranking Chinese politicians and business leaders would have met with their European counterparts.

${ }_{13}$ "China tells France Dalai Lama meeting could hurt trade," $A F P$, December 4, 2008, available at: http://www.google.com/hostednews/afp/article/ALeqM5ifBAQ8quVIihgqVgOrfEUzkzrHWg (accessed: July 12, 2012).

${ }_{14}$ "He Yafei Lodges a Strong Protest to France over Sarkozy's Meeting with the Dalai Lama," Ministry of Foreign Affairs of the People's Republic of China, December 12, 2010, available at: http://www.fmprc.gov.cn/eng/wjb/zzjg/xos/gjlb/3291/3293/t525570.htm (accessed: July 12, 2012).

15 "Premier: We all know why," China Daily, February 2, 2009, available at: http://www.chinadaily.com.cn/china/2009-02/03/content_7440286.htm (accessed: July 12, 2012).
} 


\section{Hypothesis 2: Importance of the rank of the dignitary met}

Political leaders are aware that meetings with the Dalai Lama put considerable stress on countries' bilateral relations with China, and that it may also have negative implications for the economic ties between them. A first alternative to not receiving the Dalai Lama at all is to meet with him but not in official capacity as head of state. For example, when the Dalai Lama planned to visit Switzerland in 2008, Pascal Couchepin announced that he would be meeting with the religious leader not in his function as president of the Swiss Confederation, but as minister of culture. ${ }^{16}$ Similarly, the Clinton administration granted him the opportunity to visit the White House, even though he was formally received only by a minister and not the president himself. Despite official sources emphasizing that no formal encounter between the Dalai Lama and the US president was scheduled, Clinton nevertheless dropped in during the talks. In September 1995, a New York Times article concluded that a better treatment of the Dalai Lama "would [have] cost us [the US] trade with the Chinese.",

As a second alternative, leaders delegate the task to lower-ranked government representatives in the hope of reducing the negative effect that such meetings may have on bilateral relations with China. At the same time, the government still sedates pro-Tibet lobby groups, human rights organizations and other sympathizers of the Dalai Lama. For example, during his trip to the Netherlands in 2009, the Dalai Lama was received by some members of parliament and met with the country's foreign minister during a conference between Dutch religious leaders. Prime Minister Jan Peter Balkenende, however, reportedly feared that a personal encounter with the Tibetan leader would bring "unwarranted risk" to Sino-Dutch relations. ${ }^{18}$ A similar strategy seems to have been employed in Germany in 2008, one year after the first reception of the Dalai Lama by a German chancellor. In what could be interpreted as giving in to Chinese pressure, high-ranking members of the German government avoided a further encounter with the Dalai Lama, referring to their "tight schedules." Allowing all parties to save face, the Tibetan leader was received by the president of the German Bundestag, the minister of economic cooperation and other non-government politicians.

\footnotetext{
16 "Dalai Lama sagt Besuch in der Schweiz ab," NZZ Online, September 13, 2008, available at: http://www.nzz.ch/nachrichten/schweiz/dalai lama_sagt_besuch_in_der_schweiz_ab 1.831028.html (accessed: July 12, 2012).

17“'On My Mind; If He Can, Can I?" The New York Times, September 15, 1995, available at: http://www.nytimes.com/1995/09/15/opinion/on-my-mind-if-he-can-can-i.html (accessed: July 12, 2012).

18 "Dalai lama meets foreign minister, but not prime minister," $N R C$ Handelsblad, June 5, 2009, available at: http://www.nrc.nl/international/article2262841.ece/Dalai_lama_meets_foreign_minister,_but_not_prime ministe

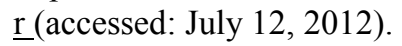


A shift to lower-ranking officials is also observable in Latin American countries. The Dalai Lama embarked on several trips throughout the region between 1989 and 2006. With respect to Dalai Lama receptions, a clear downward trend can be observed in terms of the rank of dignitaries met in the most important destination countries in the region, namely Argentina, Brazil, Chile and Mexico. While the Tibetan leader had been received by the respective presidents of these countries until 1999, he has had to content himself with being received by dignitaries of less political importance ever since. The case of Chile in 2006 provides a particularly interesting example, where the local media suspected Chilean President Michelle Bachelet of avoiding a meeting with the Dalai Lama so as not to jeopardize ongoing negotiations for the country's first trade agreement with China. ${ }^{19}$ By that time, China had also become Chile's second most important trading partner after the United States.

While receptions of the Dalai Lama by official state representatives such as government members may provoke trade reductions, the matter should be different in instances where the Dalai Lama meets with leaders of the political opposition. In an interview conducted in 2008, the Dalai Lama himself remarked that most politicians meet with him before they become minister or president. After taking office, however, the very same politicians tend to avoid meeting with him so as not to endanger trade ties with China. The Dalai Lama concluded that "economic relations with China gain the upper hand." ${ }^{20} \mathrm{New}$ Zealand provides a prime example of such behavior. Prime Minister John Key, who was still in opposition in 2007 and critical of the incumbent government's decision not to receive the Dalai Lama, also chose not to meet with the religious figure in 2009 after his party had come into power.

Therefore, the 'Dalai Lama Effect' should depend on the rank or the political importance of the dignitary met. Meetings with higher-ranking politicians pose a greater affront to the Chinese, who may then retaliate through a more pronounced reduction in bilateral trade:

Hypothesis 2: The detrimental effect of meetings with the Dalai Lama on exports increases with the rank of the dignitary met.

\footnotetext{
19 “DALAI LAMA: CAN I EVER TELL YOU HOW SORRY I AM?” The Santiago Times, May 16, 2006, see: http://www.santiagotimes.cl/index.php?option=com content\&view=article\&id=9130:DALAI-LAMA:-CAN-IEVER-TELL-YOU-HOW-SORRY-I-AM?\&catid=1:other\&Itemid=38 (accessed: July 12, 2012).

20 "Ich will eine echte Autonomie," Cicero Magazin für Politische Kultur, January 1, 2008, own translation, available at: http://www.cicero.de/97.php?ress id=1\&item=2503 (accessed: July 12, 2012).
} 


\section{Hypothesis 3: Evolvement over time}

Assuming that the reduction of commercial activity is intended to convey a warning to other trading partners, extensive prolongation of the measure might cause the implied welfare losses to outweigh the political benefits that China attains from the increased political compliance of its trading partners. In particular, it seems reasonable to believe that China cannot afford to substitute more differentiated goods from a Dalai Lama-receiving country in the long run. Therefore, China and its trading partners both have incentives to revive their bilateral relations.

Anecdotal evidence confirms that diplomatic ties are usually restored after some period of time has passed following a reception of the Dalai Lama. However, China expects countries to make diplomatic concessions to correct for what it coins as their "wrongdoings." For example, nine months after the meeting between French President Nicolas Sarkozy and the Dalai Lama, bilateral relations were mended with considerable diplomatic efforts towards reconciliation. Shortly after a declaration by France that it recognized Tibet as an integral part of the Chinese territory, France was due to receive a new Chinese trade delegation. In an article titled "France goes back on China's shopping list," the China Daily emphasizes a causal link between France's compliance and the re-establishment of bilateral relations. ${ }^{21}$

Similar reconciliation had to be achieved between China and Austria in September 2007. After a meeting between the Dalai Lama and Austrian Chancellor Alfred Gusenbauer, diplomatic relations between Austria and China deteriorated significantly, leading to what the media described as a "minor ice-age" between the two countries. The media reported that Austrian diplomats were banned from contact with Chinese officials for about a year. In October 2008, a state visit of the Austrian chancellor in Beijing marked the end of the diplomatic tensions caused by the Dalai Lama reception. ${ }^{22}$

Therefore, we expect the trade-deteriorating effect of meetings with the Dalai Lama to be only of temporary nature:

Hypothesis 3: The trade-deteriorating 'Dalai Lama Effect' disappears as bilateral relations between China and partner countries recover.

\footnotetext{
21 "France goes back on China's shopping list," China Daily, October 29, 2009, available at: http://www.chinadaily.com.cn/china/2009-10/29/content_8865307.htm (accessed: July 12, 2012).

22 „Gusenbauer: Irritationen mit China ausgeräumt," Die Presse.com, October 24, 2008, available at: http://diepresse.com/home/politik/aussenpolitik/425083/index.do?from=suche.intern.portal (accessed: July 12, 2012).
} 
Appendix V.2: Data description

\begin{tabular}{|c|c|c|}
\hline Variable & Description & Data source \\
\hline (log) Exports & $\begin{array}{l}\text { Log of exports to China in given year from partner country } \\
\text { (SITC Rev. 3) (in current US\$) }\end{array}$ & $\begin{array}{l}\begin{array}{l}\text { COMTRADE via } \\
\text { (http://wits.worldbank.org) }\end{array} \\
\text { WITS }\end{array}$ \\
\hline $\begin{array}{l}\text { Dalai Lama (DL) } \\
\text { meeting }\end{array}$ & $\begin{array}{l}\text { Binary dummy variable that is } 1 \text { if the Dalai Lama met } \\
\text { with } \\
\text { - a head of state or head of government } \\
\text { - a member of government (additionally includes } \\
\text { - all ministers) } \\
\text { a national official representative (additionally } \\
\text { - ancludes speakers of parliament) } \\
\text { Lama (additionally includes former heads of } \\
\text { state or government, regional leaders, party } \\
\text { leaders, scientists, special envoys and religious } \\
\text { leaders, among others) }\end{array}$ & $\begin{array}{l}\text { Office of His Holiness the } 14^{\text {th }} \\
\text { Dalai Lama }\end{array}$ \\
\hline $\begin{array}{l}\text { Dalai Lama (DL) visits } \\
\text { country }\end{array}$ & $\begin{array}{l}\text { Binary dummy variable that is } 1 \text { if the Dalai Lama } \\
\text { travelled to partner country }\end{array}$ & $\begin{array}{l}\text { Office of His Holiness the } 14^{\text {th }} \\
\text { Dalai Lama }\end{array}$ \\
\hline $\begin{array}{l}\text { Duration of Dalai Lama } \\
\text { visit }\end{array}$ & Number of days the Dalai Lama visited a partner country & $\begin{array}{l}\text { Office of His Holiness the } 14^{\text {th }} \\
\text { Dalai Lama }\end{array}$ \\
\hline Tibet Support Groups & $\begin{array}{l}\text { Number of Tibet Support Groups (TSG) in partner country } \\
\text { and year (based on information on year of foundation of } \\
\text { TSG) }\end{array}$ & $\begin{array}{l}\text { Central Tibetan Administration, } \\
\text { own research }\end{array}$ \\
\hline$(\log )$ GDP & $\begin{array}{l}\text { Log of gross domestic product of partner country in } \\
\text { current US dollars }\end{array}$ & $\begin{array}{l}\text { World Development Indicators } \\
\text { (World Bank 2009) }\end{array}$ \\
\hline (log) Population & Log of population size of partner country & $\begin{array}{l}\text { World Development Indicators } \\
\text { (World Bank 2009) }\end{array}$ \\
\hline (log) Exchange rate & $\begin{array}{l}\text { Log of nominal exchange rate index (local currency unit } \\
\text { per Yuan) }(2000=1) \text {, which is calculated as the ratio of the } \\
\text { official exchange rate LCU per US\$ and the official } \\
\text { exchange rate US\$ per Chinese yuan }\end{array}$ & $\begin{array}{l}\text { World Development Indicators } \\
\text { (World Bank 2009) }\end{array}$ \\
\hline Other exports / GDP & $\begin{array}{l}\text { Total exports to all countries except China (as a share of } \\
\text { GDP) }\end{array}$ & $\begin{array}{l}\text { COMTRADE via } \\
\text { (http://wits.worldbank.org) }\end{array}$ \\
\hline$(\log )$ Tariff rate & Log of trade-weighted bilateral tariff rate & $\begin{array}{l}\text { UNCTAD TRAINS via WITS } \\
\text { (http://wits.worldbank.org) }\end{array}$ \\
\hline UNGA voting alignment & $\begin{array}{l}\text { Number of times that a trading partner had the same voting } \\
\text { behavior as China in the United General Assembly (as a } \\
\text { share of all voting instances; abstentions and absences are } \\
\text { counted as } 0.5 \text { ) }\end{array}$ & Voeten and Merdzanovic (2009) \\
\hline
\end{tabular}

Note: All data are available for the 1991-2008 period. Information on Dalai Lama meetings and Dalai Lama visits were cross-checked and completed with information provided on http://www.buddhismtoday.com (accessed: April 2010). 
Appendix V.3: Descriptive statistics

\begin{tabular}{|c|c|c|c|c|c|}
\hline Variable & Obs. & Mean & Std. Dev. & Min & Max \\
\hline \multicolumn{6}{|l|}{ Exports to China (in million US\$) } \\
\hline Total & 2066 & 1780 & 7560 & 0 & 125000 \\
\hline Food, life animals & 1564 & 53 & 156 & 0 & 2320 \\
\hline Beverages and Tobacco & 963 & 9 & 37 & 0 & 451 \\
\hline Crude materials, inedible, except fuels & 1770 & 267 & 1190 & 0 & 20500 \\
\hline Mineral fuels, lubricants and related materials & 1028 & 278 & 979 & 0 & 11800 \\
\hline Animal and vegetable oils, fats and waxes & 706 & 64 & 267 & 0 & 3900 \\
\hline Chemicals and related products, n.e.s. & 1524 & 282 & 1230 & 0 & 17200 \\
\hline Manufactured goods classified chiefly by material & 1768 & 286 & 1200 & 0 & 19700 \\
\hline Machinery and transport equipment & 1649 & 919 & 4200 & 0 & 62900 \\
\hline Miscellaneous manufactured articles & 1630 & 132 & 768 & 0 & 13900 \\
\hline Commodities and transactions not classified elsewhere & 1042 & 82 & 445 & 0 & 7490 \\
\hline \multicolumn{6}{|l|}{ Variable of interest } \\
\hline Dalai Lama meeting with political leader in $\mathrm{t}$ or $\mathrm{t}-1$ & 2066 & 0.07 & 0.26 & 0 & 1 \\
\hline Dalai Lama meeting with government member in $\mathrm{t}$ or $\mathrm{t}-1$ & 2066 & 0.11 & 0.31 & 0 & 1 \\
\hline Dalai Lama meeting with national official in $\mathrm{t}$ or $\mathrm{t}-1$ & 2066 & 0.11 & 0.31 & 0 & 1 \\
\hline Dalai Lama meeting with all dignitaries in t or $\mathrm{t}-1$ & 2066 & 0.12 & 0.33 & 0 & 1 \\
\hline Dalai Lama visits country in $\mathrm{t}$ or $\mathrm{t}-1$ & 2066 & 0.16 & 0.37 & 0 & 1 \\
\hline \multicolumn{6}{|l|}{ Instruments } \\
\hline Number of Tibet Support Groups & 2066 & 0.79 & 2.83 & 0 & 31 \\
\hline Dalai Lama visit dummy & 2066 & 0.10 & 0.30 & 0 & 1 \\
\hline Duration of Dalai Lama visit (in days) & 2066 & 1.36 & 7.68 & 0 & 124 \\
\hline \multicolumn{6}{|l|}{ Controls } \\
\hline GDP (in million US\$) & 2066 & 282000 & 1060000 & 106 & 14200000 \\
\hline Population (in million) & 2066 & 35 & 102 & 0 & 1140 \\
\hline Exchange rate $(2000=100)$ & 2066 & 1.28 & 11.45 & 0.0001 & 508.66 \\
\hline Other exports / GDP & 2053 & 27.15 & 20.74 & 0.31 & 176.26 \\
\hline Tariff rate & 1983 & 11.80 & 11.62 & 0.00 & 95.50 \\
\hline UNGA voting alignment with China & 2041 & 78.89 & 12.88 & 13.64 & 96.10 \\
\hline
\end{tabular}


Appendix V.4: List of countries

\begin{tabular}{|c|c|c|c|c|c|c|c|c|c|c|c|c|c|c|c|c|}
\hline $\begin{array}{l}\mathbf{A} \\
\mathbf{B} \\
\mathbf{C} \\
\mathbf{D} \\
\mathbf{E} \\
\mathbf{F} \\
\mathbf{G} \\
\mathbf{H} \\
\end{array}$ & $\begin{array}{l}\mathrm{Nb} \text { of } \\
\mathrm{Nb} \text { of } \\
\mathrm{Nb} \text { of } \\
\mathrm{Nb} \text { of } \\
\mathrm{Nb} \text { of } \\
\mathrm{Nb} \text { of } \\
\mathrm{Sum} \\
\mathrm{Nb} \text { of }\end{array}$ & $\begin{array}{l}\text { yea } \\
\text { yea } \\
\text { yea } \\
\text { yea } \\
\text { yea } \\
\text { yea } \\
\text { f d } \\
\text { Tib }\end{array}$ & $\begin{array}{l}\text { s D } \\
\text { s D } \\
\text { s D } \\
\text { s D } \\
\text { s D } \\
\text { s D } \\
\text { ys D } \\
\text { t St }\end{array}$ & $\begin{array}{l}\text { tra } \\
\text { me } \\
\text { me } \\
\text { tra } \\
\text { me } \\
\text { me } \\
\text { L sp } \\
\text { ppor }\end{array}$ & $\begin{array}{l}\text { ell } \\
\text { wi } \\
\text { wi } \\
\text { ell } \\
\text { wi } \\
\text { wi } \\
\text { ent } \\
\text { Gi }\end{array}$ & $\begin{array}{l}\text { to } \\
\text { l gc } \\
\text { a pc } \\
\text { to } \\
\text { gc } \\
\text { ac } \\
\text { co } \\
\text { up }\end{array}$ & $\begin{array}{l}\text { untry } \\
\text { rnment } \\
\text { ical lea } \\
\text { untry ( } \\
\text { rnment } \\
\text { cal lea } \\
\text { try ( }(200 \\
008)\end{array}$ & $\begin{array}{l}\text { 991- } \\
\text { nem } \\
\text { er }(1 \\
\text { D02- } \\
\text { nem } \\
\text { er }(2 \\
2-20\end{array}$ & $\begin{array}{l}008) \\
\text { er (1991-2008) } \\
91-2008) \\
008) \\
\text { er (2002-2008) } \\
02-2008) \\
8)\end{array}$ & & & & & & & \\
\hline Country & $\mathbf{A}$ & B & $\mathbf{C}$ & D & $\mathbf{E}$ & $\mathbf{F}$ & G & H & Country & $\mathbf{A}$ & B & $\mathrm{C}$ & D & $\mathbf{E}$ & $\mathbf{F}$ & G \\
\hline Albania* & 0 & 0 & 0 & 0 & 0 & 0 & 0 & 0 & Lithuania* & 2 & 2 & 2 & 0 & 0 & 0 & 0 \\
\hline Algeria & 0 & 0 & 0 & 0 & 0 & 0 & 0 & 0 & Luxembourg* & 1 & 0 & 0 & 1 & 0 & 0 & 2 \\
\hline Antigua and Barbuda & 0 & 0 & 0 & 0 & 0 & 0 & 0 & 0 & Macedonia, FYR* & 0 & 0 & 0 & 0 & 0 & 0 & 0 \\
\hline Argentina & 3 & 1 & 1 & 1 & 0 & 0 & 4 & 0 & Madagascar & 0 & 0 & 0 & 0 & 0 & 0 & 0 \\
\hline Armenia & 0 & 0 & 0 & 0 & 0 & 0 & 0 & 0 & Malawi & 0 & 0 & 0 & 0 & 0 & 0 & 0 \\
\hline Aruba & 0 & 0 & 0 & 0 & 0 & 0 & 0 & 0 & Malaysia & 0 & 0 & 0 & 0 & 0 & 0 & 0 \\
\hline Australia & 5 & 4 & 3 & 3 & 2 & 1 & 29 & 4 & Maldives & 0 & 0 & 0 & 0 & 0 & 0 & 0 \\
\hline Austria* & 8 & 7 & 5 & 3 & 3 & 2 & 21 & 2 & Mali & 0 & 0 & 0 & 0 & 0 & 0 & 0 \\
\hline Azerbaijan & 0 & 0 & 0 & 0 & 0 & 0 & 0 & 0 & Malta* & 0 & 0 & 0 & 0 & 0 & 0 & 0 \\
\hline Bahamas, The & 0 & 0 & 0 & 0 & 0 & 0 & 0 & 0 & Mauritania & 0 & 0 & 0 & 0 & 0 & 0 & 0 \\
\hline Bahrain & 0 & 0 & 0 & 0 & 0 & 0 & 0 & 0 & Mauritius & 0 & 0 & 0 & 0 & 0 & 0 & 0 \\
\hline Bangladesh & 0 & 0 & 0 & 0 & 0 & 0 & 0 & 0 & Mexico & 1 & 1 & 0 & 1 & 1 & 0 & 6 \\
\hline Barbados & 0 & 0 & 0 & 0 & 0 & 0 & 0 & 0 & Moldova & 0 & 0 & 0 & 0 & 0 & 0 & 0 \\
\hline Belarus & 0 & 0 & 0 & 0 & 0 & 0 & 0 & 0 & Mongolia & 5 & 2 & 1 & 2 & 1 & 1 & 13 \\
\hline Belgium* & 5 & 4 & 4 & 2 & 2 & 2 & 13 & 2 & Morocco & 0 & 0 & 0 & 0 & 0 & 0 & 0 \\
\hline Belize & 0 & 0 & 0 & 0 & 0 & 0 & 0 & 0 & Mozambique & 0 & 0 & 0 & 0 & 0 & 0 & 0 \\
\hline Benin & 0 & 0 & 0 & 0 & 0 & 0 & 0 & 0 & Namibia & 0 & 0 & 0 & 0 & 0 & 0 & 0 \\
\hline Bhutan & 0 & 0 & 0 & 0 & 0 & 0 & 0 & 0 & Nepal & 0 & 0 & 0 & 0 & 0 & 0 & 0 \\
\hline Bolivia & 0 & 0 & 0 & 0 & 0 & 0 & 0 & 0 & Netherlands* & 4 & 3 & 1 & 0 & 0 & 0 & 0 \\
\hline Bosnia and Herzegovina* & 0 & 0 & 0 & 0 & 0 & 0 & 0 & 0 & New Caledonia & 0 & 0 & 0 & 0 & 0 & 0 & 0 \\
\hline Botswana & 0 & 0 & 0 & 0 & 0 & 0 & 0 & 0 & New Zealand & 4 & 4 & 4 & 2 & 2 & 2 & 9 \\
\hline Brazil & 3 & 2 & 1 & 1 & 1 & 0 & 5 & 1 & Nicaragua & 1 & 2 & 2 & 0 & 0 & 0 & 0 \\
\hline Brunei & 0 & 0 & 0 & 0 & 0 & 0 & 0 & 0 & Niger & 0 & 0 & 0 & 0 & 0 & 0 & 0 \\
\hline Bulgaria* & 1 & 2 & 2 & 0 & 0 & 0 & 0 & 0 & Nigeria & 1 & 0 & 0 & 1 & 0 & 0 & 3 \\
\hline Burkina Faso & 0 & 0 & 0 & 0 & 0 & 0 & 0 & 0 & Norway* & 6 & 5 & 4 & 1 & 1 & 1 & 3 \\
\hline Burundi & 0 & 0 & 0 & 0 & 0 & 0 & 0 & 0 & Oman & 0 & 0 & 0 & 0 & 0 & 0 & 0 \\
\hline Cambodia & 0 & 1 & 1 & 0 & 0 & 0 & 0 & 0 & Pakistan & 0 & 0 & 0 & 0 & 0 & 0 & 0 \\
\hline Cameroon & 0 & 0 & 0 & 0 & 0 & 0 & 0 & 0 & Panama & 0 & 0 & 0 & 0 & 0 & 0 & 0 \\
\hline Canada & 4 & 3 & 2 & 3 & 3 & 2 & 30 & 3 & Papua New Guinea & 0 & 0 & 0 & 0 & 0 & 0 & 0 \\
\hline Central African Republic & 0 & 0 & 0 & 0 & 0 & 0 & 0 & 0 & Paraguay & 0 & 0 & 0 & 0 & 0 & 0 & 0 \\
\hline Chile & 3 & 3 & 2 & 1 & 1 & 0 & 5 & 0 & Peru & 1 & 1 & 1 & 1 & 1 & 1 & 4 \\
\hline Colombia & 1 & 0 & 0 & 1 & 0 & 0 & 3 & 0 & Philippines & 0 & 0 & 0 & 0 & 0 & 0 & 0 \\
\hline Congo, Rep. & 0 & 0 & 0 & 0 & 0 & 0 & 0 & 0 & Poland* & 3 & 4 & 4 & 1 & 1 & 1 & 8 \\
\hline Costa Rica & 1 & 1 & 1 & 1 & 1 & 1 & 4 & 1 & Portugal* & 2 & 1 & 1 & 1 & 0 & 0 & 6 \\
\hline Cote d'Ivoire & 0 & 0 & 0 & 0 & 0 & 0 & 0 & 0 & Qatar & 0 & 0 & 0 & 0 & 0 & 0 & 0 \\
\hline Croatia* & 1 & 1 & 1 & 1 & 1 & 1 & 4 & 0 & Romania* & 0 & 0 & 0 & 0 & 0 & 0 & 0 \\
\hline Cyprus* & 0 & 0 & 0 & 0 & 0 & 0 & 0 & 0 & Russian Federation & 5 & 0 & 0 & 1 & 0 & 0 & 3 \\
\hline Czech Republic* & 6 & 5 & 4 & 4 & 3 & 2 & 17 & 4 & Rwanda & 0 & 0 & 0 & 0 & 0 & 0 & 0 \\
\hline Denmark* & 4 & 4 & 2 & 1 & 1 & 1 & 7 & 2 & Samoa & 0 & 0 & 0 & 0 & 0 & 0 & 0 \\
\hline Dominican Republic & 0 & 0 & 0 & 0 & 0 & 0 & 0 & 0 & Saudi Arabia & 0 & 0 & 0 & 0 & 0 & 0 & 0 \\
\hline Egypt, Arab Rep. & 0 & 0 & 0 & 0 & 0 & 0 & 0 & 0 & Senegal & 0 & 0 & 0 & 0 & 0 & 0 & 0 \\
\hline El Salvador & 1 & 1 & 1 & 1 & 1 & 1 & 3 & 0 & Serbia (Yugoslavia)* & 0 & 0 & 0 & 0 & 0 & 0 & 0 \\
\hline Eritrea & 0 & 0 & 0 & 0 & 0 & 0 & 0 & 0 & Seychelles & 0 & 0 & 0 & 0 & 0 & 0 & 0 \\
\hline Estonia* & 2 & 2 & 1 & 0 & 0 & 0 & 0 & 0 & Singapore & 0 & 0 & 0 & 0 & 0 & 0 & 0 \\
\hline Ethiopia & 0 & 0 & 0 & 0 & 0 & 0 & 0 & 0 & Slovak Republic* & 1 & 0 & 0 & 0 & 0 & 0 & 0 \\
\hline Fiji & 0 & 0 & 0 & 0 & 0 & 0 & 0 & 0 & Slovenia* & 1 & 1 & 1 & 1 & 1 & 1 & 3 \\
\hline Finland* & 2 & 1 & 0 & 1 & 0 & 0 & 4 & 0 & Solomon Islands & 0 & 0 & 0 & 0 & 0 & 0 & 0 \\
\hline France* & 12 & 5 & 3 & 3 & 1 & 1 & 24 & 31 & South Africa & 3 & 1 & 1 & 1 & 0 & 0 & 7 \\
\hline French Polynesia & 0 & 0 & 0 & 0 & 0 & 0 & 0 & 0 & Spain* & 4 & 0 & 0 & 2 & 0 & 0 & 8 \\
\hline Gabon & 1 & 0 & 0 & 0 & 0 & 0 & 0 & 0 & Sri Lanka & 0 & 0 & 0 & 0 & 0 & 0 & 0 \\
\hline Gambia, The & 0 & 0 & 0 & 0 & 0 & 0 & 0 & 0 & St. Kitts and Nevis & 0 & 0 & 0 & 0 & 0 & 0 & 0 \\
\hline Georgia & 0 & 0 & 0 & 0 & 0 & 0 & 0 & 0 & St. Lucia & 0 & 0 & 0 & 0 & 0 & 0 & 0 \\
\hline Germany* & 14 & 5 & 1 & 5 & 3 & 1 & 43 & 8 & St. Vincent and the G. & 0 & 0 & 0 & 0 & 0 & 0 & 0 \\
\hline Ghana & 0 & 0 & 0 & 0 & 0 & 0 & 0 & 0 & Sudan & 0 & 0 & 0 & 0 & 0 & 0 & 0 \\
\hline Greece* & 0 & 0 & 0 & 0 & 0 & 0 & 0 & 1 & Suriname & 0 & 0 & 0 & 0 & 0 & 0 & 0 \\
\hline Grenada & 0 & 0 & 0 & 0 & 0 & 0 & 0 & 0 & Swaziland & 0 & 0 & 0 & 0 & 0 & 0 & 0 \\
\hline Guatemala & 1 & 1 & 1 & 1 & 1 & 1 & 3 & 0 & Sweden* & 6 & 3 & 2 & 2 & 0 & 0 & 7 \\
\hline Guinea & 0 & 0 & 0 & 0 & 0 & 0 & 0 & 0 & Switzerland* & 10 & 4 & 0 & 2 & 1 & 0 & 15 \\
\hline Guyana & 0 & 0 & 0 & 0 & 0 & 0 & 0 & 0 & Syrian Arab Republic & 0 & 0 & 0 & 0 & 0 & 0 & 0 \\
\hline Honduras & 0 & 0 & 0 & 0 & 0 & 0 & 0 & 0 & Tanzania & 0 & 0 & 0 & 0 & 0 & 0 & 0 \\
\hline Hungary* & 4 & 1 & 1 & 0 & 0 & 0 & 0 & 0 & Thailand & 1 & 0 & 0 & 0 & 0 & 0 & 0 \\
\hline Iceland* & 0 & 0 & 0 & 0 & 0 & 0 & 0 & 0 & Togo & 0 & 0 & 0 & 0 & 0 & 0 & 0 \\
\hline India & 18 & 9 & 7 & 7 & 4 & 2 & 616 & 2 & Tonga & 0 & 0 & 0 & 0 & 0 & 0 & 0 \\
\hline Indonesia & 1 & 0 & 0 & 0 & 0 & 0 & 0 & 1 & Trinidad and Tobago & 1 & 0 & 0 & 0 & 0 & 0 & 0 \\
\hline Iran, Islamic Rep. & 0 & 0 & 0 & 0 & 0 & 0 & 0 & 0 & Tunisia & 0 & 0 & 0 & 0 & 0 & 0 & 0 \\
\hline Ireland* & 1 & 2 & 2 & 0 & 0 & 0 & 0 & 1 & Turkey* & 0 & 0 & 0 & 0 & 0 & 0 & 0 \\
\hline Israel & 3 & 2 & 0 & 1 & 0 & 0 & 5 & 1 & Turkmenistan & 0 & 0 & 0 & 0 & 0 & 0 & 0 \\
\hline Italy* & 12 & 6 & 2 & 5 & 3 & 0 & 31 & 3 & Uganda & 0 & 0 & 0 & 0 & 0 & 0 & 0 \\
\hline Jamaica & 0 & 0 & 0 & 0 & 0 & 0 & 0 & 0 & Ukraine & 0 & 0 & 0 & 0 & 0 & 0 & 0 \\
\hline Japan & 12 & 0 & 0 & 7 & 0 & 0 & 69 & 3 & United Arab Emirates & 0 & 0 & 0 & 0 & 0 & 0 & 0 \\
\hline Jordan & 3 & 3 & 3 & 3 & 3 & 3 & 13 & 0 & United Kingdom* & 10 & 6 & 3 & 4 & 2 & 1 & 33 \\
\hline Kazakhstan & 0 & 0 & 0 & 0 & 0 & 0 & 0 & 0 & United States & 16 & 11 & 10 & 6 & 3 & 3 & 169 \\
\hline Kenya & 0 & 0 & 0 & 0 & 0 & 0 & 0 & 0 & Uruguay & 0 & 0 & 0 & 0 & 0 & 0 & 0 \\
\hline Korea, Rep. & 0 & 0 & 0 & 0 & 0 & 0 & 0 & 0 & Vanuatu & 0 & 0 & 0 & 0 & 0 & 0 & 0 \\
\hline Kuwait & 0 & 0 & 0 & 0 & 0 & 0 & 0 & 0 & Venezuela & 1 & 0 & 0 & 0 & 0 & 0 & 0 \\
\hline Kyrgyz Republic & 0 & 0 & 0 & 0 & 0 & 0 & 0 & 0 & Vietnam & 0 & 0 & 0 & 0 & 0 & 0 & 0 \\
\hline Latvia* & 2 & 2 & 2 & 0 & 0 & 0 & 0 & 1 & Yemen & 0 & 0 & 0 & 0 & 0 & 0 & 0 \\
\hline Lebanon & 0 & 0 & 0 & 0 & 0 & 0 & 0 & 0 & Zambia & 0 & 0 & 0 & 0 & 0 & 0 & 0 \\
\hline Lesotho & 0 & 0 & 0 & 0 & 0 & 0 & 0 & 0 & Zimbabwe & 0 & 0 & 0 & 0 & 0 & 0 & 0 \\
\hline Libya & 0 & 0 & 0 & 0 & 0 & 0 & 0 & 0 & & & & & & & & \\
\hline
\end{tabular}

Note: All countries included in the European subsample are marked with an asterix $\left(^{*}\right)$. 
Appendix V.5: Exports to China and Dalai Lama meetings of government members

(Hypothesis 1, all countries, excluding SITC9)

\begin{tabular}{|l|ccc|ccc|}
\hline & \multicolumn{3}{|c|}{ Fixed Effects } & \multicolumn{3}{c|}{ FGLS AR(1) } \\
& $\mathbf{1 9 9 1 - 2 0 0 8}$ & $\mathbf{1 9 9 1 - 2 0 0 1}$ & $\mathbf{2 0 0 2 - 2 0 0 8}$ & $\mathbf{1 9 9 1 - 2 0 0 8}$ & $\mathbf{1 9 9 1 - 2 0 0 1}$ & $\mathbf{2 0 0 2 - 2 0 0 8}$ \\
& $(1)$ & $(2)$ & $(3)$ & $(4)$ & $(5)$ & $(6)$ \\
\hline DL meets government member & -0.048 & -0.002 & $-0.128^{* *}$ & $-0.065^{*}$ & -0.019 & $-0.056^{* *}$ \\
& $(0.583)$ & $(0.978)$ & $(0.032)$ & $(0.051)$ & $(0.527)$ & $(0.014)$ \\
$(\log )$ GDP & $0.537^{* *}$ & $0.849^{* *}$ & 0.034 & $0.218^{* * *}$ & $0.359^{* * *}$ & $0.406^{* * *}$ \\
& $(0.033)$ & $(0.032)$ & $(0.914)$ & $(0.005)$ & $(0.001)$ & $(0.000)$ \\
$(\log )$ Population & $3.551^{* * *}$ & $3.077^{*}$ & $3.409^{* *}$ & $0.468^{* * *}$ & 0.189 & $2.740^{* * *}$ \\
& $(0.001)$ & $(0.050)$ & $(0.041)$ & $(0.001)$ & $(0.338)$ & $(0.000)$ \\
$(\log )$ Exchange rate & -0.089 & -0.108 & 0.210 & 0.030 & $-0.058^{*}$ & $0.305^{* * *}$ \\
& $(0.365)$ & $(0.335)$ & $(0.241)$ & $(0.293)$ & $(0.083)$ & $(0.000)$ \\
\hline R squared & & & & & & \\
Observations & 0.426 & 0.119 & 0.260 & & & \\
Number of countries & 2,051 & 1,132 & 911 & 2,051 & 1,132 & 911 \\
\hline
\end{tabular}

Notes:

- All regressions with country and time fixed effects.

- Robust p-values in brackets; * significant at 10\%; ** significant at 5\%; *** significant at $1 \%$

- Standard errors in Fixed Effects regressions are adjusted for clustering across partner countries.

- FGLS regressions are corrected for cross-sectional heteroskedasticity across panels and first order autocorrelation. 
Appendix V.6: Exports to China and Dalai Lama meetings at various political levels (Hypothesis 2, European countries, 2002-2008)

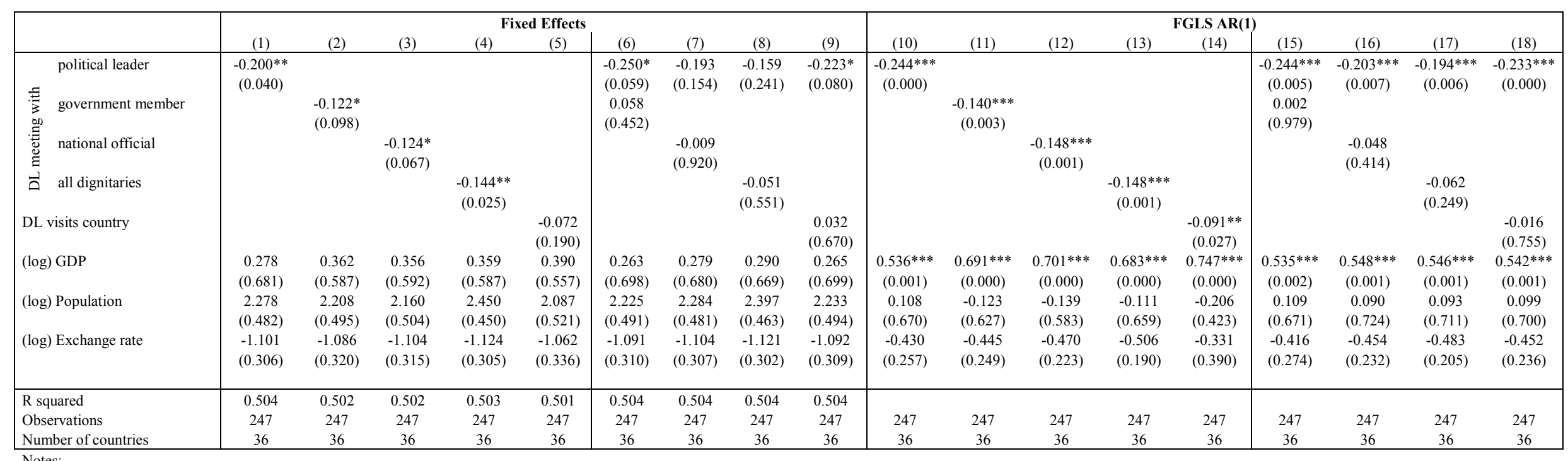

Notes:

- Robust p-values in brackets; * significant at $10 \% ; * *$ significant at $5 \% ; * * *$ significant at $1 \%$

- Standard errors in Fixed Effects regressions are adjusted for clustering across partner countries.

- FGLS regressions are corrected for cross-sectional heteroskedasticity across panels and first order autocorrelation. 
Appendix V.7: Exports to China and Dalai Lama meetings of political leaders (first-stage results for 2SLS regressions, 2002-2008)

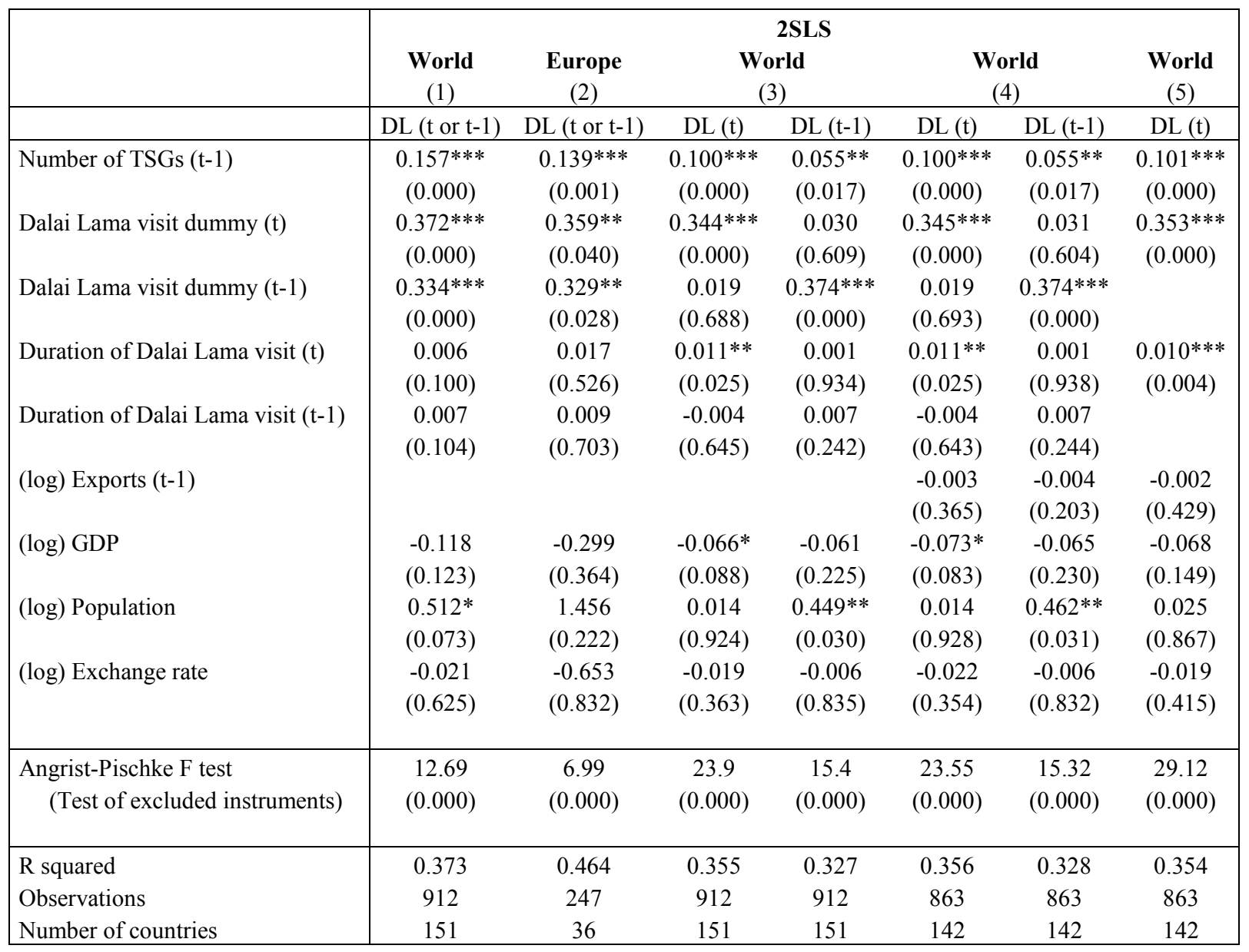

Notes:

- First stage results for 2SLS regressions reported in Table V.4. All regressions with clustered standard errors, country and time fixed effects.

- * significant at $10 \%$;* significant at $5 \%$; ** significant at $1 \%$ 
